


\section{DISCLAIMER}

This report was prepared as an account of work sponsored by an agency of the United States Government. Neither the United States Government nor any agency thereof, nor any of their employees, makes any warranty, express or implied, or assumes any legal liability or responsibility for the accuracy, completeness, or usefulness of any information, apparatus, product, or process disclosed, or represents that its use would not infringe privately owned rights. Reference herein to any specific commercial product, process, or service by trade name, trademark, manufacturer, or otherwise does not necessarily constitute or imply its endorsement, recommendation, or favoring by the United States Government or any agency thereof. The views and opinions of authors expressed herein do not necessarily state or reflect those of the United States Government or any agency thereof. 


\section{DISCLAIMER}

Portions of this document may be illegible electronic image products. Images are produced from the best available original document. 


\section{1}

\section{Disclaimer}

This report has been reviewed by the U.S. Department of Energy and approved for publication. Approval does not signify that the contents necessarily reflect the view and policies of the DOE nor does mention of trade names or commercial products constitute endorsement or recommendation for use. 


\title{
CHARACTERIZATION OF OIL AND GAS WASTE DISPOSAL PRACTICES AND ASSESSMENT OF TREATMENT COSTS
}

\author{
FINAL REPORT
}

Contract Number

University

Date of Report

Contract Date

Anticipated Completion Date

Government Award

Program Manager

Principal Investigator

Technical Project Officer

Reporting Period
DE-AC22-92-MT92007

Rice University

January 16, 1995

July 1, 1992 - June 30, 1994

September 30, 1994

$\$ 199,071$

Philip B. Bedient

Philip B. Bedient

Brent Smith

U.S. Department of Energy

Metairie Site Office

900 Commerce Road E.

New Orleans, LA 70123

July 1, 1992 - September 30, 1994 


\section{TABLE OF CONTENTS}

Section

Page

Disclaimer

ii

Title Page

iii

Table of Contents

iv

List of Tables

vii

List of Figures

$x$

Abstract xiii

EXECUTIVE SUMMARY

E.1 Introduction 1

E.2 Objectives 2

E.3 The Production Environmental Database 2

E.4 Evaluation of Technologies and Costs for Produced

$\begin{array}{ll}1.0 \text { INTRODUCTION } & 12\end{array}$

$\begin{array}{ll}1.1 \text { Background } & 12\end{array}$

1.2 Oil and Gas Drilling and Production 13

1.3 Objectives 15

1.3.1 The Production Environmental Database 15

1.3.2 Feasible Technologies for Treatment of Waste Streams 16

1.3.3 The Cost of Produced Water Treatment Technologies $\quad 17$

$\begin{array}{ll}1.4 \text { Scope of Study } & 18\end{array}$

1.4.1 The Production Environmental Database 18

1.4.2 Feasible Technologies for Treatment of Waste Streams 21

1.4.3 The Cost of Produced Water Treatment Technologies 21

1.5 Methods and Approach 22

1.5.1. The Production Environmental Database 22

1.5.2 Feasible Technologies for Treatment of Waste Streams 28

1.5.3 The Cost of Produced Water Treatment Technologies $\quad 30$

1.6 Organization of this Report 31 
2.0 HISTORICAL PERSPECTIVE 33

2.1 The EPA Oil and Gas Waste Study 34

2.1.1 Waste Volumes and Characteristics 34

2.1.2 Risk Assessment Modeling 37

2.2 The API Oil and Gas Waste Study 40

2.3 Regulatory Actions $\quad 42$

2.4 Recent Industry Trends 44

$\begin{array}{ll}3.0 \text { LITERATURE REVIEW } & 47\end{array}$

3.1 Drilling Wastes 47

3.1.1 Composition 48

3.1.2 Environmental Impact $\quad 50$

3.2 Produced Water 54

3.2.1 Composition $\quad 55$

3.2.2 Environmental Impact $\quad 59$

3.3 Produced Water Treatment Technologies 63

3.3.1 Conventional Treatment (liquid/solid separation) 64

3.3.2 Packed Tower Aeration 69

3.3.3 Granular Activated Carbon Adsorption $\quad 72$

3.3.4 Reverse Osmosis $\quad 76$

4.0 THE PRODUCTION ENVIRONMENTAL DATABASE 81

4.1 Introduction $\quad 81$

4.2 Nationwide Waste Quantities $\quad 82$

4.2.1 Drilling Waste Production 83

4.2.2 Drilling Waste Disposal 92

4.2.3 Produced Water Production 93

4.2.4 Produced Water Disposal 102

4.3 Environmental Settings in 8 Texas Counties 102

4.3.1 Area of Study 102

4.3.2 The PED Geographic Information System 103

$\begin{array}{ll}\text { 4.3.3 Landuse } & 104\end{array}$

4.3.4 Surface Water 112

4.3.5 Water Supply Wells 121

4.3.6 Groundwater Usage 126

4.3.7 Aquifer Regions 132

4.3.8 DRASTIC Regions 133

4.3.9 Floodplains 148

4.3.10 Wetlands $\quad 150$

4.3.11 Parklands $\quad$. 154 
Section

4.4 Summary

5.0 EVALUATION OF TECHNOLOGIES AND COSTS FOR

PRODUCED WATER TREATMENT

5.1 Introduction

5.2 Liquid/Solid Separation

5.2.1 Evaluation Methodology

5.2.2 Sludge Disposal

162

5.2.3 Results

5.3 Packed Tower Aeration

5.3.1 Evaluation Methodology

5.3.2 Results

5.4 Carbon Adsorption Processes

5.4.1 Evaluation Methodology

168

5.4.2 Granular Activated Carbon

170

5.4.3 Powdered Activated Carbon

5.4.4 Results

176

5.5 Desalination Processes

184

5.5.1 Evaluation Methodology

5.5.2 Reverse Osmosis

5.5.3 Forced Evaporation

5.5.4 Results

5.6 Aggregate Costs

Acknowledgments 


\section{LIST OF TABLES}

Table

EXECUTIVE SUMMARY

E.1 Reduction trends in drilled wells, drilled footage, and waste volumes.

E.2 Nationwide annual production and produced water disposal volumes.

E.3 Environmental settings GIS coverages.

\subsection{INTRODUCTION}

1.1 Selected Texas counties for the PED environmental settings analysis.

1.2 Agencies contacted for produced water and other production and disposal information.

1.3 Environmental settings GIS coverages.

1.4 Constituents used to characterize produced water.

\subsection{HISTORICAL PERSPECTIVE}

2.1 Constituents of concern in oil and gas waste streams.

\subsection{LITERATURE REVIEW}

3.1 Potential drilling wastes.

3.2 Hazardous characteristics of oil and gas wastes. 50

3.3 Phenols and volatile aromatic compounds in produced water. 57

3.4 PAH's in produced water.

3.5 Heavy metals in produced water.

3.6 Radionuclides in produced water.

3.7 Constituents found in oilfield brines.

\subsection{THE PRODUCTION ENVIRONMENTAL DATABASE}

4.11988 drilling waste volumes by modified API method.

4.21990 drilling waste volumes by modified API method.

4.3 1992 drilling waste volumes by modified API method.

4.4 Ratios of waste volume to drilled footage per API survey.

4.5 Reduction trends in drilled wells, drilled footage, and waste volumes.

4.6 Annual produced water production and disposal volumes.

4.7 Level II landuse/landcover classifications.

4.8 Drilling sites versus landuse.

4.9 Injection, plugged, and abandoned well sites versus landuse. 
4.10 Landuse distributions for 8 Texas counties versus API survey distributions.

4.11 Drilling sites versus proximity to surface water bodies. 114

4.12 Injection, plugged, and abandoned well sites versus proximity to surface water bodies.

4.13 Travel distance distributions from drilling sites to the nearest surface water body.

4.14 Travel distance distributions from injection, plugged, and abandoned wells to the nearest surface water body.

4.15 Drilling sites versus proximity to water supply wells.

122

4.16 Injection, plugged, and abandoned well sites versus proximity to water supply wells.

4.17 Travel distance distributions from injection, plugged, and abandoned wells to the nearest water supply well.

4.18 Drilling sites versus groundwater usage.

128

4.19 Injection, plugged, and abandoned well sites versus groundwater usage.

4.20 Drilling sites versus freshwater aquifer regions.

130

4.21 Injection, plugged, and abandoned well sites versus freshwater aquifer regions.

4.22 Drilling sites versus DRASTIC regions.

4.23 Injection, plugged, and abandoned well sites versus DRASTIC regions.

4.24 Generic DRASTIC parameter values.

4.25 Estimated DRASTIC index numbers using EPA hydrogeologic settings for drilling sites.

4.26 Estimated DRASTIC index numbers using EPA hydrogeologic settings for production sites.

4.28 Comparison of DRASTIC region distributions for injection

4.29 Drilling sites located with

4.30 Injection, plugged, and abandoned well sites within floodplain areas.

4.31 Drilling sites within parklands.

4.32 Injection, plugged, and abandoned well sites within parklands.

\subsection{EVALUATION OF TECHNOLOGIES AND COSTS FOR PRODUCED WATER TREATMENT}

5.1 Cost equations for package plant.

5.2 Cost equations for gravity thickener. 161

5.3 Cost equations for sand drying bed. 162

5.4 Cost equations for packed tower aeration. 166

5.5 Cost equations for GAC adsorption. 172 
5.6 Cost equations for PAC adsorption.

5.7 Cost equations for reverse osmosis.

5.8 Cost equations for forced evaporation. 


\section{LIST OF FIGURES}

Figure

Page

EXECUTIVE SUMMARY

E.1 Location of counties used in the PED environmental settings analysis.

E.2 Total costs associated with the treatment of several representative waste streams.

1.0 INTRODUCTION

1.1 Location of counties used in the PED environmental settings analysis.

2.0 HISTORICAL PERSPECTIVE

2.1 EPA estimated onshore drilling waste volumes (not incl. Alaska). 35

2.2 Domestic onshore well completions. 35

2.3 EPA estimated produced water volumes. $\quad 36$

2.4 USGS quad map selection procedure used by EPA. 39

2.5 Annual domestic well completions. 45

2.6 Annual domestic production of oil, gas, and produced water. 46

\subsection{LTERATURE REVIEW}

3.1 Schematic representation of a conventional package treatment plant.

3.2 Typical packed tower aerator.

3.3 Schematic representation of a GAC adsorption system.

3.4 Schematic representation of the reverse osmosis treatment process.

\subsection{THE PRODUCTION ENVIRONMENTAL DATABASE}

4.1 Typical API waste volume models showing curve modifications. 89

4.2 API exploration and production basins with attributed areas. $\quad 90$

4.3 Annual total U.S. onshore drilling waste volumes (not incl. Alaska).

4.4 Injection, plugged, and abandoned well locations versus surface water features in Lee County.

4.5 Injection well locations versus water supply wells in Panola County.

4.6 Drilling sites versus public water supply wells in Brazoria County.

4.7 Drilling sites versus freshwater aquifer regions in Wise County. 136

4.8 Drilling sites versus DRASTIC regions in Panola County. 143 
4.9 Drilling sites versus floodplain areas in Brazoria County. 151

4.10 Drilling sites versus wetland areas in Panola County.

4.11 Drilling sites and injection well locations versus parkland areas in Wise County.

5.0 EVALUATION OF TECHNOLOGIES AND COSTS FOR PRODUCED WATER TREATMENT

5.1 Package plant treatment costs as a function of influent TSS concentration.

5.2 Packed tower aeration costs as a function of influent VOC concentration.

5.3 Carbon costs for powdered and granular activated carbon adsorption of organics from produced water.

5.4 A comparison of total system costs for activated carbon adsorption using PAC and GAC as a function of the influent concentration of adsorbable organic compounds ( $0.01 \mathrm{MGD}$ ).

5.5 A comparison of total system costs for activated carbon adsorption using PAC and GAC as a function of the influent concentration of adsorbable organic compounds (0.1 MGD).

5.6 A comparison of total system costs for activated carbon adsorption using PAC and GAC as a function of the influent concentration of adsorbable organic compounds (1 MGD).

5.7 PAC treatment costs presented as a function of the initial concentration of adsorbable organic compounds (0.01 MGD).

5.8 PAC treatment costs presented as a function of the initial concentration of adsorbable organic compounds (0.1 MGD). $\quad 180$

5.9 PAC treatment costs presented as a function of the initial concentration of adsorbable organic compounds (1 MGD).

5.10 GAC treatment costs presented as a function of the initial concentration of adsorbable organic compounds (0.01 MGD). 181

5.11 GAC treatment costs presented as a function of the initial concentration of adsorbable organic compounds (0.1 MGD).

5.12 GAC treatment costs presented as a function of the initial concentration of adsorbable organic compounds (1 MGD).

5.13 Carbon costs associated with the removal of adsorbable organic compounds onto GAC as a function of the initial concentration of adsorbable organic compounds in untreated produced waters.

5.14 GAC adsorption costs for flow rates of $0.01,0.1$, and 1 MGD plotted against the influent concentration of adsorbable organic compounds.

5.15 Comparison of cost estimating methods for treatment using reverse osmosis.

5.16 Forced evaporation costs versus system capacity. 
5.17 The estimated costs of RO desalination of produced waters for flow rates of $0.01,0.1$, and $1 \mathrm{MGD}$ as a function of initial waste stream TDS concentration.

5.18 RO treatment costs presented as a function of influent TDS concentration and effluent requirements (0.01 MGD).

191

5.19 RO treatment costs presented as a function of influent TDS concentration and effluent requirements (0.1 MGD).

192

5.20 RO treatment costs presented as a function of influent TDS concentration and effluent requirements (1 MGD).

192

5.21 Total costs associated with the treatment of several representative waste streams. 


\section{ABSTRACT}

This study examines wastes associated with the onshore exploration and production of crude oil and natural gas in the United States. The objective of this study was to update and enhance the current state of knowledge with regard to oil and gas waste quantities, the potential environmental impact of these wastes, potential methods of treatment, and the costs associated with meeting various degrees of treatment. To meet this objective, the study consisted of three tasks: 1) the development of a Production Environmental Database (PED) for the purpose of assessing current oil and gas waste volumes by state and for investigating the potential environmental impacts associated with current waste disposal practices on a local scale; 2) the evaluation of available and developing technologies for treating produced water waste streams and the identification of unit process configurations; and 3) the evaluation of the costs associated with various degrees of treatment achievable by different treatment configurations.

An updated assessment of the annual domestic production volume of drilling waste and produced water by onshore drilling and production activity showed there to be a general decline in the volumes of drilling waste being produced over the period $1985-1992$ as well as an apparent reduction in the volume of produced water generated since 1986. A 59\% reduction in the volume of drilling waste over 1985 levels was estimated. This reduction is tied to a reduction in the amount of drilling activity and, more closely, to a reduction in the amount of drilled footage taking place. Current estimates show that some 150 million barrels of drilling waste and 18.3 billion barrels of produced water are being generated annually.

An analysis of the environmental settings surrounding oil and gas activities in 8 Texas counties showed that local conditions can be far different from those described by the EPA in their nationwide study and used in their risk assessment.

The evaluation of feasible technologies for the treatment of produced water waste streams was handled in the context of comparing the level of treatment achievable with the associated cost of treatment. Treatment processes were evaluated for the removal of four categories of produced water contaminants: particulate material, volatile organic compounds, adsorbable organic compounds, and dissolved inorganic species. Results showed dissolved inorganic species to be the most costly to remove. The potential cost of treating all 18.3 billion barrels of produced water generated in a year amounts to some 15 billion dollars annually. 


\section{EXECUTIVE SUMMARY}

\section{E.1 Introduction}

Wastes from the exploration, development, and production of crude oil and natural gas have historically been exempt from Federal regulation as hazardous wastes under the Resource Conservation and Recovery Act (RCRA) (Section 3001(b)(2)(A)). An extensive study of these wastes by the Environmental Protection Agency (EPA) in 1986 concluded that they do not pose a significant threat to human or environmental health and that regulating them as hazardous under RCRA would be unjustified and would place an undo economic burden on the oil and gas industry as well as severely strain existing hazardous waste transportation, disposal, and regulatory resources (U.S.EPA, 1987a). Rather, the EPA concluded that these wastes could be adequately managed according to other existing state and Federal regulatory programs. However, because a level of uncertainty continues to surround the composition and fate of oil and gas wastes in the environment, the issue of just how they should be regulated continues to be debated. The U.S. Department of Energy (DOE) recently initiated a new program of research relating to the environmental aspects of oil and gas extraction. The program's

mandate presents needs for improving the cost effectiveness of environmental protection, managing drilling and production wastes and emissions, determining the environmental impacts of advanced recovery processes and developing technologies to minimize those impacts, and developing data management systems and technology transfer plans to oil and gas operators, Federal and state agencies, and to the scientific community. This study, funded by DOE, is a product of that program.

The justification for this work stems from the lack of environmental impact assessment data associated with oil and gas extraction activities, and the need for studies on the feasibility of current and alternative treatment methods for generated waste streams. The EPA study and an independent study completed by the American 
Petroleum Institute (API) (Wakim, 1987) both provide data on volumes of wastes generated and disposal practices used prior to 1985, but contain limited and largely generalized information on the impacts those practices have on the environment. Neither of the two studies provides sufficient site-specific environmental data that could be used in a comparative analysis with nationwide, state or regional disposal practices.

\section{E.2 Objectives}

The objective of this study was to update and enhance the current state of knowledge with regard to oil and gas waste quantities, the potential environmental impact of these wastes, potential methods of treatment, and the costs associated with meeting various degrees of treatment. To meet this objective, the study consisted of three tasks: 1) the development of a PED for the purpose of assessing current oil and gas waste volumes by state and for investigating the potential environmental impacts associated with current waste disposal practices on a local scale; 2) the evaluation of available and developing technologies for treating produced water waste streams and the identification of unit process configurations; and 3) the evaluation of the costs associated with various degrees of treatment achievable by different treatment configurations.

\section{E.3 The Production Environmental Database}

The Production Environmental Database (PED) includes, on a state by state basis, current nationwide estimates of oil and gas extraction waste quantities generated, and an assessment of the disposition of these wastes by disposal method. The methods used for the estimation of waste quantities were adapted from the earlier oil and gas waste studies completed by the EPA (U.S. EPA, 1987a) and the API (Wakim, 1987). Specifically, drilling waste volumes were estimated using data on drilled footage 
obtained from the Petroleum Information well completion database and relationships between drilled footage and waste quantities developed by the API from their 1985 operator survey. Produced water volumes were estimated from state agency records and information obtained via telephone survey. The disposition of wastes (by volume) were estimated from API developed ratios where available.

Table E.1 compares the reduction in drilling waste with the reductions in the number of drilled wells and the total drilled footage since 1985. Note that the percent reduction in waste volume lags behind the percent reduction in drilling activity by about $8 \%$. As would be expected, waste volume is more closely linked with drilled footage lagging behind a reduction in this value by only about $4 \%$. On a volume percentage basis, approximately $55 \%$ of reserve pit waste is drilling mud, $33 \%$ is water, $9 \%$ is drill cuttings, $2 \%$ is other wastes, and the remaining $1 \%$ is cement and test fluid. The API reported slightly different percentages in their 1985 study with $63 \%$ mud, $24 \%$ water, $10 \%$ cuttings, $2 \%$ other wastes, and $1 \%$ cement and test fluid. The data in Table E.1 indicate that the volumes of drilling waste generated in the U.S. has steadily decreased over the last several years. Information on the disposition of drilling waste could not be developed because of insufficient data.

Table E.1. Reduction trends in drilled wells, drilled footage, and waste volumes.

\begin{tabular}{|c|c|c|c|c|c|c|}
\hline Year & $\begin{array}{c}\text { \# Drilled } \\
\text { Wells }\end{array}$ & $\begin{array}{c}\text { \% Reduction } \\
\text { Since 1985 }\end{array}$ & $\begin{array}{c}\text { Total Drilled } \\
\text { Footage }\end{array}$ & $\begin{array}{c}\text { \% Reduction } \\
\text { Since 1985 }\end{array}$ & $\begin{array}{c}\text { Waste Volume } \\
\text { (bbls) }\end{array}$ & $\begin{array}{c}\text { \% Reduction } \\
\text { Since 1985 }\end{array}$ \\
\hline 1985 & 69,734 & 0 & $306,897,643$ & 0 & $361,409,000$ & 0 \\
\hline 1988 & 35,959 & 48 & $170,726,402$ & 44 & $216,542,355$ & 40 \\
\hline 1990 & 33,820 & 52 & $161,159,143$ & 47 & $209,141,723$ & 42 \\
\hline 1992 & 23,506 & 66 & $120,046,451$ & 61 & $149,877,313$ & 59 \\
\hline
\end{tabular}

To develop produced water production information, various agencies in 31 states identified as having significant oil and/or gas production activity were contacted and asked to provide information on the number of active wells in the state and annual production volumes of oil, gas, and produced water for the years $1986-1991$. Twenty 
of the 31 states contacted were able to provide produced water data. Produced water estimates were computed for the remaining 11 states using either:

1. water/oil ratios developed in the API Survey or,

2. water/oil ratios from nearby states where API ratios were not available.

The collected data, summarized in Table E.2 for the nation as a whole, indicate that the annual production of produced water has followed a general decline over the six year period 1986 - 1991 falling from 19.5 billion barrels to 18.3 billion barrels. If a decreasing trend in produced water volumes were assumed to exist, this range of volumes would be in agreement with the 1985 API figure of 20.9 billion barrels estimated from the operator survey, though the API estimate was based on only 22 states. The range of produced water volumes estimated for the years $1986-1991$ is largely in excess of the 1985 estimates made using state agency data by both the API (16.3 billion barrels) and the EPA (11.7 billion barrels) which included 31 and 33 states respectively. The disposition of produced water, also summarized in Table E.2 for the nation as a whole, was determined from ratios developed by the API in their 1985 operator survey.

Table E.2. Nationwide annual production and produced water disposal volumes.

\begin{tabular}{|c|c|c|c|c|c|c|c|}
\hline Year & $\begin{array}{c}\text { Oil } \\
\text { (bbls) }\end{array}$ & $\begin{array}{c}\text { Gas } \\
\text { (MCF) }\end{array}$ & \multirow{2}{*}{$\begin{array}{c}\text { Water } \\
\text { (bbls) }\end{array}$} & Deep Well Inj. & EOR & NPDES & Other \\
\hline 1986 & $2,720,646,186$ & $17,957,909,937$ & $19,534,658,680$ & $5,875,842,286$ & $11,854,463,254$ & $1,117,708,761$ & $585,796,227$ \\
\hline 1987 & $2,627,634,902$ & $18,794,213,261$ & $18,939,917,234$ & $5,774,333,897$ & $11,402,261,401$ & $1,084,927,919$ & $575,966,702$ \\
\hline 1988 & $2,575,643,843$ & $19,482,614,541$ & $18,823,091,098$ & $5,764,520,484$ & $11,344,847,501$ & $1,049,948,155$ & $572,213,310$ \\
\hline 1989 & $2,398,956,463$ & $19,615,524,034$ & $18,165,928,450$ & $5,635,050,428$ & $10,903,476,234$ & $991,228,666$ & $542,483,575$ \\
\hline 1990 & $2,324,506,158$ & $20,056,865,852$ & $18,411,434,852$ & $5,779,805,218$ & $11,032,607,924$ & $975,836,411$ & $543,034,575$ \\
\hline 1991 & $2,306,576,111$ & $20,340,724,339$ & $18,330,045,271$ & $5,830,546,684$ & $10,926,716,921$ & $960,198,024$ & $533,264,834$ \\
\hline
\end{tabular}

Though it includes nationwide data on waste volumes, the main thrust of the PED was to complete an assessment of potential environmental impacts associated with current oil and gas drilling and production activities at the local scale. The most 
significant component of the PED is the collection of environmental settings data that is necessary to evaluate the impacts of oil and gas activities on their surroundings. The environmental settings data collected for the PED includes information on the physical characteristics of the land surface and the potential pollution "receptors" surrounding drilling and extraction activities. Information of this type has been gathered for eight counties within the state of Texas (Figure E.1), representing a cross section of oil and gas activities in that state. The state of Texas is being used as a model with the idea that this model can be duplicated for other states in the future.

The environmental settings analysis was performed using a Geographic Information System (GIS). The GIS system provided for the storage, processing, and manipulation of several hundred megabytes of electronic data required for the environmental assessment. In the GIS, each set of data or information is known as a coverage. A coverage is an electronic map layer that may be derived from a physical map that is digitized, from tabular data, or from a combination of the two. Information contained on separate coverages may be combined and geographic relationships may be developed between them. Data on environmental settings were obtained from various state and federal agencies and assimilated into the GIS to develop the coverages listed in Table E.3.

The environmental analysis was performed in two parts. The first part was concerned with assessing the potential environmental impacts of oil and gas well drilling operations. A portion of the Well History Control System (WHCS) database obtained from Petroleum Information containing well completion data for the years 1988, 1990, and 1992 served as the basis for this analysis. The second part of the environmental analysis dealt with the potential environmental impact of produced water. To perform this analysis, information on the location of injection, plugged, and abandoned wells (three primary sources of produced water impacts) was extracted from the Well Bore Database maintained by the Railroad Commission of Texas. 


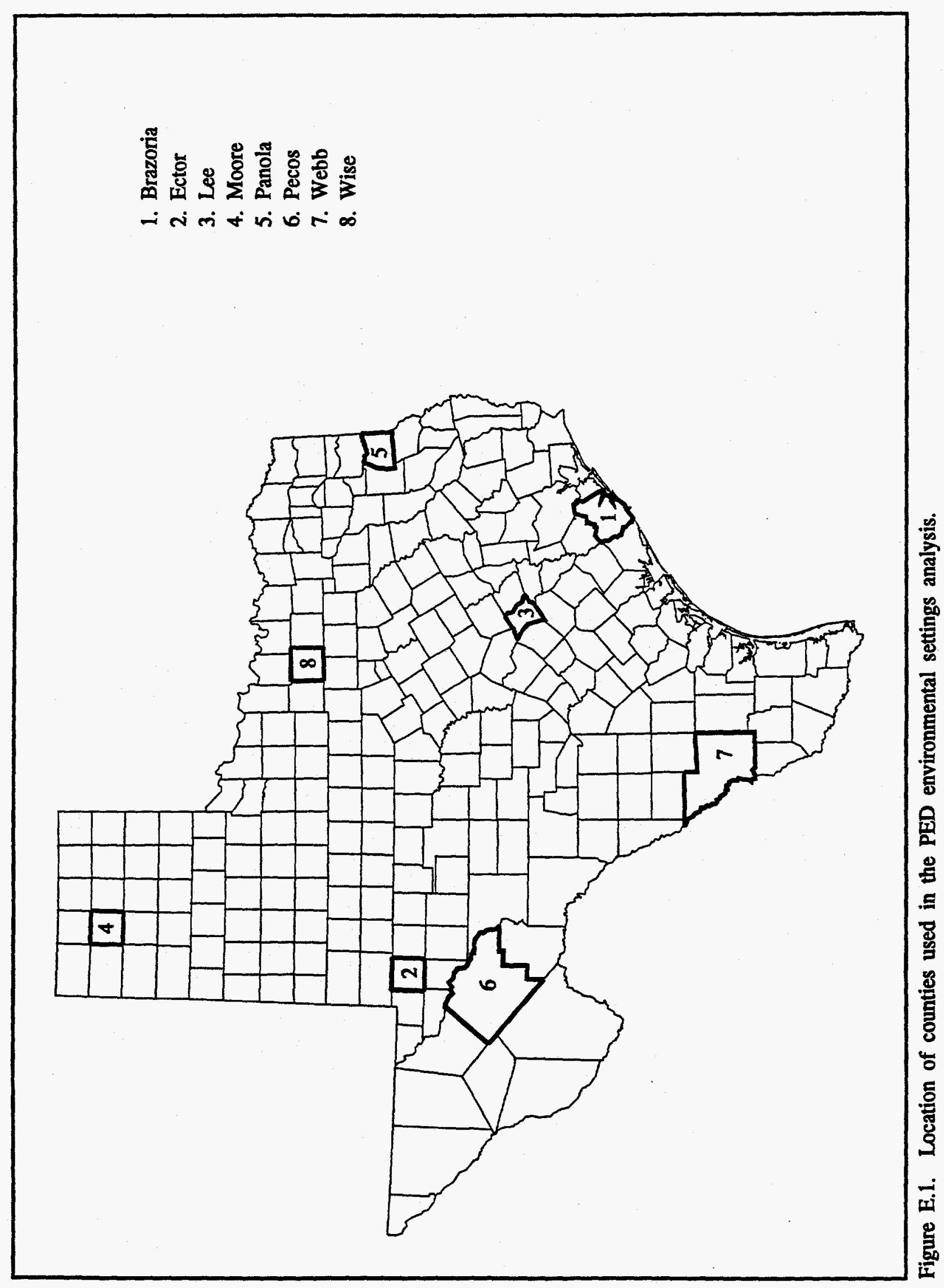


Table E.3. Environmental settings GIS coverages.

\begin{tabular}{|l|c|}
\hline \multicolumn{1}{|c|}{ Coverage } & Source \\
\hline State \& county boundaries & USGS \\
\hline Hydrography & USGS \\
\hline Transportation & USGS \\
\hline Landuse/landcover & USGS \\
\hline Parklands & Texas Parks and Wildlife \\
\hline Freshwater aquifer regions & Texas Natural Resource Information System \\
\hline DRASTIC regions & Texas Water Commission \\
\hline Soil type & Soil Conservation Service \\
\hline Floodplains & Federal Emergency Management Agency \\
\hline Water supply wells & Texas Water Development Board \\
\hline Rain gages (mean precip.) & National Weather Service \\
\hline NPDES brine discharges & Railroad Commission of Texas \\
\hline Drilled wells 1988,1990,1992 & Petroleum Information Corp. \\
\hline Oil and gas well bores & Railroad Commission of Texas \\
\hline
\end{tabular}

The analysis of environmental settings surrounding oil and gas activities in the 8 Texas counties showed that local conditions can be far different from those described by the EPA in their nationwide study and used in their risk assessment (U.S.EPA, 1987b). In the counties examined, oil and gas drilling sites and injection, plugged, and abandoned well sites were generally found to be nearer to surface water features and farther from water supply wells than estimated by EPA in their nationwide analysis. Despite being distributed farther from water supply wells, however, the number of domestic and public supply wells in close proximity to oil and gas activities was found to be surprisingly high in several counties including Brazoria, Ector, Lee, Panola, Webb, and Wise. The DRASTIC indices representing hydrogeologic settings surrounding oil and gas activities in the 8 counties generally point to lower aquifer vulnerability than suggested by the EPA settings. DRASTIC refers to an aquifer vulnerability indexing system developed by the National Water Well Association and is discussed further in section 4.3.8

By placing the environmental settings data in a Geographical Information System, the relationships between oil and gas drilling and production activities and 
surrounding features can be quickly assessed and the scale of potential impacts can be readily quantified. In addition, drilling sites or injection well sites that pose a particular risk can be identified, and singled out for more rigorous environmental control. Likewise, abandoned wells can be prioritized for plugging according to the relative level of risk defined by surrounding features. These are among the potential uses of the PED.

\section{E.4 Evaluation of Technologies and Costs for Produced Water Treatment}

The evaluation of feasible technologies for the treatment of produced water waste streams was handled in the context of comparing the level of treatment achievable with the associated cost of treatment. Treatment schemes were evaluated for three representative flow rates: $0.01,0.1$, and 1 million gallons per day (MGD) (37.85, 378.5 , and $3,785 \mathrm{~m}^{3} / \mathrm{d}$ ). The quality of a produced water was judged by quantifying the amounts of material present in four different categories of produced water contaminants. These categories were: 1) particulate and emulsified materials, 2) volatile organic compounds (VOCs), 3) adsorbable organic materials, and 4) dissolved inorganic constituents. Treatment processes were selected for evaluation based their ability to remove contaminants in one of these four categories. Different levels of treatment, up to and including drinking water quality, were assessed. The chemical analyses of approximately 120 produced waters were compiled and assembled into a database. This database served as the source of produced water characterization data used in the evaluation of treatment technologies and costs.

The treatment technologies evaluated were limited to those that are known to be capable of removing one of the four categories of contaminant listed above. For the removal of particulate materials, coagulation/settling processes were evaluated in the context of commercially available package treatment plants. For the removal of volatile organic compounds, packed tower aeration (PTA) was evaluated. Two different 
processes, granular activated carbon (GAC) adsorption and powdered activated carbon (PAC) addition, were evaluated and compared for the removal of adsorbable organics. Finally, the removal of dissolved inorganic species was evaluated using both reverse osmosis (RO) and forced evaporation.

In a project for the EPA, Gumerman et al. (1979) developed cost curves for processes commonly used to remove waterborne contaminants listed in the National Interim Primary Drinking Water Regulations (Federal Register, title 45, part 168, August 27, 1980). These curves describe construction costs that were formulated from conceptual designs of unit processes and operation and maintenance costs developed from projected costs associated with labor, maintenance materials, and energy requirements for the processes. These cost curves served as the basis for the cost analyses completed in this study. Cost updating was performed to bring the cost data of Gumerman et al. (1979) in line with current market conditions. Cost data from different times are updated using cost indices. Indices for broad categories of items or for specific items are available and can be used to update a group of associated costs. The exact procedure for updating costs that was used in this study is described in Qasim et al. (1992).

The total costs for the treatment of several representative waste streams are represented in Figure E.2. The columns in this figure are labeled with the dominant waste stream characteristic. Representative waste stream R14 represents a produced water that has a total disolved solids (TDS) concentration of 500,000 ppm. The desalination cost for this waste stream dominates the costs associated with the removal of all other contaminants found in the water. Waste stream R7 is described as high quality because suspended solids is the only category of contaminant contained in this water that requires treatment in order to bring the quality of the waste stream to the drinking water standard. The cost bars shown in Figure E.2 illustrate which of the waste stream constituents are the most expensive to remove. The removal of dissolved 
solids from any waste stream which has a significant amount of TDS will usually dominate the cost of treatment. The costs associated with the treatment necessary to remove the highest levels of contaminants found in the other categories are overshadowed by the cost of removing a significant amount of TDS. The total treatment costs shown in Figure E. 2 were obtained from the cost curves that have been created for each of the different treatment processes.

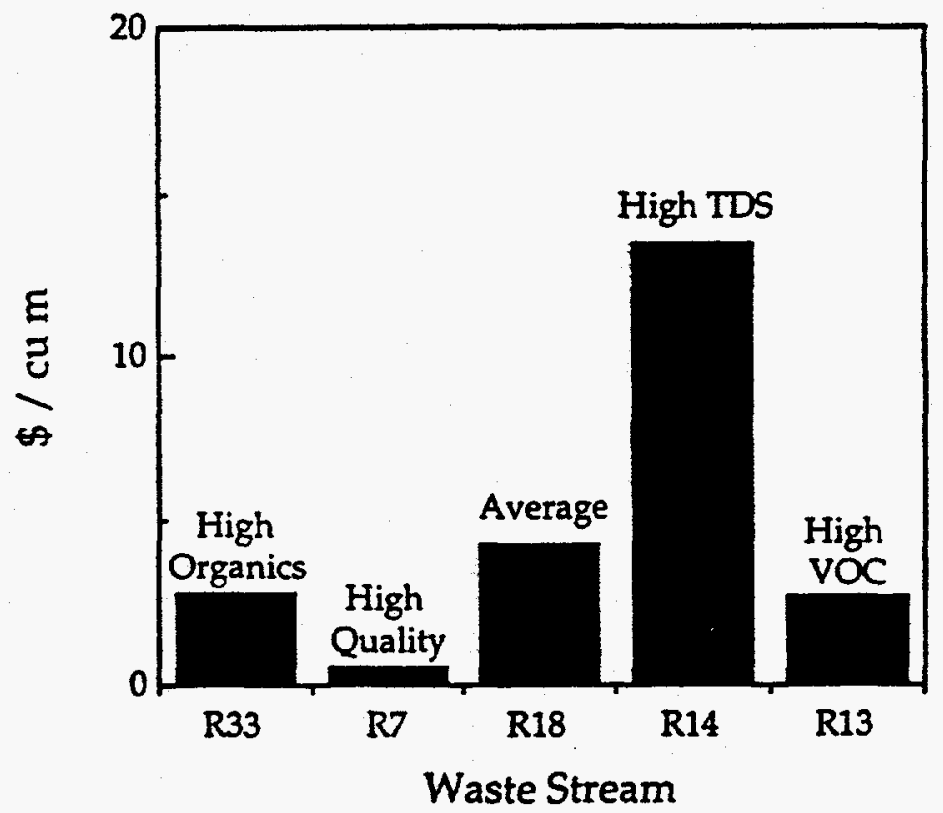

Figure E.2. Total costs associated with the treatment of several representative waste streams. The flow rate of each stream is equal to $0.1 \mathrm{MGD}\left(378.5 \mathrm{~m}^{3} / \mathrm{d}\right)$.

The costs associated with the treatment of the representative waste streams shown in Figure E.2 can be used to estimate the costs associated with the treatment of all of the produced water that is generated in a typical year in the United States. The relative levels of contaminants found in produced waters were identified from a simple statistical analysis of the 120 waters contained in the assembled produced water database. Geometric means were calculated for all of the constituents contained in the database. Using these mean values, a particular produced water that most nearly 
matched the mean contaminant levels was chosen to represent the average quality of produced water. This average water is labeled R18 in Figure E.2. The estimated cost of treating this water, achieving the removal of most solids and undesirable inorganic contaminants (TDS levels at or below $500 \mathrm{mg} / \mathrm{l}$ ), as well as adsorbable and strippable organic levels of 0.5 and $0.8 \mathrm{mg} / \mathrm{l}$, respectively was found to be almost $\$ 5 / \mathrm{m}^{3}$. If the annual total U.S. volume of produced water in a given year is taken to be 3 billion $\mathrm{m}^{3}$ ( 18.3 billion bbls), the cost of treating all of it to this level would be 15 billion dollars per year. 


\subsection{INTRODUCTION}

\subsection{Background}

Wastes from the exploration, development, and production of crude oil and natural gas have historically been exempt from Federal regulation as hazardous wastes under the RCRA (Section 3001(b)(2)(A)). An extensive study of these wastes by the EPA in 1986 concluded that they do not pose a significant threat to human or environmental health and that regulating them as hazardous under RCRA would be unjustified and would place an undo economic burden on the oil and gas industry as well as severely strain existing hazardous waste transportation, disposal, and regulatory resources (U.S.EPA, 1987a). Rather, the EPA concluded that these wastes could be adequately managed according to other existing state and Federal regulatory programs. However, because a level of uncertainty continues to surround the composition and fate of oil and gas wastes in the environment, the issue of just how they should be regulated continues to be debated. The DOE recently initiated a new program of research relating to the environmental aspects of oil and gas extraction. The program's mandate presents needs for improving the cost effectiveness of environmental protection, managing drilling and production wastes and emissions, determining the environmental impacts of advanced recovery processes and developing technologies to minimize those impacts, and developing data management systems and technology transfer plans to oil and gas operators, Federal and state agencies, and to the scientific community. This study, funded by DOE, is a product of that program.

The justification for this work stems from the lack of environmental impact assessment data associated with oil and gas extraction activities, and the need for studies on the feasibility of current and alternative treatment methods for generated waste streams. The EPA study and an independent study completed by the API (Wakim, 1987) both provide data on volumes of wastes generated and disposal 
practices used prior to 1985 , but contain limited and largely generalized information on the impacts those practices have on the environment. Neither of the two studies provides sufficient site-specific environmental data that could be used in a comparative analysis with nationwide, state or regional disposal practices.

\subsection{Oil and Gas Drilling and Production}

Petroleum resources (crude oil and natural gas) are generally recovered from within the earth through drilled holes. From 1981 through 1985 oil and gas well drilling activity in the United States occurred at an average rate of 73,000 wells per year (U.S.EPA, 1987b). A worldwide drop in oil prices in 1986 caused a dramatic decrease in the amount of domestic drilling activity with only 38,000 wells drilled that year. Since 1986, drilling activity has continued at a slower pace averaging only 25,000 wells per year through 1991. Approximately $30 \%$ of drilled wells turn out to be dry holes and are not converted to production wells. Drilling and production activity in the United States is almost entirely limited to 31 states excluding most of New England, the upper Midwest, and a few Mid-Atlantic and Western states.

The primary method of well drilling is rotary drilling. In this method, a drill bit is attached to the end of a drill pipe and the pipe and bit are rotated causing the rock at the bottom of the hole to be chipped away. As the well is drilled, fluid is circulated down the drill pipe to cool the drill bit and to pick up the cuttings and carry them to the surface through the open well bore. This drilling fluid, sometimes referred to as mud because of its appearance, also acts to maintain pressure in the well to prevent collapse of the well bore. At the surface, the drilling fluid is separated from the cuttings and largely recirculated. The cuttings and excess fluid are deposited into an earthen pit excavated near the drill site and known as a reserve pit. The reserve pit may also receive other wastes such as spent well-completion and reservoir stimulation fluids, 
produced water, waste lubricants and hydraulic fluids, sewage, and miscellaneous drill site waste.

Because of its multi-purpose function, drilling fluid is a complex mixture of colloidal materials (primarily clays), weighting materials (barite or fine sand), and various chemical additives such as corrosion inhibitors, wetting agents, defoamers, flocculants, surfactants, biocides, and lubricants. Drilling fluids are commonly classified according to the base fluid as water-based, oil-based, or gaseous. In the United States, water-based fluids predominate. Oil-based drilling fluids account for approximately $5-10 \%$ of the total volume of drilling fluids used and the oil base may consist of crude oil, refined oil (usually kerosene or diesel oil), or mineral oil. Gaseous drilling fluids may be used in special drilling operations such as in hard and dry rock or in very shallow wells where the maintenance of subsurface pressure is not required.

If, after drilling, downhole tests show a hydrocarbon zone to be economical for production, a production casing will be set and the well will be completed. The production casing seals off the well bore and creates a permanent well through which the production zones may be reached. Well casing requirements vary from state to state. Completion of a production well may involve various reservoir stimulation techniques to enhance production. Specialized fluids are used to perform reservoir stimulation and to provide long term corrosion protection of the casing. These fluids may also end up as part of the reserve pit wastes.

Once placed in production, an oil or gas well will produce water along with the crude oil or natural gas. The amount of water produced can be significant, sometimes constituting as much as $98 \%$ of the wellhead fluids. This water must be separated from the production stream. Typically, the amount of water produced increases with the age of the well. Produced water is generally high in dissolved solids (brackish or brine) and may contain a variety of residual components that result from drilling and recovery operations. It represents the largest volume of oil and gas production waste that must 
be disposed of. Methods of produced water disposal include reinjection to the subsurface, surface water discharge, evaporation from pits, livestock watering, and road spreading.

\subsection{Objectives}

The objective of this study was to update and enhance the current state of knowledge with regard to oil and gas waste quantities, the potential environmental impact of these wastes, potential methods of treatment, and the costs associated with meeting various degrees of treatment. To meet this objective, the study consisted of three tasks: 1) the development of a Production Environmental Database for the purpose of assessing current oil and gas waste volumes by state and for investigating the potential environmental impacts associated with current waste disposal practices on a local scale; 2) the evaluation of available and developing technologies for treating produced water waste streams and the identification of unit process configurations; and 3) the evaluation of the costs associated with various degrees of treatment achievable by different treatment configurations.

\subsubsection{The Production Environmental Database}

The purpose of the Production Environmental Database is to establish current estimates of the volume of waste generated by onshore oil and gas exploration and production activity and to make an assessment of the impact those wastes have on the natural environment. The PED was initially conceived as a nationwide database as outlined in the technical proposal to DOE. An environmental profile of oil and gas waste disposal practices by state and by region was to have been developed. However, the scope of this task was narrowed significantly when the planned oil and gas operator survey could not be completed. This survey was to have provided the necessary information for construction of the PED. Instead, only waste volumes were estimated 
on a national scale and the environmental analysis was limited to the state of Texas (specifically, 8 counties within the state). The revised objectives for the PED were therefore:

1. Estimate the nationwide annual quantities of drilling waste generated by oil and gas exploration and development activities by state.

2. Estimate the nationwide annual quantities of produced water generated by oil and gas production activities by state.

3. Estimate the nationwide waste disposal volumes by type of disposal practice on a state by state basis.

4. Establish the characteristics of the environmental settings that surround oil and gas activities at the local scale and develop some statistical distributions of important parameters.

5. Investigate the potential surface and subsurface environmental impacts of oil and gas drilling and production waste disposal at the local scale using the established environmental settings.

6. Assess the differences in potential environmental impacts analyzed on a local scale from those determined from the EPA nationwide analysis.

7. Assimilate all the data in an electronic database that can be used for technology transfer purposes and future updates as applicable.

\subsubsection{Feasible Technologies for Treatment of Waste Streams}

Assessment of the impacts of waste generation and disposal must be made within the context of the technologies available for treating and disposing of these wastes as well as the relative costs of these technologies. Task 2 of this project was aimed at delineating the candidate physical-chemical processes and configurations that could be used to treat produced water for the removal colloidal contaminants, volatile organic compounds, adsorbable organic materials, and dissolved inorganic species. The objective of Task 2 was to evaluate process configurations capable of achieving various 
degrees of purity of the treated water using five purity goals corresponding to waters of suitable quality for:

1. discharge to a sanitary sewer (high levels of low-toxicity contaminants),

2. ground water re-injection (low levels of colloids, organics, and certain inorganics),

3. discharge to the ocean (low levels of toxic organic compounds, high salinity),

4. irrigation (low levels of high-valence metals, organics, and moderate salinities) and,

5. potable water (extremely high quality water).

\subsubsection{The Cost of Produced Water Treatment Technologies}

For each of the process configurations developed in Task 2, costs estimates, valid for purposes of facility planning, were generated. Cost estimates of this accuracy are frequently necessary to eliminate non-cost-effective alternatives and to concentrate research and engineering efforts leading to the most promising end results (Clark, 1982). However, such estimates are not based on detailed design as would be required to produce a definitive estimate for the actual construction of a treatment facility.

The objective of this task was to produce cost estimates from flow diagrams for configurations of unit processes determined to provide a specific level of treatment and to construct trade-off curves for treatment cost versus the level of treatment. By comparing level of the treatment with the associated environmental impacts, this method provides an indication of the increased investment in treatment necessary to achieve a certain reduction in the level of impacts. 


\subsection{Scope of Study}

\subsubsection{The Production Environmental Database}

Annual drilling waste volume estimates were computed for all onshore oil and gas wells completed in the years 1988, 1990, and 1992 in the lower 48 states and are reported by state and by waste type. Despite having significant oil and gas activity, Alaska was excluded from the study of drilling waste because of the unique operating environment in that region. Produced water volumes, obtained from the Alaska Oil and Gas Conservation Commission are reported for that state, however. The year 1992 was chosen for the study because it represented the most recent data available when this study began. The years 1988 and 1990 were included in order to gain insight into any recent trends that may exist.

Annual produced water production and disposal volumes for the years 1986 1991 were estimated from state agency data obtained through a survey of 31 oil and gas producing states and are reported on a per state basis. Along with volumes of produced water, annual volumes of oil and gas production and information on the number of production related wells are also reported. The 31 states selected for the survey represent essentially all of the domestic oil and gas production activity. States were excluded on the basis of drilling activity. Those states that averaged 5 or fewer wells drilled annually over the period 1986 - 1991 were considered to be minor contributors of oil and gas wastes and were therefore not surveyed. In the case of production data, the year 1991 represents the most recent available data due to the typical one year lag in assembling and publishing information by state agencies.

The analysis of environmental settings surrounding oil and gas drilling and extraction activities was completed for 8 counties within the state of Texas. The state of Texas was selected for analysis because, in addition to the logistical benefits of having the research team located within the state, the state met the additional criteria of being a major oil and gas producer and having multiple producing basins located within varied 
physiographic regions. The environmental analysis was further restricted to 8 individual counties within the state in order to keep the amount of data processing within a reasonable level for this project. The counties included in the analysis were the following:
1. Brazoria
2. Ector
3. Lee
4. Moore
5. Panola
6. Pecos
7. Webb
8. Wise

These counties were selected according to the level of drilling and production activity relative to all counties within the state with the added constraint that a good geographic cross section of the state be represented in the selection set. Some of the features of the selected counties are outlined in Table 1.1. The locations of the counties within the state are shown in Figure 1.1.

Table 1.1. Selected Texas counties for the PED environmental settings analysis.

\begin{tabular}{|l|l|c|c|c|c|c|c|c|}
\hline County & Location Descriptor & $\begin{array}{c}1990 \text { Oil } \\
\text { Production } \\
\text { (bbls) }\end{array}$ & $\begin{array}{c}\text { *Oil } \\
\text { Prod. } \\
\text { Rank }\end{array}$ & $\begin{array}{c}1990 \text { Gas } \\
\text { Production } \\
\text { (MCF) }\end{array}$ & $\begin{array}{c}\text { *Gas } \\
\text { Prod. } \\
\text { Rank }\end{array}$ & $\begin{array}{c}\text { Comb. } \\
\text { Prod. } \\
\text { Rank }\end{array}$ & $\begin{array}{c}1990 \\
\text { Total } \\
\text { Wells }\end{array}$ & $\begin{array}{c}\text { Total } \\
\text { Wells } \\
\text { Rank }\end{array}$ \\
\hline Brazoria & Gulf Coast & $3,707,818$ & 39 & $66,341,595$ & 16 & 16 & 2,226 & 54 \\
\hline Ector & West Texas & $35,881,311$ & 3 & $73,291,963$ & 12 & 6 & 12,487 & 2 \\
\hline Lee & Hill Country & $3,063,824$ & 45 & $4,180,115$ & 109 & 112 & 1,232 & 95 \\
\hline Moore & Panhandle & 793,658 & 116 & $77,330,497$ & 9 & 10 & 2,337 & 52 \\
\hline Panola & Sabine River Valley & 553,161 & 132 & $197,819,125$ & 4 & 4 & 2,616 & 47 \\
\hline Pecos & West Texas & $25,733,390$ & 7 & $256,884,555$ & 3 & 1 & 6,939 & 8 \\
\hline Webb & Rio Grande Valley & 449,911 & 142 & $269,887,422$ & 1 & 2 & 3,241 & 34 \\
\hline Wise & High Plains & $1,099,395$ & 101 & $61,973,017$ & 18 & 18 & 3,840 & 28 \\
\hline
\end{tabular}

*Ranking out of 254 total counties ( 215 with oil and/or gas production). 


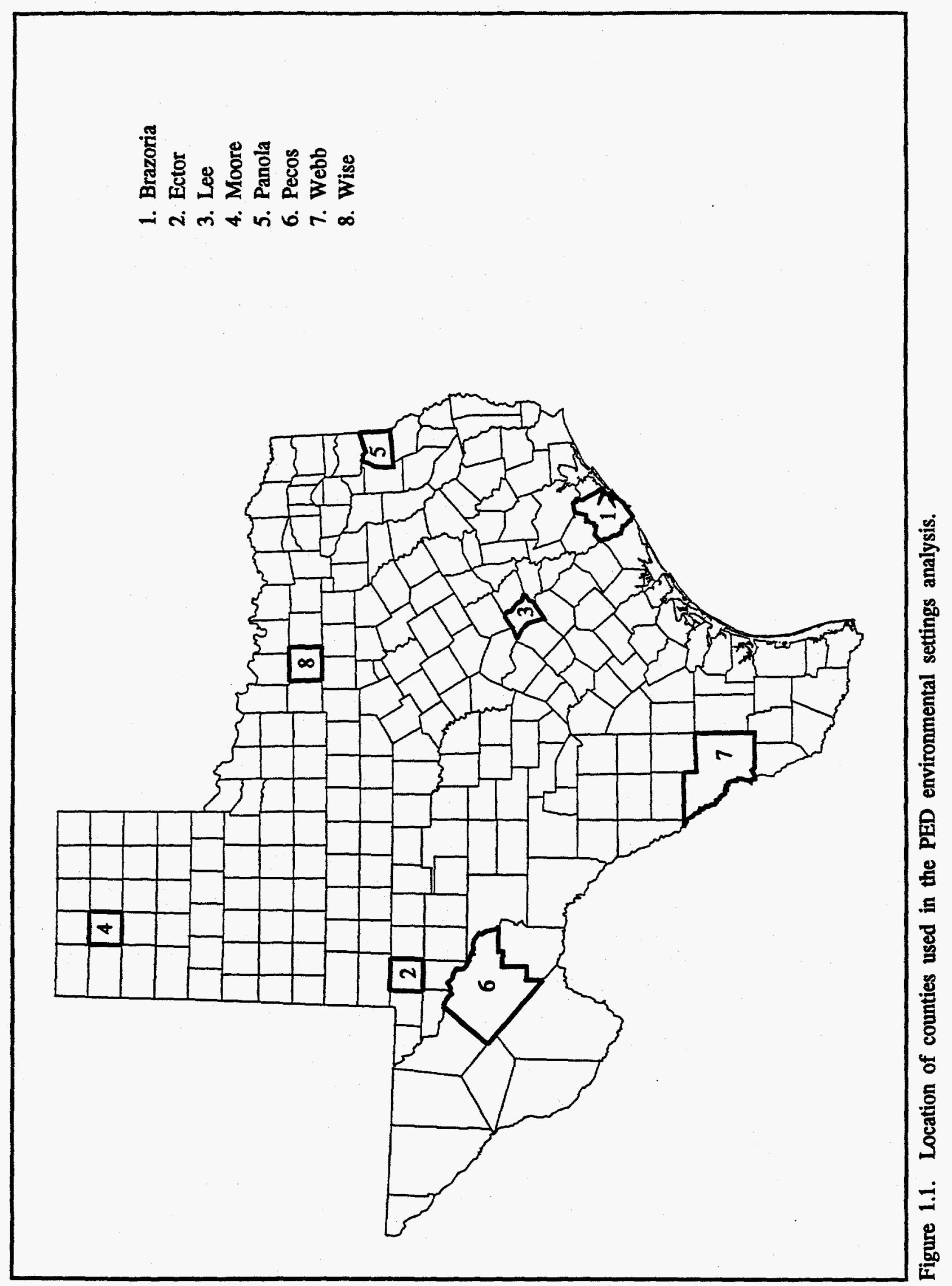




\subsubsection{Feasible Technologies for Treatment of Waste Streams}

The technologies evaluated were limited to those that are known to be capable of removing one of four categories of contaminant from water: 1) particulate and emulsified materials, 2) volatile organic compounds, 3) adsorbable organic compounds, and 4) dissolved inorganic constituents. For the removal of particulate materials, coagulation/settling processes were evaluated in the context of commercially available package treatment plants. For the removal of volatile organic compounds, packed tower aeration was evaluated. Two different processes, GAC adsorption and PAC addition, were evaluated and compared for the removal of adsorbable organics. Finally, the removal of dissolved inorganic species was evaluated using both reverse osmosis and forced evaporation.

\subsubsection{The Cost of Produced Water Treatment Technologies}

Cost estimates in this study were limited to those items directly included in the construction and operation of a water treatment facility. Capital cost describes the investment required to construct and begin operation of the treatment plant, principally the cost of materials, labor, and interest. Operation and maintenance costs include the costs associated with the labor, material, and energy required to operate and maintain the treatment plant. Disposal costs associated with residual waste streams were also included, though the residual waste stream generated during the execution of a water treatment unit process will not always have a cost associated with its disposal that is directly imputable to the disposer. 


\subsection{Methods and Approach}

\subsubsection{The Production Environmental Database}

The methods used for the estimation of waste quantities were adapted from the earlier oil and gas waste studies completed by the EPA (U.S.EPA, 1987b) and the API (Wakim, 1987). For purposes of their study, the EPA divided oil and gas wastes into two broad categories: drilling wastes and production wastes. Estimates were made of the annual volumes of these wastes generated during the period 1981 - 1985. Drilling wastes included drilling fluids, drill cuttings, well completion fluids, packing fluids, reservoir stimulation fluids, and other miscellaneous wastes that are normally deposited in a drill site reserve pit. Production wastes were defined to include produced water and associated wastes such as tank bottoms. In order to estimate drilling waste quantities, the EPA developed a set of generic reserve pit volumes to represent small, medium, and large pits. Assumptions were made about the percentage of each pit size used in each state. For example, for the state of Texas, it was assumed that no pits were small, $50 \%$ of pits were medium, and $50 \%$ of pits. were large. Estimates of drilling waste volumes were made for each state by multiplying the total number of wells drilled in a given year by the reserve pit volume, then multiplying the result by the percentage of pits of that size in the state.

The API based their waste volume estimates on the results of an operator survey. The survey sample contained 659 wells, about $1 \%$ of all the wells drilled in 1985 . The API also chose to divide the reserve pit wastes into six individual components as follows:

1. Mud and completion fluid (including water phase)

2. Drill cuttings

3. All other water

4. Circulated cement

5. Formation testing fluids 


\section{Other fluids or solids}

For purposes of waste volume estimations, components $1-4$ were handled differently than components 5 and 6. For components $1-4$, the continental United States was divided into 48 producing basins (46 in the lower states, 2 in Alaska) having similar drilling and production characteristics. Each well in the survey sample was then assigned to its corresponding production basin. This method of grouping wells was based on the notion that it is the type of formation and geological conditions that determine most drilling practices, and not the state in which the well is located. Because many producing basins were underrepresented in the sample, individual producing basins were grouped together according to similar waste volume/drilled footage ratios computed for the wells in the basin. This grouping was done without regard to the geographical location of the basin, and a separate grouping was developed for each type of waste (i.e. four different basin groupings were developed). This procedure resulted in 10 to 12 basin groups for each type of waste. Using regression analysis of the survey data, a statistical model was developed for each basin group in the form of:

waste volume $=a($ footage $)+b(\text { footage })^{2}+c$

For waste components 5 and 6 a statistical model could not be developed because of many zero and missing entries on the survey forms. Instead, the wells were grouped into four depth classes:

1. $0-3,750 \mathrm{ft}$

2. $3,751-7,500 \mathrm{ft}$

3. $7,501-15,000 \mathrm{ft}$

4. over $15,000 \mathrm{ft}$

For each depth class, the volume of waste per foot of well was calculated based on the available survey data. These ratios were then applied to the total footage in each depth class in each state to compute the waste volumes. 
The API method of waste volume estimation, because of its statistical base, is clearly superior to that used by the EPA and was therefore adopted for use in this study. Drilling waste volumes for the years 1988, 1990, and 1992 were computed using the API procedure and are presented in Section 4.1. Unfortunately, due to external factors, a new industry survey could not be completed. The waste volume estimates presented in Section 4.1 are therefore based on the statistical models and ratios developed by the API using the 1985 survey data. The API statistical models were modified somewhat, however, in order to address the problem of negative waste volumes generated for some well depths in certain basin groups and to force the curve intercepts through the origin. While these modifications may degrade the statistical validity of the models, they act to make the models more reasonable. It does not make sense for a well bore to generate a negative volume of waste or for a well of zero depth to produce a positive volume of waste. The well data used in the waste volume estimates was obtained from the WHCS database maintained by Petroleum Information Corporation. The state of Alaska was not included in the analysis because of the unique factors associated with drilling and production activity in that region.

Information on produced water is generally more readily available than information on drilling waste because most state agencies maintain some produced water records. In their studies, both the EPA and the API reported produced water volumes gathered from state agencies. In many cases, however, the state maintained produced water records represent injected volumes as reported to local Underground Injection Control (UIC) offices and do not include produced water disposed of by other means. Still, because more than $90 \%$ of produced water is injected, the injected water volume typically stands as a good estimate of the total produced water volume. In cases where produced water information was not available from agency records, oil/water ratios from nearby states were used by EPA and API to compute volume estimates. 
The API actually computed two independent estimates of produced water volumes. In addition to compiling state agency data, the API generated an estimate based on an operator survey that requested crude oil and produced water volumes and produced water disposal volumes. From the responses to the survey, water/oil ratios were developed for each state and multiplied by the total oil production in the state to create an estimate of the total produced water volume.

Following the procedures used by EPA and API, the produced water data gathered for this study, and presented in Section 4.3, were obtained from state agency records. Thirty-one states were identified as having significant oil and/or gas production activity. Various agencies in each of these states were contacted and asked to provide information on the number of active wells in the state and annual production volumes of oil, gas, and produced water for the years 1986-1991. A list of the agencies contacted in each state is given in Table 1.2.

Many states were only able to provide partial information. The states of Illinois, Louisiana, and New Mexico were unable to provide any information at all. The oil and gas production statistics for these three states were obtained from data published by the Energy Information Administration (1991,1992). Only 20 of the 31 states contacted were able to provide produced water information. Data from 4 of these states (Colorado, Kansas, Texas, and West Virginia) represent injection data. Produced water estimates were computed for the remaining 11 states using either:

1. water/oil ratios developed in the API Survey or,

2. water/oil ratios from nearby states where API ratios were not available.

This computational procedure assumes that all produced water is attributable to oil production; gas production is ignored. It also assumes that water/oil ratios are similar for production in adjacent states. 
Table 1.2. Agencies contacted for produced water and other production and disposal information.

\begin{tabular}{|c|c|c|c|}
\hline State & Agency & Primary Contact & Phone \\
\hline Alabama & Alabama State Oil and Gas Board & Mr. Richard Raymond & $(205) 349-2852$ \\
\hline Alaska & Oil and Gas Conservation Commission & Ms. Blair Wondzell & $(907) 279-1433$ \\
\hline Arkansas & Arkansas Oil and Gas Commission & Mr. Marty Perdue & $(501) 862-4965$ \\
\hline California & Department of Conservation - Division of Oil and Gas & Mr. Mike Stettner & $(916) 323-1777$ \\
\hline Colorado & Dept. Natural Resources - Oil and Gas Conservation Comm. & Mr. Jim Kenny & $(303) 894-2100$ \\
\hline Florida & Department of Natural Resources & Mr. David Curry & $(904) 487-2219$ \\
\hline Illinois & Dept. Mines and Minerals - Oil and Gas Division & Mr. Doug Shutt & $(217) 782-7756$ \\
\hline \multirow[t]{2}{*}{ Indiana } & Dept. Natural Resources - Division of Oil and Gas & Mr. Bill Bye & (317)232-4055 \\
\hline & Indiana Geological Survey Division & Mr. John Rupp & $(812) 855-5412$ \\
\hline Kansas & Kansas Corporation Commission & Ms. Jonelle Rains & $(316) 263-3238$ \\
\hline \multirow[t]{3}{*}{ Kentucky } & Dept. Mines and Mining - Division of Oil and Gas & Mr. Brian Gilpin & $(606) 254-0367$ \\
\hline & Kentucky Division of Water & Mr. Dan Juwett & $(502) 564-3410$ \\
\hline & Revenue Cabinet - Severence Section (Production Volumes) & Ms. Stacy Crume & $(502) 564-4581$ \\
\hline Louisiana & Dept. Natural Resources - Office of Conservation & Mr. Jim Welsh & $(504) 342-5515$ \\
\hline Michigan & Dept. Natural Resources - Geological Survey Division & Mr. Ray Vugrinovich & (517) $334-6945$ \\
\hline Mississippi & State Oil and Gas Board & Mr. Fred Hille & $(601) 354-7127$ \\
\hline Missouri & Dept. Natural Resources - Div. of Geology and Land Survey & Mr. Kent Deason & $(314) 368-2100$ \\
\hline Montana & Department of Natural Resources - Oil and Gas Division & Mr. Tim Fox & $(406) 656-0040$ \\
\hline Nebraska & Oil and Gas Conservation Commission & Mr. Stan Belieu & $(308) 254-4595$ \\
\hline Nevada & Nevada Department of Minerals & Ms. Cathy Loomis & $(702) 687-5050$ \\
\hline New Mexico & Energy, Minerals, and Nat. Res. Dept. - Oil Conservation Div. & Ms. Kathy Brown & $(518) 457-3682$ \\
\hline New York & Dept. Env. Cons. - Div. of Oil, Gas, and Program Management & Mr. Brad Field & $(518) 457-3682$ \\
\hline North Dakota & Industrial Commission - Oil and Gas Division & Mr. Jack Wileorn & $(701) 224-2969$ \\
\hline Ohio & Dept. Natural Resources - Division of Oil and Gas & Mr. Tom Tugend & (614)265-1037 \\
\hline \multirow[t]{2}{*}{ Oklahoma } & Oklahoma Corporation Commission - UIC Department & Mr. Tim Baker & $(405) 521-2500$ \\
\hline & Oklahoma Corporation Commission - Statistical Department & Mr. Larry Claxton & $(405) 521-2489$ \\
\hline Oregon & Oregon Department of Geology and Mineral Industries & Mr. Dan Wermiel & $(503) 731-4100$ \\
\hline Pennsylvania & Dept. Env. Res. - Bureau of Oil and Gas Management & Mr. Ron Gilius & $(717) 783-9645$ \\
\hline South Dakota & Department of Water and Natural Resources & Mr. Mack McGillivray & $(605) 394-2229$ \\
\hline \multirow[t]{2}{*}{ Tennessee } & State Oil and Gas Board & Mr. Mike Hoyal & $(615) 532-0166$ \\
\hline & Tennessee Division of Geology & Mr. Gary Pinkerton & $(615) 532-1511$ \\
\hline \multirow[t]{2}{*}{ Texas } & Railroad Commission of Texas - Oil and Gas Division & Ms. Paula Middleton & $(512) 463-6729$ \\
\hline & Railroad Commission of Texas - Environmental Services Div. & Ms. Lori Wrotenbery & $(512) 463-6810$ \\
\hline Utah & Dept. Natural Resources - Division of Oil, Gas, and Mining & Mr. Gill Hunt & $(801) 538-5340$ \\
\hline Virginia & Dept. Mines, Minerals, and Energy - Division of Gas and Oil & Mr. Steve Walz & $(804) 367-0330$ \\
\hline West Virginia & Dept. Environmental Protection - Oil and Gas Division & Ms. Jean Smith & $(304) 759-0516$ \\
\hline Wyoming & Oil and Gas Conservation Commission & Ms. Janie Nelson & $(307) 234-7147$ \\
\hline
\end{tabular}


The environmental settings data collected for the PED includes information on the physical characteristics of the land surface and the potential "receptors" surrounding extraction activities. Information of this type was gathered for eight counties within the state of Texas, representing a cross section of oil and gas activities in that state. The data was assimilated into a Geogeaphical Information System. Geographic Information Systems are ideally suited to answering the types of questions to be answered by the PED and can assist policy makers in developing an appropriate means of regulating oil and gas wastes. For this project, a commercial GIS software package developed by Environmental Systems Research Institute (ESRI) known as ARC/INFO (ESRI, 1992) was used. A Sun Microsystems SPARCstation computer served as the hardware platform.

The environmental settings analysis was performed within the ARC/INFO GIS. The GIS system provided for the storage, processing, and manipulation of several hundred megabytes of electronic data required for the environmental assessment. In the GIS, each set of data or information is known as a coverage. A coverage is an electronic map layer that may be derived from a physical map that is digitized, from tabular data, or from a combination of the two. Information contained on separate coverages may be combined and geographic relationships may be developed between them. Data on environmental settings were obtained from various state and Federal agencies and assimilated into the GIS. Table 1.3 lists the coverages developed for the PED and the sources of the data.

The environmental analysis was performed in two parts. The first part was concerned with assessing the potential environmental impacts of oil and gas well drilling operations. A portion of the WHCS database obtained from Petroleum Information containing well completion data for the years 1988, 1990, and 1992 served as the basis for this analysis. The second part of the environmental analysis dealt with the potential environmental impact of produced water. To perform this analysis, 
information on the location of injection, plugged, and abandoned wells (three primary sources of produced water impacts) was extracted from the Well Bore Database maintained by the Railroad Commission of Texas.

Table 1.3. Environmental settings GIS coverages.

\begin{tabular}{|l|c|}
\hline \multicolumn{1}{|c|}{ Coverage } & Source \\
\hline State \& county boundaries & USGS \\
\hline Hydrography & USGS \\
\hline Transportation & USGS \\
\hline Landuse/landcover & USGS \\
\hline Parklands & Texas Parks and Wildlife \\
\hline Freshwater aquifer regions & Texas Natural Resource Information System \\
\hline DRASTIC regions & Texas Water Commission \\
\hline Soil type & Soil Conservation Service \\
\hline Floodplains & Federal Emergency Management Agency \\
\hline Water supply wells & Texas Water Development Board \\
\hline Rain gages (mean precip.) & National Weather Service \\
\hline NPDES brine discharges & Railroad Commission of Texas \\
\hline Drilled wells 1988,1990,1992 & Petroleum Information Corp. \\
\hline Oil and gas well bores & Railroad Commission of Texas \\
\hline
\end{tabular}

\subsubsection{Feasible Technologies for Treatment of Waste Streams}

The evaluation of feasible technologies for the treatment of produced water waste streams was handled in the context of comparing the level of treatment achievable with the associated cost of treatment. The quality of a produced water was judged by quantifying the amounts of material present in four different categories of produced water contaminants. These categories were: 1) particulate and emulsified materials, 2) volatile organic compounds ,3) adsorbable organic materials, and 4) dissolved inorganic constituents. Treatment processes were selected for evaluation based on their ability to remove contaminants in one of these four categories. A list of the produced water constituents that were used in the characterization of individual waters is given in Table 1.4. This list of constituents was taken from API (1987). The chemical analyses of approximately 120 produced waters were compiled and assembled 
into a database. This database served as the source of produced water characterization data used in the evaluation of treatment technologies and costs.

Table 1.4. Constituents used to characterize produced water. From API (1987).

\begin{tabular}{|lll|}
\hline 1,1,1-Trichloroethane \# & Calcium & Oil \& Grease \\
1,1,2,2-Tetrachloroethane \# & Carbazole * & p-Cymene \\
1,1,2-Trichloroethane \# & Carbon Tetrachloride \# & p-Xylene \\
1,1-Dichloroethane \# & Carbonate & Pentachlorophenol * \\
1,1-Dichloroethene \# & Chloride & pH \\
1,2-Dichlorobenzene \# & Chlorobenzene \# & Phenanthrene \# \\
1,2-Dichloroethane \# & Chloroform & Phenol * \\
1,3-Dichlorobenzene \# & Chromium & Phosphorous as P \\
1,4-Dichlorobenzene \# & Chrysene * & Potassium \\
2,4,5-Trichlorophenol * & Cobalt & Pyrene * \\
2,4,6-Trichlorophenol * & COD & Selenium \\
2,4-Dimethylphenol * & Copper & Silica (SiO2) \\
2,4-Dinitrotoluene * & Cyanide & Silicate as SiO2 \\
2-Chlorophenol * & Di-n-octyl phthalate * & Silver \\
4-Chloro-3-methylphenol * & Dibenzothiophene * & Sodium \\
Acenaphthene * & Ethylbenzene & Strontium \\
Acetone \# & Fluorene * & Styrene * \\
Acrylonitrile * & Hexachlorobenzene & Sulfate \\
Alpha-Terpineol * & Hexachlorobutadiene \# & Sulfide \\
Aluminum & Hexachloroethane \# & TDS \\
Amonia as N & Hydroxide & Thallium \\
Anthracene * & Iron & Tin \\
Antimony & Lead & Titanium \\
Arsenic & m-Xylene & TOC \\
Barium & Magnesium & Toluene \# \\
Benzene \# & Manganese & Total Cyanide \\
Beryllium & Mercury & Trans-1,2-Dichloroethene \# \\
Bicarbonate & Methyl ethyl keytone \# & Trichloroethene \# \\
Biphenyl \# & Methylene chloride \# & TSS \\
Bis(2-ethylhexyl)phthalate * & Molybdenum & Turbidity (elec) \\
BOD & Napthalene \# & Vanadium \\
Bromine & Nickel & Vinyl chloride \\
Boron & Nitrate + Nitrite as N & Xylene(total) \\
Cadmium & o-Xylene & Zinc \\
\hline & & \\
& &
\end{tabular}

* = adsorbable

$\#$ = volatile 


\subsubsection{The Cost of Produced Water Treatment Technologies}

The minimum cost of produced water management is the cost of simply disposing of the water without treatment. This is most frequently accomplished by onsite deep well injection, permitted surface discharge, or hauling to an offsite disposal facility. Some pretreatment, particularly before deep well injection, is likely to be needed, however, in order to maintain well injectability and minimize well maintenance costs. Typical values given for produced water disposal range from $\$ 0.63$ to $\$ 3.15$ per cubic meter $\left(\mathrm{m}^{3}\right)$. When more extensive pretreatment is required before disposal, or when the produced water is destined for an end use such as irrigation, livestock watering, or drinking water, the cost of produced water treatment will also include the capital and operating costs of unit processes applied to the treatment of the produced water stream. These costs vary over time in response to changing prices for consumables (due to inflation or market trends) used in the treatment of the water. Cost functions must account for these time variable aspects of cost as well as relate costs to the design and operating variables for each unit process.

In a project for the EPA, Gumerman et al. (1979) developed cost curves for processes commonly used to remove waterborne contaminants listed in the National Interim Primary Drinking Water Regulations. These curves describe construction costs that were formulated from conceptual designs of unit processes and operation and maintenance costs developed from projected costs associated with labor, maintenance materials, and energy requirements for the processes. These cost curves served as the basis for the cost analyses completed in this study. Cost updating was performed to bring the cost data of Gumerman et al. (1979) in line with current market conditions. Cost data from different times are updated using cost indices. Indices for broad categories of items or for specific items are available and can be used to update a group of associated costs. The exact procedure for updating costs that was used in this study is described in Qasim et al. (1992). 
Capital costs were amortized over the useful life of the design facility. The capital recovery factor (CRF), used to spread out a capital cost over a given number of years at a specific interest rate, is defined as:

$$
C R F=\frac{I(1+I)^{N}}{\left[(I+1)^{N}-1\right]}
$$

where $I$ is the interest rate and $N$ is the number of years over which the cost will be spread. All capital costs considered in this study were spread over a period of 20 years at a 10 percent annual rate of interest. All costs, in general, are presented per unit $\left(\mathrm{m}^{3}\right)$ of treated produced water.

\subsection{Organization of this Report}

This report is organized into a series of chapters that are devoted to background information on oil and gas wastes and to the three tasks described under the objectives. The first chapter following the introduction (Chapter 2) describes the history of oil and gas waste regulation and historical and recent trends within the industry. Chapter 3 presents a review of the literature on the subjects of waste characterization and waste environmental impacts for drilling waste and for produced water as well as an overview of the produced water treatment technologies evaluated in this study.

Chapter 4 describes the Production Environmental Database. Waste volume estimates are discussed in the first part of this chapter while the second part details the analysis of environmental settings for the 8 counties within the state of Texas. Results are presented for both drilling sites and injection, plugged, and abandoned well sites and are compared with the EPA nationwide data. A separate subsection of this chapter is devoted to each setting characteristic evaluated.

Because Tasks 2 and 3 of the study are interrelated, they are combined for discussion in Chapter 5. This chapter outlines the evaluation of treatment processes 
and the assessment of costs for produced water treatment. One subsection of Chapter 5 is devoted to each of the categories of treatment evaluated: particulate removal (liquid/solid separation), volatile organic compound removal (packed tower aeration), adsorbable organic compound removal (carbon adsorption processes), and dissolved inorganic species removal (desalination processes). 


\subsection{HISTORICAL PERSPECTIVE}

In 1976, in response to growing concerns over the handling and disposal of environmentally hazardous waste materials, Congress passed the Federal Resource Conservation and Recovery Act. Regulations under this act govern the storage, treatment, transportation, and disposal of hazardous wastes. RCRA (42 USC, Sect. 6903(5)) defines a hazardous waste as a solid waste, or combination of solid wastes, which because of its quantity, concentration, or physical, chemical, or infectious characteristics may:

1. cause, or significantly contribute to an increase in mortality or an increase in serious irreversible, or incapacitating reversible, illness; or

2. pose a substantial present or potential hazard to human health or the environment when improperly treated, stored, transported, or disposed of, or otherwise managed.

Though potentially classified as hazardous wastes under RCRA, a 1980 amendment to the act granted a statutory exclusion to wastes associated with the exploration, development, and production of oil, natural gas, and geothermal energy. Provisions under this amendment required the EPA to conduct a study of oil, gas, and geothermal energy wastes to determine the effects of such wastes on human health and the environment. Upon review of the results of this study, the EPA was to make a determination as to whether the RCRA exemption was warranted. This Congressional action led to the production of two key studies: 1) the EPA Report to Congress (U.S.EPA, 1987a) and 2) an independent study of oil and gas wastes conducted by the American Petroleum Institute (Wakim, 1987). 


\subsection{The EPA Oil and Gas Waste Study}

The EPA study completed pursuant to the requirements of the 1980 RCRA amendment resulted in a rather extensive report encompassing three volumes (U.S.EPA, 1987a). The report begins with an overview of the oil and gas industry and presents estimates of waste volumes generated by the industry's activities. The report also includes an analysis of current (1985) and alternative waste management and disposal practices and a human and environmental health risk assessment. In addition, the report contains a baseline cost estimate of waste management practices and an economic impact analysis of alternative waste management practices.

\subsubsection{Waste Volumes and Characteristics}

For purposes of the study, the EPA divided oil and gas wastes into two broad categories: drilling wastes and production wastes. Estimates were made of the annual volumes of these wastes generated during the period 1981 - 1985. Drilling wastes included drilling fluids, drill cuttings, well completion fluids, packing fluids, reservoir stimulation fluids, and other miscellaneous wastes that are normally deposited in a drill site reserve pit. Production wastes were defined to include produced water and associated wastes such as tank bottoms. Using a set of generic reserve pit volumes and information on the number of wells drilled annually, the EPA study estimated that an average 2.72 billion barrels of drilling wastes were generated annually over the period 1981 - 1985 (Figure 2.1). During this time, the number of onshore drilled wells averaged about 73,000 per year (Figure 2.2). Using data gathered from state agencies, the EPA study estimated that an average 11.2 billion barrels of produced water were generated annually over the 1981 - 1985 period (Figure 2.3).

In order to chemically characterize oil and gas wastes, the EPA conducted a field sampling program. Three types of samples consisting of pit liquids, pit solids, and produced water were collected at 49 field sites across the nation during the summer of 


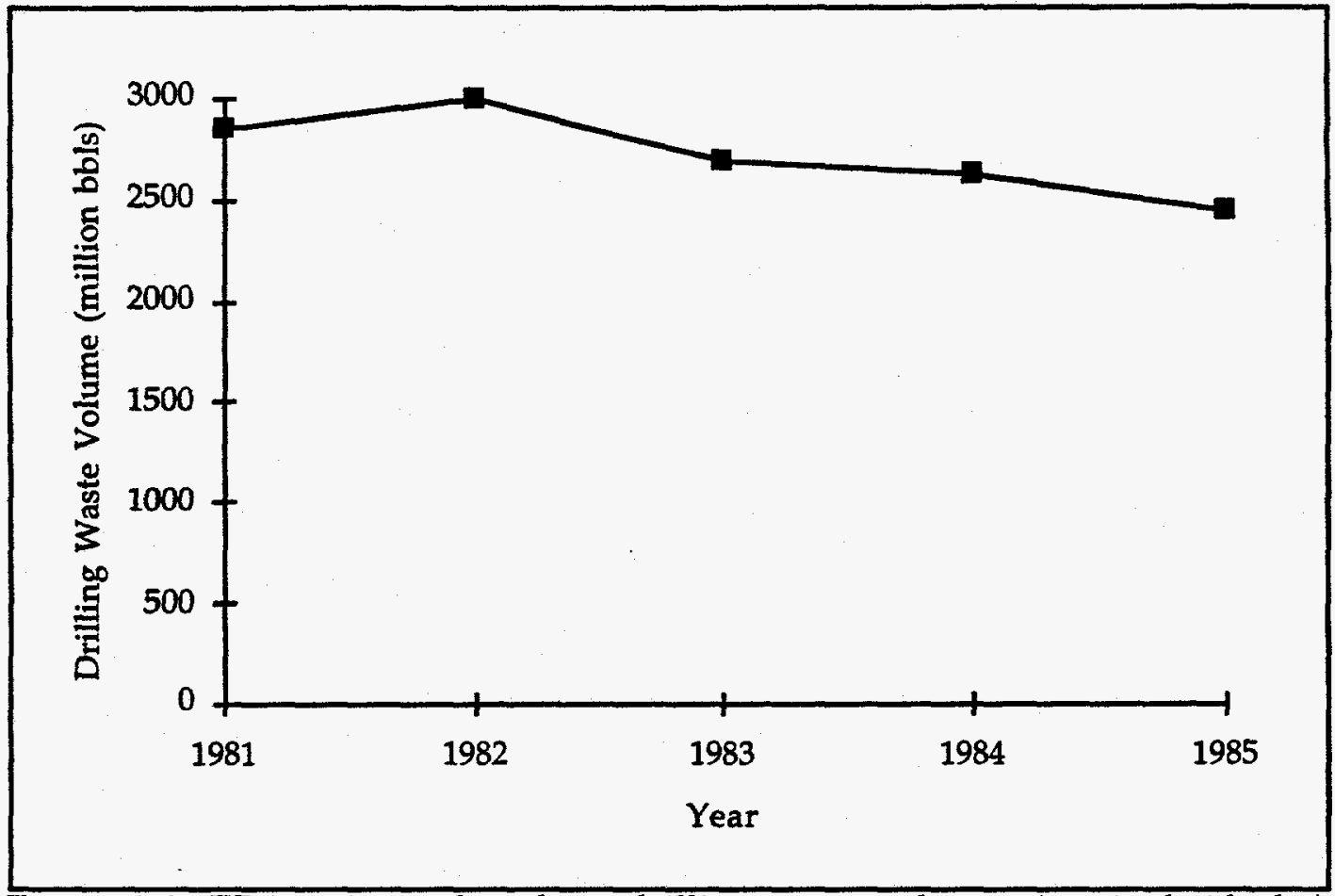

Figure 2.1. EPA estimated onshore drilling waste volumes (not incl. Alaska). Source: U.S.EPA, 1987b.

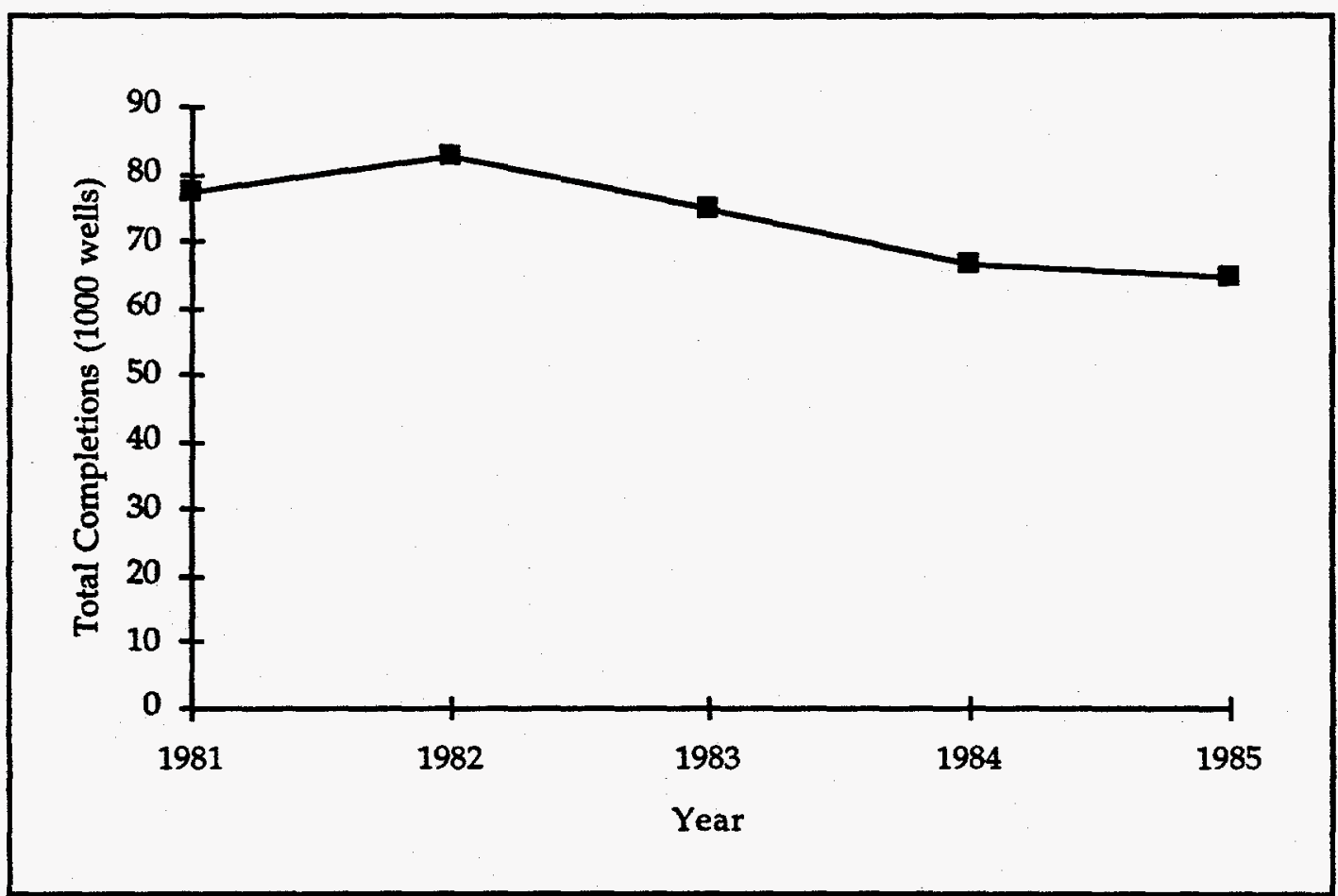

Figure 2.2. Domestic onshore well completions. Source: U.S.EPA, 1987b. 


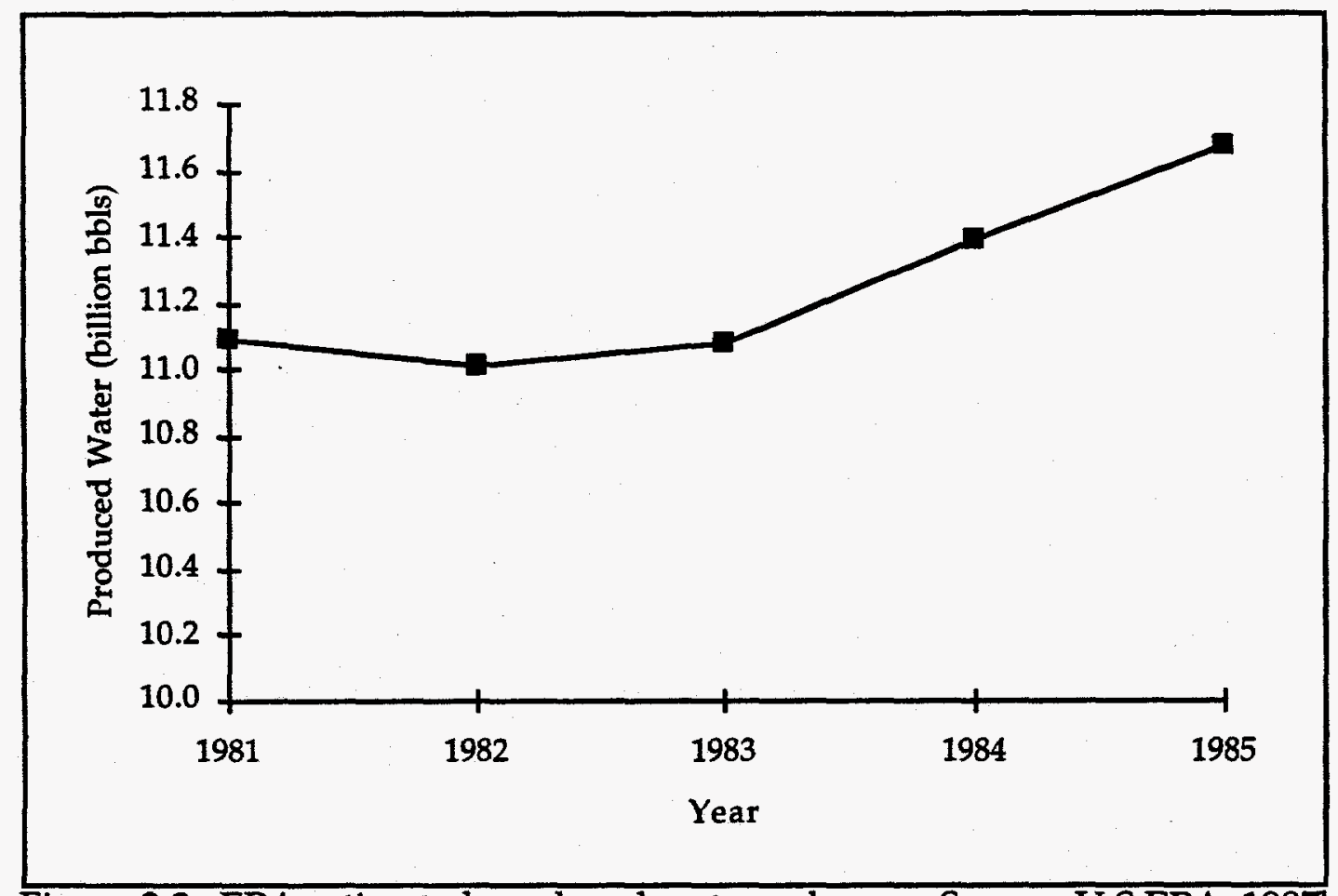

Figure 2.3. EPA estimated produced water volumes. Source: U.S.EPA, $1987 \mathrm{~b}$.

1986. These samples were analyzed for 229 organic compounds, 68 metals, and 22 conventional analytes. The analytical results were published in a separate report (U.S.EPA, 1987c). This report draws no conclusions regarding the sample results but found that the highest detection frequencies and highest average concentrations were for pollutants normally associated with oil and gas exploration activities (i.e. normal and aromatic hydrocarbons, aluminum, silicon, barium, magnesium, etc.). In the Report to Congress, EPA identified a limited number of "constituents of concern". Constituents were defined as being of primary concern if they were measured in excess of 1,000 times the health-based limit. Constituents were defined as being of secondary concern if they were measured in the range of $100-1,000$ times the health-based limit. Table 2.1 shows the listed constituents. 
Table 2.1. Constituents of concern in oil and gas waste streams (U.S.EPA, 1987a).

\begin{tabular}{|l|l|}
\hline \multicolumn{1}{|c|}{ Primary } & \multicolumn{1}{|c|}{ Secondary } \\
\hline Benzene & Arsenic \\
Phenanthrene & Fluoride \\
Lead & Antimony \\
Barium & \\
\hline
\end{tabular}

\subsubsection{Risk Assessment Modeling}

The EPA study was quite extensive in its coverage, however, the main thrust of the study, as directed by Congress, was to identify the risk to the environment from oil and gas drilling and production activities. For purposes of risk assessment modeling, constituent concentrations in drilling pit wastes (solids and liquids) and produced water were obtained from data collected as part of the nationwide sampling study. Given the short time frame and funding limitations imposed by Congress, it was impossible for the EPA to collect field and site-specific data on some of the other parameters that are of concern in predicting environmental impact such as exposure distances and hydrogeologic variables. The alternative approach used by EPA employed ranges of values for those parameters and the work that was completed utilized nationwide model scenarios that were considered to be "reasonable and representative" of a typical exploration and production site.

In conducting the risk assessment, the EPA sought to identify the general locations within each of 12 drilling/production zones where the greatest amount of drilling and production wastes are generated and disposed and to select an appropriate number of USGS quadrangle maps to represent those areas for risk assessment modeling and analysis. To do this, two weighting factors were established for each state: 1) the fraction of total drilling activity made up by the activity in the state and 2) fraction of total oil and gas production made up by production in the state. These weighting factors were then multiplied by total number of drilling sites $(100)$ and total number of production sites $(200)$ that could be examined within the resource constraints 
of the project to yield the total number of drilling and production sites to be examined in each state. A constraint was imposed to ensure that at least one sample site was selected from each of the 12 zones having significant activity. The counties within each selected state were then ranked in terms of relative level of drilling and production activity within that state.

The number of drilling sites and production sites to be represented by each USGS quad map examined (unit value) was determined by dividing the total number of U.S. drilling sites by 100 and the total U.S. production volume by 200 . The number of maps selected from each county corresponded to the number of "unit values" in that county. A set of maps was independently selected for drilling sites and for production sites. Figure 2.4 outlines the map selection procedure. Appropriate features were lifted from the selected USGS maps and used to develop average parameter values for use in risk assessment modeling. It is important to note that the selected maps represented oil and gas drilling and production sites themselves, not offsite locations where wastes may be treated and disposed such as offsite injection wells. In the risk assessment, the environmental setting at those offsite locations were assumed to be roughly the same as that at the drilling or production site (U.S.EPA, 1987b).

As an example of the type of data used, in EPA's risk assessment analysis the distance to the nearest exposure well from a drilling or production site was assumed to have a close value of $60 \mathrm{~m}$, a medium value of $200 \mathrm{~m}$, and a far value of $1,500 \mathrm{~m}$ as measured from the USGS quad maps. Similarly, the distance to the nearest surface water intake was assumed to be close at a value of $1 \mathrm{~km}$, and far at a distance of $10 \mathrm{~km}$. This approach may have been sufficient from a health and risk based point of view at the time the study was completed, however, it did not allow for regional or state differentiated environmental impact, and did not allow for analyzing site-specific data. 


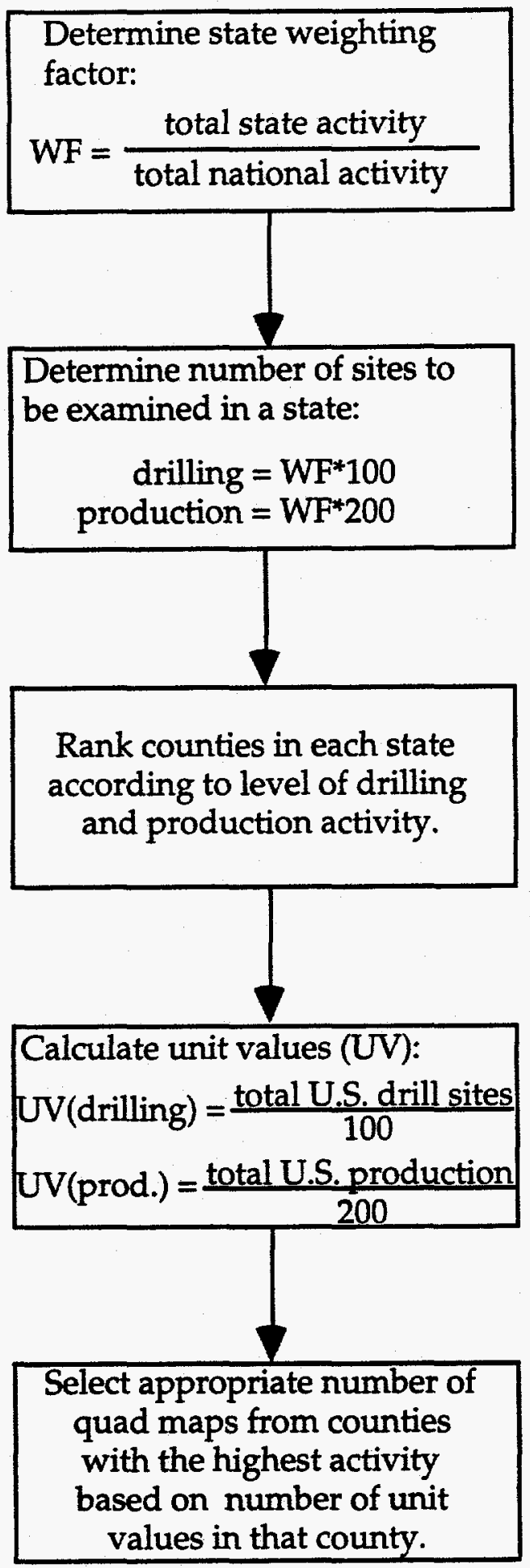

Figure 2.4. USGS quad map selection procedure used by EPA (U.S.EPA, 1987b). 
While EPA recognized the limitations of their risk assessment, the following general conclusions were given in the Report to Congress (U.S.EPA, 1987a):

1. For the vast majority of the model scenarios evaluated, only very small to negligible risks would be expected to occur even if the toxic chemical(s) of concern were of relatively high concentration in the wastes and there was a release into groundwater. Nonetheless, the model results also show that there are realistic combinations of measured chemical concentrations and release scenarios that could be of substantial concern.

2. The modeling of resource damages to surface water - both in terms of ecological impact and of resource degradation - generally did not show significant risk.

3. Of the hundreds of chemical constituents detected in both reserve pits and produced water, only a few from either source appear to be of primary concern relative to health or environmental damages. These constituents include arsenic, benzene, sodium, chloride, cadmium, chromium, boron, and mobile salts. Cadmium, chromium, and boron did not produce risks or resource damages under the conditions modeled.

4. Both for reserve pit waste and produced water, there is a very wide (six or more orders of magnitude) variation in estimated health risks across scenarios.

\subsection{The API Oil and Gas Waste Study}

During the period of the EPA study, the American Petroleum Institute, in a separate effort, completed parallel studies aimed at establishing independent estimates of waste volumes, waste sources, waste management practices, waste disposal methods, waste characteristics, and pit closure practices. The results of API's study are documented in two unpublished reports (Wakim, 1987 and Wakim, 1988). In order to collect information on exploration and production wastes, the API initiated an industry survey. Exploration and production wastes were divided in the survey into three basic categories: drilling wastes, produced waters, and other associated wastes. 
Drilling wastes, for the purposes of the API survey, consisted primarily of drilling muds, cuttings from the well bore, and chemicals added to drilling fluid systems to improve mud properties. Produced water consisted of formation water plus chemicals added for treatment such as corrosion inhibitors. Associated wastes consisted of small volumes of waste such as tank bottoms and produced sands generated in conjunction with drilling and production operations.

The data collected in the survey were used to produce an estimate of the volume of drilling wastes generated for all wells drilled in 1985 based on a sample of 659 wells (about $1 \%$ of the 69,734 wells drilled in 1985). The API study estimated that 0.36 billion barrels of drilling wastes were generated in 1985 in contrast to EPA's estimate of 2.44 billion barrels for that year. The volume of associated wastes was not estimated on a nationwide basis because of the unclear relationship between the volume of associated wastes and the volume of crude oil production. Produced water estimates were arrived at through the survey process and also by reviewing records from state agencies and industry sources (operator inventories). Based on state and industry records, the API estimated that a total of 16.3 billion barrels of produced water were generated in 1985. The survey data that were collected indicated a volume closer to 20.9 billion barrels. These numbers are in contrast to EPA's estimate of 11.7 billion barrels of produced water generated in 1985.

The API conducted a field sampling study concurrent with the EPA field sampling program. The API independently collected and analyzed samples from $\mathbf{4 5}$ of the 49 sites sampled by EPA (API, 1987). Interestingly, an analysis by Holliday and Deuel (1990) showed no correlation to exist between the analytical results reported by API and EPA for a large percentage of the constituents measured in the waste samples including several key constituents such as arsenic, barium, toluene, ethylbenzene, and chlorides. This lack of correlation was attributed to the different sampling protocols used by API and EPA and led the authors to question any conclusions drawn by EPA 
regarding the magnitude of constituent concentrations and the frequency with which they are present in oil and gas wastes. No attempt was made in the API study to assess the potential environmental impacts of these wastes.

\subsection{Regulatory Actions}

The results of the EPA oil and gas waste study were documented in the Report to Congress (U.S.EPA, 1987a). Based on the findings outlined in this report, the EPA published its regulatory determination concerning the exemption of oil and gas wastes in July 1988, stating that these wastes should not be regulated under RCRA Subtitle C. The EPA concluded that oil and gas wastes pose little risk to human health and the environment when managed according to other existing state and Federal regulatory programs. Further, the EPA concluded that regulating oil and gas wastes under RCRA would place an undue economic burden on the energy industry and would severely strain existing hazardous waste transportation, disposal, and regulatory resources. The EPA did find, however, that certain regulatory gaps and inadequate enforcement existed in some states. The agency therefore resolved to improve Federal programs and to work with states and with Congress to develop any additional statutory authority that may be required to control these wastes.

The Interstate Oil and Gas Compact Commission (IOGCC) recently formed a Council on Regulatory Needs to assist EPA in their effort to work with states to encourage improvements in the states' regulations and enforcement programs. The Council developed guidelines for effective state waste management regulatory programs and recommended a strategy that includes pursuing improvements in data management, and waste characterization (IOCC, 1990). Subsequent to publication of the guidance document, the IOGCC initiated a program in cooperation with the EPA to conduct formal reviews of existing oil and gas regulatory programs in its member states. Under the voluntary program, states are required to complete a detailed 
questionnaire addressing all aspects of their regulatory program and undergo a one week on-site review. Following the review, the IOGCC panel publishes a document outlining their findings and recommendations. The first review was completed for the state of Wyoming and published in 1991 (IOGCC, 1991). Since that time, reviews have been completed for ten additional states including Pennsylvania, Oklahoma, Alaska, Texas, California, Kansas, Arkansas, West Virginia, New Mexico, and Louisiana. This review program represents a firm commitment on the part of EPA and the states to strengthen oil and gas regulatory programs at the state level where regulations can be tailored to meet local needs.

In order to document the improvements taking place in state regulatory programs as a result of the IOGCC/EPA reviews and self reviews by individual states, the IOGCC undertook a joint study with DOE to examine changes in the regulatory programs in 17 oil and gas producing states since the mid 1980s (ICF Resources, Inc., 1993). Among the conclusions of this study were:

1. since the 1980s, states have made numerous improvements in their regulatory programs to increase environmental protection,

2. site-specific regulations at the state level appear to be generally appropriate,

3. state regulations are likely to continue to become more stringent, and

4. operator exploration and production waste management practices have evolved in response to changing regulations and growing public interest.

Of particular interest among the findings of the 1993 ICF study is the fact that, where oil and gas wastes are concerned, most states make determinations about the protective measures to be required based on site-specific conditions. As noted in the study, this type of policy, "allows the State the flexibility to require additional protection where needed, without unnecessarily placing added requirements and costs on operations by imposing a uniform statewide standard." 
In order to establish a sound basis for recommending improvements in the states' regulatory and enforcement programs as proposed by EPA and the IOGCC, it is first necessary to assess whether sufficient environmental data have been collected on a statewide and regional basis. The two studies completed by EPA and API provide an excellent starting point for developing an environmental database that is oil-and-gas specific. The data and information contained in the two studies may not be sufficient, however, to establish a thorough understanding of the environmental impacts of oil and gas activities and to investigate the need for alternative management and disposal technologies on a statewide and regional basis.

\subsection{Recent Industry Trends}

The years following the period of the EPA and API studies have been characterized by a general decline in world oil prices accompanied by a resulting decline in new domestic drilling activity. Figure 2.5 shows this trend for the period 1986 - 1991. Data collected from state agencies representing 28 oil and gas producing states were supplemented with data published by the Energy Information Administration to produce Figures 2.6(a) and (b) which show domestic oil and gas production for this same period. The data presented in these figures represent 31 states that were identified as having significant production activity. Figure 2.6(a) shows domestic oil production to follow an annual decline over the six year period. Meanwhile, the data in Figure 2.6(b) indicate that domestic gas production has increased during this time.

Information on produced water production is somewhat more sketchy as many states do not maintain records of produced water volumes while others keep records of injected volumes only and do not account for produced water disposed of by other means. Twenty of the 31 states contacted were able to provide some produced water information. Produced water production volumes were estimated for the remaining 11 
states using the method outlined in Section 4.2.3. The combined data, shown in Figure 2.6(c), indicate an apparent decreasing trend in the yearly volume of produced water generated during the period $1986-1991$.

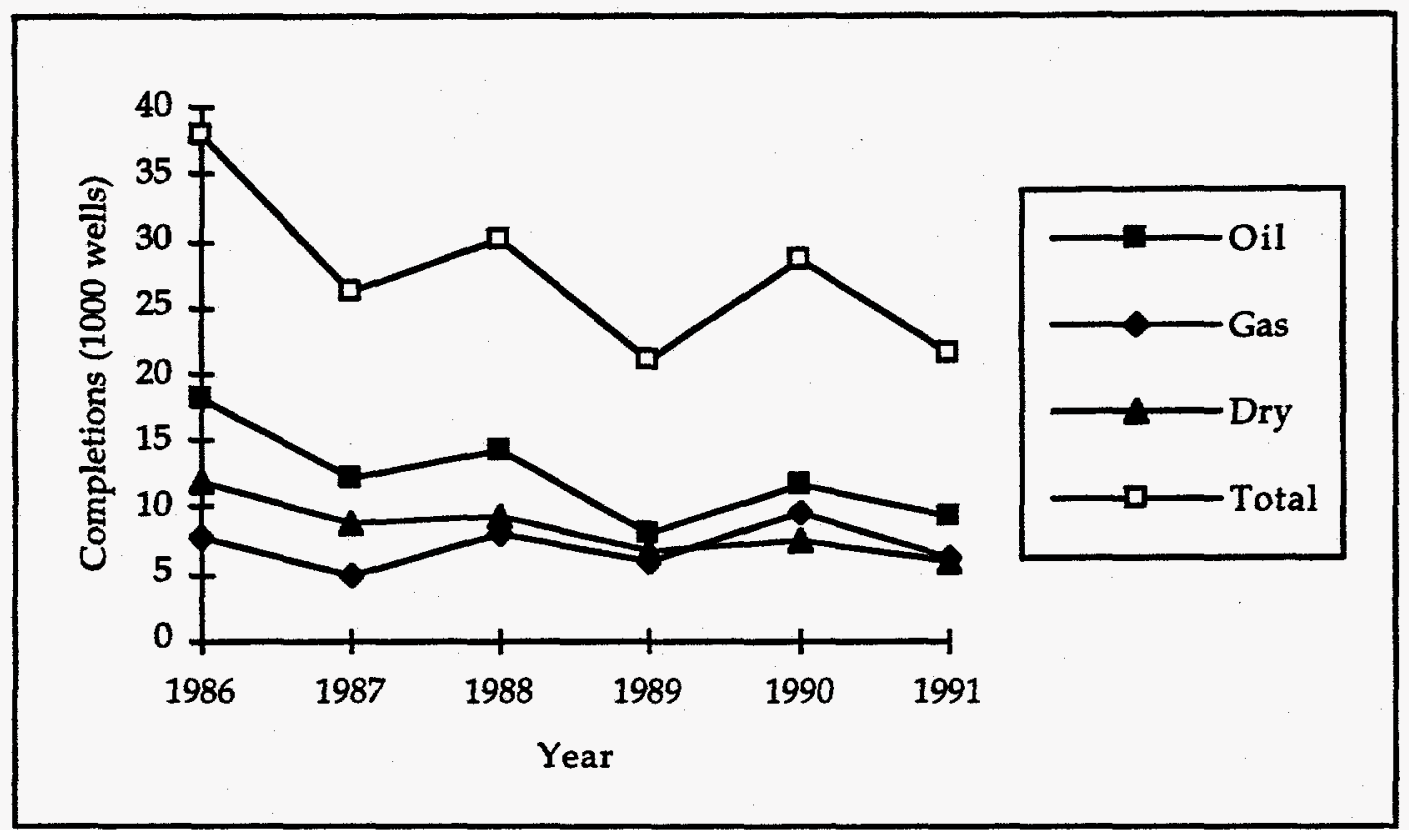

Figure 2.5. Annual domestic well completions.

In view of the available data, the existing regulatory climate, and recent changes in the industry, a current assessment of the environmental consequences of oil and gas exploration and production is needed on a statewide and regional basis. Both EPA's and API's studies were completed for the years 1980 - 1985 and are now somewhat dated. The discrepancies that exist between the waste volume estimates and the chemical composition of the wastes reported in the two studies have never been fully evaluated. Further, it is not possible to assess site-specific impacts on the environment using the EPA and API databases.

State or region-specific chemical, hydrogeologic, surface water, and exposure point characteristics related to oil and gas activities need to be developed for the producing states and regions before an adequate assessment of the environmental impacts of such activities can be determined. Such data are currently very scarce. 


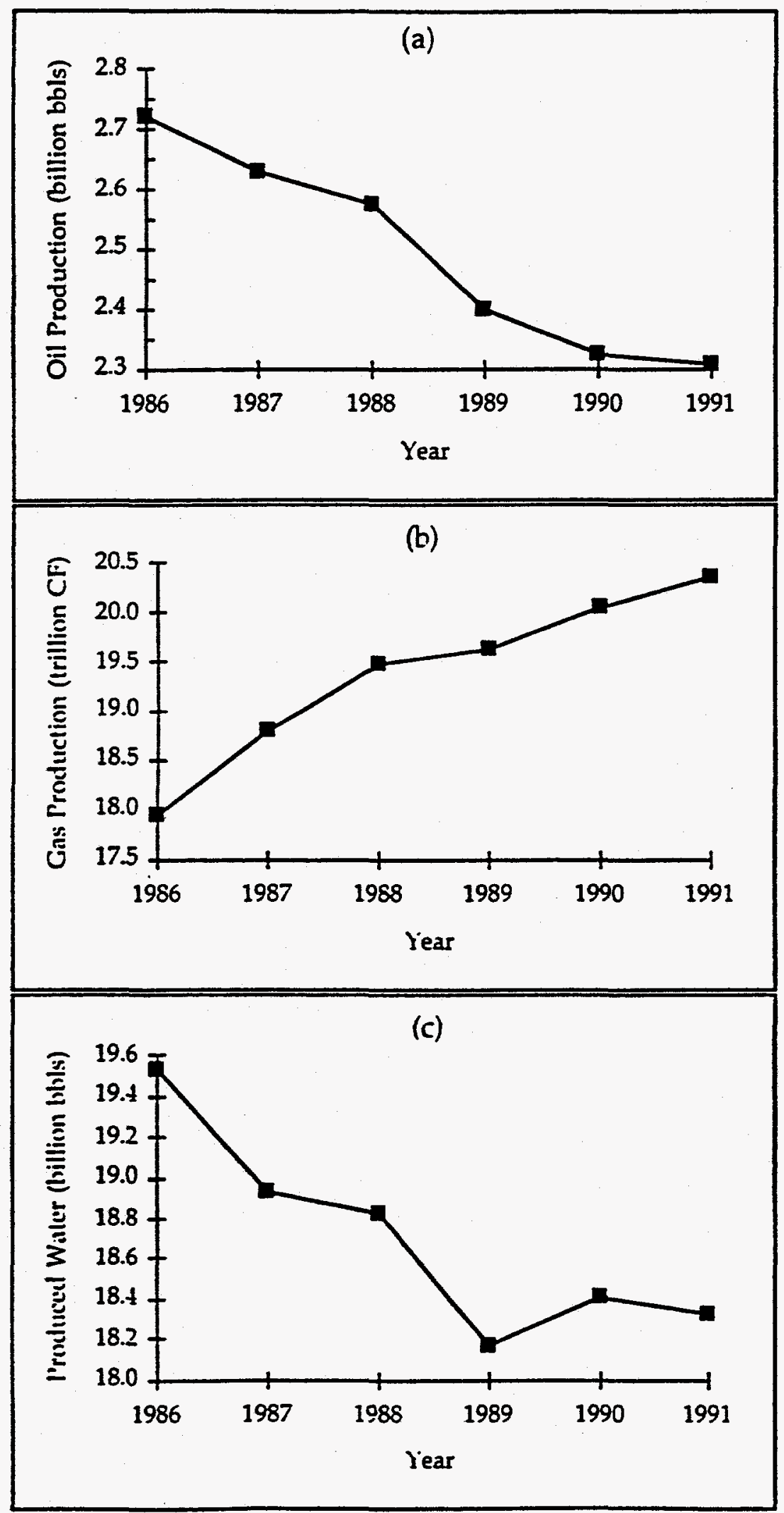

Figure 2.6. Annual domestic production of (a) oil, (b) gas, and (c) produced water. Data represent 31 states having significant production activity. 


\subsection{LITERATURE REVIEW}

\subsection{Drilling Wastes}

A well drilling operation generates many different types of waste materials as listed in Table 3.1. During drilling, all of these waste materials, known collectively as drilling waste, are normally deposited in an on-site disposal pit, or reserve pit. Once the drilling operation is complete, the reserve pit wastes may be handled by one of several methods. The method used is often region or site-specific and is determined by the volume and consistency of the waste and by local regulation. For example, results of the 1985 API survey indicated that $29 \%$ (by volume) of reserve pit wastes were evaporated from the pit, $28 \%$ were hauled off-site for disposal, $13 \%$ were injected to the subsurface, $12 \%$ were buried on-site, $10 \%$ were discharged to the land surface, $7 \%$ were land spread, and $1 \%$ were solidified. The chemical make-up of reserve pit wastes has not been well studied. Outside of the results of the EPA and API sampling program, very little has been reported.

Table 3.1. Potential drilling wastes (U.S.EPA, 1987b).

\begin{tabular}{|l|}
\hline Drilling fluid \\
$\quad$ Water-based \\
$\quad$ Oil-based \\
$\quad$ Pneumatic \\
Produced fluids \\
Drill cuttings \\
Deck drainage \\
Well completion fluids \\
Reservoir stimulation fluids \\
Packing fluids \\
Waste lubricants \\
Waste cement \\
Waste hydraulic fluids \\
Waste solvents \\
Waste paints \\
Sanitary waste \\
\hline
\end{tabular}




\subsubsection{Composition}

During the period 1979 - 1986, Leuterman et al. (1987) conducted a fairly extensive study in which samples were collected from reserve pits containing wastes from water-based drilling operations. Samples were collected from both the water phase and the sludge phase shortly after drilling operations ceased at 125 pits located in Texas, Oklahoma, Louisiana, California, and the Rocky Mountain states. The samples were analyzed for heavy metals and ion concentrations. The results showed that more than $85 \%$ of the reserve pits had soluble heavy metal concentrations below hazardous waste standards. Lead and chromium levels were generally found to be below concentrations found in typical soils. In all cases, the mud phase samples had a higher heavy metal content than the water phase samples indicating that the metals are bound to the organic and clay particles. Conversely, the water phase samples were found to contain higher average concentrations of major ions than the mud phase. This is in contrast to the EPA data which suggest the reverse to be true regarding major ions (U.S.EPA, 1987c). While the average values of ions in both phases were found to be above concentrations suitable for human use, the average values did not exceed limits for irrigation.

In a study for Shell Oil Company, Freeman and Deuel (1984) completed an extensive analysis of drilling waste pits in Louisiana and Mississippi for purposes of developing pit closure guidelines in wetland and upland areas. As part of the study, samples were collected from 309 drilling waste disposal pits prior to closure. The samples were chemically analyzed for soluble salts, oil and grease, and heavy metals. The majority of the samples showed the pit wastes to be within the limitations set for environmentally safe on-site soil mixing as a method of disposal. Barium, chromium, lead, and zinc were the predominant metals found in the waste fluids. Barium concentrations exceeded limitations in $16 \%$ of the pits sampled while other metals 
exceeded limitations in less than $3 \%$ of the pits. Eight percent $(8 \%)$ of the pits had oil and grease levels above the submerged wetland closure limit of $5 \%$ while $4 \%$ of the pits had oil and grease levels above the limit of $10 \%$ for closure in elevated wetland and upland areas. The greatest limitation to reserve pit closure by soil mixing appeared to be salts. While the presence of salts did not present a problem in wetland areas, $54 \%$ of the pits sampled contained salts in excess of the limit for disposal without treatment in upland areas.

Wojtanowicz et al. (1989) sampled four drilling waste reserve pits in Louisiana. The objective of their study was to develop a recommended method of reserve pit sampling for use in meeting pit closure regulations. Consequently, the reserve pits were extensively sampled with 80 to 100 samples collected from each pit. Two waterbased mud pits and two oil-based mud pits were sampled. The samples were analyzed for chlorides and four metals $(\mathrm{Cr}, \mathrm{Pb}, \mathrm{Ba}$, and $\mathrm{Zn})$. Chloride levels in the water based mud pits were found to be in the range of $2,000-4,000 \mathrm{ppm}$. This range of yalues is in agreement with the data reported by Leuterman et al. (1987) and by the EPA (1987c). The oil based mud pits were observed to be stratified with respect to chlorides. Mud phase samples from these pits showed concentrations of approximately $1,500 \mathrm{ppm}$ while combined mud and water phase samples showed much higher concentrations (4,890 and 7,425 ppm chlorides). The average concentrations of chromium, lead, and zinc were found to be below the limits specified in the Louisiana pit closure regulations, however, the average concentrations of barium in the four pits exceeded the allowable limit by 4 to 5 times. The distribution of metals within the pits was found to be entirely random with regard to depth and to distance from the drill rig discharge point. This is in contrast to the data of Freeman and Deuel (1984) which indicated the highest metals concentrations could be found nearest the drill rig discharge point.

McHugh et al. (1993) present the results of a study completed by the Montana Board of Oil and Gas Conservation in which field samples were collected from active 
and inactive well sites, produced water disposal facilities, landfarms, and waste oil disposal sites. Four types of samples were analyzed from 74 sites across the state of Montana for possible classification as hazardous materials under RCRA, Subtitle $C$. The results of their analysis are presented in Table 3.2. No samples were found to be corrosive or reactive. Also, no samples were found to be toxic with regard to metals, semivolatiles, or volatiles other than benzene.

Table 3.2. Hazardous characteristics of oil and gas wastes (McHugh et al., 1993).

\begin{tabular}{|l|c|c|c|}
\hline Sample Type & \# Analyzed & \# Toxic (Benz.) & \# Ignitable \\
\hline Soil & 61 & 2 & 1 \\
\hline Sludge & 51 & 19 & 13 \\
\hline Water & 16 & 9 & 9 \\
\hline Produced Oil & 4 & 3 & 4 \\
\hline
\end{tabular}

\subsubsection{Environmental Impact}

Due to their low cost, pit burial and land spreading are two of the most commonly used methods of reserve pit waste disposal. The primary environmental concerns associated with these waste handling methods are salinity induced plant kills, the uptake of contaminants by crops and other vegetation, and the potential impact on shallow groundwater aquifers. Consequently, much of the literature that has been written on the subject of the environmental impact of drilling waste disposal concerns these three topics.

In a report to the Environmental Protection Agency, Ferrante (1981) presents a review of the literature on the subject of the effect of drilling fluids and fluid components on plants and aquatic animals. The results from 20 individual studies are summarized. The basic conclusions drawn from this review are the following:

1. drilling fluid components, whole fluids, and reserve pit wastes have been shown to decrease seed germination, reduce plant growth, and reduce crop yields, 
2. metal uptake from drilling fluids by plants has been shown to have a direct relationship with the concentration of metals in the rooting medium, and

3. drilling fluids have been shown to exhibit a variety of toxicities on aquatic organisms depending on the specific drilling fluid component tested.

Despite these generalized conclusions, however, Ferrante notes that there is a lack of uniformity in testing protocols used to develop toxicity data and he questions the practice of interpolating whole fluid toxicity from the results of individual component studies. The report stresses the need for in-situ studies that take into account exposure characteristics when measuring toxic effects. Some of the published field scale studies of drilling waste impacts are reviewed below.

During the period 1974 - 1981 the American Petroleum Institute sponsored four major studies into the environmental impacts of drilling muds and produced water. The results of these studies are summarized in a report by Moseley (1983a) as well as in a conference paper (Moseley, 1983b). The first study, completed by researchers at Utah State University, was concerned with the effects of drilling mud components and mixtures on plant growth rates when combined with different soils and was conducted at both a laboratory and field scale (Miller, 1978). The second study, conducted at Purdue University, assessed the bioavailability of, and the "worst case" effects of, heavy metals contained in drilling muds on plants (Nelson, 1982). The third study, conducted by Forsgren-Perkins Engineering, focused on a Bureau of Land Management (BLM) test site near Cody, Wyoming (Whitmore, 1981). At this site, the BLM was experimenting with the use of drilling muds in reclaiming and revegetating lands disturbed by drilling activity under the hypothesis that the bentonite present in the muds would improve the water retention of the soils in this arid region. The API used this site to evaluate the effects of drilling muds on the growth of native vegetation, the uptake of heavy metals by the vegetation, and the migration of metals into the soil profile. The final API study, 
completed by Dames and Moore, investigated the leaching behavior of possible hazardous constituents from drilling site reserve pits and emergency produced water impoundments (Henderson, 1982). In this study, eight field sites in Texas, Louisiana, Arkansas, North Dakota, and Wyoming were equipped with monitoring wells and periodic sampling of ground and surface waters, surface and subsurface soils, and vegetation was conducted.

The overall conclusions drawn from the API sponsored studies as outlined by Moseley (1983b) are the following:

1. The main constituents in drilling muds which cause detrimental effects to soils and plants are excess soluble salts and exchangeable sodium ions.

2. Some of the metals present in drilling muds are available for uptake by plants.

3. Some of the constituents found in mud pits and produced water impoundments do leach from these facilities. The most motile ions are soluble salts and sodium, but the concentration of these ions is rapidly attenuated with distance from the source.

4. Certain metals can be found at elevated levels in soils and ground water surrounding mud pits and produced water impoundments, but these metals have not been observed to migrate appreciably from the source and none have been measured in excess of regulatory limits.

In an investigation for the Northern Regional Office of the U.S. Forest Service, Hicks (1983a) reports on saline seeps from several reclaimed reserve pits located in the Custer National Forest, Montana. Eight drill sits were visited and areas of dead or depressed vegetation were documented and geographical links were established between these areas and the mud disposal pits. In a follow-up report, Hicks (1983b) describes detailed investigations that were conducted at two of the sites. A hydrogeologic characterization of these sites confirmed the disposal pits as the sources of the saline discharges causing the plant kills. 
Murphy and Kehew (1984) studied the impact of drilling fluids on shallow groundwater in western North Dakota. In the study, four reclaimed oil and gas well disposal pit sites were investigated. The age of the sites ranged from 2 to 23 years. Soil water and groundwater samples collected at these sites indicated that leachate was being generated at each of the sites. Water in the unsaturated zone beneath each of the sites contained elevated levels of arsenic, chloride, lead, selenium, and nitrate. The concentrations of these ions, however, were rapidly attenuated with depth. Two sites representing "typical" geohydrologic settings showed no contamination of the saturated zone. Two other sites representing a high potential for leachate migration showed groundwater contamination. A chloride plume $60-90 \mathrm{~m}$ in length was measured at one of the latter sites while the second site exhibited a plume of elevated cadmium, lead, and selenium concentrations over a 60 by $110 \mathrm{~m}$ area. The second site represented a potential threat to a drinking water supply.

O'Leary et al. (1989) studied the environmental impact of a pit buried drilling waste in Alberta, Canada where $22,000 \mathrm{~m}^{3}$ of drilling waste solids were dried and mixed with $42,000 \mathrm{~m}^{3}$ of clay till before being buried on an 8 hectare (ha) site. A clay cap was subsequently installed over the site. Piezometers were used to monitor the site for leachate. After a 3 year period, groundwater samples showed no increase in chloride, sulfate, or total organic carbon (TOC) around the perimeter of the site. Increased chloride levels were measured in the interior of the site but the chance for chloride migration was considered to be small given the limited infiltration allowed by the clay cap and the low hydraulic conductivity $\left(10^{-6} \mathrm{~cm} / \mathrm{s}\right)$ of the native soil media.

In a rather unique study, Jones (1989) investigated the effects of drilling mud discharges on a shallow estuarine system. Treatment cells were constructed in Christmas Bay, Texas and dosed with four field collected muds over a 1.5 month period to simulate discharges from a drilling rig. Impacts on water quality were noted to be limited to a short period of time following mud application for most parameters. Only 
barium and aluminum were measured at elevated levels in the water column after a 24 hour water exchange period. Barium was used as a geochemical tracer to test the impact of the mud discharges on the bay sediments. Levels of barium in the treatment cell sediments were observed to return to ambient levels within 6 months after termination of the mud applications.

Crawley and Branch (1990) conducted an evaluation of the soil conditions beneath a land treatment operation in Louisiana. At the time of the investigation, the soil treatment pits were five years old and had received three applications of reserve pit wastes at $16,000-26,000$ barrels/acre. Soil cores taken at the site revealed limited mobility of sodium, chloride, barium, and zinc. Elevated barium and zinc concentrations were limited to the upper 3 inches of soil while elevated sodium and chloride concentrations were noted to a depth of $18-24$ inches. The low levels of contaminant migration were attributed to the low permeability of the native soils $\left(10^{-7}\right.$ $\mathrm{cm} / \mathrm{s})$.

Finally, Hall (1990) presents some of the findings of the EPA's investigation into the environmental impacts of oil and gas operations conducted as part of the 1987 Report to Congress. The documentary paper contains numerous photographs documenting seepage through unlined pits, breached pits, saline discharges to the land surface and to freshwater streams, and vegetal and wildlife damage.

\subsection{Produced Water}

An oil or gas production well produces water along with the crude oil or natural gas. The amount of water produced can be significant, sometimes constituting as much as $98 \%$ of the wellhead fluids. Typically, the amount of water produced increases with the age of the well. Produced water is generally high in dissolved solids (brackish or brine) and may contain a variety of residual components that result from drilling and recovery operations. It represents the largest volume of oil and gas production waste 
that must be disposed of. As with drilling wastes, a number of disposal options exist for produced water. By far the most common method is subsurface injection. Results of the 1985 API survey indicated that $91 \%$ by volume of produced water was disposed of by this method. Sixty-two percent of this total was used for enhanced oil recovery operations and the remaining $29 \%$ was injected into deep salt water aquifers. A second commonly used method of produced water disposal is by discharge to the land surface. These types of discharges, which according to the API survey account for $6 \%$ of the disposal volume, normally require an National Pollutant Discharge Elimination System (NPDES) permit from the EPA. Other lesser used methods of disposal include evaporation from pits, livestock watering, and road spreading.

\subsubsection{Composition}

Most research that has been conducted on the composition of produced waters has revolved around offshore production operations as these waters are commonly discharged to the oceans and are therefore required to meet Federal regulations governing ocean discharges. Stephenson (1992) summarizes many of these studies and groups the components of produced water into six categories: oil, heavy metals, radionuclides, treating chemicals, salt, and dissolved oxygen. Tables $3.3-3.6$ list some of the data compiled by Stephenson. According to Stephenson, produced waters containing treating chemicals, when present in the production stream, are normally captured and treated prior to discharge. The levels of these chemicals in the waste stream are normally not at toxic concentrations, and therefore generally do not cause an environmental problem. Produced waters normally will have a high salt content and contain little to no dissolved oxygen The high salt content of produced waters is generally not a concern with ocean discharges as the dilution of a 200,000 ppm salt solution in a $35,000 \mathrm{ppm}$ ocean is very rapid. Also, the discharge of low oxygen water 
to a high energy environment such as the ocean creates little detrimental impact. These last two problems are less easily dealt with in land based production operations.

In the context of a larger report on groundwater pollution by oil and gas well operations, Collins (1975) listed some of the constituents commonly found in oilfield brines. Table 3.7 shows some of this data, grouped by the geologic age of the source formation.

The Gas Research Institute (GRI) sponsored one of the few published characterization studies of onshore produced water (Wesolowski et al., 1987, 1988). Fillo et al. (1992) compared the results of the GRI study with the data collected by the EPA and API in their waste characterization studies. The GRI study included an analysis of 24 produced water samples taken from 17 natural gas production operations and 7 underground storage operations (Shepherd, 1992). Dissolved salts were reported to range between less than $100 \mathrm{ppm}$ to over $300,000 \mathrm{ppm}$. Most metals were reported to have been detected in at least some of the samples with arsenic, barium, strontium, and zinc among those detected most frequently. Benzene, toluene, and ethylbenzene were detected in roughly $80 \%$ of produced water samples, with higher levels found in produced waters from gas production operations versus oil production facilities. Semivolatile organic compounds reported to have been detected with some frequency include phenols, carboxylic acids, and naphthalene.

Fucik (1992) discusses the toxicity characteristics of produced water samples collected throughout Colorado and Wyoming as part of routine NPDES permit monitoring requirements. Toluene, ethylbenzene, xylene, and naphthalene along with other volatiles and semivolatiles were detected in all samples reported. Toxicity experiments conducted with these waters showed total dissolved solids to be the primary source of toxicity in some of the samples while petroleum hydrocarbons were suspected of being the cause of toxicity in others. 
Table 3.3. Phenols and volatile aromatic compounds in produced water (Stephenson, 1992).

\begin{tabular}{|l|c|c|c|c|}
\hline & $\begin{array}{c}\text { Phenols } \\
(\mu \mathrm{g} / \mathrm{L})\end{array}$ & $\begin{array}{c}\text { Benzene } \\
(\mu \mathrm{g} / \mathrm{L})\end{array}$ & $\begin{array}{c}\text { Toluene } \\
(\mu \mathrm{g} / \mathrm{L})\end{array}$ & $\begin{array}{c}\mathrm{C}_{2} \text { Benzenes } \\
(\mu \mathrm{g} / \mathrm{L})\end{array}$ \\
\hline Gas Production \\
\hline average & 4743 & 5771 & 5190 & 700 \\
\hline std. deviation & 5986 & 4694 & 4850 & 1133 \\
\hline maximum & 21522 & 12150 & 19800 & 3700 \\
\hline minimum & 150 & 683 & 1010 & 51 \\
\hline Oil Production & 1049 & 1318 & 1065 & 221 \\
\hline average & 889 & 1468 & 896 & 754 \\
\hline std. deviation & 3660 & 8722 & 4902 & 6010 \\
\hline maximum & 0 & 2 & 60 & 6 \\
\hline minimum &
\end{tabular}

Table 3.4. PAH's in produced water (Stephenson, 1992).

\begin{tabular}{|l|c|c|}
\hline & $\begin{array}{c}\text { Naphthalene } \\
(\mu \mathrm{g} / \mathrm{L})\end{array}$ & $\begin{array}{c}\text { Other } \\
(\mu \mathrm{g} / \mathrm{L})\end{array}$ \\
\hline average & 132 & 7 \\
\hline std. deviation & 161 & 18 \\
\hline maximum & 1179 & 108 \\
\hline minimum & 0 & 0 \\
\hline
\end{tabular}

Table 3.5. Heavy metals in produced water (Stephenson, 1992).

\begin{tabular}{|l|c|c|c|c|c|c|c|}
\hline & $\mathrm{Cd}(\mu \mathrm{g} / \mathrm{L})$ & $\mathrm{Cr}(\mu \mathrm{g} / \mathrm{L})$ & $\mathrm{Cu}(\mu \mathrm{g} / \mathrm{L})$ & $\mathrm{Pb}(\mu \mathrm{g} / \mathrm{L})$ & $\mathrm{Ni}(\mu \mathrm{g} / \mathrm{L})$ & $\mathrm{Ag}(\mu \mathrm{g} / \mathrm{L})$ & $\mathrm{Zn}(\mu \mathrm{g} / \mathrm{L})$ \\
\hline average & 27 & 186 & 104 & 315 & 192 & 63 & 170 \\
\hline std. deviation & 12 & 68 & 180 & 670 & 307 & 17 & 253 \\
\hline maximum & 98 & 390 & 1455 & 5700 & 1674 & 152 & 1600 \\
\hline minimum & 0 & 0 & 0 & 2 & 0 & 12 & 17 \\
\hline
\end{tabular}

Table 3.6. Radionuclides in produced water (Stephenson, 1992).

\begin{tabular}{|c|c|c|}
\hline & $\begin{array}{c}{ }^{226} \mathrm{Ra} \\
(\mathrm{pCi} / \mathrm{L})\end{array}$ & $\begin{array}{c}{ }_{228} \mathrm{Ra} \\
(\mathrm{pCi} / \mathrm{L})\end{array}$ \\
\hline \multicolumn{3}{|c|}{ OOC 44-platform study } \\
\hline average & 262 & 277 \\
\hline std. deviation & 156 & 146 \\
\hline maximum & 584 & 586 \\
\hline minimum & 4 & 18 \\
\hline \multicolumn{3}{|c|}{ La. Dept. Env. Quality } \\
\hline average & 159 & 165 \\
\hline std. deviation & 144 & 150 \\
\hline maximum & 930 & 928 \\
\hline minimum & 0 & 0 \\
\hline \multicolumn{3}{|c|}{ EPA 3-facility study } \\
\hline average & 68 & 29 \\
\hline std. deviation & 65 & 19 \\
\hline maximum & 218 & 68 \\
\hline minimum & 4 & 0 \\
\hline
\end{tabular}


Table 3.7. Constituents found in oilfield brines (Collins, 1975).

\begin{tabular}{|l|c|c|c|c|c|c|c|c|c|}
\hline \multirow{2}{*}{ Constituent } & \multicolumn{3}{|c|}{ Tertiary System } & \multicolumn{3}{c|}{ Jurassic System } & \multicolumn{3}{c|}{ Pennsylvanian System } \\
\cline { 2 - 11 } & Concentration (mg/L) & Number of & Concentration (mg/L) & Number of & Concentration (mg/L) & Number of \\
\cline { 2 - 11 } & average & maximum & Samples & average & maximum & Samples & average & maximum & Samples \\
\hline Barium & 60 & 240 & 140 & 10 & 50 & 7 & 30 & 640 & 41 \\
\hline Boron & 36 & 450 & 170 & 13 & 50 & 9 & 15 & 70 & 54 \\
\hline Bromide & 85 & 1,300 & 323 & 1,200 & 6,000 & 80 & 490 & 3,900 & 57 \\
\hline Copper & 0.63 & 1 & 3 & - & - & - & - & - & - \\
\hline Chloride & 64,600 & 201,300 & 380 & 141,000 & 210,000 & 85 & 87,600 & 270,000 & 950 \\
\hline Lithium & 4 & 27 & 169 & 10 & 400 & 80 & 7 & 35 & 45 \\
\hline Magnesium & 530 & 5,800 & 368 & 2,500 & 5,200 & 84 & 1,900 & 15,000 & 947 \\
\hline Sodium & 39,000 & 108,000 & 379 & 57,300 & 120,000 & 85 & 43,000 & 101,000 & 951 \\
\hline Strontium & 130 & 420 & 142 & 320 & 2,080 & 9 & 600 & 4,500 & 70 \\
\hline Sulfate & 320 & 8,400 & 139 & 210 & 1,480 & 78 & 430 & 5,400 & 756 \\
\hline
\end{tabular}


Mount et al. (1993) studied the toxicity of produced waters as well. The goal of this study was to develop multivariate regression equations that could be used to predict the toxicity of a produced water on freshwater species (water fleas and fathead minnows) given measured concentrations of major ions $\left(\mathrm{Na}, \mathrm{K}, \mathrm{Ca}, \mathrm{Mg}, \mathrm{Cl}, \mathrm{SO}_{4}\right.$, and $\left.\mathrm{HCO}_{3}\right)$ in the water. Four of the six sampled waters were found to be acutely toxic to the water flea. In addition, the study included an analysis of a produced water from Wyoming known to contain hydrogen sulfide. This water was found to be acutely toxic to fathead minnows with reduced survival observed in concentrations as low as $25 \%$ by volume.

\subsubsection{Environmental Impact}

Concern over the impact of produced water on the environment has existed for many years. In 1966 Payne (1966) published an article in which he discussed existing and potential problems associated with brine disposal in Texas and actions taken by the Railroad Commission of Texas aimed at mitigating those problems. The primary sources of brine pollution as outlined by Payne are improperly plugged or abandoned wells, breached or leaking earthen pits used for the disposal of produced water, and unmonitored injection well operations. In a similar article published two decades later, Paddock (1985) reiterated these same problems. In response to these pollution concerns, Texas, as well as most other oil and gas producing states, has adopted local brine pollution control measures, such as the banning of surface impoundments, in addition to the Federally mandated Underground Injection Control program. Oil and gas production related injection wells are regulated as Class II injection wells under the 1974 Safe Drinking Water Act which is, in part, aimed at protecting underground sources of drinking water. These wells must be completed to a depth below all freshwater aquifers and must undergo periodic mechanical integrity testing (MIT) to 
insure that the well casing is sound and does not allow leakage of fluids above the designated injection zone.

Still, not all of the brine pollution problems have been resolved. Old and improperly constructed surface disposal pits continue to seep. Also, improperly plugged and abandoned wells remain as one of the primary causes of brine related environmental impact. These wells act as conduits to allow salt water to travel upwards and contaminate freshwater aquifer regions or to discharge at the surface and impact the land and surface water. This problem can be exasperated by nearby injection operations which increase the hydraulic pressure in salt water zones, forcing this water upwards through open well bores. Adding to the problem are leaking brine disposal pipelines and accidental discharges.

Baker and Brendecke (1983) studied the problem of seepage of oilfield brines from surface disposal ponds in Utah. Mass balance calculations performed by the authors showed that only $5-16 \%$ of the produced water placed in surface pits over a ten year period from 1971 to 1980 was actually evaporated. The remainder, or 4,430 ac$\mathrm{ft}$, was lost through seepage to the local shallow aquifer system. Estimates of salt water plume movement indicated a threat to shallow irrigation and domestic water supply wells in the area.

One case study of oilfield brine pollution is presented by Bozzo et al. (1990). In June 1989 a cluster of pipeline leaks in a brine disposal pipeline caused 24 million gallons of salt water (0-224 $\mathrm{g} / \mathrm{L})$ to be discharged onto a coastal marsh. Meanwhile, 11 million gallons of salt water were simultaneously released from a leak in a nearby pipe at the bottom of the Gulf Intracoastal Waterway. In total, 8.3 acres of marshland were impacted. A 10 month study evaluated vegetative damage and recovery as well as surface and groundwater impacts and recovery. Pronounced recovery was observed in higher elevation areas during this period, while lower elevation areas, where the brine concentrated and infiltrated, were extremely slow to recover. Recovery was observed to 
be enhanced by frequent heavy precipitation during the study period that promoted flushing.

Kaszuba and Buys (1993) discuss remediation strategies for seven sites in New Mexico that contained brine impacted soil resulting from leakage from pipelines and reserve pits. The size of the investigated spills ranged from 5 barrels to 130 barrels. One site contained an unknown spill volume. Soil samples from these sites were collected and analyzed for comparison with background soils. Vegetation at all but one of the sites was noted to be dead, and some sites were observed to have hard and crusted soils. Reclamation of the impacted areas involved the leaching of soluble salts from the soils through the application water containing soil amendments. The time frame for complete reclamation of the impacted areas was estimated to be 3 - 5 years.

Not all brine discharges to the surface are accidental. But even where allowed by regulation, the permitted discharge of produced waters to surface water receiving systems can have adverse impact. Most surface discharges of this type occur in coastal areas where the existence of salt water marshes lessens the impact of brine disposal. Still, as some investigations have shown (see below), the magnitude of the discharges can sometimes overwhelm the capacity of the marshland to assimilate them. Other pollutants contained in the discharged waters can also have toxic effects.

VanSickle and Groat (1990) present a general discussion of the impact of oilfield brines on coastal wetlands. A strong correlation was observed between areas of disappearing or rapidly deteriorating wetlands and locations of produced water discharges along the Louisiana coast. The report also includes analytical results for four produced water discharges in south Louisiana. In addition to elevated ion levels, the waters were shown to contain benzene ( $1-3 \mathrm{ppm})$, toluene (1-3 ppm), and other organics.

In a summary of a report prepared for the API and the Louisiana Division of the Mid-Continent Oil and Gas Association (Steimle and Associates, Inc., 1991), Rayle and 
Mulino (1992) present the results of a study of the impact of produced water discharges to Louisiana coastal wetlands. Data were collected from 38 discharge locations representing a wide range of discharge rates, produced water salinities, produced water hydrocarbon concentrations, marsh habitat types, and receiving water body configurations. The reported results were the following:

1. TPH concentrations decreased to below detection limits within $300 \mathrm{~m}$ of the discharges. Less than half the stations had any detectable TPH concentrations in the bottom water.

2. Salinity stratification was observed at 20 of the stations sampled. Three of these stations exhibited area-wide stratification not related to the discharges.

3. Sediment TPH concentrations above background concentrations of 10 $50 \mathrm{mg} / \mathrm{kg}$ were measured up to $300 \mathrm{~m}$ (the extent of the study) from the discharge locations at several sites.

4. Water column radionuclide activities ranged from 0 to $3.5 \mathrm{pCi} / \mathrm{L}$ $(226+228 \mathrm{Ra})$ and were above background at a distance of $15 \mathrm{~m}$ from the discharge at some sites, but were below primary drinking water standards of $5.0 \mathrm{pCi} / \mathrm{L}\left({ }^{226+228} \mathrm{Ra}\right)$.

5. Two of 10 sediment samples collected showed ${ }^{226} \mathrm{Ra}$ activities of 1.7 $\mathrm{pCi} / \mathrm{g}$ and $6.3 \mathrm{pCi} / \mathrm{g}$ respectively, both above the control value of 1.05 to $1.47 \mathrm{pCi} / \mathrm{g}$.

Roach et al. (1993) also studied the adverse effects of produced water discharges to estuarine systems. Sediment samples were collected below the point of discharge at two tidewater disposal locations in Galveston Bay, Texas. Hydrocarbon (2-3 ppm), barium, and strontium concentrations in bottom sediments were observed to be elevated over background levels in the vicinity of the discharges and to decrease with distance away. Detrimental impacts on benthic community parameters were also observed. Infauna surrounding the discharge locations was observed to be minimal or absent. Sediment and pore water toxicity data indicated significant impact within $\mathbf{3 7 0}$ meters of one of the discharge locations. 
In one of the few studies of brine discharges to freshwater systems, O'Neil et al. (1992) assessed the long-term impacts of produced water discharges to several freshwater receiving streams from a methane gas production field in Alabama. A series of studies conducted during the period 1983 - 1989 led to the following basic conclusions:

1. Discharge of coalbed methane produced waters resulting in in-stream chloride concentrations $<100 \mathrm{mg} / \mathrm{L}$ yielded no additional biological impact to stream fauna already experiencing severe stress from surface coal mine runoff.

2. A significant impact threshold value of $565 \mathrm{mg} / \mathrm{L}$ chloride was experimentally determined through concentration-response testing of entire benthic invertebrate communities.

3. Long-term biomonitoring of benthic invertebrate and fish communities in a stream receiving continuous discharge of produced water resulted in no detectable toxic effects to either group of organisms. Chloride during these studies ranged from 5 to $650 \mathrm{mg} / \mathrm{L}$.

\subsection{Produced Water Treatment Technologies}

Effecting a change in the quality of produced water prior to reuse or disposal requires the creation of a treatment system that will remove various levels of undesirable constituents. This removal must be accomplished under a specific set of circumstances for each water. Tao et al. (1993) present one such system for treating produced water that will produce a product water of drinking water quality from a relatively clean oilfield waste stream. This work focuses on reverse osmosis and specific pretreatment requirements for several reverse osmosis systems and does not

consider various levels of produced water quality or treatment. A more extensive treatment scheme was examined for treating produced waters generated during the production of natural gas (Lawrence et al., 1993). This paper describes the results of a Gas Research Institute sponsored study that evaluated the technical and economic feasibility of a spectrum of produced water treatment and disposal methods. The 
evaluation of the performance of two desalination techniques (reverse osmosis and forced evaporation) and the methods used to estimate the costs associated with these techniques are the most useful aspects of this work with respect to produced water.

Though a large body of work specifically addressing the treatment of produced waters does not exist, unit processes typically associated with potable water treatment can be used to treat produced waters and water treatment systems containing these types of processes have been extensively studied. For example, in a study sponsored by the EPA, Gumerman et al. (1979) evaluated approximately 100 water treatment processes for the purpose of quantifying the attainable levels of treatment and the costs associated with these treatment levels.

Water treatment processes that remove contaminants listed in the National Interim Primary Drinking Water Regulations (Federal Register, title 45, part 168, August $27,1980)$ make up the group of processes that was examined in the current study. The specific unit process evaluated for the treatment of produced water include package plant conventional treatment (liquid/solid separation), packed tower aeration, granular activated carbon adsorption, powdered activated carbon adsorption, and reverse osmosis. A review of each of these processes is presented in the following sections.

\subsubsection{Conventional Treatment (liquid/solid separation)}

The term conventional treatment is traditionally used to describe the routine treatment processes used in the primary treatment of drinking water. The combination of coagulation, flocculation, sedimentation, and filtration unit processes constitutes conventional treatment. The separation of the liquid and suspended solid portions of a waste stream is generally accomplished by destabilizing the solid portion, bringing the solids that make up this portion into contact with each other, forming groups of these solids, and finally settling them out of solution. The solids that do not settle are then brought into contact with granular media (filter) to which they become attached and are 
thus removed. These mechanisms of removal are executed within the four aforementioned unit processes. Any undesirable portion of the suspended solids found in a waste stream is a candidate for removal by this type of treatment. For example, many heavy metals found in water are typically sorbed to the suspended solids, and thus will be removed at the same rate as the solids. Under a select group of circumstances, powdered activated carbon addition will be deemed appropriate during the coagulation process and will result in the removal of adsorbable organic compounds during package treatment. When employing activated carbon treatment, PAC is generally selected over GAC (see Section 3.3.3) for low to moderate carbon usage rates (Sontheimer, 1976). The PAC is added during or before the coagulation section of the package treatment plant. The organic contaminants are removed during this stage of treatment because they are adsorbed to the PAC particles by the time that the powdered carbon granules settle out of solution.

A single unit assembly containing the four conventional treatment unit processes is often marketed as small package facility for water treatment, hence the term package plant. Several characteristics of package treatment plants make them more suitable than a treatment train consisting of four separate unit processes when being used in the oilfield. First, a package plant can be preassembled in a factory or assembled in the field from prefabricated sections, and is usually portable (i.e. skid mounted). Second, package treatment plants are often automated, requiring reduced attention from an operator (Logsdon et al., 1990). Most importantly, however, these types of plants are available with design capacities suited to treat smaller rates of flow than can be economically achieved using individual unit process. These features usually make package plants more attractive than constructing permanent separate facilities. 


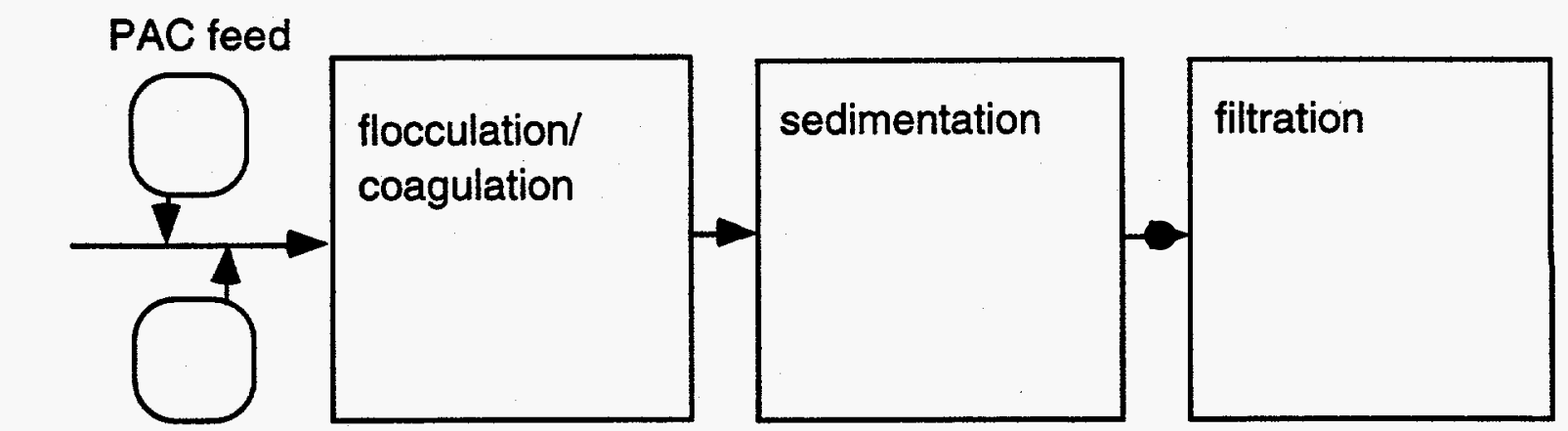

chemical feed

Figure 3.1. Schematic representation of a conventional package treatment plant.

Figure 3.1. depicts a typical package water treatment plant configuration. In a package plant, the waste stream is pumped into the first section of the plant as chemicals are added. Chemicals added include various coagulants and possibly PAC. Coagulants are added to destabilize the contaminant particles. PAC may be added to adsorb some of the organic contaminants out of the produced water. The mixing which occurs in the first section results in the chemicals being distributed throughout the waste solution and brings the contaminant particles into contact with the coagulants and with each other which causes some of the particles to stick together. Some of these groups of coagulated particles form flocs large enough to settle out of solution, which happens inside the sedimentation basin. The sedimentation basin provides a hydraulic residence time long enough for the average particle to settle out. Further removal is then accomplished in the filtering section of the plant. Rapid filtration is a water treatment unit process during which a solution is passed over a bed of porous granular media so that a portion of the suspended particles found in the solution can be removed. Particles that come into contact with the filter media may attach to the media and be removed from the waste stream. Some of the particles that are removed by the filter media become, in effect, part of the filter media and facilitate further particle removal. The mechanisms that function to transport contaminant particles in the waste 
water up to the granules of media are advection, Brownian diffusion, and gravity settling (Bauman, 1978). The actual removal of the particles, once they are transported up to or near a grain of media, is accomplished by straining, sedimentation, interception, adhesion, or flocculation.

The shape and configuration of the treatment unit processes contained in a conventional package treatment plant are variable. For each of the unit processes comprising the package treatment plant, the process unit size, application rate, and waste solution residence time are design variables. Residence time for the waste solution is equal to the unit process basin volume divided by the volumetric flow rate and describes the average time that a molecule of waste solution spends in the basin. In addition to the flow variables, the list of design variables for the coagulation and flocculation section of the plant also includes the shape (circular or rectangular) and the power input per volume for mixing. The mixing is done by passing paddles through the water and the power input controls the amount of mixing that takes place during the execution of the mixing process. For the sedimentation basin, the unique design variables are the amount of basin volume reserved for sludge storage and type of sludge removal. Bed porosity and allowable head loss as well as the common variables mentioned above are considered during the design of the package plant filter. The porosity of a filter is a function of granule size, shape, and uniformity and refers to the ratio of volume taken up by the pores within a bed to the volume taken by the total bed. A range of filter configurations can also be employed. Single, double and multi media filters of many different media types are possible. Upflow, downflow and pulsed-flow filters represent three more choices that can be made when selecting a filtration scheme (Bauman, 1978).

Head loss through the filter is equivalent to the amount of pressure that builds up across the filter as a result of the accumulation of particles in the filter. This accumulation of particles can reduce the capacity of the bed to remove particles below 
an acceptable level or cause some of the removed and attached particles to re-enter the waste stream due to shear forces. At some point, the accumulation of particles within the filter bed can cause the quality of the filter effluent stream to deteriorate below an acceptable level. Based on a predetermined amount of head loss, the deterioration of the filter effluent stream quality below a certain level, or perhaps a prescribed interval of time, the filter may be backwashed by introducing a stream of water through the bed in an upflow direction and at a high rate of flow. This backwashing of the filter flushes the removed particles out of the filter so that operation of the filter can resume.

Residual waste streams produced during package plant operation result from the sedimentation and filter backwash processes. These waste streams are a mixture of liquids and concentrated solids referred to as sludge. The amount of total dissolved solids initially present in the waste stream and the volume of coagulant and PAC addition will determine the type and amount of sludge that is produced (Nielsen et al., 1973). The produced sludge is typically dewatered (dried) prior to disposal.

For purposes of this study, the package treatment plant used to evaluate the conventional treatment of produced water was deemed to be rectangular in shape, constructed of standard materials, and variable in size as a function of capacity (Gumerman et al., 1979). The rectangular shape is divided into the mixing, settling and filtering sections. Pumps and piping used for moving the waste stream, backwashing the filter media, and feeding chemical additives surround the rectangular form of the package treatment plant. The process configuration used in the package treatment plants considered herein included 20 minutes of flocculation, tube settlers rated at 150 gallons per day per square foot of sedimentation basin plan area, and mixed media filters (Gumerman et al., 1979). Mixed media filters possess three types of media. From top to bottom these are sand, anthracite (coal), and garnet. 


\subsubsection{Packed Tower Aeration}

Volatile organic compounds can be removed from produced waters via packed tower aeration, or air stripping. The process of aeration involves bringing a solution into contact with air. Constituents can be transferred from solution to air or vice versa. Desorption of a contaminant out of solution into air is commonly referred to as air stripping. The driving force for the transfer of contaminant from solution into air is the difference in concentration between the two phases. The amount of transfer that will take place is a function of the contaminant concentrations in the air and in solution once the system has reached equilibrium (Adams and Clark, 1991). These equilibrium concentrations are proportional to each other and this proportionality is described by Henry's Law. The greater the Henry's Law constant, the lower the concentration of the contaminant found in solution at equilibrium.

A packed tower is a cylindrical or square column packed with relatively small, usually inert pieces of material. This material, which may be arranged within the tower in a specific pattern or dumped into the tower randomly, is used to bring the waste stream into contact with an air stream that is blown up through the tower as the water cascades downward. The outer shell of a packed tower is usually constructed of steel or fiberglass. The packing material is typically made of plastic or steel and ranges in size from 1 to 3 inches in diameter. Various packing material shapes are possible. The corrosiveness of the waste stream with respect to both the outer shell and the packing material must be considered when choosing the materials for these tower components (Hand et al., 1986).

In packed tower aeration, the waste stream is pumped to the top of the tower where it enters and is distributed. It then cascades down over the packing material and exits at the bottom of the tower. Meanwhile, air is blown into the bottom of the tower and forced upwards until it is released out of the top of the tower or sent to an off gas treatment chamber. The term "off gas" refers to the air exiting the tower that contains 
organic contaminants stripped from the water. A packed tower can be equipped with a granular activated carbon contactor to remove the organic constituents from the off gas before the gas is released to the atmosphere. A GAC contactor is just one of several possible methods that can be used for the treatment of off gas.

Figure 3.2 depicts a standard packed tower of the type evaluated for the removal of volatile organics from produced water in this study. For the treatment of produced water, a fiberglass tower with plastic berl-saddle type packing material was considered.

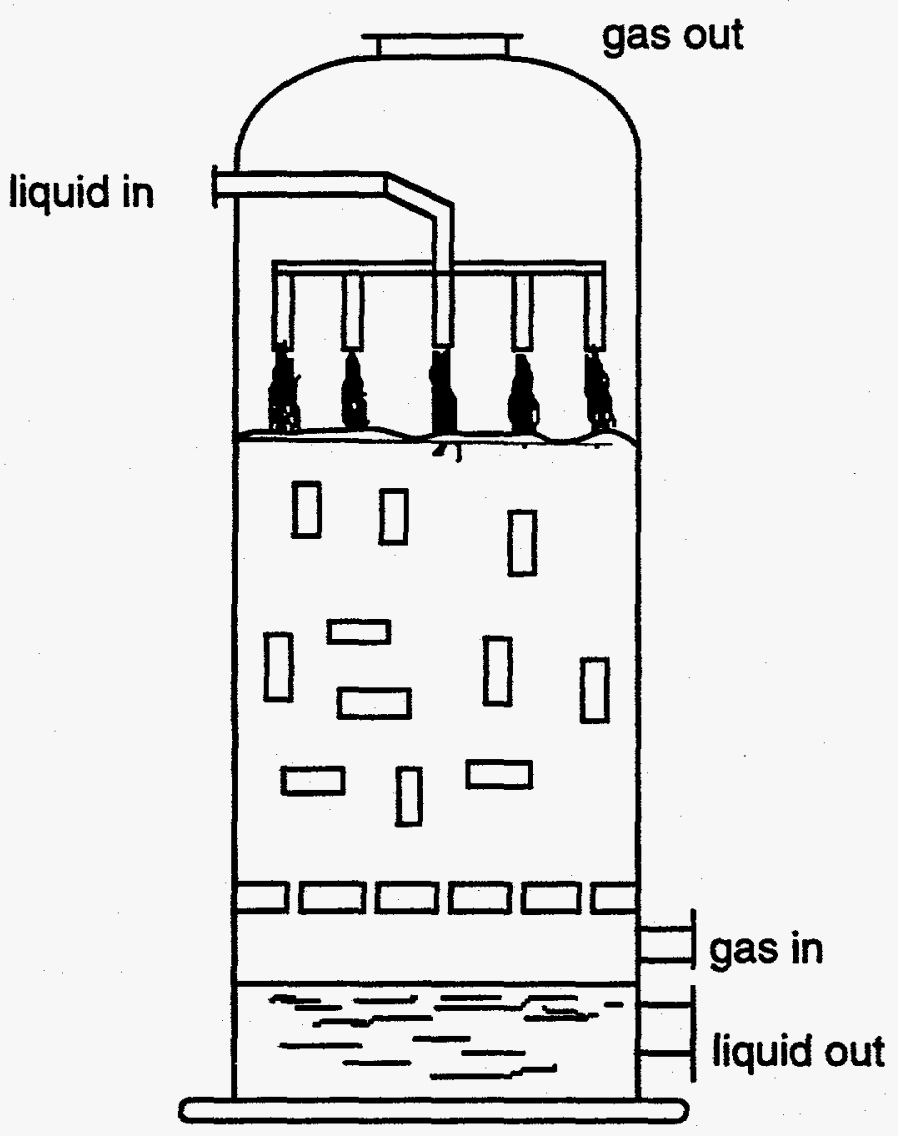

Figure 3.2. Typical packed tower aerator.

The organic compounds present in produced waters that have Henry's Law constants equal to or greater than $1.9 \mathrm{E}-4 \mathrm{~atm}-\mathrm{m}^{3} / \mathrm{mol}$ are considered volatile and may generally be stripped from waste streams. The removal of strippable organic 
contaminants, unlike that of adsorbable organic contaminants via GAC adsorption, is not affected by the contaminant matrix found in the waste stream. The Henry's Law relationships for single strippable organic compounds in solution remain unchanged when other organic contaminants are added to those solutions. There is some correlation between an organic compound's strippablity and its adsorbability. A trend has been observed using Freundlich isotherm constants that would suggest poor adsorption characteristics corresponding to high Henry's Law constants. In extreme cases this can lead to high costs for off gas treatment because in this type of treatment a compound is required to be first stripped from solution and then adsorbed from the off gas (Adams and Clark, 1991).

The area within a packed tower where the transfer of pollutants takes place is on the surface of the packing material. The surface of the individual pieces of packing material provides space for the waste stream solution to come into contact with the air that is being blown through the tower. As the waste stream flows through the tower a thin film of solution is formed on the surface of the packing material. It is through this thin film that the organic contaminant diffuses and is brought into contact with the air. A larger amount of surface area will allow a greater transfer of organic compounds. The total surface area of packing material increases as the size of the individual pieces of packing material decreases. However, there is a trade off between the increase in amount of transfer area and the resistance to flow through the system caused by decreasing packing material size and increased packing density.

The design variables that will affect the performance of a packed tower include the ratio of air to water passing through the tower, the height and diameter of the tower, and the characteristics of the packing material. The application rate of the waste stream as well as the rate of air flow entering the tower will control the air/water ratio (Kavanaugh and Trussell, 1980). The packing material size and shape will control the amount of surface area provided for contaminant transfer as well as the drop in 
pressure through the tower. When off gas treatment is required, the variables mentioned in Section 3.3.3 detailing GAC adsorption must also be considered. In addition, when using GAC treatment of the off gas, the relative humidity of the off gas can affect the rate of adsorption of contaminants found in the air leaving the tower. This humidity can be controlled by keeping the temperature of the off gas within a certain range.

\subsubsection{Granular Activated Carbon Adsorption}

Dissolved organic compounds constitute some of the pollutants of greatest concern in produced waters. Granular activated carbon adsorption is an effective method of treatment that can be implemented to remove adsorbable organic compounds from produced water. The adsorbability of a compound has been likened to a low level of volatility. All organic contaminants whose Henry's Law constants are below a certain level (here taken as $1.9 \mathrm{E}-4 \mathrm{~atm}-\mathrm{m}^{3} / \mathrm{mol}$ ) are considered adsorbable. Among the organic compounds that can be removed by GAC are synthetic organic compounds, volatile organic compounds, and taste and odor causing compounds. Compounds from all of these categories are found in produced water. These desired removal levels are a function of the disposal/final use scenarios selected for each waste stream. Taste and odor causing compounds, for instance, are of little concern for a waste stream that is not destined for potable use.

A GAC contactor is a porous bed of granular carbon resembling the bed of a rapid filter. The bed of carbon is held in a fixed container that is usually constructed of concrete or steel. The choice of material used to construct the container is dependent on the system's capacity and the force used to drive the process (gravity or pressure). Pressurized GAC package plants are constructed of steel and are generally used when the total bed volume is less than or equal to $28 \mathrm{~m}^{3}$. A GAC contactor may be thought of as a group of unit process modules that must be operated together to achieve the 
treatment objective (Clark and Lykens, 1989). The removal of organic material from the waste stream through adsorption by GAC is accomplished by passing a volume of waste water over a bed of specially prepared (activated) granular carbon. The GAC bed must be backwashed periodically to prevent a build up of excessive head loss due to the inherent ability of the carbon bed's granular media to remove and collect suspended solids. Pumps are necessary for backwashing the contactor. A mechanism must also be provided to wash the top surface of the carbon bed to remove the build up of particles collected there. In addition to the contactor itself, process modules are needed for activated carbon transfer equipment, carbon storage, and carbon regeneration. When the adsorptive capacity of the activated carbon is exhausted, the GAC must be replaced or regenerated (typically using thermal regeneration). There are several methods of thermal regeneration and the three most common types are fluidized beds, multi-hearth furnaces, and infrared furnaces. These facilities can be built on site or regeneration can take place off site. The use of virgin carbon is also an option. Figure 3.3 illustrates all of the necessary components of a GAC adsorption module with onsite regeneration.

The specific contaminant matrix found within a particular waste stream is the most important factor to be considered when determining whether $\mathrm{GAC}$ will be used or not. In addition, factors such as temperature and $\mathrm{pH}$ of the waste stream will affect removals. Different types of carbon that may be used have different properties which affect all aspects of the adsorption process. There are several ways in which specific types of activated carbon may be compared with respect to their ability to adsorb contaminants. Two such measures are the molasses and the iodine numbers. These numbers represent the amounts of adsorption into pores that are roughly 10 and 30 angstroms in diameter respectively. 


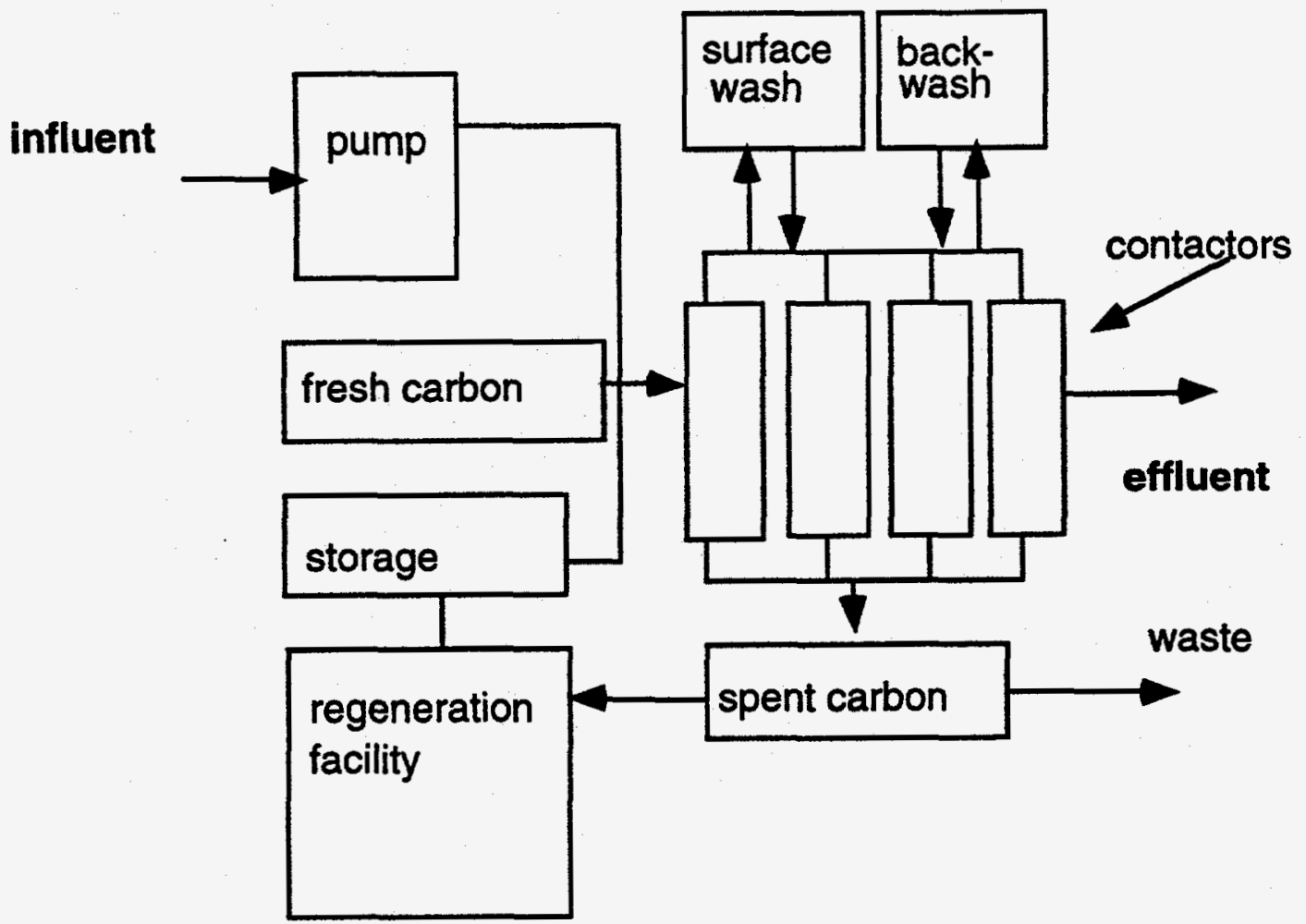

Figure 3.3. Schematic representation of a GAC adsorption system. From Clark and Lykens (1989).

The prediction of performance in a column of activated carbon is accomplished with the use of adsorption isotherms. The adsorbability of a compound on a specific substrate such as GAC can be quantified in terms of it's adsorption isotherm. The Freundlich isotherm is most frequently used for this purpose. The Freundlich equation has the form:

$$
\mathrm{q}_{\mathrm{e}}=\mathrm{KC}_{\mathrm{e}} 1 / \mathrm{n}
$$

where,

$\mathrm{q}_{\mathrm{e}}=\mathrm{a}$ ratio that is equal to the amount of contaminant adsorbed onto the carbon per mass of adsorbent when the system has reached a state of equilibrium.

$\mathrm{C}_{\mathrm{e}}=$ the concentration of adsorbate left in solution when the system has reached a state of equilibrium. 
$\mathrm{K}=$ an empirical constant that is related to the adsorption capacity of the adsorbent for a specific adsorbate.

$1 / n=$ an empirical constant that is related to the intensity of adsorption.

The Freundlich constants are typically empirical. As a result, precautions must be taken to apply a given isotherm only over the range of contaminant concentrations used to generate the isotherm. Also, $\mathrm{q}_{e}$ is a function of $\mathrm{C}_{\mathrm{e}}$ only up until the adsorbent becomes saturated. These limitations have been considered during the evaluation of GAC adsorption performance and cost in Chapter 5.

The performance of GAC adsorption columns as well as the costs associated with building and operating these columns and the rest of the GAC unit process module are all controlled by the decisions made during their design. Choices made during the design of a GAC adsorption module include those affecting contactor plan area, the bed depth, type, and capacity, and the empty bed contact time (EBCT). Empty bed contact time is the average amount of time that the waste water is in contact with the activated carbon. The EBCT can easily be calculated by dividing the bed depth by the hydraulic loading rate or, equivalently, by dividing the volume of the contactor by the applied volumetric flow rate. Contactor capacity refers to the volume of waste water per time that can be treated.

The application rate of the waste stream, the shape, size, and size distribution of the granules that compose the carbon bed, allowable head loss, and type or applicability of carbon reactivation must all be considered in the design of a GAC adsorption system as well. The application rate is defined as the volume of waste water that enters the adsorption column per area of column per time and the head loss is the difference in the pressure found in the waste stream between the entrance and exit of the carbon bed. There are several common types of GAC contactors. There are packed bed, down flow, and up flow contactors as well as expanded bed up flow contactors. Beds can be 
operated singularly or in groups. The groups of carbon beds can be arranged in parallel or in series. GAC carbon beds can also serve a dual purpose in the treatment of a given water. The granular media of the GAC bed can serve as the primary liquid/solid separation mechanism of a treatment train. In this capacity, the carbon bed functions as filter media. Alternatively, the GAC bed can be exclusively used as a post filter form of treatment.

Several of the design variables mentioned above are interrelated. The size of the contactor is directly proportional to the EBCT for a given application rate. Also, the characteristics of the activated carbon granules can influence the amount of head loss observed during module operation. The size and shape of the granules affect the porosity of the bed and, consequently, the resistance to flow. As stated, the flow through a GAC contactor can be driven by gravity or pressure. Package plants treating smaller flows are preassembled and generally employ pressure contactors. The allowable loss of head through the contactor is less for a pressure driven package plant contactor than for the gravity or pressure flow contactors used in larger facilities. Time to backwash is usually therefore longer for the larger systems under similar circumstances. Site specific limitations may dictate additional constraints on the ranges of possible values for GAC contactor design parameters.

\subsubsection{Reverse Osmosis}

There are a host of undesirable inorganic constituents found in produced water. The number of these that are considered saline can be particularly troubling. The salinity of a solution is measured by the combined amounts of these inorganic saline constituents. Reverse osmosis is the forced transport of a solvent through a semipermeable membrane and is one of the methods that can be used in the desalination of produced waters. Osmotic pressure exists across a membrane if the solute concentration in the volume on one side of the membrane is higher than that 
which exists on the other side. The origin of an osmotic pressure difference is the difference in chemical activity between the molecules found in the two compartments. This pressure will result in transport of solvent across the membrane from the low solute concentration side to the high concentration side. In this way, the system will attempt naturally to come to a state of equilibrium. If a pressure that is greater than the osmotic pressure of the system is applied to the side of a system that contains the solution with the higher solute concentration, reverse osmosis will occur. The amount of solvent/solute separation witnessed in reverse osmosis is dependent on, among other factors, the chemical nature of the solute. Reverse osmosis is very effective at removing ions from water.

Reverse osmosis unit processes can be constructed using many different forms. Several common configurations of reverse osmosis modules are spiral wound, hollow fiber, plate and frame, and tubular. The spiral wound configuration was evaluated for the treatment of produced water in this study for reasons of strength, durability, and the availability of cost data pertaining to it. This type of reverse osmosis module consists of a flat membrane, the type of which will vary with the TDS concentration level found in the waste stream, wound around a central compartment that serves as a conduit for the permeate (Mehrotra and Banerjee, 1986). The waste water, or feed, flows into a pressurized vessel that contains one or more membrane modules (up to 6 modules may be contained in a single vessel). The direction of flow, upon it's entrance into the vessel and subsequently the first module, is along the horizontal of the cylinder created by the wound flat membranes and parallel to the central permeate chamber. At this point, the system pressure forces a portion of the solution through the membrane towards the center of the module. After permeation through the membrane, the direction of flow is changed to tangential with respect to the membrane cylinder and is directed by separators that partition the concentrate from the permeate. These separators direct the flow towards the central permeate chamber whereupon it's 
direction is changed once more. Permeate that reaches the central permeate chamber enters the chamber through collection holes and flows in the same direction that it was flowing initially. A separate stream within the individual reverse osmosis modules is created as the feed passes through the membranes. This stream is that portion of the feed that is rejected or the concentrate. At the time that the concentrate is separated from the permeate, it resumes it's initial direction of flow and exits the module. The feed enters the membrane module at variable radial distances away from the central permeate chamber. The permeate is carried to and is transported out of the module within this central chamber while the concentrate is removed from the module one membrane thickness away towards the center of the module from it's point of entrance. The addition of a scale inhibitor and $\mathrm{pH}$ adjustment are frequently used in the pretreatment of waste streams prior to the reverse osmosis treatment process (Figure 3.4).

At the pressures that are necessary to separate the levels of inorganic constituents found in produced water, a rigid, spoked, circular support device is necessary to prevent the $\mathrm{RO}$ module from being compressed at the feed end. The necessity of this anti-telescoping devise (ATD) is caused by the pressure differential between the feed and concentrate ends. 


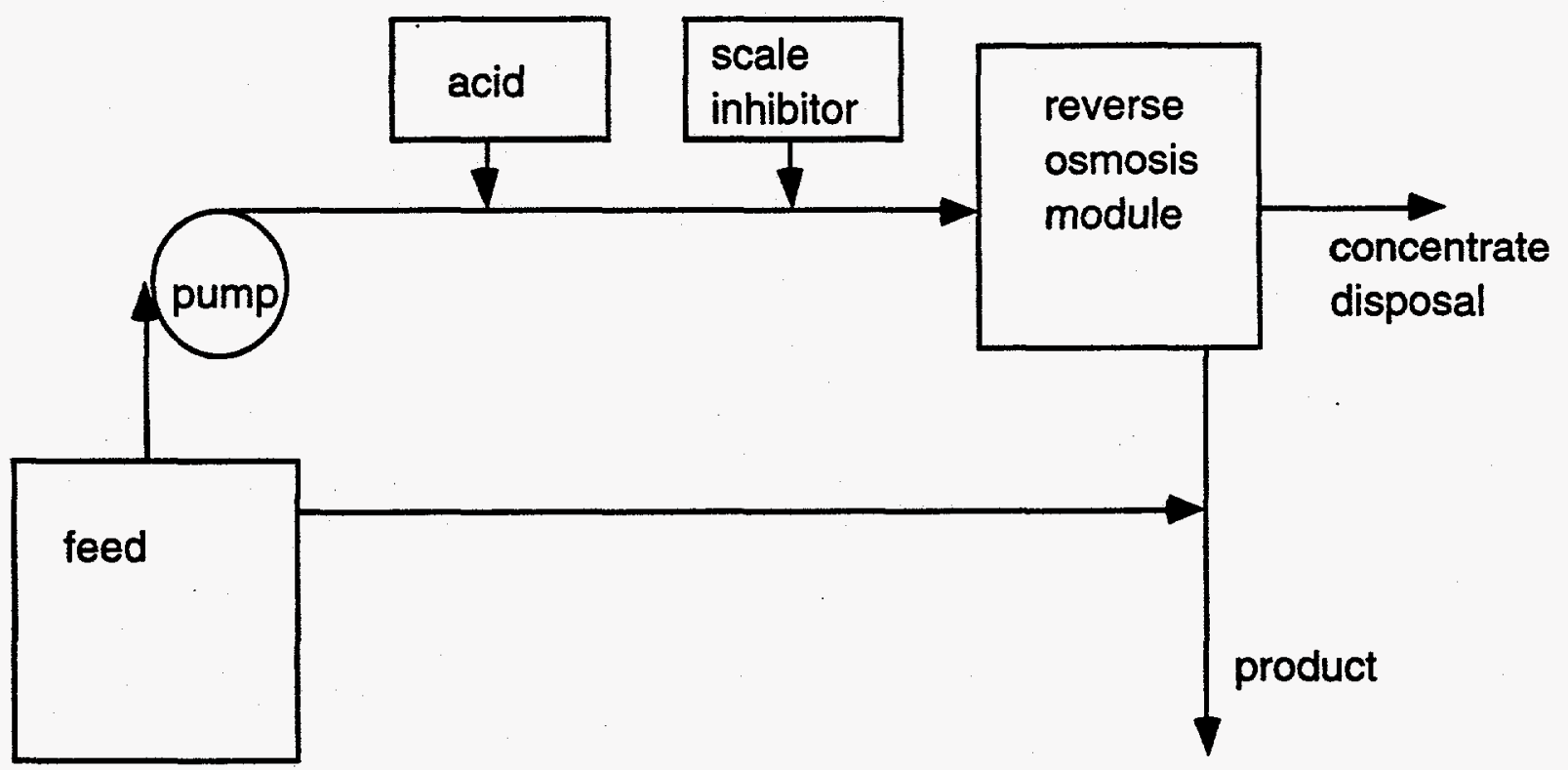

Figure 3.4 Schematic representation of the reverse osmosis treatment process.

Among the contaminants that will be removed by reverse osmosis are chloride, sodium, calcium, barium, and selenium. These constituents make up a major portion of the total dissolved solids carried by produced water waste streams. Dissolved sodium and chloride salts are found in greater concentrations than any other single contaminant. The TDS concentrations of wastewaters that can be successfully treated by reverse osmosis range from $500-6,000 \mathrm{ppm}$. Desalination of produced waters containing higher TDS concentrations must be accomplished by other methods (forced evaporation for example).

The percent recovery of a reverse osmosis system is equal to the percentage of feed that is converted to desirable product with the remaining feed converted to concentrate or brine. Percent recovery is a function of the capacity of the membrane with respect to the system operating pressure and will affect the cost of treatment because of variable disposal costs for waste streams (Remediation Technologies, Inc., 1993). The percentage of contaminant that can be removed from solution is known as the rejection across the membrane. This rejection will be specific and constant for a 
given type of membrane that is functioning properly (i.e. without fouling). Should a situation arise where the treatment goal is exceeded by the rejection across a chosen membrane type, blending can become a viable option. The blending procedure involves blending an untreated portion of the feed stream with the treated product stream to achieve the desired effluent contaminant concentration. 


\subsection{THE PRODUCTION ENVIRONMENTAL DATABASE}

\subsection{Introduction}

A review of the available data as presented above would seem to confirm the validity of the EPA's 1988 regulatory determination. In general, investigators have found oil and gas drilling and production wastes to have limited adverse environmental impact and to pose a minimal toxic threat. Any attempt to regulate these wastes on a global scale may therefore be inappropriate. Rather, the environmentally safe handling of oil and gas wastes needs to be evaluated on a case by case basis as suggested by the 1993 IOGCC study. This is what the EPA has attempted to do by delegating regulatory authority to the states. Yet sufficient site-specific data does not exist to allow the states to develop appropriate policies. Currently, most states must therefore rely on sparse nationwide data as the only available source of information concerning oil and gas wastes.

The Production Environmental Database developed for this project includes, on a state by state basis, current nationwide estimates of oil and gas extraction waste quantities generated, and an assessment of the disposition of these wastes by disposal method. The main thrust of the PED, however, was to complete an assessment of potential environmental impacts associated with current oil and gas drilling and production activities on a local scale.

The most significant component of the PED is the collection of environmental settings data that is necessary to evaluate the impacts of oil and gas activities on their local surroundings. The EPA, in their 1987 study, completed a nationwide health and risk assessment of oil and gas activities. In order to complete their study, the EPA had to make several assumptions about environmental parameters such as the proximity of the extraction activities to potential pollution receptors. The API database actually contains very little environmental information (landuse patterns surrounding oil and 
gas wells were developed in the survey). The PED was developed to overcome some of these shortcomings.

From an environmental standpoint, the PED is used to answer questions such as: What are the landuse patterns surrounding oil and gas activities? What is the average distance from an oil and gas well to a water supply well or to a stream or lake? What are the potential impacts of reserve pits on surface water and ground water quality in a particular region?

The environmental settings data collected for the PED includes information on the physical characteristics of the land surface and the potential "receptors" surrounding extraction activities. Information of this type has been gathered for eight counties within the state of Texas, representing a cross section of oil and gas activities in that state. The state of Texas is being used as a model with the idea that this model can be duplicated for other states in the future. The data have been assimilated into a Geographic Information System. Geographic Information Systems are ideally suited to answering the types of questions to be answered by the PED and can assist policy makers in developing an appropriate means of regulating oil and gas wastes. For this project, a commercial GIS software package developed by Environmental Systems Research Institute known as ARC/INFO (ESRI, 1992) was used. A Sun Microsystems SPARCstation computer served as the hardware platform.

\subsection{Nationwide Waste Quantities}

The general decline in new domestic drilling activity over the last decade has no doubt resulted in a reduction in the amount of drilling waste generated by the oil and gas industry. Meanwhile, a trend in the volume of produced water generated over this same time period is unclear. Oil production has decreased (Figure 2.6(a)), but at the same time, as production wells mature, the ratio of produced water to produced oil increases thereby offsetting the apparent reduction in water volumes. The first step in 
the development of the PED, therefore, was to develop new nationwide estimates of oil and gas waste quantities. The years 1988, 1990, and 1992 were selected for analysis. The year 1992 was chosen because it represented the most recent data available when this study began. The years 1988 and 1990 were included in order to gain insight into any recent trends that may exist.

\subsubsection{Drilling Waste Production}

Both the EPA and the API oil and gas waste studies contained estimates of the volume of drilling waste generated on a state by state basis. The EPA study included annual estimates for the years 1981 - 1985 while the API study reported estimated volumes for 1985 only. The two studies differed in the method used to compute the waste volumes. The EPA chose to base their estimates on a set of generic reserve pit volumes. Three pit volumes representing small, medium, and large reserve pits were developed. Assumptions were made as to the percentage of reserve pits in each state representing each pit size. For example, for the state of Texas, no pits were considered to be small, $50 \%$ of the pits were assumed to be medium, and $50 \%$ of the pits were assumed to be large. Estimates of drilling waste volumes for each state were made by multiplying the total number of reserve pits constructed in each year (given by the number of drilled wells) by the volume of the pit, and then multiplying the result by the percentage of pits of that size in the state.

The API based their waste volume estimates on the results of an operator survey. The survey sample contained 659 wells, about $1 \%$ of all the wells drilled in 1985 . The API also chose to divide the reserve pit wastes into six individual components as follows:

1. Mud and completion fluid (including water phase)

2. Drill cuttings

3. All other water 


\section{Circulated cement}

5. Formation testing fluids

6. Other fluids or solids

For purposes of waste volume estimations, components 1 - 4 were handled differently than components 5 and 6 . For components $1-4$, the continental United States was divided into 48 producing basins (46 in the lower states, 2 in Alaska) having similar drilling and production characteristics. Each well in the survey sample was then assigned to its corresponding production basin. This method of grouping wells was based on the notion that it is the type of formation and geological conditions that determine most drilling practices, and not the state in which the well is located. Because many producing basins were underrepresented in the sample, individual producing basins were grouped together according to similar waste volume/drilled footage ratios computed for the wells in the basin. This grouping was done without regard to the geographical location of the basin, and a separate grouping was developed for each type of waste (i.e. four different basin groupings were developed). This procedure resulted in 10 to 12 basin groups for each type of waste. Using regression analysis of the survey data, a statistical model was developed for each basin group in the form of:

waste volume $=a($ footage $)+b(\text { footage })^{2}+c$

For waste components 5 and 6 a statistical model could not be developed because of many zero and missing entries on the survey forms. Instead, the wells were grouped into four depth classes:

1. $0-3,750 \mathrm{ft}$

2. $3,751-7,500 \mathrm{ft}$

3. $7,501-15,000 \mathrm{ft}$

4. over $15,000 \mathrm{ft}$ 
For each depth class, the volume of waste per foot of well was calculated based on the available survey data. These ratios were then applied to the total footage in each depth class in each state to compute the waste volumes.

The API method of waste volume estimation, because of its statistical base, is clearly superior to that used by the EPA and was therefore adopted for use in this study. Drilling waste volumes for the years 1988, 1990, and 1992 were computed using the API procedure and are presented in Tables 4.1, 4.2, and 4.3. Unfortunately, due to external factors, a new industry survey could not be completed. The waste volume estimates presented in Tables 4.1, 4.2, and 4.3 are therefore based on the statistical models and ratios developed by the API using the 1985 survey data. The API statistical models were modified somewhat, however, in order to address the problem of negative waste volumes generated for some well depths in certain basin groups and to force the curve intercepts through the origin. While these modifications may degrade the statistical validity of the models, they act to make the models more reasonable. It does not make sense for a well bore to generate a negative volume of waste or for a well of zero depth to produce a positive volume of waste. Figure 4.1 shows some typical API regression models and the modifications made. Table 4.4 shows the waste per foot ratios used to compute formation testing fluid and other fluids and solids volumes.

All drilling waste volume computations were performed within the ARC/INFO GIS. The well data used in the waste volume estimates was obtained from the Well WHCS database maintained by Petroleum Information Corporation. Figure 4.2 shows the regions of the continental U.S. associated with each of the 46 API defined production basins. Two additional basins, located in Alaska, were not used. The state of Alaska was not included in the analysis because of the unique factors associated with drilling and production activity in that region. After discarding offshore wells, each well in the WHCS database was assigned to one of the production regions shown in Figure 4.2 using an overlay procedure in ARC/INFO. 
Table 4.1. 1988 Drilling waste volumes by modified API method.

\begin{tabular}{|c|c|c|c|c|c|c|c|c|c|}
\hline \multirow[b]{2}{*}{ State } & \multirow{2}{*}{$\begin{array}{l}\text { \# Onshore } \\
\text { Completions }\end{array}$} & \multirow{2}{*}{$\begin{array}{c}\text { Total Drilled } \\
\text { Footage }\end{array}$} & \multicolumn{6}{|c|}{ Total Waste Volumes Discharged to Reserve Pits (bbls) } & \multirow{2}{*}{$\begin{array}{l}\text { Total Waste } \\
\text { Volume (bbls) }\end{array}$} \\
\hline & & & Mud & Cuttings & Water & Cement & TestFluid & Other & \\
\hline Alabama & 353 & $1,535,603$ & $1,217,098$ & 335,504 & $3,367,899$ & 6,494 & 5,967 & 187,756 & $5,120,718$ \\
\hline Atizona & 1 & 4,000 & 4,192 & 352 & 2,673 & 18 & 6 & 33 & 7,274 \\
\hline Arkansas & 441 & $1,895,209$ & $1,180,185$ & 195,843 & $2,741,215$ & 6,061 & 3,333 & 14,296 & $4,140,933$ \\
\hline California & 2,768 & $7,099,224$ & $3,105,253$ & 808,911 & 503,635 & 38,226 & 14,350 & 76,070 & $4,546,445$ \\
\hline Colorado & 1,132 & $6,488,845$ & $4,696,312$ & 689,774 & $1,000,606$ & 23,418 & 13,450 & 66,225 & $6,489,785$ \\
\hline \multicolumn{10}{|l|}{ Connecticut } \\
\hline \multicolumn{10}{|l|}{ Delaware } \\
\hline Florida & 4 & 59,910 & 56,705 & 25,475 & 148,289 & 331 & 530 & 30,456 & 261,786 \\
\hline Georgia & 1 & 3,820 & 841 & 280 & 449 & 8 & 6 & 32 & 1,616 \\
\hline Idaho & 2 & 26,212 & 24,819 & 9,199 & 27,999 & 113 & 208 & 9,936 & 72,274 \\
\hline Illinois & 1,312 & $2,459,847$ & 549,492 & 213,437 & 27,395 & 16,785 & 1,086 & 5,588 & 813,783 \\
\hline Indiana & 328 & 490,719 & 115,437 & 42,757 & 7,018 & 3,177 & 87 & 566 & 169,042 \\
\hline Iowa & 1 & 3,610 & 784 & 322 & 117 & 25 & 1 & 5 & 1,254 \\
\hline Kansas & 3,315 & $10,342,740$ & $7,427,685$ & $1,001,077$ & 754,883 & 63,722 & 10,685 & 58,589 & $9,316,641$ \\
\hline Kentucky & 1,288 & $2,419,038$ & 535,012 & 207,776 & 179,878 & 9,418 & 1,007 & 5,328 & 938,419 \\
\hline Louisiana & 1,684 & $11,509,932$ & $9,689,089$ & $1,573,121$ & $12,921,352$ & 166,700 & 52,090 & $1,031,145$ & $25,433,497$ \\
\hline \multicolumn{10}{|l|}{ Maine } \\
\hline Maryland & 2 & 8,809 & 1,911 & 618 & 1,034 & 20 & 14 & 73 & 3,670 \\
\hline \multicolumn{10}{|l|}{ Massachusetts } \\
\hline Michigan & 677 & $2,598,400$ & $2,096,474$ & 291,673 & 500,860 & 10,144 & 5,547 & 20,565 & $2,925,263$ \\
\hline \multicolumn{10}{|l|}{ Minnisota } \\
\hline Mississippi & 285 & $2,581,189$ & $2,026,426$ & 391,115 & $5,800,656$ & 10,648 & 13,144 & 308,889 & $8,550,878$ \\
\hline Missouri & 13 & 41,777 & 17,935 & 4,821 & 22,889 & 252 & 73 & 240 & 46,210 \\
\hline Montana & 388 & $1,683,669$ & $1,329,616$ & 187,931 & 529,979 & 9,763 & 5.329 & 25,335 & $2,087,953$ \\
\hline Nebraska & 147 & 787,133 & 384,703 & 80,144 & 46,733 & 1,978 & 1,563 & 6,933 & 522,054 \\
\hline Nevada & 26 & 125,379 & 97,607 & 12,719 & 80,854 & 1,165 & 398 & 1,255 & 193,998 \\
\hline \multicolumn{10}{|l|}{ New Hampshire } \\
\hline \multicolumn{10}{|l|}{ New Jersey } \\
\hline New Mexico & 1,145 & $7,361,630$ & $7,148,684$ & $1,070,316$ & $6,460,602$ & 113,534 & 27,783 & 162,902 & $14,983,821$ \\
\hline New York & 247 & 749,714 & 164,498 & 59,905 & 87,963 & 1,609 & 706 & 3,814 & 318,495 \\
\hline \multicolumn{10}{|l|}{ North Carolina } \\
\hline North Dakota & 282 & $2,426,948$ & $1,963,930$ & 286,587 & 395,905 & 8,799 & 10,914 & 39,677 & $2,705,812$ \\
\hline Ohio & 1,510 & $6,211,577$ & $1,477,624$ & 471,442 & 712,949 & 13,736 & 7,578 & 40,891 & $2,724,220$ \\
\hline Oklahoma & 4,203 & $23,549,242$ & $21,005,846$ & $3,045,341$ & $11,841,382$ & 79,627 & 85,283 & $1,217,943$ & $37,275,422$ \\
\hline Oregon & 20 & 58,765 & 22,252 & 6,547 & 9,655 & 265 & 76 & 220 & 39,015 \\
\hline Pennsylvania & 1,081 & $4,365,292$ & $1,085,343$ & 338,241 & 511,770 & 9,687 & 6,038 & 39,201 & $1,990,280$ \\
\hline \multicolumn{10}{|l|}{ Rhode Island } \\
\hline South Carolina & 1 & 2,135 & 470 & 212 & 251 & 4 & 1 & 3 & 941 \\
\hline South Dakota & 21 & 98,985 & 61,784 & 10,728 & 8,935 & 267 & 347 & 991 & 83,052 \\
\hline Tennessee & 106 & 169,276 & 37,659 & 14,835 & 3,989 & 1,017 & 26 & 194 & 57,720 \\
\hline Texas & 11,506 & $63,808,912$ & $44,145,887$ & $7,400,620$ & $18,525,165$ & 390,029 & 209,090 & $1,410,029$ & $72,080,820$ \\
\hline Utah & 161 & $1,038,839$ & $1,046,399$ & 175,434 & 207,828 & 3,929 & 3,660 & 68,529 & $1,505,779$ \\
\hline \multicolumn{10}{|l|}{ Vermont } \\
\hline Virginia & 53 & 237,601 & 54,810 & 17,510 & 27,387 & 528 & 361 & 1,871 & 102,467 \\
\hline Washington & 4 & 28,253 & 13,620 & 3,082 & $\mathbf{5 , 2 7 1}$ & 120 & 111 & 340 & 22,544 \\
\hline West Virginia & 691 & $2,875,988$ & 660,296 & 219,047 & 333,109 & 6,345 & 3,784 & 19,746 & $1,242,327$ \\
\hline \multicolumn{10}{|l|}{ Wisconsin } \\
\hline Wyoming & 760 & $5,578,180$ & $5,399,322$ & 912,058 & $3,160,102$ & 69,158 & 24,031 & 201,476 & $9,766,147$ \\
\hline Total & 35,959 & $170,726,402$ & $118,846,000$ & $20,104,754$ & $70,958,676$ & $1,067,120$ & 508,663 & $5,057,142$ & $216,542,355$ \\
\hline
\end{tabular}

Note: Waste volumes are computed based on modified 1985 API Production Waste Survey statistical models (see text). 
Table 4.2. 1990 Drilling waste volumes by modified API method.

\begin{tabular}{|c|c|c|c|c|c|c|c|c|c|}
\hline \multirow[b]{2}{*}{ State } & \multirow{2}{*}{$\begin{array}{l}\text { \#Onshore } \\
\text { Completions }\end{array}$} & \multirow{2}{*}{$\begin{array}{c}\text { Total Drilled } \\
\text { Footage }\end{array}$} & \multicolumn{6}{|c|}{ Total Waste Volumes Discharged to Reserve Pits (bbls) } & \multirow{2}{*}{$\begin{array}{c}\text { Total Waste } \\
\text { Volume (bbls) }\end{array}$} \\
\hline & & & Mud & Cuttings & Water & Cement & Testrluid & Other & \\
\hline Alabama & 1,218 & $4,099,204$ & $3,079,544$ & 616,585 & $8,367,619$ & 15,179 & 8,018 & 140,445 & $12,227,390$ \\
\hline Arizona & 5 & 18,350 & 15,262 & 1,717 & 3,644 & 113 & 27 & 151 & 20,914 \\
\hline Arkansas & 345 & $1,737,796$ & $1,215,912$ & 182,387 & $2,380,576$ & 5,574 & 4,158 & 15,064 & $3,803,671$ \\
\hline California & 2,623 & $6,323,243$ & $2,580,621$ & 704,918 & 442,361 & 32,847 & 10,580 & 75,822 & $3,847,149$ \\
\hline Colorado & 1,237 & $6,895,853$ & $5,036,073$ & 722,370 & $1,059,349$ & 22,984 & 16,929 & 63,035 & $6,920,740$ \\
\hline \multicolumn{10}{|l|}{ Connecticut } \\
\hline \multicolumn{10}{|l|}{ Delaware } \\
\hline Florida & 4 & 47,798 & 45,753 & 19,323 & 116,925 & 254 & 381 & 19,640 & 202,276 \\
\hline Georgia & 1 & 3,700 & 814 & 276 & 434 & 8 & 1 & 5 & 1,538 \\
\hline \multicolumn{10}{|l|}{ Idaho } \\
\hline Illinois & 822 & $1,896,159$ & 432,947 & 165,096 & 27,862 & 12,998 & 977 & 4,824 & 644,704 \\
\hline Indiana & 177 & 264,015 & 62,563 & 23,159 & 5,791 & 1,710 & 67 & 420 & 93,710 \\
\hline Lowa & 2 & 6,126 & 1,330 & 547 & 198 & 43 & 2 & 8 & 2,128 \\
\hline Kansas & 3,473 & $10,664,196$ & $7,707,963$ & $1,030,789$ & 710,893 & 66,514 & 10,932 & 59,752 & $9,586,843$ \\
\hline Kentucky & 1,296 & $2,835,167$ & 623,754 & 234,185 & 226,515 & 10,555 & 1,581 & 8,724 & $1,105,314$ \\
\hline Louisiana & 1,399 & $9,657,120$ & $8,588,743$ & $1,305,498$ & $11,110,853$ & 134,630 & 45,934 & 876,771 & $22,062,429$ \\
\hline \multicolumn{10}{|l|}{ Maine } \\
\hline \multicolumn{10}{|l|}{ Maryland } \\
\hline \multicolumn{10}{|l|}{ Massachusetts } \\
\hline Michigan & 970 & 2515,525 & $2,006,845$ & 271,328 & 451,573 & 10,159 & 3,733 & 14,186 & $2,757,824$ \\
\hline \multicolumn{10}{|l|}{ Minnisota } \\
\hline Mississippi & 190 & $1,686,604$ & 1258,138 & 249,758 & $3,819,232$ & 7,244 & 9,372 & 267,512 & $5,611,256$ \\
\hline Missouri & 15 & 11,847 & 2,599 & 1,051 & 378 & 78 & 1 & 9 & 4,116 \\
\hline Montana & 336 & 963,949 & 751,136 & 100,672 & 299,709 & 5,540 & 2,253 & 7,075 & $1,166,385$ \\
\hline Nebraska & 137 & 724,389 & 369,063 & 73,479 & 42,546 & 2,000 & 1,498 & 6,453 & 495,039 \\
\hline Nevada & 46 & 227,461 & 169,905 & 22,801 & 150,374 & 2,149 & 544 & 1,911 & 347,684 \\
\hline \multicolumn{10}{|c|}{ New Hampshire } \\
\hline \multicolumn{10}{|l|}{ New Jersey } \\
\hline New Mexico & 1,704 & $9,029,172$ & $8,708,006$ & $1,325,222$ & $5,290,966$ & 123,029 & 27,503 & 183,582 & $15,658,308$ \\
\hline New York & 141 & 395,975 & 87,328 & 32,876 & 46,314 & 846 & 324 & 1,749 & 169,437 \\
\hline \multicolumn{10}{|l|}{ North Carolina } \\
\hline North Dakota & 274 & $2,562,769$ & $2,061,848$ & 306,841 & 453,199 & 9,782 & 12,166 & 33,748 & $2,877,584$ \\
\hline Ohio & 1,333 & $5,757,977$ & $1,393,458$ & 435,831 & 658,323 & 12,787 & 7,599 & 40,144 & $2,548,142$ \\
\hline Oklahoma & 3,560 & $20,548,362$ & $18,733,320$ & $2,777,314$ & $12,019,370$ & 71,137 & 73,732 & 877,908 & $34,552,781$ \\
\hline Oregon & 4 & 9,509 & 2,578 & 816 & 306 & 41 & 4 & 13 & 3,758 \\
\hline Pennsylvania & 625 & $2,923,685$ & 693,081 & 215,971 & 338,395 & 6,512 & 4,183 & 21,169 & $1,279,311$ \\
\hline \multicolumn{10}{|l|}{ Rhode Island } \\
\hline \multicolumn{10}{|l|}{ South Carolina } \\
\hline South Dakota & 14 & 68,164 & 43,955 & 7,475 & 6,517 & 186 & 258 & 740 & 59,131 \\
\hline Tennessee & 57 & 112,340 & 25,339 & 9,765 & 7,170 & 484 & 42 & 288 & 43,088 \\
\hline Texas & 9,892 & $58,777,263$ & $42,528,360$ & $6,793,535$ & $17,449,791$ & 337,169 & 209,140 & $1,270,985$ & $68,588,980$ \\
\hline Utah & 103 & 747,691 & 772,559 & 133,806 & 164,992 & 2,558 & 2,823 & 46,149 & $1,122,887$ \\
\hline \multicolumn{10}{|l|}{ Vermont } \\
\hline Virginia & 70 & 262,925 & 57,354 & 20,689 & 30,729 & 575 & 295 & 1,563 & 111,205 \\
\hline Washington & 1 & 2,700 & 700 & 217 & 87 & 12 & 1 & 4 & 1,021 \\
\hline West Virginia & 814 & $3,687,230$ & 840,017 & 272,755 & 428,200 & 8,165 & 5,087 & 27,023 & $1,581,247$ \\
\hline \multicolumn{10}{|l|}{ Wisconsin } \\
\hline Wyoming & 932 & $5,694,879$ & $5,244,606$ & 859,365 & $3,310,022$ & 58,673 & 24,554 & 146,513 & $9,643,733$ \\
\hline Total & 33,820 & $161,159,143$ & $115,141,474$ & $18,918,417$ & $69,421,213$ & 962,535 & 484,699 & $4,213,385$ & $209,141,723$ \\
\hline
\end{tabular}


Table 4.3. 1992 Drilling waste volumes by modified API method.

\begin{tabular}{|c|c|c|c|c|c|c|c|c|c|}
\hline \multirow[b]{2}{*}{ State } & \multirow{2}{*}{$\begin{array}{l}\text { \# Onshore } \\
\text { Completions }\end{array}$} & \multirow{2}{*}{$\begin{array}{c}\text { Total Drilled } \\
\text { Footage }\end{array}$} & \multicolumn{6}{|c|}{ Total Waste Volumes Discharged to Reserve Pits (bbls) } & \multirow{2}{*}{$\begin{array}{l}\text { Total Waste } \\
\text { Volume (bbls) }\end{array}$} \\
\hline & & & Mud & Cuttings & Water & Cement & TestFluid & Other & \\
\hline Alabama & 364 & $1,748,073$ & $1,444,193$ & 339,413 & $3,695,275$ & 6,889 & 5,101 & 100,747 & $5,591,618$ \\
\hline Arizona & 2 & 12,290 & 10,287 & 1,206 & 4,520 & 61 & 19 & 102 & 16,195 \\
\hline Arkansas & 275 & $1,368,759$ & 966,058 & 150,882 & $2,125,149$ & 4,501 & 3,006 & 23,679 & $3,273,275$ \\
\hline California & 1,387 & $3,621,546$ & $1,455,657$ & 385,519 & 257,494 & 18,096 & 6,711 & 32,883 & $2,156,360$ \\
\hline Colorado & 1,530 & $9,691,177$ & $6,948,934$ & $1,037,231$ & $1,010,811$ & 27,673 & 25,857 & 104,266 & $\overline{9,154, \overline{772}}$ \\
\hline \multicolumn{10}{|l|}{ Connecticut } \\
\hline \multicolumn{10}{|l|}{ Delaware } \\
\hline Florida & 2 & 29,791 & 28,964 & 11,680 & 72,506 & 153 & 225 & 9,624 & 123,152 \\
\hline Georgia & 1 & 7,650 & 3,259 & 664 & 825 & 19 & 41 & 109 & 4,917 \\
\hline \multicolumn{10}{|l|}{ Idaho } \\
\hline Dlinois & 613 & $1,396,472$ & 325,952 & 121,951 & 24,426 & 9,537 & 893 & 4,606 & 487,365 \\
\hline Indiana & 130 & 212,179 & 52,435 & 18,464 & 3,114 & 1,403 & 58 & 286 & 75,760 \\
\hline \multicolumn{10}{|l|}{ lowa } \\
\hline Kansas & 2,213 & $7,078,391$ & $5,116,214$ & 690,885 & 494,439 & 43,889 & 7,823 & 43,036 & $6,396,286$ \\
\hline Kentucky & 914 & $2,008,179$ & 472,385 & 166,395 & 150,161 & 8,615 & 1,283 & 6,894 & 805,733 \\
\hline Louisiana & 396 & $3,045,530$ & $2,745,324$ & 453807 & $3,509,984$ & 44,933 & 15,331 & 309,593 & $7,078,972$ \\
\hline \multicolumn{10}{|l|}{ Maine } \\
\hline \multicolumn{10}{|l|}{ Maryland } \\
\hline \multicolumn{10}{|l|}{ Massachusetts } \\
\hline Michigan & 798 & $1,720,139$ & $1,362,710$ & 169,163 & 268,254 & 7,225 & 1,383 & 5,914 & $1,814,649$ \\
\hline \multicolumn{10}{|l|}{ Minnisota } \\
\hline Mississippi & 96 & 991,051 & 703,075 & 158,694 & $2,300,621$ & 4,573 & 6,373 & 263,502 & $3,436,838$ \\
\hline \multicolumn{10}{|l|}{ Missouri } \\
\hline Montana & 266 & 802,361 & 618,814 & 84,726 & 262,239 & 4,853 & 1,924 & 6,088 & 978,644 \\
\hline Nebraska & 82 & 471,620 & 279,781 & 48,231 & 29,262 & 1,235 & 1,431 & 4,788 & 364,728 \\
\hline Nevada & 24 & 134,457 & 107,111 & 13,843 & 81,088 & 1,276 & 382 & 1,328 & 205,028 \\
\hline \multicolumn{10}{|c|}{ New Hampshire } \\
\hline \multicolumn{10}{|l|}{ New Jersey } \\
\hline New Mexico & 1,134 & $6,830,443$ & $6,239,355$ & $1,074,151$ & $3,896,222$ & 97,679 & 24,783 & 229,671 & $11,561,861$ \\
\hline New York & 68 & 171,712 & 37,426 & 13,795 & 20,155 & 354 & 135 & 767 & 72,632 \\
\hline \multicolumn{10}{|l|}{ North Carolina } \\
\hline North Dakota & 193 & $1,762,584$ & $1,426,902$ & 209,939 & 292,053 & 6,442 & 8,043 & 22,803 & $1,966,182$ \\
\hline Ohio & 837 & $3,430,836$ & 825,367 & 259,622 & 391,200 & 7,589 & 4,531 & 24,238 & $1,512,547$ \\
\hline Oklahoma & 2,582 & $15,228,496$ & $14,202,329$ & $2,105,593$ & $8,671,540$ & 52,771 & 54,874 & 682,763 & $25,769,870$ \\
\hline Oregon & 4 & 10,283 & 2,709 & 846 & 331 & 45 & 4 & 14 & 3,949 \\
\hline Pennsylvania & 565 & $2,585,636$ & 613,195 & 192,491 & 293,222 & 5,762 & 3,110 & 16,684 & $1,124,464$ \\
\hline \multicolumn{10}{|l|}{ Rhode Island } \\
\hline \multicolumn{10}{|l|}{ South Carolina } \\
\hline South Dakota & 11 & 58,114 & 36,656 & 6,311 & 5,270 & 157 & 210 & 633 & 49,237 \\
\hline Tennessee & 47 & 115,255 & 25,568 & 9,767 & 7,664 & 494 & 45 & 217 & 43,755 \\
\hline Texas & 7,164 & $45,462,158$ & $32,027,197$ & $5,387,991$ & $14,000,965$ & 271,320 & 174,391 & $1,045,192$ & $52,907,056$ \\
\hline Utah & 307 & $2,092,538$ & $1,834,979$ & 304,341 & 243870 & 6,084 & 5,671 & 67,069 & $2,462,014$ \\
\hline Vermont & & & & & & & & & \\
\hline Virginia & 140 & 377,824 & 88,609 & 33,618 & 44,525 & 807 & 332 & 1,542 & 169,433 \\
\hline Washington & 1 & 1,411 & 509 & 175 & 45 & 6 & 0 & 2 & 737 \\
\hline West Virginia & 502 & $2,275,438$ & 528,303 & 169,076 & 260,421 & 5,052 & 3,076 & 16,633 & 982,561 \\
\hline Wisconsin & 1 & 4,700 & 3,824 & 392 & 682 & 20 & 7 & 39 & 4,964 \\
\hline Wyoming & 857 & $5,299,358$ & $4,829,706$ & 829,266 & $3,409,086$ & 42,781 & 25,216 & 145,704 & $9,281,759$ \\
\hline Total & 23,506 & $120,046,451$ & $85,363,787$ & $14,450,128$ & $45,827,419$ & 682,294 & 382,269 & $3,171,416$ & $149,877,313$ \\
\hline
\end{tabular}




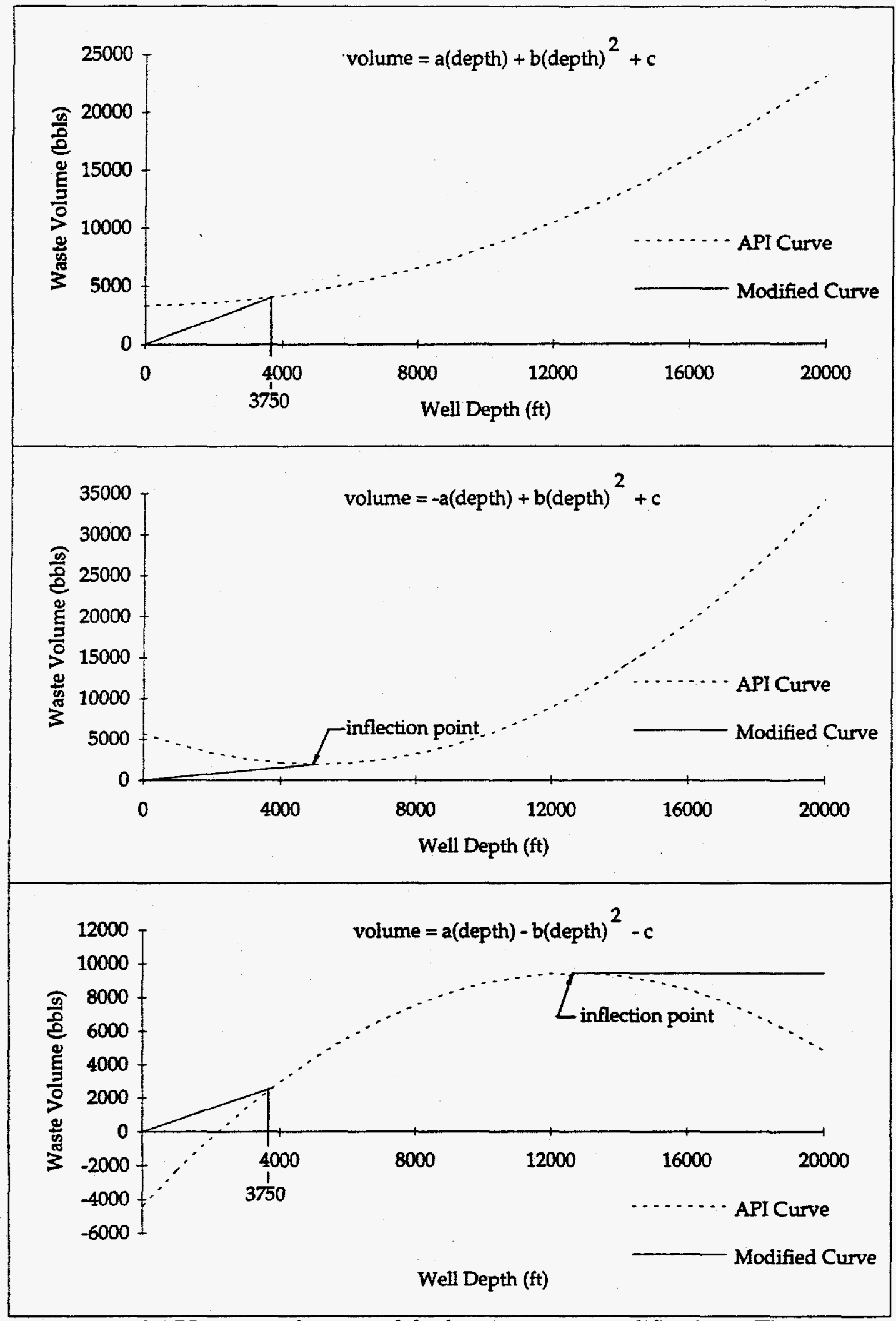

Figure 4.1. Typical API waste volume models showing curve modifications. These curves represent typical shapes only. The form of the curve is defined independently for each basin group and for each waste type based on the statistical data. 


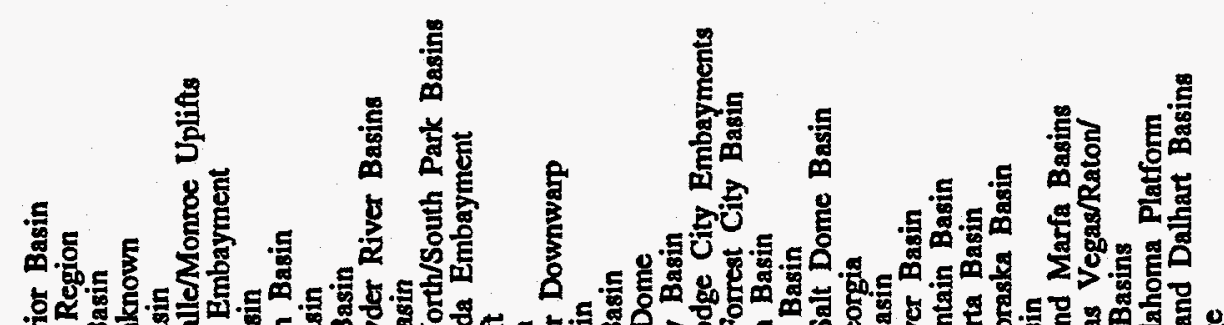
畐 3 5 出

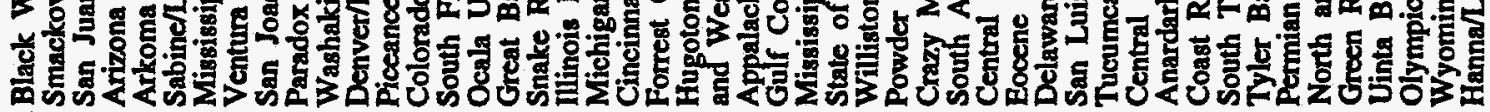

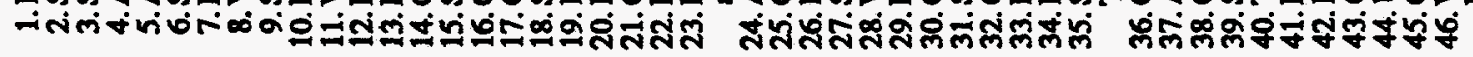

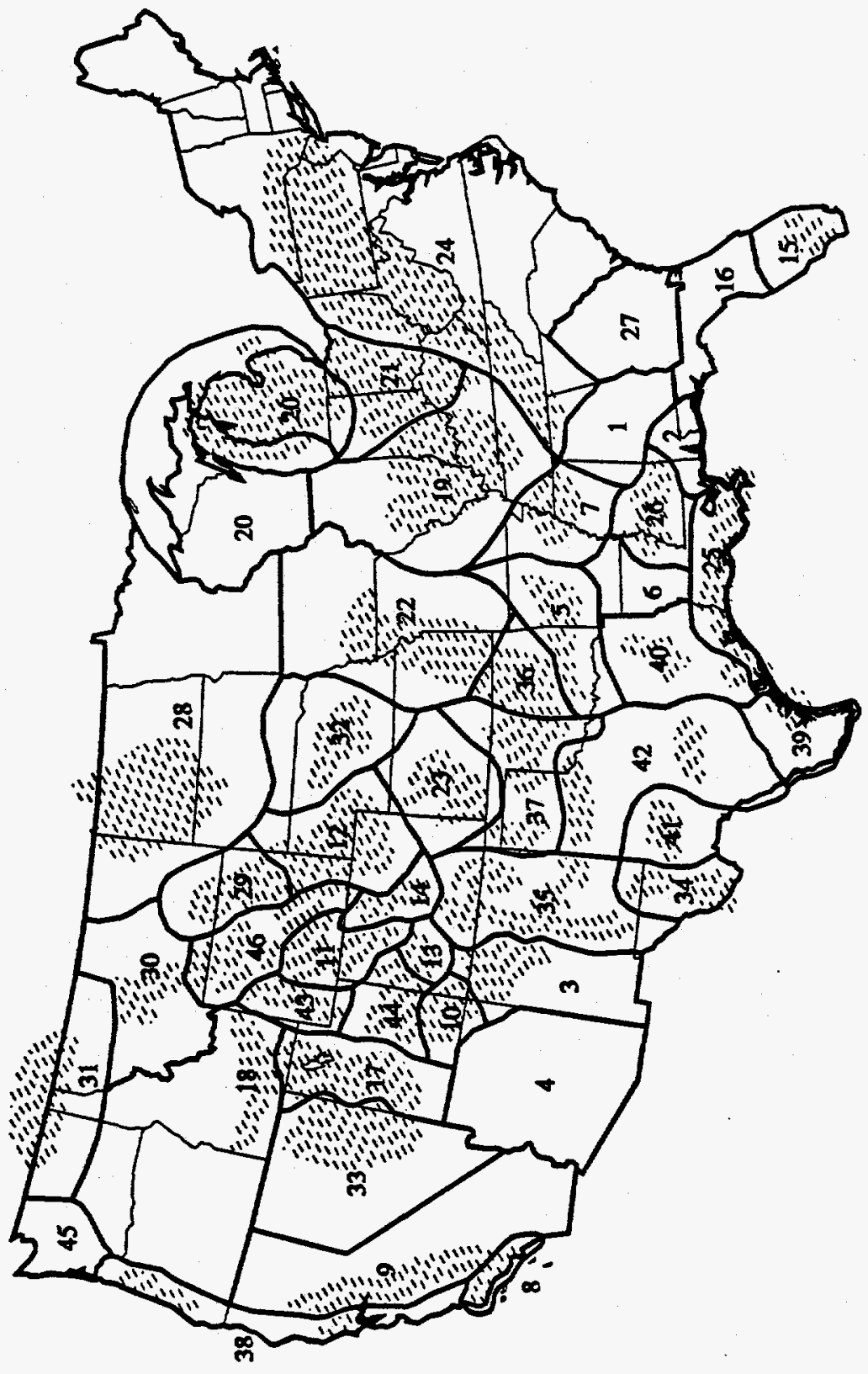


Table 4.4. Ratios of waste volume to drilled footage per API survey.

\begin{tabular}{|c|c|c|}
\hline \multirow{2}{*}{ Depth Class } & \multicolumn{2}{|c|}{ Waste/Drilled Footage Ratio } \\
\cline { 2 - 3 } & Test Fluid & Other \\
\hline 1 & 0.0005302 & 0.0015140 \\
\hline 2 & 0.0016050 & 0.0084119 \\
\hline 3 & 0.0054105 & 0.0142894 \\
\hline 4 & 0.0095672 & 0.6045260 \\
\hline
\end{tabular}

As predicted by the decline in new drilling activity (Figure 2.5), the volumes of drilling waste generated in the U.S. has steadily decreased over the last several years (Figure 4.3). The 1992 waste volume is only $41 \%$ of the volume generated in 1985 as computed by API. Table 4.5 compares the reduction in drilling waste with the reductions in the number of drilled wells and the total drilled footage since 1985 . Note that the percent reduction in waste volume lags behind the percent reduction in drilling activity by about $8 \%$. As would be expected, waste volume is more closely linked with drilled footage lagging behind a reduction in this value by only about $4 \%$. On a volume percentage basis, approximately $55 \%$ of reserve pit waste is drilling mud, $33 \%$ is water, $9 \%$ is drill cuttings, $2 \%$ is other wastes, and the remaining $1 \%$ is cement and test fluid. The API reported slightly different percentages with $63 \%$ mud, $24 \%$ water, $10 \%$ cuttings, $2 \%$ other wastes, and $1 \%$ cement and test fluid.

Table 4.5. Reduction trends in drilled wells, drilled footage, and waste volumes.

\begin{tabular}{|c|c|c|c|c|c|c|}
\hline Year & $\begin{array}{c}\text { \# Drilled } \\
\text { Wells }\end{array}$ & $\begin{array}{c}\text { \% Reduction } \\
\text { Since 1985 }\end{array}$ & $\begin{array}{c}\text { Total Drilled } \\
\text { Footage }\end{array}$ & $\begin{array}{c}\text { \% Reduction } \\
\text { Since 1985 }\end{array}$ & $\begin{array}{c}\text { Waste Volume } \\
\text { (bbls) }\end{array}$ & $\begin{array}{c}\text { \% Reduction } \\
\text { Since 1985 }\end{array}$ \\
\hline 1985 & 69,734 & 0 & $306,897,643$ & 0 & $361,409,000$ & 0 \\
\hline 1988 & 35,959 & 48 & $170,726,402$ & 44 & $216,542,355$ & 40 \\
\hline 1990 & 33,820 & 52 & $161,159,143$ & 47 & $209,141,723$ & 42 \\
\hline 1992 & 23,506 & 66 & $120,046,451$ & 61 & $149,877,313$ & 59 \\
\hline
\end{tabular}




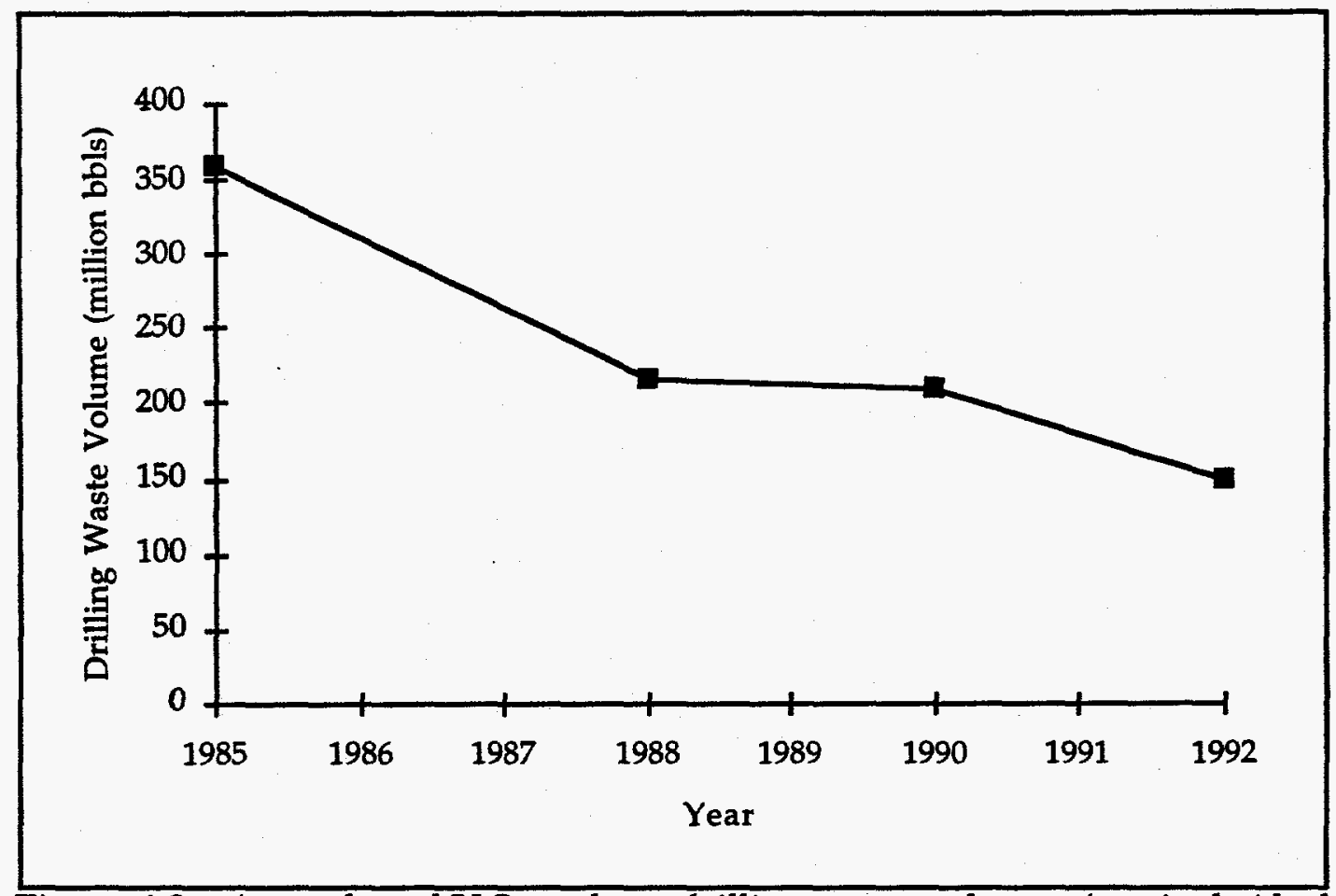

Figure 4.3. Annual total U.S. onshore drilling waste volumes (not incl. Alaska).

\subsubsection{Drilling Waste Disposal}

In their 1985 report the API included an analysis of waste disposal methods. Based on the results of the operator survey, the proportion of drilling wastes (liquids and solids) disposed of by various methods was computed for each state and for the nation as a whole. These proportions were then applied to the total waste volumes to determine the volume of waste disposed of by each method in each state. However, because the necessary proportion factors are not published and could not be obtained directly from API, this type of analysis could not be performed as part of this study. Furthermore, as confirmed by telephone survey, information on drilling waste disposal practices is generally unavailable from state agencies because no records are kept. The sole source of this type of information is the drilling operators. In the absence of an operator survey, then, no information on drilling waste disposal quantities can be generated. In their 1985 survey, the API found that, nationwide, $29 \%$ by volume of reserve pit wastes are evaporated from the pit, $28 \%$ are hauled offsite, $13 \%$ are injected 
down the well annulus, $12 \%$ are buried onsite, $10 \%$ are discharged to the surface, $7 \%$ are land spread, $1 \%$ are solidified, and none are incinerated.

\subsubsection{Produced Water Production}

Information on produced water production is much more readily available than drilling waste data because the disposal of this waste is subject to regulation under the Clean Water Act and the Safe Drinking Water Act. Most state agencies maintain some produced water records. In their studies, both the EPA and the API reported produced water volumes gathered from state agencies. In many cases, however, the state maintained produced water records represent injected volumes as reported to local Underground Injection Control offices and do not include produced water disposed of by other means. Still, because more than $90 \%$ of produced water is injected, the injected water volume typically stands as a good estimate of the total produced water volume. In cases where produced water information was not available from agency records, oil/water ratios from nearby states were used by EPA and API to compute volume estimates.

The API actually computed two independent estimates of produced water volumes. In addition to compiling state agency data, the API generated an estimate based on an operator survey that requested crude oil and produced water volumes and produced water disposal volumes. From the responses to the survey, water/oil ratios were developed for each state and multiplied by the total oil production in the state to create an estimate of the total produced water volume.

Following the procedures used by EPA and API, the produced water data gathered for this study, and presented in Table 4.6, were obtained from state agency records. Thirty-one states were identified as having significant oil and/or gas production activity. Various agencies in each of these states were contacted and asked to provide information on the number of active wells in the state and annual production 
volumes of oil, gas, and produced water for the years 1986 - 1991. As indicated by blanks in the table, many states were only able to provide partial information. The states of Illinois, Louisiana, and New Mexico were unable to provide any information at all. The oil and gas production statistics for these three states were obtained from data published by the Energy Information Administration (1991,1992). The 1985 API data are included in the table for reference.

Twenty of the 31 states contacted were able to provide produced water information. Data from 4 of these states (Colorado, Kansas, Texas, and West Virginia) represent injection data. Produced water estimates were computed for the remaining 11 states using either:

1. water/oil ratios developed in the API Survey or,

2. water/oil ratios from nearby states where API ratios were not available.

This computational procedure assumes that all produced water is attributable to oil production; gas production is ignored. It also assumes that water/oil ratios are similar for production in adjacent states.

The data in Table 4.6 indicate that the annual production of produced water has followed a general decline over the six year period 1986 - 1991 falling from 19.5 billion barrels to 18.3 billion barrels. If a decreasing trend in produced water volumes were assumed to exist, this range of volumes would be in agreement with the 1985 API figure of 20.9 billion barrels estimated from the operator survey, though the API estimate was based on only 22 states. The range of produced water volumes estimated for the years 1986 - 1991 is largely in excess of the 1985 estimates made using state agency data by both the API (16.3 billion barrels) and the EPA (11.7 billion barrels) which included 31 and 33 states respectively. 
Table 4.6. Annual produced water production and disposal volumes.

\begin{tabular}{|c|c|c|c|c|c|c|c|c|c|c|c|c|c|}
\hline \multirow[t]{2}{*}{ State } & \multirow[t]{2}{*}{ Year } & \multirow[t]{2}{*}{ Prod Wells } & \multirow[t]{2}{*}{ Injec Wells } & \multirow[t]{2}{*}{ Shut in Wells } & \multirow[t]{2}{*}{ Total Wells } & \multirow{2}{*}{$\begin{array}{c}\text { OAl } \\
\text { (bbls) }\end{array}$} & \multirow{2}{*}{$\begin{array}{c}\text { Gas } \\
\text { (MCF) }\end{array}$} & \multirow{2}{*}{$\begin{array}{l}\text { Water } \\
\text { (bbls) }\end{array}$} & \multirow{2}{*}{$\begin{array}{c}\text { Water/OII } \\
\text { Ratio }\end{array}$} & \multicolumn{4}{|c|}{ Disposal Volumes (bbls) } \\
\hline & & & & & & & & & & Deep Well In]. & EOR & NPDES & Other \\
\hline \multirow[t]{8}{*}{ ALABAMA } & 1985 & & & & & $21,581,000$ & & $87,619,000$ & 4.06 & $74,116,000$ & $13,503,000$ & 0 & 0 \\
\hline & 1986 & - & 8 & $=$ & $\overline{-}$ & $10,495,327$ & $146,605,998$ & $34,768,828$ & 3.31 & $29,410,952$ & $5,357,876$ & 0 & 0 \\
\hline & 1987 & - & 15 & - & $=$ & $10,089,006$ & $155,555,275$ & $36,494,907$ & 3.62 & $30,871,042$ & $5,623,865$ & 0 & 0 \\
\hline & 1988 & 2,151 & 13 & $=$ & $=$ & $9,618,183$ & $176,691,100$ & $37,005,450$ & 3.85 & $31,302,910$ & $5,702,540$ & 0 & 0 \\
\hline & 1989 & - & 29 & - & $=$ & $8,978,248$ & $181,001,831$ & $45,896,929$ & 5.11 & $38,824,212$ & $7,072,717$ & 0 & 0 \\
\hline & 1990 & - & 29 & $=$ & - & $8,467,864$ & $187,961,218$ & $66,149,157$ & 7.81 & $55,955,572$ & $10,193,585$ & 0 & 0 \\
\hline & 1991 & 4,310 & 22 & - & - & $8,858,484$ & $224,470,382$ & $133,392,477$ & 15.06 & $112,836,696$ & $20,555,781$ & 0 & 0 \\
\hline & & & & & & & & & & & & & \\
\hline \multirow[t]{8}{*}{ ALASKA } & 1985 & & & & & $651,599,000$ & & $97,740,000$ & 0.15 & $27,902,000$ & $69,444,000$ & 394,000 & $\overline{0}$ \\
\hline & \begin{tabular}{|l|}
1986 \\
\end{tabular} & $=$ & $=$ & $=$ & $=$ & $681,634,899$ & $1,381,888,437$ & $174,796,180$ & 0.26 & $49,904,309$ & $124,192,686$ & 699,185 & 0 \\
\hline & 1987 & $=$ & - & $=$ & - & $715,842,735$ & $1,704,343,572$ & $275,665,676$ & 0.39 & $78,702,550$ & $195,860,463$ & $1,102,663$ & 0 \\
\hline & 1988 & - & - & - & - & $738,226,829$ & $1,952,069,158$ & $344,293,037$ & 0.47 & $98,295,662$ & $244,620,203$ & $1,377,172$ & 0 \\
\hline & 1989 & - & $=$ & - & - & $683,977,736$ & $1,974,728,403$ & $396,005,248$ & 0.58 & $113,059,498$ & $281,361,729$ & $1,584,021$ & 0 \\
\hline & 1990 & 1,599 & 517 & 30 & 2,146 & $647,309,636$ & $2,064,522,212$ & $449,312,128$ & 0.69 & $128,278,613$ & $319,236,267$ & $1,797,249$ & 0 \\
\hline & 1991 & 1,663 & 554 & 28 & 2,245 & $656,348,731$ & $2,391,900,281$ & $539,376,019$ & 0.82 & $153,991,853$ & $383,226,661$ & $2,157,504$ & 0 \\
\hline & & & & & & & & & & & & & \\
\hline \multirow{8}{*}{ ARKANSAS } & 1989 & & & & & & & & & & & & \\
\hline & & $=$ & $=$ & $\overline{-}$ & & $19,044,000$ & & $184,536,000$ & 9.69 & $83,983,000$ & $100,218,000$ & 0 & 335,000 \\
\hline & \begin{tabular}{|l|}
1986 \\
1987 \\
\end{tabular} & $=$ & $=$ & $=$ & $=$ & $15,819,000$ & $156,580,518$ & $203,240,401$ & 12.85 & $92,494,706$ & $110,379,862$ & 0 & 365,833 \\
\hline & \begin{tabular}{|l|}
1988 \\
\end{tabular} & 7,080 & $=$ & $=$ & - & $\begin{array}{l}14,230,000 \\
13,456,000\end{array}$ & $\frac{166.998 .000}{164,438,632}$ & $\frac{205,044,975}{222,819,711}$ & $\begin{array}{l}14.41 \\
16.56\end{array}$ & $\begin{array}{c}93,315,968 \\
101,405,250\end{array}$ & \begin{tabular}{|l|}
$111,359,926$ \\
$121,013,385$
\end{tabular} & $\frac{0}{0}$ & $\begin{array}{l}369,081 \\
401,075\end{array}$ \\
\hline & 1989 & 7,405 & $=$ & - & $=$ & $11,428,000$ & $175,734,554$ & $235,804,261$ & 20.63 & $107,314,519$ & $128,065,294$ & 0 & 424,448 \\
\hline & 1990 & 7,249 & $=$ & $=$ & $=$ & $12,230,000$ & $187,084,887$ & $241,020,532$ & 19.71 & $109,688,444$ & $130,898,251$ & 0 & 433,837 \\
\hline & 1991 & $=$ & $=$ & $=$ & $=$ & $10,300,000$ & $=$ & $202,985,403$ & 19.71 & $92,378,657$ & $110,241,372$ & 0 & 365,374 \\
\hline & & & & & & & & & & & & & \\
\hline \multirow{8}{*}{ CALIFORNIA } & & & [1] & & & & & & & & & & \\
\hline & 1985 & & & & & $353,550,000$ & & $2,846,078,000$ & 8.05 & $666,743,000$ & $1,525,857,000$ & $184,307,000$ & $469,171,000$ \\
\hline & 1986 & 56,175 & 15,280 & 19,199 & 90,654 & $378,537,427$ & $416,413,361$ & $2,644,330,017$ & 6.99 & $619,566,523$ & $1,417,625,322$ & $171,352,585$ & $435,785,587$ \\
\hline & 1987 & 53,106 & 15,836 & 23,765 & 92,707 & $365,934,296$ & $382,217,947$ & $2,604,287,666$ & 7.12 & $610,184,600$ & $1,396,158,618$ & $168,757,841$ & $429,186,607$ \\
\hline & \begin{tabular}{|l|}
1988 \\
\end{tabular} & 52,376 & 15,824 & 24,820 & 93,020 & $355,517,714$ & $363,009,097$ & $2,570,979,053$ & 7.23 & $602,380,392$ & $1,378,301,870$ & $166,599,443$ & $423,697,348$ \\
\hline & 1989 & - & - & - & - & $331,178,337$ & $336,015,095$ & $2,409,923,634$ & 7.28 & $564,645,107$ & $1,291,960,060$ & $156,163,051$ & $397,155,415$ \\
\hline & 1990 & 51,076 & 15,280 & 24,372 & 90,728 & $320,782,333$ & $320,327,916$ & $2,378,575,844$ & 7.41 & $557,300,320$ & $1,275,154,510$ & $154,131,715$ & $391,989,299$ \\
\hline & \begin{tabular}{|l|}
1991 \\
\end{tabular} & 50,332 & 17,641 & 24,332 & 92,305 & $319,235,058$ & $335,983,693$ & $2,320,280,525$ & 7.27 & $543,641,727$ & $1,243,902,389$ & $150,354,178$ & $382,382,231$ \\
\hline \multirow{9}{*}{ COLORADO } & & & & & & & & [3] & & & & & \\
\hline & 1985 & & & & & $30,246,000$ & & $388,661,000$ & 12.85 & $31,343,000$ & $357,286,000$ & 28,000 & 4,000 \\
\hline & 1986 & 10,178 & $=$ & 2,482 & $=$ & $29,660,465$ & $175,347,040$ & $225,620,618$ & 7.61 & $18,194,047$ & $207,408,522$ & 15,793 & 2,256 \\
\hline & 1987 & 10,705 & [2] & [2] & [2] & $29,360, A 05$ & $186,286,548$ & $226,955,931$ & 7.73 & $18,301,726$ & $208,636,048$ & 15,887 & 2,270 \\
\hline & 1988 & 10,923 & 199 & 2,488 & 13,610 & $32,818,715$ & $212,614,658$ & $257,755,312$ & 7.85 & $20,785,388$ & $236,949,303$ & 18,043 & 2,578 \\
\hline & 1989 & 11,706 & 210 & 2009 & 13,925 & $31,101,825$ & $237,372,354$ & $239,389,237$ & 7.70 & $19,304,348$ & $220,065,738$ & 16,757 & 2,394 \\
\hline & 1990 & 12,441 & 203 & 1,799 & 14,443 & $30,886,191$ & $268,384,541$ & $225,142,715$ & 7.29 & $18,155,509$ & $206,969,195$ & 15,760 & 2,251 \\
\hline & 1991 & 13,096 & 220 & 2,576 & 15,892 & $31,497,969$ & $299,025,314$ & $206,888,690$ & 6.57 & $16,683,504$ & $190,188,635$ & 14,482 & 2,069 \\
\hline & & & & & & & & & & & & & \\
\hline
\end{tabular}


Table 4.6 continued. Annual produced water production and disposal volumes.

\begin{tabular}{|c|c|c|c|c|c|c|c|c|c|c|c|c|c|}
\hline \multirow[t]{2}{*}{ State } & \multirow[t]{2}{*}{ Year } & \multirow[t]{2}{*}{ Prod Wells } & \multirow[t]{2}{*}{ Injec Wells } & \multirow[t]{2}{*}{ Shut In Wellis } & \multirow[t]{2}{*}{ Total Wells } & \multirow{2}{*}{$\begin{array}{c}\text { Oil } \\
\text { (bbls) }\end{array}$} & \multirow{2}{*}{$\begin{array}{c}\text { Gas } \\
\text { (MCF) }\end{array}$} & \multirow{2}{*}{$\begin{array}{l}\begin{array}{l}\text { Water } \\
\text { (bbls) }\end{array} \\
\end{array}$} & \multirow{2}{*}{$\begin{array}{c}\text { Water/Oil } \\
\text { Rato } \\
\end{array}$} & \multicolumn{4}{|c|}{ Disposal Volumes (bbls) } \\
\hline & & & & & & & & & & Deep Well In] & EOR & NPDES & Other \\
\hline \multirow{8}{*}{ FLORIDA } & 1985 & & & & & & & & & & & & \\
\hline & 1986 & 113 & 41 & 108 & 278 & $9,382,973$ & $9,818.562$ & 68804025 & 733 & & & & \\
\hline & 1987 & 123 & 37 & 110 & 286 & $8,269,632$ & $9,181,890$ & $74,206,329$ & 8.97 & & & & \\
\hline & 1988 & 92 & 29 & 162 & 283 & $7,746,048$ & $8,452,999$ & $64,498,985$ & 8.33 & & & & \\
\hline & 1989 & 99 & 37 & 126 & 262 & $7,289,390$ & $8,821,292$ & $70,304,219$ & 9.64 & & & & \\
\hline & \begin{tabular}{|l|}
1990 \\
\end{tabular} & 88 & 39 & 117 & 244 & $5,674,382$ & $7,484,621$ & $59,167,303$ & 10.43 & & & & \\
\hline & 1991 & 94 & 29 & 99 & 222 & $4,726,747$ & $5,929,916$ & $58,415,711$ & 12.36 & & & & \\
\hline & & & & & & & & & & & & & \\
\hline \multirow{9}{*}{ ILLINOIS } & & & & & & & & & & & & & \\
\hline & 1985 & & & & & $30,265,000$ & & $1,282,933,000$ & 42.39 & $61,851,000$ & $1,221,077,000$ & 0 & 6,000 \\
\hline & 1986 & - & $=$ & $=$ & - & 27245000 & 1887.000 & $1,154,915,550$ & 42.39 & $55,678,479$ & $1,099,231,297$ & 0 & 5,775 \\
\hline & 1987 & $=$ & - & - & $=$ & 24.096 .000 & 1.371000 & $1,021,429,440$ & $\$ 2.39$ & $49,243,113$ & $972,181,220$ & 0 & 5,107 \\
\hline & \begin{tabular}{|l|}
1988 \\
\end{tabular} & - & - & - & - & 22.476 .000 & $1,338,000$ & $952,757,640$ & 42.39 & $45,932,446$ & $906,820,430$ & 0 & 4,764 \\
\hline & 1989 & - & - & $=$ & $=$ & $20,380.000$ & 1.477 .000 & $863,908,200$ & $\$ 2.39$ & $41,649,014$ & $822,254,866$ & 0 & 4,320 \\
\hline & \begin{tabular}{|l|}
1990 \\
\end{tabular} & - & - & - & - & 19.954 .000 & 677.000 & $845,850,060$ & 42.39 & $40,778,431$ & $805,067,399$ & 0 & 4,229 \\
\hline & 1991 & $=$ & $=$ & $=$ & $=$ & 19068,000 & $=$ & $808,292,520$ & 42.39 & $38,967,782$ & $769,320,696$ & 0 & 4,041 \\
\hline & & & & & & & & & & & & & \\
\hline & & & & & & & & & & & & & \\
\hline \multirow[t]{8}{*}{ INDIANA } & 1985 & & & & & & & & & & & & \\
\hline & 1986 & 8,649 & - & - & - & $4,758,609$ & 365,084 & $3,140,682$ & 0.66 & & & & \\
\hline & \begin{tabular}{|l|}
1987 \\
\end{tabular} & 8,899 & - & - & $=$ & $3,901,753$ & 217,328 & $2,497,122$ & 0.64 & & & & \\
\hline & \begin{tabular}{|l|}
1988 \\
\end{tabular} & 8,747 & $=$ & $=$ & $=$ & $3,572,397$ & 411,647 & $2,429,230$ & 0.68 & & & & \\
\hline & 1989 & 8,838 & - & $=$ & $=$ & $3,309,394$ & 415,876 & $1,919,449$ & 0.58 & & & & \\
\hline & 1990 & 8,817 & $=$ & $=$ & $=$ & $3,000,092$ & 398,714 & $1,740,053$ & 0.58 & & & & \\
\hline & 1991 & 8,844 & - & $=$ & $=$ & $3,013,324$ & 232,485 & $1,747,728$ & 0.58 & & & & \\
\hline & & & & & & & & & & & & & \\
\hline \multirow{8}{*}{ KANSAS } & & & & & & & & [3] & & & & & \\
\hline & 1985 & & & & & $75,407,000$ & & $999,143,000$ & 13.25 & $603,655,000$ & $391,562,000$ & 0 & $3,926,000$ \\
\hline & \begin{tabular}{|l|}
1986 \\
\end{tabular} & $=$ & $=$ & - & $=$ & $67,819,000$ & $470,313,594$ & $1,042,378,030$ & 15.37 & $629,804,806$ & $408,507,950$ & 0 & $4,065,274$ \\
\hline & \begin{tabular}{|l|}
1987 \\
\end{tabular} & $=$ & $=$ & $=$ & $=$ & $65,544,000$ & $474,093,863$ & $1,147,020,000$ & 17.50 & $693,029,484$ & $449,517,138$ & 0 & $4,473,378$ \\
\hline & \begin{tabular}{|l|}
1988 \\
\end{tabular} & - & - & $=$ & $=$ & $58,824,000$ & $586,451,218$ & $1,154,715,120$ & 19.63 & $697,678,876$ & $452,532,856$ & 0 & $4,503,389$ \\
\hline & \begin{tabular}{|l|}
1989 \\
\end{tabular} & - & - & - & - & $55,195,000$ & $601,385,254$ & $1,200,491,250$ & 21.75 & $725,336,813$ & $470,472,521$ & 0 & $4,681,916$ \\
\hline & 1990 & - & $=$ & $=$ & $=$ & $55,083,000$ & $581,683,890$ & $1,314,831,210$ & 23.87 & $794,421,017$ & $515,282,351$ & 0 & $5,127,842$ \\
\hline & 1991 & 75,700 & 13,063 & $=$ & 88,763 & $52,302,000$ & $635,222,016$ & $1,360,000,000$ & 26.00 & $821,712,000$ & $532,984,000$ & 0 & $5,304,000$ \\
\hline \multirow{9}{*}{ KENTUCKY } & & & & & & [4] & [4] & & & & & & \\
\hline & 1985 & & & & & $7,790,000$ & & $90,754,000$ & 11.65 & $90,754,000$ & 0 & 0 & 0 \\
\hline & 1986 & - & $=$ & - & $=$ & $7,596,106$ & $79,862,613$ & $88,494,635$ & 11.65 & $88,494,635$ & 0 & 0 & 0 \\
\hline & \begin{tabular}{|l|}
1987 \\
\end{tabular} & - & $=$ & - & - & $5,943,719$ & $72,974,415$ & $69,244,326$ & 11.65 & $69,244,326$ & 0 & 0 & 0 \\
\hline & \begin{tabular}{|l|}
1988 \\
\end{tabular} & - & $=$ & - & $=$ & $5,606,209$ & $72,177,371$ & $65,312,335$ & 11.65 & $65,312,335$ & 0 & 0 & 0 \\
\hline & \begin{tabular}{|l|}
1989 \\
\end{tabular} & $=$ & $=$ & - & $=$ & $5,452,183$ & $71,839,598$ & $63,517,932$ & 11.65 & $63,517,932$ & 0 & 0 & 0 \\
\hline & \begin{tabular}{|l|}
1990 \\
\end{tabular} & - & - & $=$ & $=$ & $5,179,380$ & $72,699,388$ & $60,339,777$ & 11.65 & $60,339,777$ & 0 & 0 & 0 \\
\hline & 1991 & - & - & - & - & $5,500,984$ & $80,097,683$ & $64,086,464$ & 11.65 & $64,086,464$ & 0 & 0 & 0 \\
\hline & & & & & & & & & & & & & \\
\hline
\end{tabular}


Table 4.6 continued. Annual produced water production and disposal volumes.

\begin{tabular}{|c|c|c|c|c|c|c|c|c|c|c|c|c|c|}
\hline \multirow[t]{2}{*}{ State } & \multirow[t]{2}{*}{\begin{tabular}{|l|} 
Year \\
\end{tabular}} & \multirow[t]{2}{*}{ Prod Wells } & \multirow[t]{2}{*}{ Injec Wells } & \multirow[t]{2}{*}{ Shut In Wells } & \multirow[t]{2}{*}{ Total Wells } & \multirow{2}{*}{$\begin{array}{c}\text { Oil } \\
\text { (bbls) }\end{array}$} & \multirow{2}{*}{$\begin{array}{c}\text { Gas } \\
\text { (MCP) }\end{array}$} & \multirow{2}{*}{$\begin{array}{l}\text { Water } \\
\text { (bbls) }\end{array}$} & \multirow{2}{*}{$\begin{array}{c}\text { Water/Oil } \\
\text { Ratio }\end{array}$} & \multicolumn{4}{|c|}{ Disposal Volumes (bbls) } \\
\hline & & & & & & & & & & Deep Well Inj. & EOR & NPDES & Other \\
\hline \multirow{7}{*}{ LOUISLANA } & \begin{tabular}{|l|}
1985 \\
\end{tabular} & & & & & $158,806,000$ & & $1,346,675,000$ & 8.48 & $621,947,000$ & $129,437,000$ & $588,141,000$ & \\
\hline & \begin{tabular}{|l|}
1986 \\
\end{tabular} & - & $=$ & $=$ & $=$ & $155,172.000$ & 4.964 .758 .000 & $1,315,858,560$ & 8.48 & $607,716,117$ & $126,467,166$ & $574,688,067$ & $6,987,209$ \\
\hline & 1987 & - & - & $=$ & - & 149.868 .000 & 5.204 .984 .000 & $1,270,880,640$ & 8.46 & $586,943,515$ & $122,144,338$ & $555,044,411$ & $6,748,376$ \\
\hline & 1988 & $=$ & $=$ & - & - & $140,320,000$ & $5,248,205,000$ & $1,189,913,600$ & 8.48 & $549,549,697$ & $114,362,596$ & $519,682,866$ & $6,318,441$ \\
\hline & 1989 & $=$ & $=$ & $=$ & $=$ & 130002000 & $5.142,971,000$ & $1,102,416,960$ & 8.48 & $509,140,249$ & $105,953,294$ & $481,469,583$ & $5,853,834$ \\
\hline & 1990 & $=$ & $=$ & - & $=$ & 124,983000 & $5,303,485000$ & $1,059,855,840$ & 8.48 & $489,483,821$ & $101,862,745$ & $462,881,440$ & $5,627,835$ \\
\hline & 1991 & $=$ & $=$ & $=$ & - & 122790000 & - & $1,041,259,200$ & 8.48 & $480,895,149$ & $100,075,422$ & $454,759,543$ & $5,529,086$ \\
\hline \multirow{9}{*}{ MICHIGAN } & & & & & & [5] & [5] & [5] & & & & & \\
\hline & 1985 & & & & & $27,300,000$ & & $76,440,000$ & 2.80 & $26,406,000$ & $50,034,000$ & 0 & 0 \\
\hline & 1986 & 5,666 & 484 & 1,052 & 7,223 & $28,684,000$ & $159,538,000$ & $101,133,000$ & 3.53 & $34,931,338$ & $66,201,662$ & 0 & 0 \\
\hline & 1987 & 5,553 & 499 & 1,136 & 7,328 & $26,900,000$ & $161,855,000$ & $107,145,000$ & 3.98 & $37,007,883$ & $70,137,117$ & 0 & 0 \\
\hline & 1988 & 5,557 & 474 & 1,116 & 7,433 & $23,958,000$ & $86,885,000$ & $55,903,000$ & 2.33 & $19,308,896$ & $36,594,104$ & 0 & 0 \\
\hline & \begin{tabular}{|l|}
1989 \\
\end{tabular} & 5,992 & 486 & 1,312 & 7,982 & $23,875,000$ & $190,073,000$ & $89,447,000$ & 3.75 & $30,894,994$ & $58,552,006$ & 0 & 0 \\
\hline & 1990 & 6,490 & 508 & 1,303 & 8,462 & $21,633,000$ & $194,957,000$ & $104,268,000$ & 4.82 & $36,014,167$ & $68,253,833$ & 0 & 0 \\
\hline & 1991 & $=$ & $=$ & - & $=$ & 17518.000 & - & $84,434,282$ & 4.82 & $29,763,601$ & $55,270,681$ & 0 & 0 \\
\hline & & & & & & & & & & & & & \\
\hline \multirow{8}{*}{ MISSISSIPPI } & 1985 & & & & & $30,641,000$ & & $318,666,000$ & 10.40 & $305,167,000$ & $12,136,000$ & 0 & $1,363,000$ \\
\hline & 1986 & 4,449 & $=$ & $=$ & - & $29,997,000$ & $207,871,000$ & $332,170,000$ & 11.07 & $318,085,992$ & $12,655,677$ & 0 & $1,428,331$ \\
\hline & 1987 & 4,429 & $=$ & $=$ & $=$ & $28,351,000$ & $222,484,000$ & $303,386,000$ & 10.70 & $290,522,434$ & $11,559,007$ & 0 & $1,304,560$ \\
\hline & 1988 & 4,484 & $=$ & $=$ & $=$ & $27,875,000$ & $234,482,000$ & $299,742,000$ & 10.75 & $287,032,939$ & $11,420,170$ & 0 & $1,288,891$ \\
\hline & 1989 & 4,517 & $=$ & $=$ & $=$ & $28,462,000$ & $202,179,000$ & $284,831,000$ & 10.01 & $272,754,166$ & $10,852,061$ & 0 & $1,224,773$ \\
\hline & \begin{tabular}{|l|}
1990 \\
\end{tabular} & 4,530 & $=$ & - & $=$ & $27,494,000$ & $200,980,000$ & $281,337,000$ & 10.23 & $269,408,311$ & $10,718,940$ & 0 & $1,209,749$ \\
\hline & \begin{tabular}{|l|}
1991 \\
\end{tabular} & 4,504 & $=$ & $=$ & $=$ & $27,055,000$ & $175,472,000$ & $288,891,000$ & 10.68 & $276,642,022$ & $11,006,747$ & 0 & $1,242,231$ \\
\hline & & & & & & & & & & & & & \\
\hline & & & & & & & & & & & & & \\
\hline \multirow[t]{8}{*}{ MISSOURI } & 1985 & & & & & & & & & & & & \\
\hline & \begin{tabular}{|l|}
1986 \\
\end{tabular} & 442 & $=$ & $=$ & $=$ & 112,667 & 0 & 764,818 & 6.79 & & & & \\
\hline & 1987 & 333 & $=$ & $=$ & $=$ & 139,068 & $\mathbf{0}$ & 611,684 & 4.40 & & & & \\
\hline & 1988 & 366 & $=$ & $=$ & $=$ & 156,358 & $\mathbf{0}$ & 882,346 & 5.64 & & & & \\
\hline & 1989 & 391 & - & - & $=$ & 140,851 & 0 & $1,349,279$ & 9.58 & & & & \\
\hline & 1990 & 402 & $=$ & $=$ & $=$ & 145,666 & 0 & $1,313,575$ & 9.02 & & & & \\
\hline & 1991 & 393 & $=$ & $=$ & $=$ & 149,881 & 0 & $1,981,647$ & 13.22 & & & & \\
\hline & & & & & & & & & & & & & \\
\hline \multirow{7}{*}{ MONTANA } & 1985 & & & & & $29,768,000$ & & $223,558,000$ & 7.51 & $35,201,000$ & $185,327,000$ & $3,015,000$ & 16,000 \\
\hline & 1986 & 7,890 & 580 & 1,942 & 10,412 & $27,164,630$ & $48,245,906$ & $204,006,371$ & 7.51 & $32,110,603$ & $169,121,282$ & $2,754,086$ & 20,401 \\
\hline & \begin{tabular}{|l|}
1987 \\
\end{tabular} & 7,204 & 598 & 2,259 & 10,061 & $25,104,049$ & $47,845,300$ & $188,531,408$ & 7.51 & $29,674,844$ & $156,292,537$ & $2,545,174$ & 18,853 \\
\hline & 1988 & 7,589 & 579 & 2,409 & 10,577 & $23,317,456$ & $53,013,554$ & $175,114,095$ & 7.51 & $27,562,958$ & $145,169,584$ & $2,364,040$ & 17,511 \\
\hline & 1989 & 7,354 & 579 & 2,503 & 10,436 & $20,969,292$ & $52,582,448$ & $157,479,383$ & 7.51 & $24,787,255$ & $130,550,408$ & $2,125,972$ & 15,748 \\
\hline & \begin{tabular}{|l|}
1990 \\
\end{tabular} & 7,400 & 545 & 2,487 & 10,432 & $19,835,087$ & $51,537,175$ & $148,961,503$ & 7.51 & $23,446,541$ & $123,489,086$ & $2,010,980$ & 14,896 \\
\hline & 1991 & 7,352 & 552 & 2,551 & 10,455 & $19,573,348$ & $53,002,530$ & $146,995,843$ & 7.51 & $23,137,146$ & $121,859,554$ & $1,984,444$ & 14,700 \\
\hline
\end{tabular}


Table 4.6 continued. Annual produced water production and disposal volumes.

\begin{tabular}{|c|c|c|c|c|c|c|c|c|c|c|c|c|c|}
\hline \multirow[t]{2}{*}{ State } & \multirow[t]{2}{*}{ Year } & \multirow[t]{2}{*}{ Prod Wells } & \multirow[t]{2}{*}{ Injec Wells } & \multirow[t]{2}{*}{ Shut In Wells } & \multirow[t]{2}{*}{ Total Wells } & \multirow{2}{*}{$\begin{array}{c}\text { Oil } \\
\text { (bbls) }\end{array}$} & \multirow{2}{*}{$\begin{array}{c}\text { Gas } \\
\text { (MCF) }\end{array}$} & \multirow{2}{*}{$\begin{array}{l}\text { Water } \\
\text { (bbls) }\end{array}$} & \multirow{2}{*}{$\begin{array}{c}\text { Water/OIl } \\
\text { Ratio }\end{array}$} & \multicolumn{4}{|c|}{ Disposal Volumes (bbls) } \\
\hline & & & & & & & & & & Deep Well Inj. & EOR & NPDES & Other \\
\hline \multirow[t]{8}{*}{ NEBRASKA } & 1985 & & & & & $6,943,000$ & & $164,688,000$ & 23.72 & $98,883,000$ & 64711,000 & 0 & $1,094,000$ \\
\hline & 1986 & 1,830 & $=$ & 789 & - & $7,097,633$ & $1,408,485$ & $168,355,855$ & 23.72 & $101,080,855$ & $66,147,015$ & $\frac{0}{0}$ & $\frac{1,094,000}{1,127984}$ \\
\hline & 1987 & 1,838 & - & 74 & $=$ & $6,090,931$ & $1,260,540$ & $144,476,883$ & 23.72 & $86,743,921$ & $56,764,967$ & 0 & 967,995 \\
\hline & 1988 & 1,702 & $=$ & 798 & $=$ & $6,231,544$ & 878,517 & $147,812,224$ & 23.72 & $88,746,459$ & $58,075,423$ & 0 & 990,342 \\
\hline & 1989 & 1,741 & - & 831 & - & $5,978,429$ & 910,468 & $141,808,336$ & 23.72 & $85,141,725$ & $55,716,495$ & 0 & 950,116 \\
\hline & 1990 & 1,753 & - & 655 & - & $5,889,722$ & 793,142 & $139,704,206$ & 23.72 & $83,878,405$ & $54,889,782$ & 0 & 936,018 \\
\hline & 1991 & 1,728 & - & 497 & - & $5,832,115$ & 783,503 & $138,337,768$ & 23.72 & $83,057,996$ & $54,352,909$ & 0 & 926,863 \\
\hline & & & & & & & & & & & & & \\
\hline & & & & & & & & & & & & & \\
\hline \multirow[t]{8}{*}{ NEVADA } & 1985 & & & & & & & & & & & & \\
\hline & 1986 & 30 & $=$ & 17 & $=$ & $3,098,654$ & $\overline{0}$ & $3,932,343$ & 1.27 & & & & \\
\hline & 1987 & 35 & $=$ & 21 & - & $3,135,515$ & 0 & $3,939,653$ & 1.26 & & & & \\
\hline & 1988 & 37 & - & 18 & $=$ & $3,487,450$ & 3,600 & $4,836,197$ & 1.39 & & & & \\
\hline & 1989 & 47 & - & 18 & $=$ & $3,221,543$ & 44,933 & $4,361,086$ & 1.35 & & & & \\
\hline & 1990 & 49 & - & 25 & $=$ & $4,013,538$ & 91,284 & $4,634,038$ & 1.15 & & & & \\
\hline & 1991 & 55 & $=$ & 17 & $=$ & $3,423,596$ & 55,558 & $4,940,056$ & 1.44 & & & & \\
\hline & & & & & & & & & & & & & \\
\hline \multirow[t]{8}{*}{ N. MEXICO } & 1985 & & & & & $78,530,000$ & & $445,265,000$ & 5.67 & $73,472,000$ & $371,440,000$ & 10,000 & 342,000 \\
\hline & 1986 & - & - & $=$ & $=$ & 25.712000 & 721,217000 & $429,287,040$ & 5.67 & $70,836,654$ & $358,111,249$ & 8,586 & 330,551 \\
\hline & 1987 & - & - & - & - & 72328.000 & 845.478 .000 & $\$ 10,099,760$ & 5.67 & $67,670,561$ & $342,105,220$ & 8,202 & 315,777 \\
\hline & 1988 & - & - & - & - & 21.235 .000 & 811,924000 & $403,902,450$ & 5.67 & $66,647,943$ & $336,935,424$ & 8,078 & 311,005 \\
\hline & 1989 & $=$ & $=$ & $=$ & - & 68.713 .000 & $878,080,000$ & $389,602,710$ & 5.67 & $64,288,343$ & $325,006,581$ & 7,792 & 299,994 \\
\hline & 1990 & - & $=$ & $=$ & - & 68.055 .000 & 984.679 .000 & $385,871,850$ & 5.67 & $63,672,714$ & $321,894,297$ & 7,717 & 297,121 \\
\hline & 1991 & - & $=$ & $=$ & $=$ & 20.416 .000 & $=$ & $399,258,720$ & 5.67 & $65,881,681$ & $333,061,624$ & 7,985 & 307,429 \\
\hline & & & & & & & & & & & & & \\
\hline \multirow{9}{*}{ NEW YORK } & & & & & & & & & & & & & \\
\hline & 1985 & & & & & & & & & & & & \\
\hline & 1986 & 9,438 & 1,651 & 2,452 & 13,541 & 743,310 & $34,151,553$ & $8,809,079$ & 11.85 & & & & \\
\hline & 1987 & 9,585 & 1,381 & 2,525 & 13,491 & 665,595 & $29,555,048$ & $7,178,510$ & 10.79 & & & & \\
\hline & 1988 & 9,532 & 1,382 & 2,333 & 13,247 & 495,263 & $27,696,220$ & $7,084,563$ & 14.30 & & & & \\
\hline & 1989 & 9,292 & 1,156 & 2,576 & 13,024 & 455,890 & $25,535,887$ & $5,021,994$ & 11.02 & & & & \\
\hline & 1990 & 9,346 & 1,210 & 2,571 & 13,127 & 381,415 & $25,398,458$ & $2,379,979$ & 6.24 & & & & \\
\hline & 1991 & 9,311 & 834 & 1,982 & 12,127 & 373,866 & $22,778, A 55$ & $1,926,988$ & 5.15 & & & & \\
\hline & & & & & & & & & & & & & \\
\hline \multirow{8}{*}{ N. DAKOTA } & 1985 & & & & & $50,857,000$ & & $59,503,000$ & 1.17 & $42,606,000$ & $16,897,000$ & 0 & 0 \\
\hline & 1986 & 3,698 & $=$ & $=$ & $=$ & $45,652,223$ & $74,715,000$ & $79,389,805$ & 1.74 & $56,843,100$ & $22,546,705$ & 0 & 0 \\
\hline & 1987 & 3,572 & - & - & - & $41,364,295$ & $74,614,000$ & $82,241,270$ & 1.99 & $58,884,749$ & $23,356,521$ & 0 & 0 \\
\hline & 1988 & 3,609 & - & - & - & $39,356,974$ & $67,728,000$ & $86,839,598$ & 2.21 & $62,177,152$ & $24,662,446$ & 0 & 0 \\
\hline & 1989 & 3,558 & - & - & $=$ & $36,743,624$ & $61,220,000$ & $81,883,997$ & 2.23 & $58,628,942$ & $23,255,055$ & 0 & 0 \\
\hline & 1990 & 3,635 & $=$ & $=$ & $=$ & $36,720,396$ & $65,984,008$ & $85,531,728$ & 2.33 & $61,240,717$ & $24,291,011$ & 0 & 0 \\
\hline & 1991 & 3,686 & $=$ & $=$ & $=$ & $35,895,278$ & $63,236,964$ & $89,133,447$ & 2.48 & $63,819,548$ & $25,313,899$ & 0 & 0 \\
\hline & & & & & & & & & & & & & \\
\hline
\end{tabular}




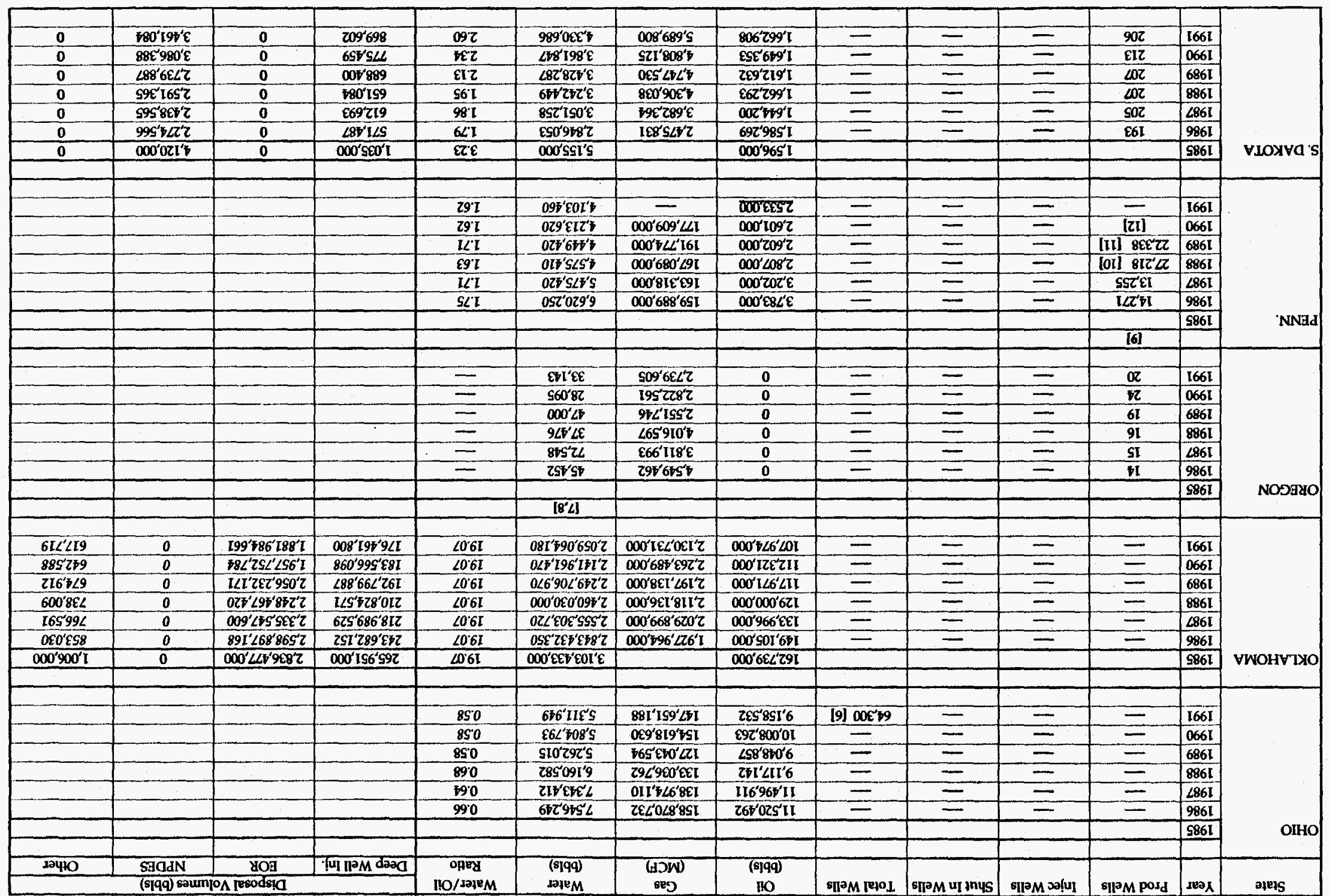




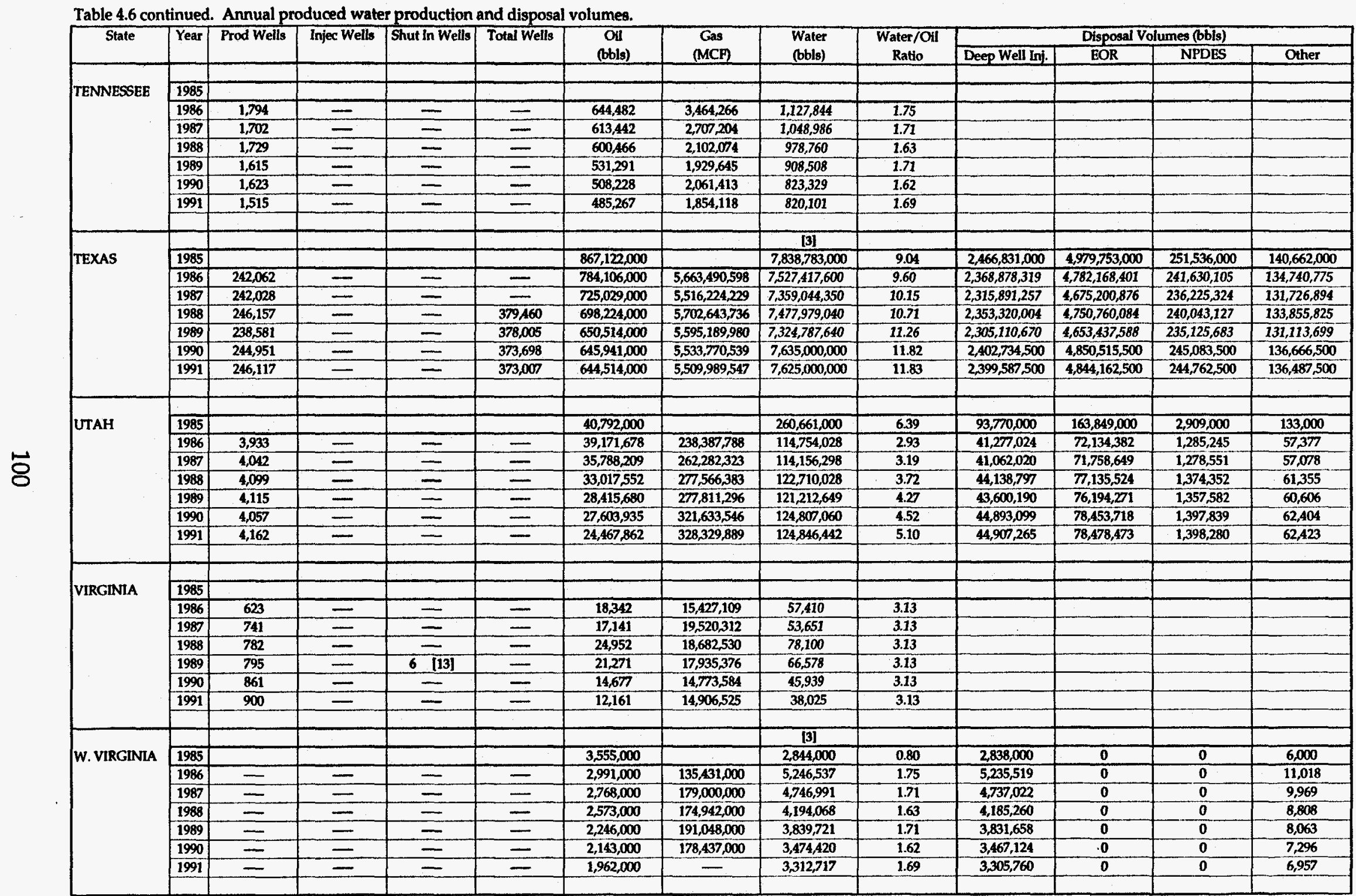


Table 4.6 continued. Annual produced water production and disposal volumes.

\begin{tabular}{|c|c|c|c|c|c|c|c|c|c|c|c|c|c|}
\hline \multirow[t]{2}{*}{ State } & \multirow[t]{2}{*}{ Year } & \multirow[t]{2}{*}{ Prod Wells } & \multirow[t]{2}{*}{ Injec Wells } & \multirow[t]{2}{*}{ Shut In Wells } & \multirow[t]{2}{*}{ Total Wells } & \multirow{2}{*}{$\begin{array}{c}\text { Oil } \\
\text { (bbls) }\end{array}$} & \multirow{2}{*}{$\begin{array}{l}\text { Gas } \\
\text { (MCF) }\end{array}$} & \multirow{2}{*}{$\begin{array}{l}\text { Water } \\
\text { (bbls) }\end{array}$} & \multirow{2}{*}{$\begin{array}{c}\text { Water/Oil } \\
\text { Ratio }\end{array}$} & \multicolumn{4}{|c|}{ Disposal Volumes (bbls) } \\
\hline & & & & & & & & & & Deep Well Inj. & EOR & NPDES & Other \\
\hline \multirow{8}{*}{ WYOMING } & 1985 & & & & & $128,514,000$ & & $785,221,000$ & 6.11 & $435,358,000$ & $219,571,000$ & 130.279 .000 & 12000 \\
\hline & 1986 & - & $=$ & $=$ & $=$ & 121.3370000 & 596.978 .000 & $741,369,070$ & 6.11 & $411,044,667$ & $207,309,033$ & $123,000,542$ & 14,827 \\
\hline & 1987 & - & - & - & - & 115.922 .000 & 733.478 .000 & $708,283,420$ & 6.11 & $392,700,659$ & $198,057,293$ & $117,511,302$ & 14,166 \\
\hline & \begin{tabular}{|l|}
1988 \\
\end{tabular} & 14,941 & 3,577 & $=$ & $=$ & $114,322,298$ & $811,553,647$ & $698,509,241$ & 6.11 & $387,281,463$ & $195,324,139$ & $115,889,668$ & 13,970 \\
\hline & 1989 & 14,788 & 3,533 & $=$ & $=$ & $109,141,990$ & $865,966,874$ & $666,857,559$ & 6.11 & $369,732,505$ & $186,473,379$ & $110,638,338$ & 13,337 \\
\hline & 1990 & - & - & - & $=$ & 103.998 .000 & 883.713 .000 & $635,427,780$ & 6.11 & $352,306,578$ & $177,684,670$ & $105,423,823$ & 12,709 \\
\hline & 1991 & - & $=$ & $=$ & - & $29.928,000$ & - & $610,560,080$ & 6.11 & $338,518,931$ & $170,730,915$ & $101,298,023$ & 12,211 \\
\hline & & & & & & & & & & & & & \\
\hline
\end{tabular}

\begin{tabular}{|c|c|c|c|c|c|c|c|c|c|c|c|c|c|}
\hline \multirow[t]{2}{*}{ State } & \multirow[t]{2}{*}{ Year } & \multirow[t]{2}{*}{ Prod Wells } & \multirow[t]{2}{*}{ Injec Wells } & \multirow[t]{2}{*}{ Shut In Wells } & \multirow[t]{2}{*}{ Total Wells } & \multirow{2}{*}{$\begin{array}{c}\text { Oil } \\
\text { (bbls) }\end{array}$} & \multirow{2}{*}{$\begin{array}{c}\text { Gas } \\
\text { (MCF) }\end{array}$} & \multirow{2}{*}{$\begin{array}{l}\text { Water } \\
\text { (bbls) }\end{array}$} & \multirow{2}{*}{$\begin{array}{c}\text { Water/Oil } \\
\text { Ratio }\end{array}$} & \multicolumn{4}{|c|}{ Disposal Volumes (bbls) } \\
\hline & & & & & & & & & & Deep Well Inj. & EOR & NPDES & Other \\
\hline \multirow[t]{7}{*}{ TOTAL } & 1985 & & & & & & & & & & & & \\
\hline & 1986 & & & & & $2,720,646,186$ & $17,957,909,937$ & $19,534,658,680$ & $=$ & $5,875,842,286$ & $11,854,463,254$ & $1,117,708,761$ & $585,796,227$ \\
\hline & 1987 & & & & & $2,627,634,902$ & $18,794,213,261$ & $18,939,917,234$ & $=$ & $5,774,333,897$ & $11,402,261,401$ & $1,084,927,919$ & $575,966,702$ \\
\hline & \begin{tabular}{|l|l}
1988 \\
\end{tabular} & & & & & $2,575,643,843$ & $19,482,614,541$ & $18,823,091,098$ & $=$ & $5,764,520,484$ & $11,344,847,501$ & $1,049,948,155$ & $572,213,310$ \\
\hline & 1989 & & & & & $2,398,956,463$ & $19,615,524,034$ & $18,165,928,450$ & $\overline{-}$ & $5,635,050,428$ & $10,903,476,234$ & $991,228,666$ & $542,483,575$ \\
\hline & 1990 & & & & & $2,324,506,158$ & $20,056,865,852$ & $18,411,434,852$ & $=$ & $5,779,805,218$ & $11,032,607,924$ & $975,836,411$ & $543,034,575$ \\
\hline & \begin{tabular}{|l|}
1991 \\
\end{tabular} & & & & & $2,306,576,111$ & $20,340,724,339$ & $18,330,045,271$ & - & $5,830,546,684$ & $10,926,716,921$ & $960,198,024$ & $533,264,834$ \\
\hline
\end{tabular}

[1] Injection well total ts for state onshore wells only.

[2] Colorado oll and gas stats is out of print for 1987.

[3] Total water represents injected volumes only.

[4] Production figures are by fiscal year ending June 30th.

[5] Average daily production figures for oil, gas, and brine were multiplied by 365 to obtain an annual figure.

[6] Number represents an estimate of the number of wells (active and inactive) in the state.

(7) All reported water volume data was divided by $42 \mathrm{gal} / \mathrm{bbl}$ to convert units to barrels.

[8] From 1986 thru Aug. 1989 water volume data is from injected volume reports. From Sep. 1989 thru Aug. 1991 water volume data is from produced volume reports.

No water data was available from Aug, 1991 forward. The average produced water volumes from Jan. to July of that year were used to estimate the monthly volumes for Aug. to Dec

(9) Total number of producing wells is for oil wells only. The numbers reflect the reported number of wells for 1986 - 1987 and the estimated number of wells for 1988 - 1989 .

[10] Number is an estimate of the number of producing wells. The reported number of producing wells was 17,736

[11] Number is an estimate of the number of producing wells. No reported number of producing wells.

(12) Because most oil is gathered from common tanks, the number of producing wells can no longer be reported.

[13] Shut-in total is for ofl shut-in wells only.

Remarks:

1) 1985 data is from API Production Waste Survey Report.

2) Disposal volumes are based on ratios developed in the 1985 API Production Waste Survey.

3) Values with underline were obtained from data published by the Energy Information Administration.

4) Values printed in italic are computed from water/oll ratios obtained from either:

a) the API Production waste survey where avallable or,

b) data for nearby states where API ratios were not avallable.

5) $\mathrm{bbls}=$ barrels; $\mathrm{MCF}=1000$ cublc feet

6) $E O R=$ enhanced oil recovery operations.

7 NPDES = National Pollutant Discharge Elimination System permitted discharge.

8) Other = evaporation, percolation, discharge to publicly owned treatment works, etc. 


\subsubsection{Produced Water Disposal}

Table 4.6 includes an analysis of produced water by disposal method. The amount of produced water in each state disposed of by each of 4 methods - deep well injection, enhanced oil recovery, surface discharge, and all other - was computed using proportions developed from the 1985 API Survey (Wakim, 1987). Note that the API only obtained produced water survey information from 22 states, therefore, disposal volumes could not be computed for all states listed in Table 4.6. Of interest is the fact that, with the exception of Louisiana and South Dakota, the vast majority of produced water in all states is disposed of by injection (deep well or enhanced oil recovery (EOR)). Nationwide, an average of $91 \%$ of the produced water volume is disposed of by this method. While injection is also used as a disposal method in both states, in Louisiana some $44 \%$ of produced water is disposed of by NPDES discharge and in South Dakota $80 \%$ of produced water is disposed of by this method.

\subsection{Environmental Settings in 8 Texas Counties}

\subsubsection{Area of Study}

An analysis of the environmental settings surrounding oil and gas drilling and extraction activities has been completed for 8 counties within the state of Texas. The state of Texas was selected for analysis because, in addition to the logistical benefits of having the research team located within the state, the state met the additional criteria of being a major oil and gas producer and having multiple producing basins located within varied physiographic regions. The environmental analysis was further restricted to 8 individual counties within the state in order to keep the amount of data processing within a reasonable level for this project. The counties included in the analysis were the following:
1. Brazoria
2. Ector
3. Lee 

4. Moore
5. Panola
6. Pecos
7. Webb
8. Wise

These counties were selected according to the level of drilling and production activity relative to all counties within the state with the added constraint that a good geographic cross section of the state be represented in the selection set. Some of the features of the selected counties are outlined in Table 1.1. The locations of the counties within the state are shown in Figure 1.1. The environmental settings analysis performed on these 8 counties can serve as a model for similar studies completed for other counties, regions, or states in the future.

\subsubsection{The PED Geographic Information System}

The environmental settings analysis was performed using the ARC/INFO Geographic Information System. The GIS system provided for the storage, processing, and manipulation of several hundred megabytes of electronic data required for the environmental assessment. In the GIS, each set of data or information is known as a coverage. A coverage is an electronic map layer that may be derived from a physical map that is digitized, from tabular data, or from a combination of the two. Information contained on separate coverages may be combined and geographic relationships may be developed between them. Data on environmental settings were obtained from various state and Federal agencies and assimilated into the GIS. Table 1.3 lists the coverages developed for the PED and the sources of the data.

The environmental analysis was performed in two parts. The first part was concerned with assessing the potential environmental impacts of oil and gas well drilling operations. A portion of the WHCS database obtained from Petroleum Information containing well completion data for the years 1988, 1990, and 1992 served as the basis for this analysis. The second part of the environmental analysis dealt with 
the potential environmental impact of produced water. To perform this analysis, information on the location of injection, plugged, and abandoned wells (three primary sources of produced water impacts) was extracted from the Well Bore Database maintained by the Railroad Commission of Texas.

\subsubsection{Landuse}

One of the most basic factors to be considered in an environmental assessment of oil and gas drilling and production activity is the surrounding landuse. From a human health standpoint, drilling and production activity in a residential area clearly poses a greater exposure risk than activity in barren brushland far from population centers. The EPA did not quantify landuse distributions surrounding oil and gas operations in their 1985 risk assessment because landuse itself does not represent an identifiable exposure point for risk modeling purposes. However, when considering regulatory policy, landuse can be a major influence. In recognition of this, the API did develop some statewide and national landuse distributions in the vicinity of drilling sites from their 1985 operator survey.

Digital landuse/landcover maps were obtained from the USGS to cover the 8 Texas counties considered in this study. These maps were prepared from USGS 1:250,000 scale printed landuse/landcover maps and portray the Level II categories of the landuse and landcover classification system developed by Anderson et al. (1976) (Table 4.7). The basic sources of data contained on these maps are high-altitude aerial photographs and features are depicted at 16 hectare resolution (4 hectare resolution is used for some landuse categories such as urban and water). The USGS landuse/landcover maps were selected as the source of landuse/landcover information for this project because they are the only consistent source of readily available data that can be inexpensively obtained. A major shortcoming of these maps, however, is that they are far from being current. The most recently updated maps used in this project 
Table 4.7. Level II landuse/landcover classification

\begin{tabular}{|c|c|}
\hline LU-Code & Description \\
\hline & Urban or Built-up Land \\
\hline 11 & Residential \\
\hline 12 & Commercial and Services \\
\hline 13 & Industrial \\
\hline 14 & Transportation, Communications, and Utilities \\
\hline 15 & Industrial and Commercial Complexes \\
\hline 16 & Mixed Urban or Built-up Land \\
\hline \multirow[t]{2}{*}{17} & Other Urban or Built-up Land \\
\hline & Agricultural Land \\
\hline 21 & Cropland and Pasture \\
\hline 22 & Orchards, Groves, Vineyards, Nurseries, etc. \\
\hline 23 & Confined Feeding Operations \\
\hline \multirow[t]{2}{*}{24} & Other Agricultural Land \\
\hline & Rangeland \\
\hline 31 & Herbaceous Rangeland \\
\hline 32 & Shrub and Brush Rangeland \\
\hline \multirow[t]{2}{*}{33} & Mixed Rangeland \\
\hline & Forest Land \\
\hline 41 & Deciduous Forest Land \\
\hline 42 & Evergreen Forest land \\
\hline \multirow[t]{2}{*}{43} & Mixed Forest Land \\
\hline & Water \\
\hline 51 & Streams and Canals \\
\hline 52 & lakes \\
\hline 53 & Reservoirs \\
\hline \multirow[t]{2}{*}{54} & Bays and Estuaries \\
\hline & Wetland \\
\hline 61 & Forested Wetland \\
\hline \multirow[t]{2}{*}{62} & Nonforested Wetland \\
\hline & Barren Land \\
\hline 71 & Dry Salt Flats \\
\hline 72 & Beaches \\
\hline 73 & Sandy Areas other than Beaches \\
\hline 74 & Bare Exposed Rock \\
\hline 75 & Strip Mines, Quarries, and Gravel Pits \\
\hline 76 & Transitional Areas \\
\hline \multirow[t]{2}{*}{77} & Mixed Barren land \\
\hline & Tundra \\
\hline 81 & Shrub and Brush Tundra \\
\hline 82 & Herbaceous Tundra \\
\hline 83 & Bare Ground \\
\hline 84 & Wet Tundra \\
\hline \multirow[t]{2}{*}{85} & Mixed Tundra \\
\hline & Perennial Snow and Ice \\
\hline 91 & Perrenial Snowfields \\
\hline 92 & Glaciers \\
\hline
\end{tabular}


were dated 1981. Most maps dated from the 1970s, some as early as 1973. However, as most drilling activity tends to occur outside of rapidly developing areas, the general landuse patterns surrounding oil and gas operations probably have not changed significantly over this 20 year period.

Table 4.8 shows the relationship between drilling activity and landuse while Table 4.9 shows the landuse patterns surrounding injection, plugged, and abandoned wells. In most cases the distribution of drilling activity among the different landuses within each county corresponds with the areal distribution of landuse in that county and the same can be said for injection, plugged, and abandoned wells. Two notable exceptions are Brazoria and Pecos Counties in which injection and plugged wells appear to be disproportionately concentrated in industrial landuse areas. The analysis shows several of the counties to have some, though minor, drilling activity occurring within residential areas but only Ector County has active injection well operations within this landuse. Of the counties with significant amounts of cropland and pasture areas, all have equally significant amounts of drilling activity occurring within these areas as well as significant numbers of injection, plugged, and abandoned wells located within this landuse indicating a high potential for oil and gas waste impacts on crops.

Table 4.10 compares the landuse distributions of drilling sites in the 8 counties with the distributions developed by API for the state of Texas and the nation as a whole. The data given in this table for the 8 Texas counties represent the combined years of 1988, 1990, and 1992. A direct comparison of the landuse distributions is not possible due to the non-standard landuse categories defined by the API. To develop Table 4.10, the landuse categories were grouped in the following manner:

APICategory(ies)

Residential

Crops \& Pasture

Forest \& Protected Wilderness

Recreational

Other (wetland, swamp, strip mine, etc.)
USGS Categories

Urban or Built-up Land

Agricultural Land or Rangeland Forest Land

Water (lakes, reservoirs, etc.)

Wetland or Barren Land 
Table 4.8. Drilling sites versus landuse.

\begin{tabular}{|c|c|c|c|c|c|c|c|c|}
\hline \multicolumn{9}{|c|}{ Brazoria County } \\
\hline \multirow[b]{2}{*}{ LU-Code } & \multirow[b]{2}{*}{ Landuse } & \multirow{2}{*}{$\begin{array}{c}\% \text { Total } \\
\text { Area }\end{array}$} & \multicolumn{2}{|c|}{1988} & \multicolumn{2}{|c|}{1990} & \multicolumn{2}{|c|}{1992} \\
\hline & & & \# Wells & $\%$ of Total & \# Wells & $\%$ of Total & \# Wells & $\%$ of Total \\
\hline 13 & Industrial & 2 & 5 & 9 & 5 & 14 & 1 & 6 \\
\hline 21 & Cropland and Pasture & 54 & 36 & 65 & 24 & 67 & 12 & 67 \\
\hline 31 & Herbaceous Rangeland & 3 & 1 & 2 & & & & \\
\hline 41 & Deciduous Forest & 4 & 5 & 9 & & & & \\
\hline 42 & Evergreen Forest & 4 & 2 & 4 & & & 4 & 22 \\
\hline 43 & Mixed Forest & 16 & 5 & 9 & 5 & 14 & & \\
\hline 52 & Lake & 1 & 1 & 2 & & & & \\
\hline 53 & Reservoir & 1 & & & 2 & 6 & & \\
\hline 61 & Forested Wetland & $<1$ & & & & & & \\
\hline 62 & Nonforested Wetland & 9 & & & & & 1 & 6 \\
\hline \multicolumn{3}{|c|}{ Total Completions } & 55 & & 36 & & 18 & \\
\hline \multicolumn{9}{|c|}{ Ector County } \\
\hline \multirow[b]{2}{*}{ LU-Code } & \multirow[b]{2}{*}{ Landuse } & \multirow{2}{*}{$\begin{array}{c}\% \text { Total } \\
\text { Area }\end{array}$} & \multicolumn{2}{|c|}{1988} & \multicolumn{2}{|c|}{1990} & \multicolumn{2}{|c|}{1992} \\
\hline & & & \# Wells & $\%$ of Total & \#Wells & $\%$ of Total & \#Wells & $\%$ of Total \\
\hline 11 & Residential & 3 & 5 & 1 & 2 & 1 & 1 & 1 \\
\hline 12 & Commercial and Services & 1 & 5 & 1 & 1 & $<1$ & 1 & 1 \\
\hline 13 & Industrial & $<1$ & 2 & 1 & 2 & 1 & & \\
\hline 14 & Transportation and Utilities & $<1$ & & & 1 & $<1$ & 1 & 1 \\
\hline 17 & Other Urban & 2 & 5 & 1 & 3 & 1 & 2 & 1 \\
\hline 31 & Herbaceous Rangeland & 6 & 26 & 7 & 34 & 16 & 19 & 12 \\
\hline 32 & Shrub and Brush Rangeland & 42 & 151 & 39 & 104 & 50 & 90 & 55 \\
\hline 33 & Mixed Rangeland & 43 & 194 & 49 & 61 & 29 & 48 & 29 \\
\hline 75 & Quaries and Gravel Pits & $<1$ & 1 & $<1$ & 1 & $<1$ & 1 & 1 \\
\hline 76 & Transitional Area & 1 & 3 & 1 & 1 & $<1$ & 1 & 1 \\
\hline 61 & Forested Wetland & 0 & & & & & & \\
\hline 62 & Nonforested Wetland & $<1$ & & & & & & \\
\hline \multicolumn{3}{|c|}{ Total Completions } & 392 & & 210 & & 164 & \\
\hline \multicolumn{9}{|c|}{ Lee County } \\
\hline \multirow[b]{2}{*}{ LU-Code } & \multirow[b]{2}{*}{ Landuse } & \multirow{2}{*}{$\begin{array}{c}\% \text { Total } \\
\text { Area }\end{array}$} & & 88 & & 90 & & 92 \\
\hline & & & \#Wells & $\%$ of Total & \#Wells & $\%$ of Total & \# Wells & $\%$ of Total \\
\hline 12 & Commercial and Services & $<1$ & & & & & 1 & 3 \\
\hline 21 & Cropland and Pasture & 49 & 48 & 53 & 18 & 45 & 8 & 21 \\
\hline 32 & Shrub and Brush Rangeland & 2 & 16 & 18 & 2 & 5 & 1 & 3 \\
\hline 33 & Mixed Rangeland & 19 & 9 & 10 & 8 & 20 & 12 & 32 \\
\hline 41 & Deciduous Forest & 27 & 18 & 20 & 12 & 30 & 16 & 42 \\
\hline 61 & Forested Wetland & 1 & & & & & & \\
\hline 62 & Nonforested Wetland & $<1$ & & & & & & \\
\hline Total Con & mpletions & & 91 & & 40 & & 38 & \\
\hline & & & Moore & ounty & & & & \\
\hline & & $\%$ Total & & 88 & & 90 & & 92 \\
\hline LU-Code & Landuse & Area & \#Wells & $\%$ of Total & \#Wells & $\%$ of Total & \#Wells & $\%$ of Total \\
\hline 21 & Cropland and Pasture & 64 & 25 & 46 & 17 & 47 & 7 & 21 \\
\hline 31 & Herbaceous Rangeland & 32 & 27 & 50 & 19 & 53 & 26 & 79 \\
\hline 33 & Mixed Rangeland & 2 & 2 & 4 & & & & \\
\hline 61 & Forested Wetland & $<1$ & & & & & & \\
\hline 62 & Nonforested Wetland & $<1$ & & & & & & \\
\hline Total Con & npletions & & 54 & & 36 & & 33 & \\
\hline
\end{tabular}


Table 4.8 continued. Drilling sites versus landuse.

\begin{tabular}{|c|c|c|c|c|c|c|c|c|}
\hline \multicolumn{9}{|c|}{ Panola County } \\
\hline \multirow[b]{2}{*}{ LU-Code } & \multirow[b]{2}{*}{ Landuse } & \multirow{2}{*}{$\begin{array}{c}\% \text { Total } \\
\text { Area }\end{array}$} & \multicolumn{2}{|c|}{1988} & \multicolumn{2}{|c|}{1990} & \multicolumn{2}{|c|}{1992} \\
\hline & & & \#Wells & $\%$ of Total & \# Wells & $\%$ of Total & \#Wells & $\%$ of Total \\
\hline 11 & Residential & $<1$ & & & 1 & 1 & 2 & 2 \\
\hline 13 & Industrial & $<1$ & & & 2 & 1 & & \\
\hline 21 & Cropland and Pasture & 29 & 8 & 15 & 51 & 27 & 41 & 33 \\
\hline 24 & Other Agricultural Land & $<1$ & & & 1 & 1 & & \\
\hline 32 & Shrub and Brush Rangeland & $<1$ & 1 & 2 & 2 & 1 & 1 & 1 \\
\hline 41 & Deciduous Forest & 10 & 4 & 8 & 13 & 7 & 10 & 8 \\
\hline 42 & Evergreen Forest & 7 & 5 & 10 & 9 & 5 & 5 & 4 \\
\hline 43 & Mixed Forest & 50 & 33 & 63 & 109 & 58 & 62 & 50 \\
\hline 53 & Reservoir & 1 & & & & & 1 & 1 \\
\hline 61 & Forested Wetland & $<1$ & 1 & 2 & & & & \\
\hline 62 & Nonforested Wetland & $\leq 1$ & & & & & 1 & 1 \\
\hline \multicolumn{3}{|c|}{ Total Completions } & 52 & & 188 & & 123 & \\
\hline \multicolumn{9}{|c|}{ Pecos County } \\
\hline \multirow[b]{2}{*}{ LU-Code } & \multirow[b]{2}{*}{ Landuse } & \multirow{2}{*}{$\begin{array}{c}\% \text { Total } \\
\text { Area }\end{array}$} & \multicolumn{2}{|c|}{1988} & \multicolumn{2}{|c|}{1990} & \multicolumn{2}{|c|}{1992} \\
\hline & & & \#Wells & $\%$ of Total & \# Wells & $\%$ of Total & \# Wells & $\%$ of Total \\
\hline 13 & Industrial & 2 & 39 & 28 & 11 & 11 & 34 & 41 \\
\hline 14 & Transportation and Utilities & $<1$ & 1 & 1 & 1 & 1 & & \\
\hline 21 & Cropland and Pasture & 3 & 1 & 1 & 7 & 7 & 1 & 1 \\
\hline 31 & Herbaceous Rangeland & $<1$ & & & 1 & 1 & & \\
\hline 32 & Shrub and Brush Rangeland & 89 & 95 & 68 & 72 & 73 & 44 & 53 \\
\hline 33 & Mixed Rangeland & 5 & 3 & 2 & 7 & 7 & 4 & 5 \\
\hline 61 & Forested Wetland & $<1$ & & & & & & \\
\hline 62 & Nonforested Wetland & 0 & & & & & & \\
\hline \multicolumn{3}{|c|}{ Total Completions } & 139 & & 99 & & 83 & \\
\hline \multicolumn{9}{|c|}{ Webb County } \\
\hline & & $\%$ Total & & 988 & & 90 & & 92 \\
\hline LU-Code & Landuse & Area & \# Wells & $\%$ of Total & \#Wells & $\%$ of Total & \#Wells & $\%$ of Total \\
\hline 11 & Residential & $<1$ & & & & & 1 & 1 \\
\hline 21 & Cropland and Pasture & 1 & 4 & 3 & 1 & 1 & 1 & 1 \\
\hline 31 & Herbaceous Rangeland & 4 & 9 & 6 & & & 2 & 2 \\
\hline 32 & Shrub and Brush Rangeland & 75 & 81 & 54 & 96 & 64 & 85 & 65 \\
\hline 33 & Mixed Rangeland & 18 & 57 & 38 & 52 & 35 & 42 & 32 \\
\hline 41 & Deciduous Forest & $<1$ & & & 1 & 1 & & \\
\hline 61 & Forested Wetland & 0 & & & & & & \\
\hline 62 & Nonforested Wetland & $<1$ & & & & & & \\
\hline Total Con & mpletions & & 151 & & 150 & & 131 & \\
\hline & & & Wise $C$ & ounty & & & & \\
\hline & & $\%$ Total & & 988 & & 90 & & 92 \\
\hline LU-Code & Landuse & Area & \#Wells & $\%$ of Total & $\#$ Wells & $\%$ of Total & \#Wells & $\%$ of Total \\
\hline 11 & Residential & 1 & & & & & 1 & 1 \\
\hline 13 & Industrial & $<1$ & & & & & 1 & 1 \\
\hline 16 & Mixed Urban & $<1$ & & & 1 & 1 & 2 & 2 \\
\hline 21 & Cropland and Pasture & 40 & 49 & 51 & 40 & 38 & 28 & 33 \\
\hline 31 & Herbaceous Rangeland & 11 & 11 & 11 & 10 & 9 & 5 & 6 \\
\hline 32 & Shrub and Brush Rangeland & 1 & & & & & 7 & 8 \\
\hline 33 & Mixed Rangeland & 30 & 20 & 21 & 40 & 38 & 26 & 31 \\
\hline 41 & Deciduous Forest & 14 & 14 & 14 & 12 & 11 & 13 & 15 \\
\hline 75 & Quaries and Gravel Pits & 1 & 1 & 1 & & & & \\
\hline 76 & Transitional Area & $<1$ & 2 & 2 & 3 & 3 & 1 & 1 \\
\hline 61 & Forested Wetland & 0 & & & & & & \\
\hline 62 & Nonforested Wetland & 1 & & & & & & \\
\hline Total Con & mpletions & & 97 & & 106 & & 84 & \\
\hline
\end{tabular}


Table 4.9. Injection; plugged, and abandoned well sites versus landuse.

\begin{tabular}{|c|c|c|c|c|c|c|c|c|}
\hline \multicolumn{9}{|c|}{ Brazoria County } \\
\hline \multirow[b]{2}{*}{ LU-Code } & \multirow[b]{2}{*}{ Landuse } & \multirow{2}{*}{$\begin{array}{c}\% \text { Total } \\
\text { Area }\end{array}$} & \multicolumn{2}{|c|}{ Injection } & \multicolumn{2}{|c|}{ Plugged } & \multicolumn{2}{|c|}{ Abandoned } \\
\hline & & & \#Wells & $\%$ of Total & \#Wells & $\%$ of Total & \#Wells & $\%$ of Total \\
\hline 11 & Residential & 2 & & & 12 & 1 & 4 & 2 \\
\hline 12 & Commercial and Services & $<1$ & & & & & 1 & $\overline{1}$ \\
\hline 13 & Industrial & 2 & 65 & 61 & 752 & 47 & 27 & 14 \\
\hline 17 & Other Urban & $<1$ & 1 & $\overline{1}$ & 16 & 1 & & \\
\hline 21 & Cropland and Pasture & 54 & 32 & 30 & 525 & 33 & 109 & 55 \\
\hline 22 & Orchards, Groves, Vineyards & $<1$ & & & 10 & $\overline{1}$ & & \\
\hline 24 & Other Agricultural Land & $<1$ & & & 1 & $<1$ & & \\
\hline 31 & Herbaceous Rangeland & $\overline{3}$ & & & 25 & 2 & 7 & 4 \\
\hline 32 & Shrub and Brush Rangeland & $<1$ & & & 1 & $<1$ & & \\
\hline 41 & Deciduous Forest & 4 & & & 16 & 1 & 4 & 2 \\
\hline 42 & Evergreen Forest & 4 & & & 38 & 2 & 8 & 4 \\
\hline 43 & Mixed Forest & 16 & 8 & 7 & 158 & 10 & 20 & 10 \\
\hline 51 & Stream or Canal & 1 & & & 7 & $<1$ & & \\
\hline 52 & Lake & 1 & & & 6 & $<1$ & & \\
\hline 53 & Reservoir & 1 & 1 & 1 & 1 & $<1$ & 2 & 1 \\
\hline 54 & Bay or Estuary & $<1$ & & & 1 & $<1$ & & \\
\hline 61 & Forested Wetland & $<1$ & & & & & & \\
\hline 62 & Nonforested Wetland & 9 & & & 24 & 2 & 18 & 9 \\
\hline Total Wel & & & 107 & & 1593 & & 200 & \\
\hline \multicolumn{9}{|c|}{ Ector County } \\
\hline & & $\%$ Total & \multicolumn{2}{|c|}{ Injection } & \multicolumn{2}{|c|}{ Plugged } & \multicolumn{2}{|c|}{ Abandoned } \\
\hline LU-Code & Landuse & Area & \#Wells & $\%$ of Total & \# Wells & $\%$ of Total & \#Wells & $\%$ of Total \\
\hline 11 & Residential & 3 & 97 & 3 & 67 & 2 & 6 & 5 \\
\hline 12 & Commercial and Services & 1 & 43 & 1 & 32 & 1 & 1 & 1 \\
\hline 13 & Industrial & $<1$ & 14 & $<1$ & 10 & $<1$ & & \\
\hline 14 & Transportation and Utilities & $<1$ & 2 & $<1$ & 11 & $<1$ & 2 & 2 \\
\hline 16 & Mixed Urban & $<1$ & 13 & $<1$ & 4 & $<1$ & 2 & 2 \\
\hline 17 & Other Urban & 2 & 49 & 2 & 69 & 3 & 4 & 3 \\
\hline 21 & Cropland and Pasture & 1 & 1 & $<1$ & 2 & $<1$ & & \\
\hline 24 & Other Agricultural Land & $<1$ & & & 1 & $<1$ & & \\
\hline 31 & Herbaceous Rangeland & 6 & 141 & 5 & 102 & 4 & 6 & 5 \\
\hline 32 & Shrub and Brush Rangeland & 42 & 1398 & 48 & 1628 & 60 & 69 & 53 \\
\hline 33 & Mixed Rangeland & 43 & 1131 & 39 & 741 & 27 & 40 & 31 \\
\hline 75 & Quaries and Gravel Pits & $<1$ & 2 & $<1$ & 13 & $<1$ & & \\
\hline 76 & Transitional Area & 1 & 11 & $<1$ & 20 & $\overline{1}$ & $\overline{1}$ & 1 \\
\hline 61 & Forested Wetland & 0 & & & & & & \\
\hline 62 & Nonforested Wetland & $<1$ & 1 & $<1$ & & & & \\
\hline \multicolumn{3}{|c|}{ Total Wells } & 2903 & & 2700 & & 131 & \\
\hline \multicolumn{9}{|c|}{ Lee County } \\
\hline \multirow[b]{2}{*}{ LU-Code } & \multirow[b]{2}{*}{ Landuse } & \multirow{2}{*}{$\begin{array}{c}\% \text { Total } \\
\text { Area }\end{array}$} & Ini & ction & Plu & gged & Aba & doned \\
\hline & & & \#Wells & $\%$ of Total & \# Wells & $\%$ of Total & \# Wells & $\%$ of Total \\
\hline 11 & Residential & $<1$ & & & 2 & $<1$ & & \\
\hline 16 & Mixed Urban & $<1$ & & & 1 & $<1$ & & \\
\hline 21 & Cropland and Pasture & 49 & 2 & 67 & 236 & 56 & 71 & 55 \\
\hline 24 & Other Agricultural Land & $<1$ & & & 2 & $<1$ & & \\
\hline 31 & Herbaceous Rangeland & 1 & & & 3 & 1 & 3 & 2 \\
\hline 32 & Shrub and Brush Rangeland & 2 & & & 7 & 2 & 1 & 1 \\
\hline 33 & Mixed Rangeland & 19 & 1 & 33 & 62 & 15 & 17 & 13 \\
\hline 41 & Deciduous Forest & 27 & & & 103 & 25 & 35 & 27 \\
\hline 53 & Reservoir & $<1$ & & & & & 2 & 2 \\
\hline 76 & Transitional Area & $<1$ & & & 1 & $<1$ & & \\
\hline 61 & Forested Wetland & 1 & & & 3 & 1 & & \\
\hline 62 & Nonforested Wetland & $<1$ & & & & & 1 & 1 \\
\hline Total Wel & & & 3 & & 420 & & 130 & \\
\hline
\end{tabular}


Table 4.9 continued. Injection, plugged, and abandoned well sites versus landuse.

\begin{tabular}{|c|c|c|c|c|c|c|c|c|}
\hline \multirow[b]{3}{*}{ LU-Code } & \multicolumn{8}{|c|}{ Moore County } \\
\hline & \multirow[b]{2}{*}{ Landuse } & \multirow{2}{*}{\begin{tabular}{|c|}
$\%$ Total \\
Area \\
\end{tabular}} & \multicolumn{2}{|c|}{ Injection } & \multicolumn{2}{|c|}{ Plugged } & \multicolumn{2}{|c|}{ Abandoned } \\
\hline & & & \#Wells & $\%$ of Total & \#ells & $\%$ of Total & \#Wells & $\%$ of Total \\
\hline 11 & Residential & $<1$ & & & 1 & $<1$ & 9 & 5 \\
\hline 12 & Commercial and Services & $<1$ & 1 & 2 & & & & \\
\hline 13 & Industrial & $<1$ & 2 & 4 & 2 & $<1$ & & \\
\hline 14 & Transportation and Utilities & $<1$ & 1 & 2 & & & 2 & 1 \\
\hline 17 & Other Urban & $<1$ & & & & & 6 & 3 \\
\hline 21 & Cropland and Pasture & 64 & 31 & 58 & 335 & 66 & 119 & 63 \\
\hline 23 & Confined Feed Lot & $<1$ & & & 1 & $<1$ & & \\
\hline 24 & Other Agricultural Land & $<1$ & 2 & 4 & & & & \\
\hline 31 & Herbaceous Rangeland & 32 & 16 & 30 & 158 & 31 & 52 & 28 \\
\hline 33 & Mixed Rangeland & 2 & & & 7 & 1 & & \\
\hline 52 & Lake & $<1$ & & & 1 & $<1$ & & \\
\hline 53 & Reservoir & 1 & & & 5 & 1 & & \\
\hline 61 & Forested Wetland & $<1$ & & & 1 & $<1$ & & \\
\hline 62 & Nonforested Wetland & $<1$ & & & & & & \\
\hline \multicolumn{3}{|c|}{ Total Wells } & 53 & & 511 & & 188 & \\
\hline \multicolumn{9}{|c|}{ Panola County } \\
\hline \multirow[b]{2}{*}{ LU-Code } & \multirow[b]{2}{*}{ Landuse } & \multirow{2}{*}{$\begin{array}{c}\% \text { Total } \\
\text { Area }\end{array}$} & \multicolumn{2}{|c|}{ Injection } & \multicolumn{2}{|c|}{ Plugged } & \multicolumn{2}{|c|}{ Abandoned } \\
\hline & & & \#Wells & $\%$ of Total & \#Wells & $\%$ of Total & \#Wells & $\%$ of Total \\
\hline 11 & Residential & $<1$ & & & & & 1 & 1 \\
\hline 16 & Mixed Urban & $<1$ & & & 1 & $<1$ & & \\
\hline 21 & Cropland and Pasture & 29 & 8 & 26 & 130 & 26 & 19 & 25 \\
\hline 23 & Confined Feed Lot & $<1$ & & & 1 & $<1$ & & \\
\hline 32 & Shrub and Brush Rangeland & $<1$ & & & 2 & $<1$ & 2 & 3 \\
\hline 41 & Deciduous Forest & 10 & 1 & 3 & 43 & 9 & 7 & 9 \\
\hline 42 & Evergreen Forest & 7 & 2 & 6 & 47 & 9 & 6 & 8 \\
\hline 43 & Mixed Forest & 50 & 20 & 65 & 270 & 55 & 41 & 54 \\
\hline 76 & Transitional Area & $<1$ & & & 1 & $<1$ & & \\
\hline 61 & Forested Wetland & $<1$ & & & & & & \\
\hline 62 & Nonforested Wetland & $<1$ & & & & & & \\
\hline \multicolumn{3}{|c|}{ Total Wells } & 31 & & 495 & & 76 & \\
\hline \multicolumn{9}{|c|}{ Pecos County } \\
\hline \multirow[b]{2}{*}{ LU-Code } & \multirow[b]{2}{*}{ Landuse } & \multirow{2}{*}{$\begin{array}{c}\text { \% Total } \\
\text { Area } \\
\end{array}$} & & ction & Plu & gged & Abar & Lioned \\
\hline & & & \#Wells & $\%$ of Total & \#Wells & $\%$ of Total & \#Wells & $\%$ of Total \\
\hline 11 & Residential & $<1$ & & & 1 & $<1$ & & \\
\hline 12 & Commercial and Services & $<1$ & & & 3 & $<1$ & & \\
\hline 13 & Industrial & 2 & 415 & 44 & 691 & 26 & 46 & 14 \\
\hline 14 & Transportation and Utilities & $<1$ & 2 & $<1$ & 7 & $<1$ & 1 & $<1$ \\
\hline 21 & Cropland and Pasture & 3 & 13 & 1 & 50 & 2 & 11 & 3 \\
\hline 31 & Herbaceous Rangeland & $<1$ & 9 & 1 & 13 & $<1$ & 7 & 2 \\
\hline 32 & Shrub and Brush Rangeland & 89 & 474 & 51 & 1826 & 68 & 242 & 73 \\
\hline 33 & Mixed Rangeland & 5 & 23 & 2 & 107 & 4 & 25 & 8 \\
\hline 42 & Evergreen Forest & $<1$ & & & 1 & $<1$ & & \\
\hline 52 & Lake & $<1$ & & & 1 & $<1$ & & \\
\hline 76 & Transitional Area & $<1$ & & & 2 & $<1$ & 1 & $<1$ \\
\hline 61 & Forested Wetland & $<1$ & & & & & & \\
\hline 62 & Nonforested Wetland & 0 & & & & & & \\
\hline Total We & & & 936 & & 2702 & & 333 & \\
\hline
\end{tabular}


Table 4.9 continued. Injection, plugged, and abandoned well sites versus landuse.

\begin{tabular}{|c|c|c|c|c|c|c|c|c|}
\hline \multicolumn{9}{|c|}{ Webb County } \\
\hline \multirow[b]{2}{*}{ LU-Code } & \multirow[b]{2}{*}{ Landuse } & \multirow{2}{*}{$\begin{array}{c}\% \text { Total } \\
\text { Area }\end{array}$} & \multicolumn{2}{|c|}{ Injection } & \multicolumn{2}{|c|}{ Plugged } & \multicolumn{2}{|c|}{ Abandoned } \\
\hline & & & \#Wells & $\%$ of Total & \# Wells & $\%$ of Total & \# Wells & $\%$ of Total \\
\hline 11 & Residential & $<1$ & & & 1 & $<1$ & & \\
\hline 13 & Industrial & $<1$ & 7 & 8 & 41 & 2 & & \\
\hline 14 & Transportation and Utilities & $<1$ & & & 1 & $<1$ & & \\
\hline 16 & Mixed Urban & $<1$ & 1 & 1 & 2 & $<1$ & & \\
\hline 21 & Cropland and Pasture & 1 & & & 20 & 1 & & \\
\hline 24 & Other Agricultural Land & $<1$ & 1 & 1 & & & & \\
\hline 31 & Herbaceous Rangeland & 4 & 1 & 1 & 38 & 2 & 11 & 5 \\
\hline 32 & Shrub and Brush Rangeland & 75 & 53 & 63 & 1257 & 71 & 140 & 66 \\
\hline 33 & Mixed Rangeland & 18 & 21 & 25 & 398 & 23 & 60 & 28 \\
\hline 76 & Transitional Area & $<1$ & & & 1 & $<1$ & & \\
\hline 61 & Forested Wetland & 0 & & & & ? & & \\
\hline 62 & Nonforested Wetland & $<1$ & & & & & & \\
\hline \multicolumn{3}{|c|}{ Total Wells } & 84 & & 1759 & & 211 & \\
\hline \multicolumn{9}{|c|}{ Wise County } \\
\hline & & $\%$ Total & \multicolumn{2}{|c|}{ Injection } & \multicolumn{2}{|c|}{ Plugged } & \multicolumn{2}{|c|}{ Abandoned } \\
\hline LU-Code & Landuse & Area & \#Wells & $\%$ of Total & \# Wells & $\%$ of Total & \#Wells & $\%$ of Total \\
\hline 11 & Residential & 1 & & & 6 & 1 & & \\
\hline 14 & Transportation and Utilities & $<1$ & & & 2 & $<1$ & & \\
\hline 16 & Mixed Urban & $<1$ & & & 1 & $<1$ & & \\
\hline 21 & Cropland and Pasture & 40 & 11 & 26 & 450 & 53 & 64 & 42 \\
\hline 31 & Herbaceous Rangeland & 11 & 1 & 2 & 43 & 5 & 22 & 14 \\
\hline 32 & Shrub and Brush Rangeland & 1 & & & 22 & 3 & 4 & 3 \\
\hline 33 & Mixed Rangeland & 30 & 25 & 58 & 186 & 22 & 45 & 30 \\
\hline 41 & Deciduous Forest & 14 & 5 & 12 & 132 & 15 & 16 & 11 \\
\hline 53 & Reservoir & 1 & & & 1 & $<1$ & & \\
\hline 75 & Quaries and Gravel Pits & 1 & & & 11 & 1 & & \\
\hline 76 & Transitional Area & $<1$ & 1 & 2 & 2 & $<1$ & & \\
\hline 61 & Forested Wetland & $\overline{0}$ & & & & & & \\
\hline 62 & Nonforested Wetland & 1 & & & 1 & $<1$ & 1 & 1 \\
\hline \multicolumn{3}{|c|}{ Total Wells } & 43 & & 857 & & 152 & \\
\hline
\end{tabular}


Note that the API Texas distribution seems to best represent the counties located in west Texas (Ector, Moore, Pecos, and Webb), while the counties in central and east Texas (Brazoria, Lee, Panola, and Wise) tend to have more drill sites located in forest areas and less in crop and pasture areas than suggested by the API distribution. With the exception of Wise County, none of the 8 Texas counties are well represented by the API nationwide landuse distribution.

Table 4.10. Landuse distributions for 8 Texas counties vs. API survey distributions.

\begin{tabular}{|l|c|c|c|c|c|}
\hline \multirow{2}{*}{} & \multicolumn{5}{|c|}{ \% of Drill Sites Located Within Given Landuse } \\
\cline { 2 - 6 } & Urban & $\begin{array}{c}\text { Crops \& } \\
\text { Pasture }\end{array}$ & Forest & $\begin{array}{c}\text { Water / } \\
\text { Recreational }\end{array}$ & $\begin{array}{c}\text { Barren or } \\
\text { Wetland }\end{array}$ \\
\hline API - Nationwide & 3 & 80 & 9 & 1 & 8 \\
\hline API - Texas & 0 & 93 & 5 & 0 & 1 \\
\hline \hline Brazoria & 10 & 67 & 19 & 3 & 1 \\
\hline Ector & 4 & 95 & 0 & 0 & 1 \\
\hline Lee & 1 & 72 & 27 & 0 & 0 \\
\hline Moore & 0 & 100 & 0 & 0 & 0 \\
\hline Panola & 1 & 29 & 69 & 0 & 1 \\
\hline Pecos & 27 & 73 & 0 & 0 & 0 \\
\hline Webb & 0 & 100 & 0 & 0 & 0 \\
\hline Wise & 2 & 82 & 14 & 0 & 2 \\
\hline
\end{tabular}

\subsubsection{Surface Water}

The potential contamination of surface water represents one of the primary hazards of oil and gas waste disposal. Leachate from reserve pits can travel overland with surface runoff or through shallow groundwater zones to receiving streams where it can impact living species within the stream as well as travel downstream to potable water distribution intakes. Likewise, produced water entering a freshwater stream, either unintentionally or via intentional discharge, can destroy the freshwater nature of the stream as well as contaminate the stream with trace pollutants. The EPA included the potential contamination of freshwater streams in their risk assessment by developing a nationwide distribution of travel distances from drill sites and from 
production sites to the nearest receiving stream. These travel distances were used to model the transport of specific pollutants contained in drilling waste and in produced water from the drilling or production site to the stream. The EPA travel distance distributions were developed by measuring physical distances from select USGS quadrangle maps (see Section 2.1.2) and grouping the measured distances into four groups: $0-130 \mathrm{~m}, 130-850 \mathrm{~m}, 850-2,000 \mathrm{~m}$, and greater than 2,000 m. The travel distances were further grouped into those that impacted low flow streams $(0.14$ - 450 $\mathrm{cfs}$ ) and those that impacted high flow streams ( $>450 \mathrm{cfs}$ ).

For this study, digital line graph (DLG) files representing surface water hydrography were obtained from the USGS Earth Science Information Center to cover each of the 8 Texas counties. These DLG files are derived from 1:100,000 scale USGS topographical maps and contain data on all flowing and non-flowing surface water features. The travel distance distributions developed from these coverages are shown in Table 4.11 for drilling sites and Table 4.12 for injection, plugged, and abandoned well sites. These distributions were developed by creating buffer zones around all surface water features and determining the number of wells located within these buffer zones. No distinction was made between flowing (stream) and non-flowing (lake and reservoir) features in the analysis because an impact on either could be significant. Also, because most surface water features are linked in some fashion, an impact on one invariably affects all others downstream.

Table 4.13 presents a comparison of the drilling site travel distance distributions developed for each of the counties with the EPA nationwide and zone 7 (Oklahoma and Texas) distributions. These distributions represent combined data for all wells drilled in 1988, 1990, and 1992. Note that both of the EPA distributions tend to widely overestimate the distances from drilling sites to receiving streams when compared to the actual distributions for the 8 counties examined. This is especially true for Brazoria and Wise Counties where over $90 \%$ of drill sites are characterized as being at a close or 
Table 4.11. Drilling sites versus proximity to surface water bodies.

\begin{tabular}{|c|c|c|c|c|c|c|}
\hline \multicolumn{7}{|c|}{ Brazoria County } \\
\hline \multirow{2}{*}{$\begin{array}{c}\text { Distance } \\
\text { (m) }\end{array}$} & \multicolumn{2}{|c|}{1988} & \multicolumn{2}{|c|}{1990} & \multicolumn{2}{|c|}{1992} \\
\hline & \# Wells & $\%$ of Total & \# Wells & $\%$ of Total & \#Wells & $\%$ of Total \\
\hline 100 & 14 & 25 & 9 & 25 & 3 & 17 \\
\hline 500 & 35 & 64 & 29 & 81 & 13 & 72 \\
\hline 1000 & 50 & 91 & 35 & 97 & 17 & 94 \\
\hline 1500 & 53 & 96 & 36 & 100 & 18 & 100 \\
\hline 2000 & 55 & 100 & 36 & 100 & 18 & 100 \\
\hline Total Wells & 55 & & 36 & & 18 & \\
\hline \multicolumn{7}{|c|}{ Ector County } \\
\hline Distance & \multicolumn{2}{|c|}{1988} & \multicolumn{2}{|c|}{1990} & \multicolumn{2}{|c|}{1992} \\
\hline$(\mathrm{m})$ & \# Wells & $\%$ of Total & \# Wells & $\%$ of Total & \# Wells & $\%$ of Total \\
\hline 100 & 11 & 3 & 8 & 4 & 5 & 3 \\
\hline 500 & 76 & 19 & 32 & 15 & 28 & 17 \\
\hline 1000 & 166 & 42 & 80 & 38 & 58 & 35 \\
\hline 1500 & 245 & 63 & 123 & 59 & 85 & 52 \\
\hline 2000 & 308 & 79 & 149 & 71 & 124 & 76 \\
\hline Total Wells & 392 & & 210 & & 164 & \\
\hline \multicolumn{7}{|c|}{ Lee County } \\
\hline Distance & \multicolumn{2}{|c|}{1988} & \multicolumn{2}{|c|}{1990} & \multicolumn{2}{|c|}{1992} \\
\hline (m) & \# Wells & $\%$ of Total & \# Wells & $\%$ of Total & \# Wells & $\%$ of Total \\
\hline 100 & 4 & 4 & 8 & 20 & 6 & 16 \\
\hline 500 & 40 & 44 & 22 & 55 & 24 & 63 \\
\hline 1000 & 80 & 88 & 33 & 83 & 35 & 92 \\
\hline 1500 & 89 & 98 & 39 & 98 & 37 & 97 \\
\hline 2000 & 91 & 100 & 40 & 100 & 38 & 100 \\
\hline Total Wells & 91 & & 40 & & 38 & \\
\hline \multicolumn{7}{|c|}{ Moore County } \\
\hline Distance & \multicolumn{2}{|c|}{1988} & \multicolumn{2}{|c|}{1990} & \multicolumn{2}{|c|}{1992} \\
\hline (m) & \# Wells & $\%$ of Total & \# Wells & $\%$ of Total & \# Wells & $\%$ of Total \\
\hline 100 & 4 & 7 & 0 & 0 & 2 & 6 \\
\hline 500 & 18 & 33 & 4 & 11 & 21 & 64 \\
\hline 1000 & 33 & 61 & 15 & 42 & 29 & 88 \\
\hline 1500 & 37 & 69 & 28 & 78 & 30 & 91 \\
\hline 2000 & 41 & 76 & 32 & 89 & 30 & 91 \\
\hline Total Wells & 54 & & 36 & & 33 & \\
\hline
\end{tabular}


Table 4.11 continued. Drilling sites versus proximity to surface water bodies.

\begin{tabular}{|c|c|c|c|c|c|c|}
\hline \multicolumn{7}{|c|}{ Panola County } \\
\hline \multirow{2}{*}{$\begin{array}{c}\text { Distance } \\
\text { (m) }\end{array}$} & \multicolumn{2}{|c|}{1988} & \multicolumn{2}{|c|}{1990} & \multicolumn{2}{|c|}{1992} \\
\hline & \# Wells & $\%$ of Total & \#Wells & $\%$ of Total & \# Wells & $\%$ of Total \\
\hline 100 & 6 & 12 & 20 & 11 & 16 & 13 \\
\hline 500 & 23 & 44 & 89 & 47 & 59 & 48 \\
\hline 1000 & 40 & 77 & 137 & 73 & 92 & 75 \\
\hline 1500 & 49 & 94 & 164 & 87 & 112 & 91 \\
\hline 2000 & 50 & 96 & 182 & 97 & 121 & 98 \\
\hline Total Wells & 52 & & 188 & & 123 & \\
\hline \multicolumn{7}{|c|}{ Pecos County } \\
\hline Distance & \multicolumn{2}{|c|}{1988} & \multicolumn{2}{|c|}{1990} & \multicolumn{2}{|c|}{1992} \\
\hline (m) & \# Wells & $\%$ of Total & \# Wells & $\%$ of Total & \# Wells & $\%$ of Total \\
\hline 100 & 7 & 5 & 3 & 3 & 4 & 5 \\
\hline 500 & 35 & 25 & 22 & 22 & 21 & 25 \\
\hline 1000 & 64 & 46 & 35 & 35 & 43 & 52 \\
\hline 1500 & 83 & 60 & 55 & 56 & 61 & 73 \\
\hline 2000 & 94 & 68 & 60 & 61 & 64 & 77 \\
\hline Total Wells & 139 & & 99 & & 83 & \\
\hline \multicolumn{7}{|c|}{ Webb County } \\
\hline Distance & \multicolumn{2}{|c|}{1988} & \multicolumn{2}{|c|}{1990} & \multicolumn{2}{|c|}{1992} \\
\hline (m) & \# Wells & $\%$ of Total & \#Wells & $\%$ of Total & \#Wells & $\%$ of Total \\
\hline 100 & 14 & 9 & 16 & 11 & 12 & 9 \\
\hline 500 & 69 & 46 & 66 & 44 & 58 & 44 \\
\hline 1000 & 119 & 79 & 114 & 76 & 113 & 86 \\
\hline 1500 & 139 & 92 & 131 & 87 & 125 & 95 \\
\hline 2000 & 143 & 95 & 142 & 95 & 128 & 98 \\
\hline Total Wells & 151 & & 150 & & 131 & \\
\hline \multicolumn{7}{|c|}{ Wise County } \\
\hline Distance & \multicolumn{2}{|c|}{1988} & \multicolumn{2}{|c|}{1990} & \multicolumn{2}{|c|}{1992} \\
\hline (m) & \# Wells & $\%$ of Total & \# Wells & $\%$ of Total & \# Wells & $\%$ of Total \\
\hline 100 & 22 & 23 & 26 & 25 & 10 & 12 \\
\hline 500 & 70 & 72 & 80 & 75 & 57 & 68 \\
\hline 1000 & 95 & 98 & 106 & 100 & 81 & 96 \\
\hline 1500 & 96 & 99 & 106 & 100 & 84 & 100 \\
\hline 2000 & 96 & 99 & 106 & 100 & 84 & 100 \\
\hline Total Wells & 97 & & 106 & & 84 & \\
\hline
\end{tabular}


Table 4.12. Injection, plugged, and abandoned well sites versus proximity to surface water bodies.

\begin{tabular}{|c|c|c|c|c|c|c|}
\hline \multicolumn{7}{|c|}{ Brazoria County } \\
\hline \multirow{2}{*}{$\begin{array}{c}\text { Distance } \\
\text { (m) }\end{array}$} & \multicolumn{2}{|c|}{ Injection } & \multicolumn{2}{|c|}{ Plugged } & \multicolumn{2}{|c|}{ Abandoned } \\
\hline & \#Wells & $\%$ of Total & \# Wells & $\%$ of Total & \# Wells & $\%$ of Total \\
\hline 100 & 16 & 15 & 225 & 14 & 43 & 22 \\
\hline 500 & 66 & 62 & 1068 & 67 & 141 & 71 \\
\hline 1000 & 104 & 97 & 1502 & 94 & 188 & 94 \\
\hline 1500 & 107 & 100 & 1581 & 99 & 197 & 99 \\
\hline 2000 & 107 & 100 & 1592 & 100 & 200 & 100 \\
\hline Total Wells & 107 & & 1593 & & 200 & \\
\hline \multicolumn{7}{|c|}{ Ector County } \\
\hline Distance & \multicolumn{2}{|c|}{ Injection } & \multicolumn{2}{|c|}{ Plugged } & \multicolumn{2}{|c|}{ Abandoned } \\
\hline (m) & \#Wells & $\%$ of Total & \# Wells & $\%$ of Total & \# Wells & $\%$ of Total \\
\hline 100 & 87 & 3 & 86 & 3 & 3 & 2 \\
\hline 500 & 393 & 14 & 485 & 18 & 21 & 16 \\
\hline 1000 & 1206 & 42 & 1077 & 40 & 47 & 36 \\
\hline 1500 & 1714 & 59 & 1606 & 59 & 82 & 63 \\
\hline 2000 & 2108 & 73 & 1966 & 73 & 105 & 80 \\
\hline Total Wells & 2903 & & 2700 & & 131 & \\
\hline \multicolumn{7}{|c|}{ Lee County } \\
\hline Distance & \multicolumn{2}{|c|}{ Injection } & \multicolumn{2}{|c|}{ Plugged } & \multicolumn{2}{|c|}{ Abandoned } \\
\hline (m) & \# Wells & $\%$ of Total & \# Wells & $\%$ of Total & \# Wells & $\%$ of Total \\
\hline 100 & 1 & 33 & 52 & 12 & 12 & 9 \\
\hline 500 & 1 & 33 & 213 & 51 & 78 & 60 \\
\hline 1000 & 3 & 100 & 352 & 84 & 118 & 91 \\
\hline 1500 & 3 & 100 & 393 & 94 & 127 & 98 \\
\hline 2000 & 3 & 100 & 419 & 100 & 129 & 99 \\
\hline Total Wells & 3 & & 420 & & 130 & \\
\hline \multicolumn{7}{|c|}{ Moore County } \\
\hline Distance & \multicolumn{2}{|c|}{ Injection } & \multicolumn{2}{|c|}{ Plugged } & \multicolumn{2}{|c|}{ Abandoned } \\
\hline$(m)$ & \#Wells & $\%$ of Total & \# Wells & $\%$ of Total & \# Wells & $\%$ of Total \\
\hline 100 & 1 & 2 & 41 & 8 & 7 & 4 \\
\hline 500 & 13 & 25 & 157 & 31 & 38 & 20 \\
\hline 1000 & 24 & 45 & 278 & 54 & 83 & 44 \\
\hline 1500 & 34 & 64 & 385 & 75 & 121 & 64 \\
\hline 2000 & 42 & 79 & 448 & 88 & 140 & 74 \\
\hline Total Wells & 53 & & 511 & & 188 & \\
\hline
\end{tabular}


Table 4.12 cont'd. Injection, plugged, and abandoned well sites versus proximity to surface water bodies

\begin{tabular}{|c|c|c|c|c|c|c|}
\hline \multicolumn{7}{|c|}{ Panola County } \\
\hline \multirow{2}{*}{$\begin{array}{l}\text { Distance } \\
\text { (m) }\end{array}$} & \multicolumn{2}{|c|}{ Injection } & \multicolumn{2}{|c|}{ Plugged } & \multicolumn{2}{|c|}{ Abandoned } \\
\hline & \# Wells & $\%$ of Total & \# Wells & $\%$ of Total & \# Wells & $\%$ of Total \\
\hline 100 & 0 & 0 & 41 & 8 & 7 & 9 \\
\hline 500 & 8 & 26 & 189 & 38 & 33 & 43 \\
\hline 1000 & 14 & 45 & 341 & 69 & 55 & 72 \\
\hline 1500 & 21 & 68 & 424 & 86 & 68 & 89 \\
\hline 2000 & 25 & 81 & 479 & 97 & 73 & 96 \\
\hline Total Wells & 31 & & 495 & & 76 & \\
\hline
\end{tabular}

Pecos County

\begin{tabular}{|c|c|c|c|c|c|c|}
\hline \multirow{2}{*}{$\begin{array}{c}\text { Distance } \\
(\mathrm{m})\end{array}$} & \multicolumn{2}{|c|}{ Injection } & \multicolumn{2}{c|}{ Plugged } & \multicolumn{2}{c|}{ Abandoned } \\
\cline { 2 - 7 } & \# Wells & $\%$ of Total & \# Wells & $\%$ of Total & \# Wells & $\%$ of Total \\
\hline 100 & 68 & 7 & 227 & 8 & 21 & 6 \\
\hline 500 & 307 & 33 & 875 & 32 & 91 & 27 \\
\hline 1000 & 534 & 57 & 1448 & 54 & 144 & 43 \\
\hline 1500 & 671 & 72 & 1861 & 69 & 191 & 57 \\
\hline 2000 & 745 & 80 & 2077 & 77 & 220 & 66 \\
\hline Total Wells & 936 & & 2702 & & 333 & \\
\hline
\end{tabular}

Webb County

\begin{tabular}{|c|c|c|c|c|c|c|}
\hline \multirow{2}{*}{$\begin{array}{c}\text { Distance } \\
(\mathrm{m})\end{array}$} & \multicolumn{2}{|c|}{ Injection } & \multicolumn{2}{c|}{ Plugged } & \multicolumn{2}{c|}{ Abandoned } \\
\cline { 2 - 7 } & \# Wells & $\%$ of Total & \# Wells & $\%$ of Total & \# Wells & $\%$ of Total \\
\hline 100 & 1 & 1 & 121 & 7 & 18 & 9 \\
\hline 500 & 19 & 23 & 524 & 30 & 89 & 42 \\
\hline 1000 & 46 & 55 & 940 & 53 & 153 & 73 \\
\hline 1500 & 57 & 68 & 1198 & 68 & 176 & 83 \\
\hline 2000 & 67 & 80 & 1286 & 73 & 194 & 92 \\
\hline Total Wells & 84 & & 1759 & & 211 & \\
\hline
\end{tabular}

Wise County

\begin{tabular}{|c|c|c|c|c|c|c|}
\hline \multirow{2}{*}{$\begin{array}{c}\text { Distance } \\
(\mathrm{m})\end{array}$} & \multicolumn{2}{|c|}{ Injection } & \multicolumn{2}{c|}{ Plugged } & \multicolumn{2}{c|}{ Abandoned } \\
\cline { 2 - 7 } & \# Wells & $\%$ of Total & \# Wells & $\%$ of Total & \# Wells & $\%$ of Total \\
\hline 100 & 5 & 12 & 123 & 14 & 24 & 16 \\
\hline 500 & 30 & 70 & 577 & 67 & 112 & 74 \\
\hline 1000 & 41 & 95 & 807 & 94 & 147 & 97 \\
\hline 1500 & 43 & 100 & 851 & 99 & 152 & 100 \\
\hline 2000 & 43 & 100 & 856 & 100 & 152 & 100 \\
\hline Total Wells & 43 & & 857 & & 152 & \\
\hline
\end{tabular}


medium distance while the EPA zone 7 and nationwide data show only $4 \%$ and $19 \%$ of drilling sites respectively to be at a medium distance and none at a close distance. None of the 8 counties appears to be reasonably represented by either of the EPA distributions.

Table 4.13. Travel distance distributions from drilling sites to the nearest surface water body.

\begin{tabular}{|c|c|c|c|c|}
\hline & \multicolumn{4}{|c|}{$\%$ of Drilling Sites Located within Given Distance of Surface Water Body } \\
\hline & $\begin{array}{c}\text { Close } \\
0-130 \mathrm{~m}\end{array}$ & $\begin{array}{c}\text { Medium } \\
130-850 \mathrm{~m}\end{array}$ & $\begin{array}{c}\text { Far } \\
850-2,000 \mathrm{~m}\end{array}$ & $\begin{array}{l}\text { Very Far } \\
>2,000 \mathrm{~m}\end{array}$ \\
\hline EPA - Nationwide* & 0 & 19 & 30 & $51+$ \\
\hline EPA - Zone $7^{*}$ & 0 & $\overline{4}$ & 31 & $65 t$ \\
\hline Brazoria & $\overline{28}$ & 63 & 9 & 0 \\
\hline Ector & 5 & 28 & 43 & 24 \\
\hline Lee & 14 & 67 & 19 & 0 \\
\hline Moore & 6 & 50 & 28 & 16 \\
\hline Panola & 13 & 55 & 29 & 3 \\
\hline Pecos & 7 & 32 & 29 & 32 \\
\hline Webb & 12 & 60 & 24 & 4 \\
\hline Wise & 26 & 68 & 6 & 0 \\
\hline
\end{tabular}

* Percentages for low flow and high flow have been combined.

+ Includes drilling sites classified as having no surface water nearby.

Table 4.14 shows a comparison of travel distance distributions for injection, plugged, and abandoned well sites with the EPA production site distributions. The EPA distributions predict large travel distances with $80 \%$ of sites classified as being very far $(>2,000 \mathrm{~m})$ from a receiving stream. Once again, the EPA distributions grossly overestimate the travel distances as given by the 8 county distributions. Brazoria, Lee and Wise Counties in fact have no sites that are more than $2,000 \mathrm{~m}$ from a surface water feature. Figure 4.4 shows the location of injection, plugged, and abandoned well sites with respect to surface water features in Lee County. Most injection, plugged, and abandoned wells in the 8 counties (70-80\%) are located in the medium to far distance categories. 
Table 4.14. Travel distance distributions from injection, plugged, and abandoned wells to the nearest surface water body.

\begin{tabular}{|c|c|c|c|c|}
\hline & \multicolumn{4}{|c|}{$\%$ of Injection Wells Located $\mathrm{w} / \mathrm{i}$ Given Distance of Surface Water Body } \\
\hline & $\begin{array}{c}\text { Close } \\
0-130 \mathrm{~m}\end{array}$ & $\begin{array}{c}\text { Medium } \\
130-850 \mathrm{~m}\end{array}$ & $\begin{array}{c}\text { Far } \\
850-2,000 \mathrm{~m}\end{array}$ & $\begin{array}{l}\text { Very Far } \\
>2,000 \mathrm{~m}\end{array}$ \\
\hline EPA - Nationwide* & 1 & 8 & 11 & $80 t$ \\
\hline EPA - Zone $7^{*}$ & 0 & 3 & 15 & $82+$ \\
\hline Brazoria & $\overline{18}$ & $\overline{76}$ & $\overline{6}$ & 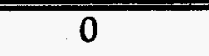 \\
\hline Ector & 4 & 31 & 38 & 27 \\
\hline Lee & 33 & 33 & 33 & 0 \\
\hline Moore & 2 & 34 & $\overline{43}$ & 21 \\
\hline Panola & 0 & 45 & 36 & 19 \\
\hline Pecos & 9 & 42 & 29 & 20 \\
\hline Webb & 5 & 45 & 30 & 20 \\
\hline \multirow[t]{3}{*}{ Wise } & 21 & 74 & 5 & 0 \\
\hline & \multicolumn{4}{|c|}{$\%$ of Plugged Wells Located w/i Given Distance of Surface Water Body } \\
\hline & $\begin{array}{c}\text { Close } \\
0-130 \mathrm{~m}\end{array}$ & $\begin{array}{c}\text { Medium } \\
130-850 \mathrm{~m}\end{array}$ & $\begin{array}{c}\text { Far } \\
850-2,000 \mathrm{~m}\end{array}$ & $\begin{array}{l}\text { Very Far } \\
>2,000 \mathrm{~m}\end{array}$ \\
\hline EPA - Nationwide* & 1 & 8 & 11 & $80 t$ \\
\hline EPA - Zone $7^{*}$ & 0 & 3 & 15 & $82+$ \\
\hline Brazoria & $\overline{18}$ & 72 & 10 & 0 \\
\hline Ector & 4 & 30 & 39 & 27 \\
\hline Lee & 16 & 60 & 24 & 0 \\
\hline Moore & 9 & 37 & 42 & 12 \\
\hline Panola & 11 & 49 & 37 & 3 \\
\hline Pecos & 11 & 37 & 29 & 23 \\
\hline Webb & 9 & 39 & 25 & 27 \\
\hline \multirow[t]{3}{*}{ Wise } & 18 & 73 & 9 & 0 \\
\hline & \multicolumn{4}{|c|}{$\%$ of Abandoned Wells Located $w / i$ Given Distance of Surface Water Body } \\
\hline & $\begin{array}{c}\text { Close } \\
0-130 \mathrm{~m}\end{array}$ & $\begin{array}{c}\text { Medium } \\
130-850 \mathrm{~m}\end{array}$ & $\begin{array}{c}\text { Far } \\
850-2,000 \mathrm{~m}\end{array}$ & $\begin{array}{l}\text { Very Far } \\
>2,000 \mathrm{~m}\end{array}$ \\
\hline EPA - Nationwide* & 1 & 8 & 11 & $80 t$ \\
\hline EPA - Zone $7^{*}$ & 0 & 3 & 15 & $82+$ \\
\hline Brazoria & 29 & 60 & 11 & 0 \\
\hline Ector & 4 & 27 & 49 & 20 \\
\hline Lee & 15 & 70 & 14 & 1 \\
\hline Moore & 6 & 30 & 38 & 26 \\
\hline Panola & 13 & 58 & 25 & 4 \\
\hline Pecos & 8 & 31 & 27 & 34 \\
\hline Webb & 10 & 52 & 30 & 8 \\
\hline Wise & 20 & 73 & 7 & 0 \\
\hline
\end{tabular}

* Percentages for low flow and high flow have been combined.

t Includes production sites classified as having no surface water nearby. 


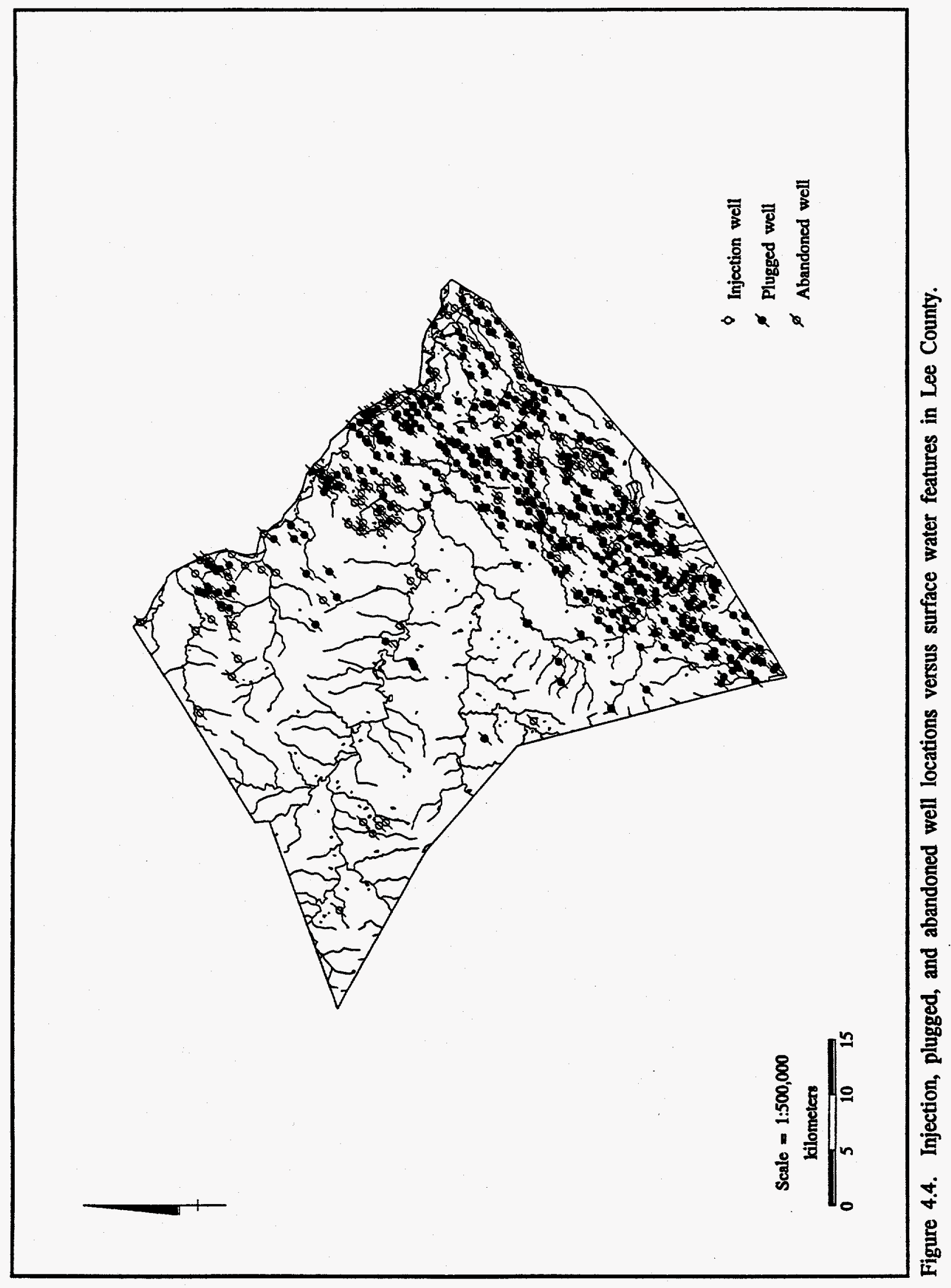




\subsubsection{Water Supply Wells}

A second major concern associated with oil and gas waste disposal is the possible contamination of groundwater aquifer systems, especially those that serve as local sources of fresh water. The EPA made an assessment of the potential risk to water supply wells in their 1985 study. Similar to the method used for the analysis of surface water impacts, the EPA developed a nationwide distribution of distances from drilling sites and from production sites to the nearest exposure well. The locations of water supply wells were inferred from USGS topographical maps by identifying residences that were located outside of corporate boundaries and therefore likely to be connected to a private well. No attempt was made to identify wells that might be used for purposes other than domestic water supply. The measured distances were again categorized into four groups: $0-130 \mathrm{~m}, 130-850 \mathrm{~m}, 850-2,000 \mathrm{~m}$, and greater than $2,000 \mathrm{~m}$. The average distances within each of these groups were used in the risk assessment modeling.

The Texas Water Development Board maintains an electronic data file containing information on all known water supply wells within the state. Data records were extracted from this file by county for each of the 8 counties analyzed in this study and used to create an ARC/INFO coverage of water well locations. This coverage was used to develop the distance distributions shown in Table 4.15 for drilling sites and Table 4.16 for injection, plugged, and abandoned well sites. The data in Table 4.15 indicates that nearly $6 \%$ of all oil and gas well drilling activity in the 8 counties that occurred in the combined years 1988, 1990, and 1992 was located within a rather short $500 \mathrm{~m}$ distance of a water supply well; in a few cases this separation distance was only a scant $100 \mathrm{~m}$. In Brazoria County a surprising $82 \%$ of all drilling activity occurs within $2,000 \mathrm{~m}$ of at least one water supply well. In the other 7 counties this percentage ranges between $40 \%$ and $68 \%$, except for Webb County where it is a relatively low $17 \%$. 
Table 4.15. Drilling sites versus proximity to water supply wells.

\begin{tabular}{|c|c|c|c|c|c|c|}
\hline \multicolumn{7}{|c|}{ Brazoria County } \\
\hline \multirow{2}{*}{$\begin{array}{c}\text { Distance } \\
\text { (m) }\end{array}$} & \multicolumn{2}{|c|}{1988} & \multicolumn{2}{|c|}{1990} & \multicolumn{2}{|c|}{1992} \\
\hline & \#Wells & $\%$ of Total & \# Wells & $\%$ of Total & \# Wells & $\%$ of Total \\
\hline 100 & 1 & 2 & 1 & 3 & 0 & 0 \\
\hline 500 & 12 & 22 & 3 & 8 & 2 & 11 \\
\hline 1000 & 26 & 47 & 13 & 36 & 9 & 50 \\
\hline 1500 & 39 & 71 & 24 & 67 & 12 & 67 \\
\hline 2000 & 47 & 85 & 28 & 78 & 14 & 78 \\
\hline Total Wells & 55 & & 36 & & 18 & \\
\hline \multicolumn{7}{|c|}{ Ector County } \\
\hline Distance & \multicolumn{2}{|c|}{1988} & \multicolumn{2}{|c|}{1990} & \multicolumn{2}{|c|}{1992} \\
\hline$(\mathrm{m})$ & \#Wells & $\%$ of Total & \#Wells & $\%$ of Total & \# Wells & $\%$ of Total \\
\hline 100 & 1 & 0 & 0 & 0 & 0 & 0 \\
\hline 500 & 43 & 11 & 5 & 2 & 7 & 4 \\
\hline 1000 & 122 & 31 & 23 & 11 & 32 & 20 \\
\hline 1500 & 208 & 53 & 64 & 30 & 67 & 41 \\
\hline 2000 & 294 & 75 & 123 & 59 & 103 & 63 \\
\hline Total Wells & 392 & & 210 & & 164 & \\
\hline \multicolumn{7}{|c|}{ Lee County } \\
\hline Distance & \multicolumn{2}{|c|}{1988} & \multicolumn{2}{|c|}{1990} & \multicolumn{2}{|c|}{1992} \\
\hline (m) & \#Wells & $\%$ of Total & \# Wells & $\%$ of Total & \# Wells & $\%$ of Total \\
\hline 100 & 0 & 0 & 0 & 0 & 0 & 0 \\
\hline 500 & 4 & 4 & 1 & 3 & 0 & 0 \\
\hline 1000 & 10 & 11 & 7 & 18 & 3 & 8 \\
\hline 1500 & 28 & 31 & 17 & 43 & 14 & 37 \\
\hline 2000 & 47 & 52 & 29 & 73 & 29 & 76 \\
\hline Total Wells & 91 & & 40 & & 38 & \\
\hline \multicolumn{7}{|c|}{ Moore County } \\
\hline Distance & \multicolumn{2}{|c|}{1988} & \multicolumn{2}{|c|}{1990} & \multicolumn{2}{|c|}{1992} \\
\hline (m) & \# Wells & $\%$ of Total & \# Wells & $\%$ of Total & \# Wells & $\%$ of Total \\
\hline 100 & 0 & 0 & 0 & 0 & 0 & 0 \\
\hline 500 & 8 & 15 & 6 & 17 & 1 & 3 \\
\hline 1000 & 24 & 44 & 11 & 31 & 4 & 12 \\
\hline 1500 & 29 & 54 & 15 & 42 & 5 & 15 \\
\hline 2000 & 33 & 61 & 20 & 56 & 8 & 24 \\
\hline Total Wells & 54 & & 36 & & 33 & \\
\hline
\end{tabular}


Table 4.15 continued. Drilling sites versus proximity to water supply wells.

\begin{tabular}{|c|c|c|c|c|c|c|}
\hline \multicolumn{7}{|c|}{ Panola County } \\
\hline \multirow{2}{*}{$\begin{array}{c}\text { Distance } \\
\text { (m) }\end{array}$} & \multicolumn{2}{|c|}{1988} & \multicolumn{2}{|c|}{1990} & \multicolumn{2}{|c|}{1992} \\
\hline & \# Wells & $\%$ of Total & \# Wells & $\%$ of Total & \# Wells & $\%$ of Total \\
\hline 100 & 0 & 0 & 0 & 0 & 0 & 0 \\
\hline 500 & 1 & 2 & 12 & 6 & 4 & 3 \\
\hline 1000 & 7 & 13 & 35 & 19 & 22 & 18 \\
\hline 1500 & 8 & 15 & 60 & 32 & 35 & 28 \\
\hline 2000 & 19 & 37 & 82 & 44 & 54 & 44 \\
\hline Total Wells & 52 & & 188 & & 123 & \\
\hline \multicolumn{7}{|c|}{ Pecos County } \\
\hline Distance & \multicolumn{2}{|c|}{1988} & \multicolumn{2}{|c|}{1990} & \multicolumn{2}{|c|}{1992} \\
\hline (m) & \# Wells & $\%$ of Total & \# Wells & $\%$ of Total & \# Wells & $\%$ of Total \\
\hline 100 & 0 & 0 & 0 & 0 & 0 & 0 \\
\hline 500 & 6 & 4 & 4 & 4 & 0 & 0 \\
\hline 1000 & 22 & 16 & 13 & 13 & 7 & 8 \\
\hline 1500 & 39 & 28 & 35 & 35 & 11 & 13 \\
\hline 2000 & 59 & 42 & 48 & 48 & 21 & 25 \\
\hline Total Wells & 139 & & 99 & & 83 & \\
\hline \multicolumn{7}{|c|}{ Webb County } \\
\hline Distance & \multicolumn{2}{|c|}{1988} & \multicolumn{2}{|c|}{1990} & \multicolumn{2}{|c|}{1992} \\
\hline (m) & \# Wells & $\%$ of Total & \# Wells & $\%$ of Total & \# Wells & $\%$ of Total \\
\hline 100 & 0 & 0 & 2 & 1 & 0 & 0 \\
\hline 500 & 5 & 3 & 3 & 2 & 0 & 0 \\
\hline 1000 & 18 & 12 & 5 & 3 & 1 & 1 \\
\hline 1500 & 30 & 20 & 14 & 9 & 5 & 4 \\
\hline 2000 & 41 & 27 & 22 & 15 & 10 & 8 \\
\hline Total Wells & 151 & & 150 & & 131 & \\
\hline \multicolumn{7}{|c|}{ Wise County } \\
\hline Distance & \multicolumn{2}{|c|}{1988} & \multicolumn{2}{|c|}{1990} & \multicolumn{2}{|c|}{1992} \\
\hline (m) & \# Wells & $\%$ of Total & \# Wells & $\%$ of Total & \# Wells & $\%$ of Total \\
\hline 100 & 0 & 0 & 1 & 1 & 0 & 0 \\
\hline 500 & 4 & 4 & 6 & 6 & 7 & 8 \\
\hline 1000 & 13 & 13 & 19 & 18 & 16 & 19 \\
\hline 1500 & 26 & 27 & 31 & 29 & 30 & 36 \\
\hline 2000 & 39 & 40 & 51 & 48 & 44 & 52 \\
\hline Total Wells & 97 & & 106 & & 84 & \\
\hline
\end{tabular}


Table 4.16. Injection, plugged, and abandoned well sites versus proximity to water supply wells.

\begin{tabular}{|c|c|c|c|c|c|c|}
\hline \multicolumn{7}{|c|}{ Brazoria County } \\
\hline \multirow{2}{*}{$\begin{array}{c}\text { Distance } \\
\text { (m) }\end{array}$} & \multicolumn{2}{|c|}{ Injection } & \multicolumn{2}{|c|}{ Plugged } & \multicolumn{2}{|c|}{ Abandoned } \\
\hline & \# Wells & $\%$ of Total & \# Wells & $\%$ of Total & \# Wells & $\%$ of Total \\
\hline 100 & 2 & 2 & 22 & 1 & 3 & 2 \\
\hline 500 & 30 & 28 & 397 & 25 & 48 & 24 \\
\hline 1000 & 73 & 68 & 1052 & 66 & 109 & 55 \\
\hline 1500 & 92 & 86 & 1372 & 86 & 157 & 79 \\
\hline 2000 & 102 & 95 & 1492 & 94 & 179 & 90 \\
\hline Total Wells & 107 & & 1593 & & 200 & \\
\hline \multicolumn{7}{|c|}{ Ector County } \\
\hline Distance & \multicolumn{2}{|c|}{ Injection } & \multicolumn{2}{|c|}{ Plugged } & \multicolumn{2}{|c|}{ Abandoned } \\
\hline (m) & \#Wells & $\%$ of Total & \# Wells & $\%$ of Total & \# Wells & $\%$ of Total \\
\hline 100 & 13 & 0 & 9 & 0 & 0 & 0 \\
\hline 500 & 231 & 8 & 164 & 6 & 2 & 2 \\
\hline 1000 & 727 & 25 & 561 & 21 & 14 & 11 \\
\hline 1500 & 1384 & 48 & 1156 & 43 & 50 & 38 \\
\hline 2000 & 2068 & 71 & 1788 & 66 & 101 & 77 \\
\hline Total Wells & 2903 & & 2700 & & 131 & \\
\hline \multicolumn{7}{|c|}{ Lee County } \\
\hline Distance & \multicolumn{2}{|c|}{ Injection } & \multicolumn{2}{|c|}{ Plugged } & \multicolumn{2}{|c|}{ Abandoned } \\
\hline (m) & \# Wells & $\%$ of Total & \# Wells & $\%$ of Total & \# Wells & $\%$ of Total \\
\hline 100 & 0 & 0 & 2 & 0 & 0 & 0 \\
\hline 500 & 1 & 33 & 17 & 4 & 5 & 4 \\
\hline 1000 & 1 & 33 & 83 & 20 & 20 & 15 \\
\hline 1500 & 1 & 33 & 191 & 45 & 51 & 39 \\
\hline 2000 & 2 & 67 & 303 & 72 & 86 & 66 \\
\hline Total Wells & 3 & & 420 & & 130 & \\
\hline \multicolumn{7}{|c|}{ Moore County } \\
\hline Distance & \multicolumn{2}{|c|}{ Injection } & \multicolumn{2}{|c|}{ Plugged } & \multicolumn{2}{|c|}{ Abandoned } \\
\hline (m) & \# Wells & $\%$ of Total & \# Wells & $\%$ of Total & \# Wells & $\%$ of Total \\
\hline 100 & 1 & 2 & 4 & 1 & 0 & 0 \\
\hline 500 & 15 & 28 & 91 & 18 & 21 & 11 \\
\hline 1000 & 30 & 57 & 237 & 46 & 54 & 29 \\
\hline 1500 & 39 & 74 & 327 & 64 & 97 & 52 \\
\hline 2000 & 45 & 85 & 377 & 74 & 122 & 65 \\
\hline Total Wells & 53 & & 511 & & 188 & \\
\hline
\end{tabular}


Table 4.16 cont'd. Injection, plugged, and abandoned well sites versus proximity to water supply wells.

\begin{tabular}{|c|c|c|c|c|c|c|}
\hline \multicolumn{7}{|c|}{ Panola County } \\
\hline \multirow{2}{*}{$\begin{array}{c}\text { Distance } \\
\text { (m) }\end{array}$} & \multicolumn{2}{|c|}{ Injection } & \multicolumn{2}{|c|}{ Plugged } & \multicolumn{2}{|c|}{ Abandoned } \\
\hline & \# Wells & $\%$ of Total & \# Wells & $\%$ of Total & \# Wells & $\%$ of Total \\
\hline 100 & 2 & 6 & 1 & 0 & 1 & 1 \\
\hline 500 & 6 & 19 & 20 & 4 & 3 & 4 \\
\hline 1000 & 8 & 26 & 59 & 12 & 9 & 12 \\
\hline 1500 & 13 & 42 & 103 & 21 & 18 & 24 \\
\hline 2000 & 17 & 55 & 156 & 32 & 35 & 46 \\
\hline Total Wells & 31 & & 495 & & 76 & \\
\hline \multicolumn{7}{|c|}{ Pecos County } \\
\hline Distance & \multicolumn{2}{|c|}{ Injection } & \multicolumn{2}{|c|}{ Plugged } & \multicolumn{2}{|c|}{ Abandoned } \\
\hline$(m)$ & \# Wells & $\%$ of Total & \# Wells & $\%$ of Total & \# Wells & $\%$ of Total \\
\hline 100 & 3 & 0 & 9 & 0 & 0 & 0 \\
\hline 500 & 37 & 4 & 117 & 4 & 17 & 5 \\
\hline 1000 & 151 & 16 & 394 & 15 & 61 & 18 \\
\hline 1500 & 317 & 34 & 760 & 28 & 120 & 36 \\
\hline 2000 & 495 & 53 & 1090 & 40 & 196 & 59 \\
\hline Total Wells & 936 & & 2702 & & 333 & \\
\hline \multicolumn{7}{|c|}{ Webb County } \\
\hline Distance & \multicolumn{2}{|c|}{ Injection } & \multicolumn{2}{|c|}{ Plugged } & \multicolumn{2}{|c|}{ Abandoned } \\
\hline (m) & \#Wells & $\%$ of Total & \# Wells & $\%$ of Total & \# Wells & $\%$ of Total \\
\hline 100 & 1 & 1 & 9 & 1 & 0 & 0 \\
\hline 500 & 2 & 2 & 77 & 4 & 3 & 1 \\
\hline 1000 & 6 & 7 & 198 & 11 & 16 & 8 \\
\hline 1500 & 13 & 15 & 323 & 18 & 31 & 15 \\
\hline 2000 & 22 & 26 & 519 & 30 & 49 & 23 \\
\hline Total Wells & 84 & & 1759 & & 211 & \\
\hline \multicolumn{7}{|c|}{ Wise County } \\
\hline Distance & \multicolumn{2}{|c|}{ Injection } & \multicolumn{2}{|c|}{ Plugged } & \multicolumn{2}{|c|}{ Abandoned } \\
\hline (m) & \# Wells & $\%$ of Total & \# Wells & $\%$ of Total & \# Wells & $\%$ of Total \\
\hline 100 & 0 & 0 & 4 & 0 & 0 & 0 \\
\hline 500 & 3 & 7 & 63 & 7 & 6 & 4 \\
\hline 1000 & 8 & 19 & 197 & 23 & 30 & 20 \\
\hline 1500 & 15 & 35 & 335 & 39 & 53 & 35 \\
\hline 2000 & 19 & 44 & 461 & 54 & 74 & 49 \\
\hline Total Wells & 43 & & 857 & & 152 & \\
\hline
\end{tabular}


The frequency with which injection well operations occur within close proximity to water supply wells is also surprisingly high. More than $50 \%$ of injection wells are located within $2,000 \mathrm{~m}$ of a water supply well in all counties except Webb and Wise. Figure 4.5 shows this condition for Panola County. In Brazoria County this percentage rises to $95 \%$. Similar percentages exist for plugged and abandoned wells. Table 4.17 compares the EPA zone 7 and nationwide separation distance distributions for production sites and water wells with the distributions developed for the 8 counties. In contrast to the surface water distribution data, the EPA distributions in this case severely underestimate the separation distances for injection, plugged, and abandoned wells. The EPA distributions predict approximately $70 \%$ of production sites to be located within $130 \mathrm{~m}$ of a domestic water supply well, while this percentage never exceeds $10 \%$ for any of the 8 counties examined and is generally on the order of only $1 \%$.

\subsubsection{Groundwater Usage}

In order to fully assess the potential impact on water supply wells surrounding oil and gas activities, an analysis of the groundwater usage in the vicinity of drilling operations and in the vicinity of injection, plugged, and abandoned wells was completed. Tables 4.18 and 4.19 show the results of this analysis. All 8 of the counties show a significant number of water wells within a 1 mile radius of drilling activity in the years examined. Particularly striking is Ector County with over 350 such wells. Seven of the 8 counties have a significant number of wells designated for domestic usage - ranging from 7 to 39 wells, or 10 to $38 \%$ of all wells within 1 mile radius. Only Moore County, where $86 \%$ of the wells are designated as irrigation wells, does not. Also of interest is the fact that all 8 of the counties have at least one public supply well within the 1 mile zone; Ector County, in fact, shows 52 public supply wells. Figure 4.6 


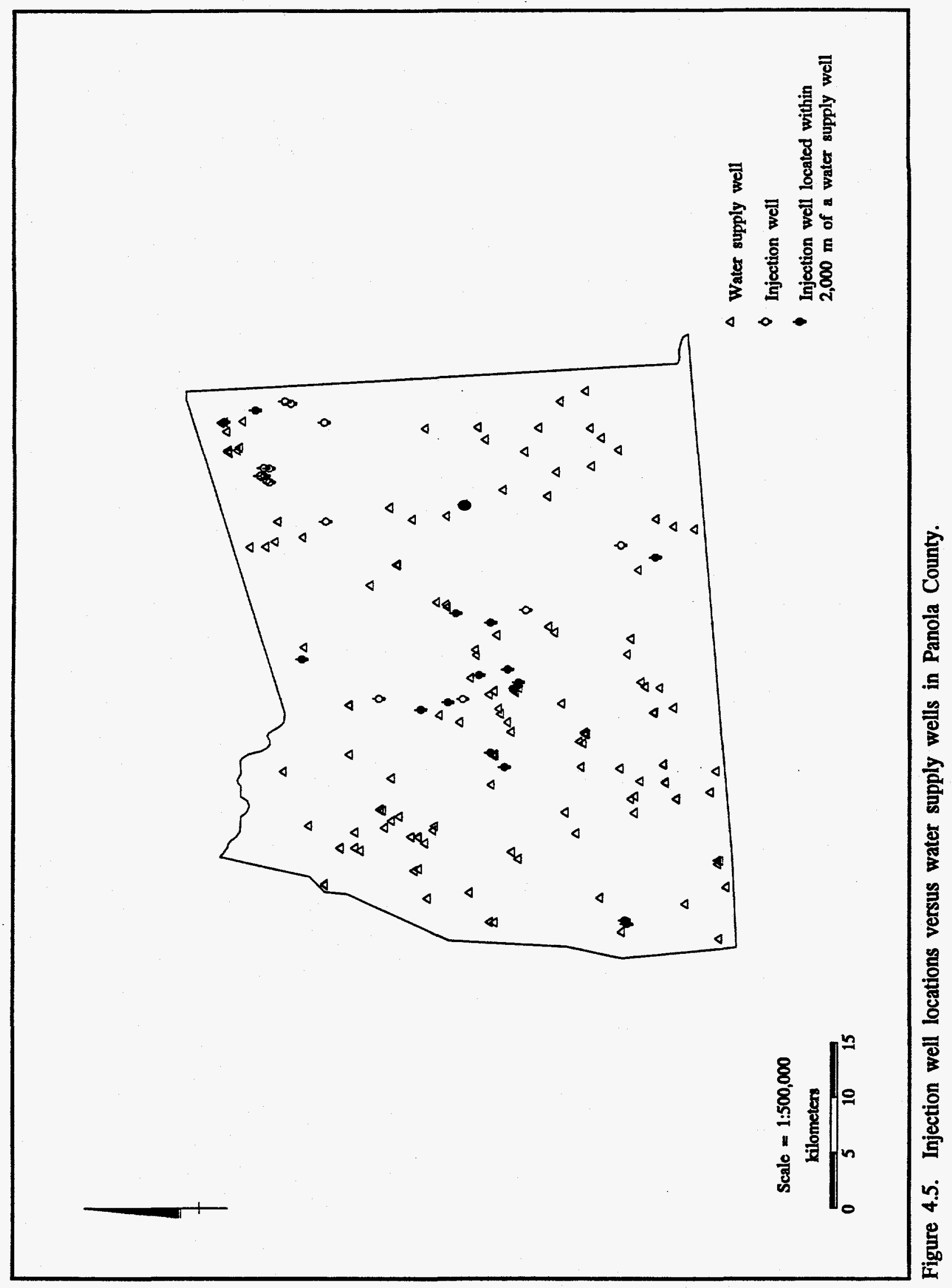


shows the relationship between drilling sites and public supply wells in Brazoria County.

Table 4.17. Travel distance distributions from injection, plugged, and abandoned wells to the nearest water supply well.

\begin{tabular}{|c|c|c|c|c|}
\hline & \multicolumn{4}{|c|}{$\%$ of Injection Wells Located $w / i$ Given Distance of a Water Supply Well } \\
\hline & $\begin{array}{c}\text { Close } \\
0-130 \mathrm{~m}\end{array}$ & $\begin{array}{l}\text { Medium } \\
130-850 \mathrm{~m}\end{array}$ & $\begin{array}{c}\text { Far } \\
850-2,000 \mathrm{~m}\end{array}$ & $\begin{array}{l}\text { Very Far } \\
>2,000 \mathrm{~m}\end{array}$ \\
\hline EPA - Nationwide & 63 & 24 & 3 & 10 \\
\hline EPA - Zone 7 & 72 & 22 & 4 & 2 \\
\hline Brazoria & 2 & 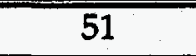 & 42 & 5 \\
\hline Ector & 1 & 18 & 52 & 29 \\
\hline Lee & $\overline{0}$ & 33 & 33 & 33 \\
\hline Moore & 7 & 40 & 38 & 15 \\
\hline Panola & 10 & 13 & 32 & 45 \\
\hline Pecos & 1 & $\overline{11}$ & 41 & 47 \\
\hline Webb & 1 & 2 & 23 & 74 \\
\hline \multirow[t]{3}{*}{ Wise } & 2 & 9 & 33 & 56 \\
\hline & \multicolumn{4}{|c|}{$\%$ of Plugged Wells Located w/i Given Distance of a Water Supply Well } \\
\hline & $\begin{array}{c}\text { Close } \\
0-130 \mathrm{~m}\end{array}$ & $\begin{array}{c}\text { Medium } \\
130-850 \mathrm{~m}\end{array}$ & $\begin{array}{c}\text { Far } \\
850-2,000 \mathrm{~m}\end{array}$ & $\begin{array}{l}\text { Very Far } \\
>2,000 \mathrm{~m}\end{array}$ \\
\hline EPA - Nationwide & 63 & 24 & 3 & 10 \\
\hline EPA - Zone 7 & 72 & 22 & 4 & 2 \\
\hline Brazoria & 2 & 53 & 39 & 6 \\
\hline Ector & 0 & 15 & 51 & 34 \\
\hline Lee & 1 & 13 & 58 & 28 \\
\hline Moore & 2 & 35 & 37 & 26 \\
\hline Panola & 1 & 10 & 21 & 68 \\
\hline Pecos & 0 & 11 & 29 & 60 \\
\hline Webb & 1 & 8 & 21 & 70 \\
\hline \multirow[t]{3}{*}{ Wise } & 1 & 17 & 36 & 46 \\
\hline & \multicolumn{4}{|c|}{$\%$ of Abandoned Wells Located $w / i$ Given Distance of a Water Supply Wel } \\
\hline & $\begin{array}{c}\text { Close } \\
0-130 \mathrm{~m}\end{array}$ & $\begin{array}{l}\text { Medium } \\
130-850 \mathrm{~m}\end{array}$ & $\begin{array}{c}\text { Far } \\
850-2,000 \mathrm{~m}\end{array}$ & $\begin{array}{l}\text { Very Far } \\
>2,000 \mathrm{~m}\end{array}$ \\
\hline EPA - Nationwide & 63 & 24 & 3 & 10 \\
\hline EPA - Zone 7 & 72 & 22 & 4 & 2 \\
\hline Brazoria & 3 & 40 & 46 & 11 \\
\hline Ector & 0 & 8 & 69 & 23 \\
\hline Lee & 0 & 9 & 57 & 34 \\
\hline Moore & 1 & 22 & 42 & 35 \\
\hline Panola & 1 & 9 & 36 & 54 \\
\hline Pecos & 0 & 14 & 45 & 41 \\
\hline Webb & 0 & 5 & 18 & 77 \\
\hline Wise & 0 & 16 & 33 & 51 \\
\hline
\end{tabular}


Table 4.18. Drilling sites versus groundwater usage.

\begin{tabular}{|c|c|c|c|c|c|c|c|c|c|c|c|c|c|c|c|c|c|}
\hline \multirow[b]{3}{*}{ Use Code } & \multirow[b]{3}{*}{ Description } & \multicolumn{16}{|c|}{ Water supply wells within 1 mile radius of all oil and gas well completions in the combined years 1988,1990 , and 1992} \\
\hline & & \multicolumn{2}{|c|}{ Brazoria County } & \multicolumn{2}{|c|}{ Ector County } & \multicolumn{2}{|c|}{ Lee County } & \multicolumn{2}{|c|}{ Moore County } & \multicolumn{2}{|c|}{ Panola County } & \multicolumn{2}{|c|}{ Pecos County } & \multicolumn{2}{|c|}{ Webb County } & \multicolumn{2}{|c|}{ Wise County } \\
\hline & & \#Wells & \% of Total & \#Wells & \% of Total & \#Wells & $\%$ of Total & \#Wells & \% of Total & \#Wells & $\%$ of Total & \#Wells & \% of Total & \#Wells & \% of Total & \#Wells & \% of Total \\
\hline C & commercial & & & & & & & & & & & 1 & 1 & & & & \\
\hline D & dewater & & & & & & & 1 & 1 & & & & & & & & \\
\hline $\mathrm{H}$ & domestic & 16 & 13 & 38 & 11 & 28 & 35 & & & 13 & 19 & 7 & 10 & 14 & 32 & 39 & 38 \\
\hline I & irrigation & 23 & 18 & 14 & 4 & 3 & 4 & 96 & 86 & 1 & 1 & 9 & 13 & 2 & 5 & 4 & 4 \\
\hline $\mathrm{J}$ & industrial-cooling & & & & & & & 1 & 1 & & & & & & & & \\
\hline$N$ & industrial-unspecified & 7 & 6 & 89 & 25 & & & 1 & 1 & 12 & 18 & 4 & 6 & 1 & 2 & 9 & 9 \\
\hline $\mathbf{P}$ & public supply & 10 & 8 & 52 & 15 & 13 & 16 & 1 & 1 & 15 & 22 & 1 & 1 & 4 & 9 & 28 & 27 \\
\hline $\mathbf{5}$ & stock & 9 & 7 & 86 & 24 & 14 & 18 & & & 1 & 1 & 12 & 17 & 12 & 27 & 1 & 1 \\
\hline$T$ & institution & & & & & & & & & & & & & 1 & 2 & 2 & 2 \\
\hline $\mathrm{U}$ & unused & 61 & 48 & 36 & 10 & 2 & 3 & 11 & 10 & 23 & 34 & 20 & 28 & 7 & 16 & 20 & 19 \\
\hline$z$ & other & & & & & & & 1 & 1 & & & & & & & & \\
\hline & undefined & 1 & 1 & 41 & 12 & 20 & 25 & & & 3 & 4 & 18 & 25 & 3 & 7 & & \\
\hline Total wat & er supply wells & 127 & & 356 & & 80 & & 112 & & 68 & & 72 & & 44 & & 103 & \\
\hline
\end{tabular}




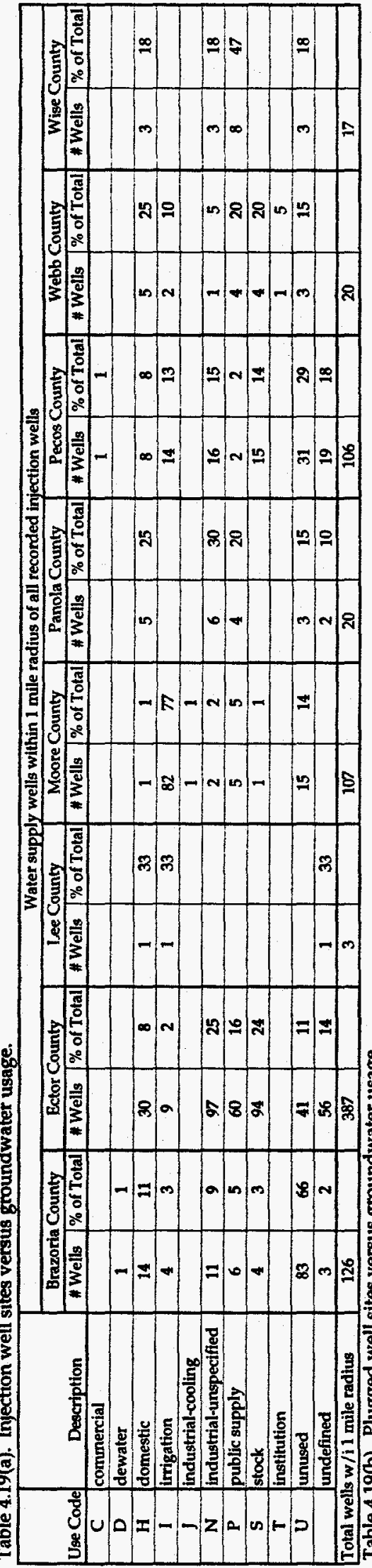

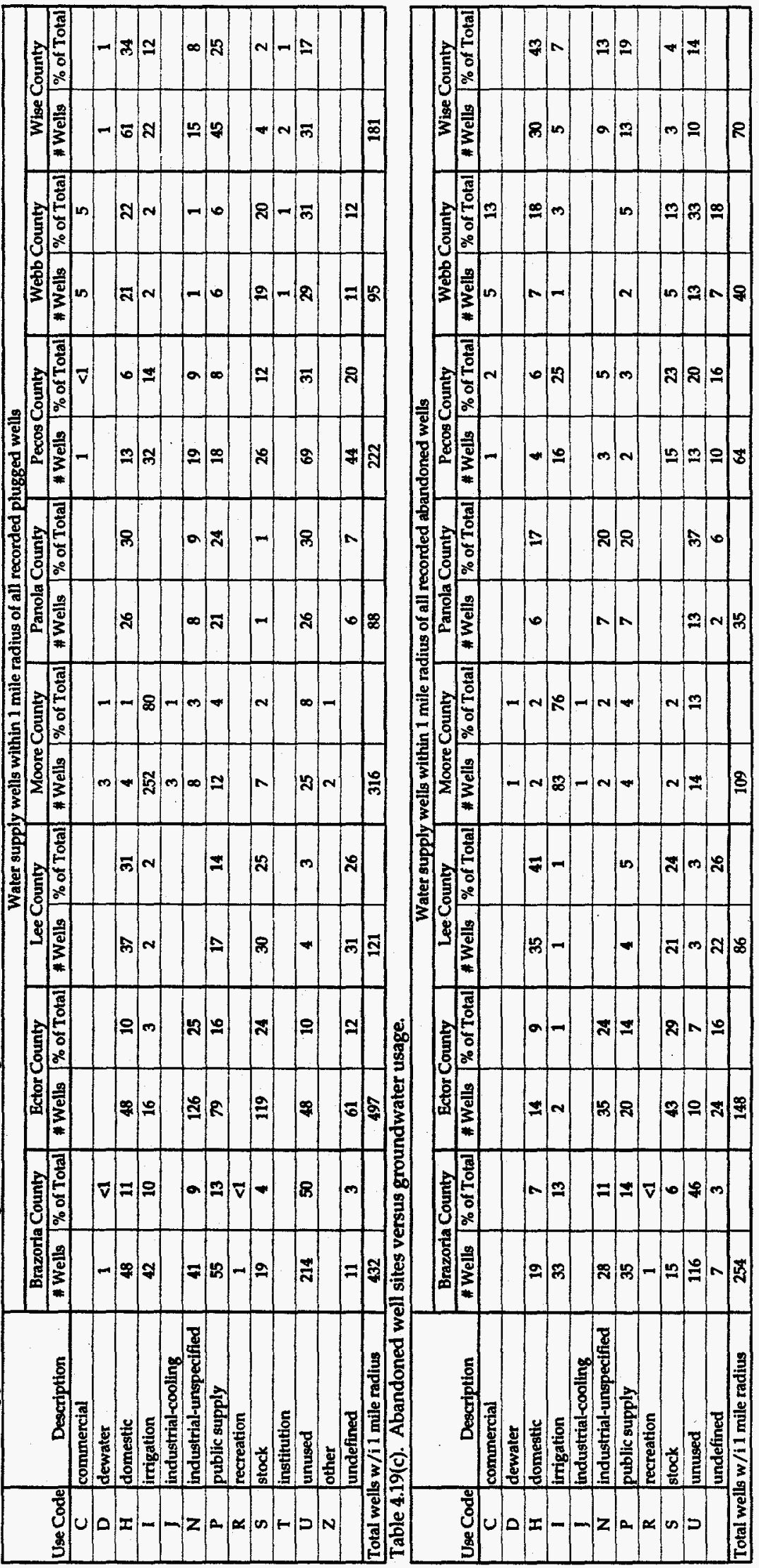




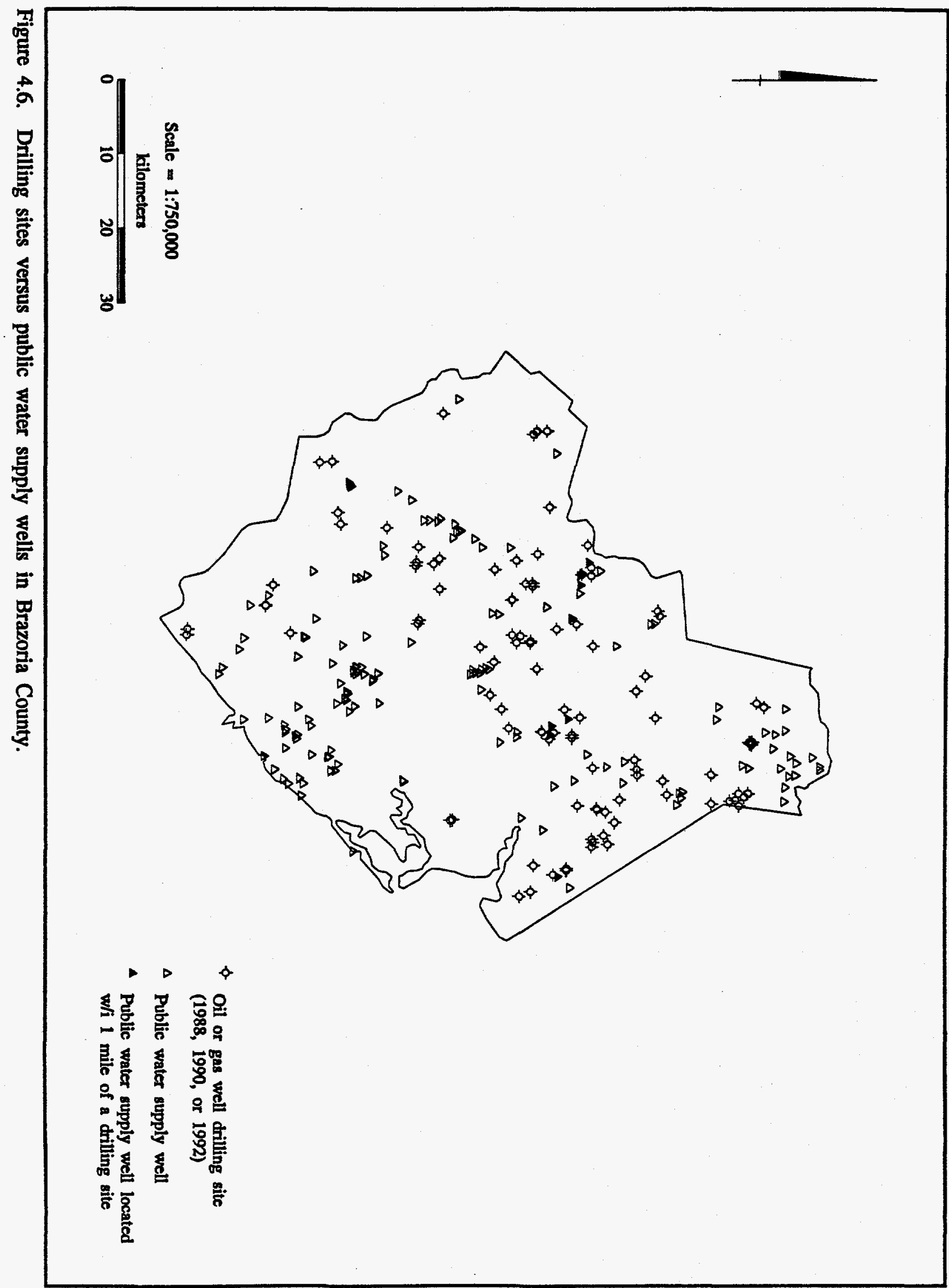


The number of water supply wells within a 1 mile radius of injection, plugged, and abandoned wells is also rather significant (Table 4.19). Ector and Brazoria Counties have an especially large number of water supply wells in close proximity to these well sites. The number of domestic supply wells within 1 mile radius of an injection well ranges from 3 to 30 for all counties except for Lee and Moore Counties where only one domestic well is within the 1 mile zone. At least 2, and as many as 79 , public supply wells can be found within 1 mile of at least one injection, plugged, and abandoned well in all counties. Only Lee County, with just 3 injection wells, has no public supply wells in close proximity to an injection well site.

There is little consistency among the counties regarding the percentage of groundwater usage attributable to each usage type as measured by the number of wells. This fact tends to support the need for local, or case by case, evaluation of potential impacts. Groundwater used for watering livestock has a higher acceptable limit of dissolved salts $(5,000 \mathrm{ppm}$ TDS) than does water used for irrigation $(2,000 \mathrm{ppm}$ TDS), or water slated for human consumption (500 ppm TDS). Domestic and public supply wells are therefore more sensitive to impact than other types of wells.

\subsubsection{Aquifer Regions}

An underground source of drinking water (USDW) is typically defined as any groundwater aquifer that contains water at less than 10,000 ppm TDS. The Texas Water

Development Board has inventoried the freshwater aquifer systems within the state and categorized these as major aquifers - those yielding large volumes of water in large areas of the state - and minor aquifers - those yielding large quantities of water in small areas of the state or small quantities of water in large areas of the state (Muller and Price, 1979). These aquifer regions have been delineated on a set of maps which are available from the Texas Natural Resource Information System (TNRIS) in the form of ARC/INFO coverages. These coverages were used to identify the number of drilled 
wells (Table 4.20) and the number of injection, plugged, and abandoned wells (Table 4.21) that penetrate each freshwater aquifer formation in the 8 counties. Two zones are typically defined for each aquifer formation: the outcrop area, where recharge occurs, and the downdip area, where the formation falls below the land surface. Figure 4.7 shows this condition for the Trinity Aquifer in Wise County. The depth values shown in Tables 4.20 and 4.21 represent estimated average depths to the base of the formations as they occur in the given county and were used to identify the wells (by depth) that are completed through the formation. In actuality, essentially all oil and gas wells are completed to a depth below the lowermost aquifer in any county and so few wells were eliminated based on the depth criteria. For this reason, the percentage of oil and gas wells in a county that penetrate any given freshwater aquifer tends to reflect the areal extent of that aquifer within the county.

\subsubsection{DRASTIC Regions}

DRASTIC refers to an aquifer vulnerability indexing system developed by the National Water Well Association (Aller et al., 1987). The system is used to assess the relative groundwater pollution potential of a region based on hydrogeologic setting. The acronym DRASTIC is derived from the seven parameters that are used to establish the hydrogeologic setting and compute the DRASTIC index:

Depth to water

Recharge

Aquifer media

Soil type

Topography

Impact of vadose zone

Conductivity (hydraulic)

The DRASTIC index is arrived at by summing the products of a rating (based on value or type) and a relative parameter weight for each parameter:

DRASTIC index $=D_{r} D_{W}+R_{r} R_{W}+A_{r} A_{W}+S_{r} S_{W}+T_{r} T_{W}+I_{r} I_{W}+C_{r} C_{W}$ 
Table 4.20. Drilling sites versus freshwater aquifer regions.

\begin{tabular}{|c|c|c|c|c|c|c|c|c|c|}
\hline \multicolumn{10}{|c|}{ Brazoria County } \\
\hline \multirow[b]{2}{*}{ Aquifer Formation 1} & \multirow[b]{2}{*}{ Occurance } & \multirow{2}{*}{\begin{tabular}{|c|}
$\%$ Total \\
Sfc. Area 2
\end{tabular}} & \multirow{2}{*}{$\begin{array}{l}\text { Depth (ft below } \\
\text { land surface) } 3\end{array}$} & \multicolumn{2}{|c|}{1988} & \multicolumn{2}{|c|}{1990} & \multicolumn{2}{|c|}{1992} \\
\hline & & & & \# Wells & $\%$ of Total & \# Welis & $\%$ of Total & \# Wells & $\%$ of Total \\
\hline Gulf Coast & outcrop & 99 & 1500 & 55 & 100 & 33 & 92 & 17 & 94 \\
\hline \multicolumn{10}{|c|}{ Ector County } \\
\hline \multirow[b]{2}{*}{ Aquifer Formation 1} & \multirow[b]{2}{*}{ Occurance } & \multirow{2}{*}{\begin{tabular}{|l|}
$\%$ Total \\
Sfc. Area 2
\end{tabular}} & \multirow{2}{*}{$\begin{array}{l}\text { Depth (ft below } \\
\text { land surface) } 3\end{array}$} & \multicolumn{2}{|c|}{1988} & \multicolumn{2}{|c|}{1990} & \multicolumn{2}{|c|}{1992} \\
\hline & & & & \#Wells & $\%$ of Total & \#Wells & $\%$ of Total & \#Wells & $\%$ of Total \\
\hline Ogallala & outcrop & 23 & 200 & 87 & 22 & 44 & 21 & 40 & 24 \\
\hline Cenozoic Alhuvium & outcrop & 20 & 200 & 28 & 7 & 38 & 18 & 36 & 22 \\
\hline Edwards Trinity & outcrop & 56 & 二 & 277 & 71 & 128 & 61 & $\overline{88}$ & 54 \\
\hline Edwards-Trinity & downdip & 23 & 400 & 87 & 22 & 44 & 21 & 40 & 24 \\
\hline Dockum & downdip & 100 & 1600 & 391 & 100 & 203 & 97 & 163 & 99 \\
\hline \multicolumn{10}{|c|}{ Lee County } \\
\hline \multirow[b]{2}{*}{ Aquifer Formation 1} & & \% Total & Depth (ft below & & 888 & & 90 & & 92 \\
\hline & Occurance & Sfc. Area 2 & land surface) 3 & \#Wells & $\%$ of Total & \# Wells & $\%$ of Total & \#Wells & \% of Total \\
\hline Sparta & outcrop & 13 & - & 1 & 1 & 0 & $\overline{0}$ & $\mathbf{0}$ & $\overline{0}$ \\
\hline Sparta & downdip & 50 & 1500 & 88 & 97 & 40 & 100 & 36 & 95 \\
\hline Queen City & outcrop & 10 & - & 2 & 2 & 0 & $\overline{0}$ & 1 & 3 \\
\hline Queen City & downdip & 70 & 2000 & 89 & 98 & 40 & 100 & 37 & 97 \\
\hline Carrizo-Wilcox & outcrop & 19 & - & 0 & $\overline{0}$ & 0 & 0 & 0 & 0 \\
\hline Carrizo-Wilcox & downdip & 80 & 2500 & 91 & 100 & 40 & 100 & 38 & 100 \\
\hline Trinity & downdip & 1 & 3500 & 0 & 0 & 0 & 0 & 0 & 0 \\
\hline & & & Moor & County & & & & & \\
\hline & & $\%$ Total & Depth (ft below & & $\overline{888}$ & & 90 & & 92 \\
\hline Aquifer Formation 1 & Occurance & Sfec. Area 2 & land surface) 3 & \#Wells & $\%$ of Total & \#Wells & $\%$ of Total & \#Wells & $\%$ of Total \\
\hline Ogallala & outcrop & 93 & 700 & 50 & 93 & 35 & 97 & 27 & 82 \\
\hline Dockum & outcrop & 1 & - & 0 & 0 & 0 & 0 & 0 & 0 \\
\hline Dockum & downdip & 39 & 800 & 11 & 20 & 5 & 14 & 20 & 61 \\
\hline & & & Panol & County & & & & & \\
\hline & & $\%$ Total & Depth (ft below & & 888 & & 990 & & 92 \\
\hline Aquifer Formation 1 & Occurance & Sfc. Area 2 & land surface) 3 & \#Wells & $\%$ of Total & \# Wells & $\%$ of Total & \# Wells & $\%$ of Total \\
\hline Carrizo-Wilcox & outcrop & 99 & - & 52 & 100 & 188 & 100 & 123 & 100 \\
\hline Carrizo-Wilcox & downdip & 1 & 600 & $\overline{0}$ & 0 & 0 & 0 & 0 & 0 \\
\hline & & & Pecor & County & & & & & \\
\hline & & $\%$ Total & Depth (ft below & & 888 & & 90 & & 92 \\
\hline Aquifer Formation 1 & Occurance & Sfc. Area 2 & land surface) 3 & \#Wells & $\%$ of Total & \#Wells & $\%$ of Total & \#Wells & $\%$ of Total \\
\hline Cenozoic Alluvium & outcrop & 21 & 700 & 26 & 19 & 41 & 41 & 15 & 18 \\
\hline Edwards Trinity & outcrop & 72 & - & 109 & 78 & 54 & 55 & 65 & 78 \\
\hline Edwards-Trinity & downdip & 14 & 900 & 7 & 5 & 23 & 23 & 10 & 12 \\
\hline Dockum & downdip & 13 & 1600 & 4 & 3 & 9 & 9 & 5 & 6 \\
\hline Rustler & downdip & 25 & 2000 & 18 & 13 & 16 & 16 & 24 & 29 \\
\hline Capitan & outcrop & 12 & 4000 & 12 & 9 & 8 & $\overline{8}$ & 6 & 7 \\
\hline & & & Wel & County & & & & & \\
\hline & & \% Total & Depth (ft below & & 888 & & 90 & & 92 \\
\hline Aquifer Formation 1 & Occurance & Sfc. Area 2 & land surface) 3 & \#Wells & $\%$ of Total & *Wells & $\%$ of Total & \#Wells & $\%$ of Total \\
\hline Gulf Coast & outcrop & 8 & 500 & $\overline{14}$ & 9 & $\overline{14}$ & 9 & 4 & 3 \\
\hline Carrizo-Wilcox & outcrop & 1 & 二 & 0 & 0 & 0 & 0 & 0 & 0 \\
\hline Carrizo-Wilcox & downdip & 54 & 3500 & 26 & 17 & 7 & 5 & 22 & 17 \\
\hline & & & se $r(t a t h$ & County & & & & & \\
\hline & & $\%$ Total & Depth (ft below & & 888 & & 90 & & 92 \\
\hline Aquifer Formation 1 & Occurance & Sfc. Area 2 & land surface) 3 & \#Wells & $\%$ of Total & *Wells & $\%$ of Total & \#Wells & $\%$ of Total \\
\hline Trinity & outcrop & 62 & $=$ & 64 & 66 & 67 & 63 & 54 & 64 \\
\hline Trinity & downdip & 26 & 500 & 17 & 18 & 27 & 25 & 14 & 17 \\
\hline
\end{tabular}

1) Aquifer formations are listed by increasing geologic age (i.e. increasing depth).

2) Percentage of total county surface area underlain by given aquifer formation.

3) Value given represents approximate depth to base of the aquifer formation or to the limit of usable water quality. 
Table 4.21. Injection, plugged, and abandoned well sites versus freshwater aquifer regions.

\begin{tabular}{|c|c|c|c|c|c|c|c|c|c|}
\hline \multicolumn{10}{|c|}{ Brazoria County } \\
\hline \multirow[b]{2}{*}{ Aquifer Formation 1} & \multirow[b]{2}{*}{ Occurance } & \multirow{2}{*}{\begin{tabular}{|c|}
$\%$ Total \\
Sfc. Area 2 \\
\end{tabular}} & \multirow{2}{*}{$\begin{array}{l}\text { Depth (ft below } \\
\text { land surface) } 3\end{array}$} & \multicolumn{2}{|c|}{ Injection } & \multicolumn{2}{|c|}{ Plugged } & \multicolumn{2}{|c|}{ Abandoned } \\
\hline & & & & \#Wells & $\%$ of Total & \#Wells & $\%$ of Total & \#Wells & $\%$ of Total \\
\hline Gulf Coast & outcrop & 99 & 1500 & 107 & 100 & 1590 & 100 & 196 & 98 \\
\hline \multicolumn{10}{|c|}{ Ector County } \\
\hline \multirow[b]{2}{*}{ Aquifer Formation 1} & \multirow[b]{2}{*}{ Occurrance } & \multirow{2}{*}{$\begin{array}{c}\% \text { Total } \\
\text { Sfc. Area } 2\end{array}$} & \multirow{2}{*}{$\begin{array}{l}\text { Depth (ft below } \\
\text { land surface) } 3\end{array}$} & \multicolumn{2}{|c|}{ Injection } & \multicolumn{2}{|c|}{ Plugged } & \multicolumn{2}{|c|}{ Abandoned } \\
\hline & & & & \#Wells & $\%$ of Total & \#Wells & $\%$ of Total & \# Wells & $\%$ of Total \\
\hline Ogallala & outcrop & 23 & 200 & 565 & 19 & 329 & 12 & 11 & 8 \\
\hline Cenozoic Alluvium & outcrop & 20 & 200 & 215 & 7 & 370 & 14 & 15 & $\overline{11}$ \\
\hline Edwards Trinity & outcrop & 56 & - & 2123 & 73 & 2001 & 74 & 105 & 80 \\
\hline Edwards-Trinity & downdip & 23 & 400 & 565 & 19 & 329 & 12 & 11 & 8 \\
\hline Dockum & downdip & 100 & 1600 & 2893 & 100 & 2696 & 100 & 131 & 100 \\
\hline \multicolumn{10}{|c|}{ Lee County. } \\
\hline \multirow[b]{2}{*}{ Aquifer Formation 1} & & \% Total & Depth (ft below & Inj & ction & Plu & gged & Aban & doned \\
\hline & Occurance & Sfc. Area 2 & land surface) 3 & \# Wells & $\%$ of Total & Wells & $\%$ of Total & \#Wells & $\%$ of Total \\
\hline Sparta & outcrop & 13 & $=$ & 0 & 0 & 9 & 2 & 7 & 5 \\
\hline Sparta & downdip & 50 & 1500 & 3 & 100 & 388 & 92 & 96 & 74 \\
\hline Queen City & outcrop & 10 & - & 0 & 0 & 15 & 4 & 19 & 15 \\
\hline Queen City & downdip & 70 & 2000 & 3 & 100 & 405 & 96 & 204 & 80 \\
\hline Carrizo-Wilcox & outcrop & 19 & - & 0 & 0 & $\mathbf{0}$ & 0 & 7 & 5 \\
\hline Carrizo-Wilcox & downdip & 80 & 2500 & 3 & 100 & 417 & 99 & 122 & 94 \\
\hline Trinity & downdip & 1 & 3500 & 0 & 0 & 0 & 0 & 0 & 0 \\
\hline & & & Moore & County & & & & & \\
\hline & & \% Total & Depth (ft below & Inj & ction & & gged & Aban & doned \\
\hline Aquifer Formation 1 & Occurance & Sfc. Area 2 & land surface) 3 & \#Wells & $\%$ of Total & \#Wells & $\%$ of Total & \#Wells & $\%$ of Total \\
\hline Ogallala & outcrop & 93 & 700 & 52 & 98 & 496 & 97 & 182 & 97 \\
\hline Dockum & outcrop & 1 & $=$ & 0 & 0 & 2 & 0 & 1 & 1 \\
\hline Dockum & downdip & 39 & 800 & 16 & 30 & 128 & 25 & 59 & 31 \\
\hline & & & Panola & County & & & & & \\
\hline & & \% Total & Depth (ft below & Ing & ction & & gged & Aban & doned \\
\hline Aquifer Formation 1 & Occurance & Sfc. Area 2 & land surface) 3 & \#Wells & $\%$ of Total & \#Wells & $\%$ of Total & $\#$ Wells & $\%$ of Total \\
\hline Carrizo-Wilcox & outcrop & 99 & $=$ & 31 & 100 & 494 & 100 & 76 & 100 \\
\hline Carrizo-Wilcox & downdip & 1 & 600 & 0 & 0 & 1 & 0 & 0 & 0 \\
\hline & & & Pecos & County & & & & & \\
\hline & & \% Total & Depth (ft below & Inj & ction & & gged & Aban & doned \\
\hline Aquifer Formation 1 & Occurance & Sfc. Area 2 & land surface) 3 & \#Wells & $\%$ of Total & "Wells & $\%$ of Total & \#Wells & $\%$ of Total \\
\hline Cenozoic Alluvium & outcrop & 21 & 700 & 278 & 30 & 856 & 32 & 115 & 35 \\
\hline Edwards Trinity & outerop & 72 & - & 613 & 65 & 1641 & 61 & 175 & 53 \\
\hline Edwards-Trinity & downdip & 14 & 900 & 71 & 8 & 374 & 14 & 45 & 14 \\
\hline Dockum & downdip & 13 & 1600 & 27 & 3 & 142 & 5 & 15 & 5 \\
\hline Rustler & downdip & 25 & 2000 & 60 & 6 & 254 & 9 & 39 & $\overline{12}$ \\
\hline Capitan & outcrop & 12 & 4000 & 93 & 10 & 353 & 13 & 42 & 13 \\
\hline & & & Webb & County & & & & & \\
\hline & & $\%$ Total & Depth (ft below & Inj & ction & & gged & Abar & doned \\
\hline Aquifer Formation 1 & Occurance & Sfc. Area 2 & land surface) 3 & \#Wells & $\%$ of Total & "Wells & \% of Total & \#Wells & $\%$ of Total \\
\hline Gulf Coast & outcrop & 8 & 500 & 51 & 61 & 986 & 56 & 53 & 25 \\
\hline Carrizo-Wilcox & outcrop & 1 & $=$ & 0 & 0 & 0 & 0 & 0 & 0 \\
\hline Carrizo-Wilcox & downdip & 54 & 3500 & 4 & 5 & 228 & 13 & 75 & 36 \\
\hline & & & Wise & county & & & & & \\
\hline & & \% Total & Depth (ft below & & ction & & gged & Aban & doned \\
\hline Aquifer Formation 1 & Occurance & Sfc. Area 2 & land surface) 3 & *Wells & $\%$ of Total & \#Wells & $\%$ of Total & \#Wells & $\%$ of Total \\
\hline Trinity & outcrop & 62 & - & 36 & 84 & 682 & 80 & 104 & 68 \\
\hline Trinity & downdip & 26 & 500 & 0 & 0 & 80 & 9 & 36 & 24 \\
\hline
\end{tabular}




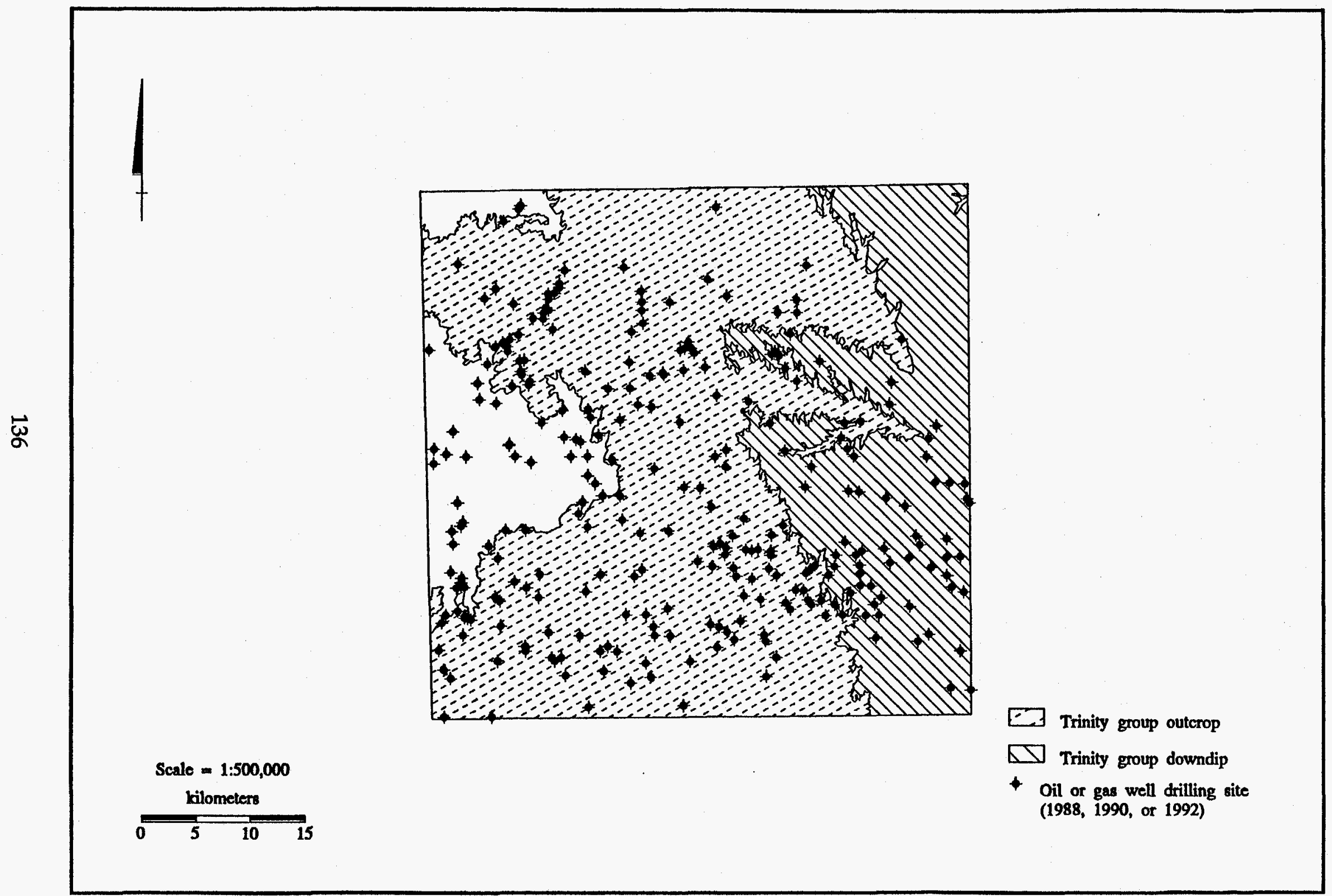

Figure 4.7. Drilling sites versus freshwater aquifer regions in Wise County. 
where the subscript $r$ refers to a rating and the subscript $w$ refers to a parameter weight. A DRASTIC index number has no intrinsic meaning, but is used in comparison with other index values to develop a relative ranking of regions. DRASTIC index numbers range from 65 to 223 for all typical hydrogeologic settings; the higher the number, the greater the groundwater pollution potential.

The EPA employed the DRASTIC system in order to estimate the hydrogeologic parameters necessary for risk assessment modeling in their 1985 study, though no DRASTIC index values were computed. Instead, a set of hydrogeologic settings was defined using 3 of the DRASTIC parameters (depth to groundwater, conductivity, and recharge) combined with 8 different flow field settings (defined by groundwater velocity and aquifer thickness). A distribution of hydrogeologic settings was developed for each EPA exploration and production zone as well as for the nation as a whole.

Because the DRASTIC system represents a widely accepted and very efficient means of assessing the potential for groundwater pollution resulting from accidental spills, leaking pipelines and tanks, and the land disposal of wastes in pits and landfills, an analysis of DRASTIC regions was adopted for inclusion in this study. Using DRASTIC, all of the important parameters that contribute to aquifer vulnerability can be assessed jointly rather than individually.

The DRASTIC regions within the state of Texas have been previously delineated and mapped by the Texas Water Commission (1989). The available map separates the regions according to a range of DRASTIC index values:
$<65$
$65-79$
$80-94$
95- 109
$110-124$
$125-139$
$140-154$
$>154$ 
A hardcopy version of this map was digitize in-house to develop the necessary ARC/INFO coverage for analysis. Table 4.22 shows the number of drilling sites located within each DRASTIC region for each of the 8 counties. Table 4.23 shows the same type of information for injection, plugged, and abandoned wells. Most of the counties analyzed are comprised of hydrogeologic regions that equate to the lower end of the DRASTIC index scale. Only a small percentage of the total surface area of the 8 counties (about $3 \%$ ) is characterized as having a DRASTIC index above the lower $1 / 3$ of the DRASTIC index scale. Consequently, only a correspondingly small percentage of the total drilling sites for the three years examined (about $4 \%$ ) and total injection, plugged, and abandoned wells (about $0.4 \%, 3 \%$, and $4 \%$ respectively) are located in the regions of highest vulnerability (DRASTIC index above 125). Figure 4.8 shows the relationship between drilling sites and DRASTIC regions in Panola County

In order to make a comparison between the distribution of hydrogeologic settings generated in this study (as defined by the DRASTIC index) and the distribution of settings developed by the EPA, the parameter values used to define the EPA settings (depth to groundwater, permeability, and net recharge) were combined with generic data for each of the counties (Table 4.24) to compute an estimated DRASTIC number for each EPA setting in each county (Tables 4.25 and 4.26). A different table was computed for drilling sites and for injection/plugged/abandoned well sites because the EPA defined the depth to groundwater differently for drilling sites and production sites. Also, two DRASTIC values were computed for Pecos County because a radical distinction exists between two general hydrogeologic settings in that county.

Using Brazoria County as an example, the EPA hydrogeologic variable values associated with a drilling site hydrogeologic setting consisting of shallow groundwater $(6.1 \mathrm{~m})$, high permeability $\left(10^{-2} \mathrm{~cm} / \mathrm{s}\right)$, and low net recharge ( $\left.1 \mathrm{in} / \mathrm{yr}\right)$ were combined with the Brazoria County generic parameter values from Table 4.24 for the remaining DRASTIC parameters (i.e. sand and gravel aquifer media, clay loam soil type, $0-2 \%$ 
Table 4.22. Drilling sites versus DRASTIC regions.

\begin{tabular}{|c|c|c|c|c|c|c|c|c|}
\hline \multicolumn{9}{|c|}{ Brazoria County } \\
\hline \multicolumn{2}{|c|}{ DRASTIC Index Range } & \multirow{2}{*}{$\begin{array}{c}\% \text { Total } \\
\text { Area }\end{array}$} & \multicolumn{2}{|c|}{1988} & \multicolumn{2}{|c|}{1990} & \multicolumn{2}{|c|}{1992} \\
\hline Low & High & & \#Wells & $\%$ of Total & \# Wells & $\%$ of Total & \#Wells & $\%$ of Total \\
\hline & 64 & & & & & & & \\
\hline 65 & 79 & & & & & & & \\
\hline 80 & 94 & & & & & & & \\
\hline 95 & 109 & 44 & 28 & 51 & 25 & 69 & 8 & 44 \\
\hline 110 & 124 & 47 & 22 & 40 & 8 & 22 & 8 & 44 \\
\hline 125 & 139 & 9 & 5 & 9 & 3 & 8 & 2 & 11 \\
\hline 140 & 154 & & & & & & & \\
\hline \multicolumn{9}{|l|}{155} \\
\hline \multicolumn{3}{|c|}{ Total Completions } & 55 & & 36 & & 18 & \\
\hline \multicolumn{9}{|c|}{ Ector County } \\
\hline \multicolumn{2}{|c|}{ DRASTIC Index Range } & $\%$ Total & \multicolumn{2}{|c|}{1988} & \multicolumn{2}{|c|}{1990} & \multicolumn{2}{|c|}{1992} \\
\hline \multirow[t]{2}{*}{ Low } & High & Area & \# Wells & $\%$ of Total & \#Wells & $\%$ of Total & \#Wells & $\%$ of Total \\
\hline & 64 & & & & & & & \\
\hline 65 & 79 & & & & & & & \\
\hline 80 & 94 & 29 & 98 & 25 & 64 & 30 & 46 & 28 \\
\hline 95 & 109 & 26 & 28 & 7 & 40 & 19 & 49 & 30 \\
\hline 110 & 124 & 46 & 266 & 68 & 106 & 50 & 69 & 42 \\
\hline 125 & 139 & & & & & & & \\
\hline 140 & 154 & & & & & & & \\
\hline \multicolumn{9}{|l|}{155} \\
\hline \multicolumn{3}{|c|}{ Total Completions } & 392 & & 210 & & 164 & \\
\hline \multicolumn{9}{|c|}{ Lee County } \\
\hline \multicolumn{2}{|c|}{ DRASTIC Index Range } & $\%$ Total & \multicolumn{2}{|c|}{1988} & \multicolumn{2}{|c|}{1990} & \multicolumn{2}{|c|}{1992} \\
\hline Low & High & Area & \# Wells & $\%$ of Total & \#Wells & $\%$ of Total & \#Wells & $\%$ of Total \\
\hline & 64 & & & & & & & \\
\hline 65 & 79 & & & & & & & \\
\hline 80 & 94 & 16 & 38 & 42 & 9 & 23 & 3 & 8 \\
\hline 95 & 109 & 14 & 7 & 8 & 11 & 28 & 7 & 18 \\
\hline 110 & 124 & 65 & 42 & 46 & 19 & 48 & 25 & 66 \\
\hline 125 & 139 & & & & & & & \\
\hline 140 & 154 & 5 & 4 & 4 & 1 & 3 & 3 & 8 \\
\hline 155 & & $<1$ & 0 & 0 & 0 & 0 & 0 & 0 \\
\hline Total Co & tions & & 91 & & 40 & & 38 & \\
\hline & & & & Ioore Count & & & & \\
\hline DRASTI & ex Range & $\%$ Total & & 88 & & 90 & & 92 \\
\hline Low & High & Area & \#Wells & $\%$ of Total & \#Wells & $\%$ of Total & \# Wells & $\%$ of Total \\
\hline & 64 & & & & & & & \\
\hline 65 & 79 & 9 & 2 & 4 & 1 & 3 & 7 & 21 \\
\hline 80 & 94 & 91 & 52 & 96 & 35 & 97 & 26 & 79 \\
\hline 95 & 109 & & 7 & & & & & \\
\hline 110 & 124 & & & & & & & \\
\hline 125 & 139 & & & & & & & \\
\hline 140 & 154 & & & & & & & \\
\hline 155 & & & & & & & & \\
\hline Total Co & tions & & 54 & & 36 & & 33 & \\
\hline
\end{tabular}


Table 4.22 continued. Drilling sites versus DRASTIC regions.

\begin{tabular}{|c|c|c|c|c|c|c|c|c|}
\hline \multicolumn{9}{|c|}{ Panola County } \\
\hline \multicolumn{2}{|c|}{ DRASTIC Index Range } & \multirow{2}{*}{$\begin{array}{c}\% \text { Total } \\
\text { Area }\end{array}$} & \multicolumn{2}{|c|}{1988} & \multicolumn{2}{|c|}{1990} & \multicolumn{2}{|c|}{1992} \\
\hline Low & High & & \# Wells & $\%$ of Total & \# Wells & $\%$ of Total & \# Wells & $\%$ of Total \\
\hline & 64 & & & & & & & \\
\hline 65 & 79 & & & & & & & \\
\hline 80 & 94 & & & & & & & \\
\hline 95 & 109 & 56 & 19 & 37 & 110 & 59 & 96 & 78 \\
\hline 110 & 124 & 21 & 11 & 21 & 36 & 19 & 8 & 7 \\
\hline 125 & 139 & 23 & 22 & 42 & 42 & 22 & 19 & 15 \\
\hline 140 & 154 & & & & & & & \\
\hline \multicolumn{9}{|l|}{155} \\
\hline \multicolumn{3}{|c|}{ Total Completions } & 52 & & 188 & & 123 & \\
\hline \multicolumn{9}{|c|}{ Pecos County } \\
\hline \multicolumn{2}{|c|}{ DRASTIC Index Range } & $\%$ Total & \multicolumn{2}{|c|}{1988} & \multicolumn{2}{|c|}{1990} & \multicolumn{2}{|c|}{1992} \\
\hline \multirow[t]{2}{*}{ Low } & High & Area & \#Wells & $\%$ of Total & \# Wells & $\%$ of Total & \# Wells & $\%$ of Total \\
\hline & 64 & & & & & & & \\
\hline 65 & 79 & $<1$ & 0 & 0 & 0 & 0 & 0 & $\mathbf{0}$ \\
\hline 80 & 94 & 14 & 5 & 4 & 5 & 5 & 1 & 1 \\
\hline 95 & 109 & 82 & 130 & 94 & 88 & 89 & 79 & 95 \\
\hline 110 & 124 & 4 & 1 & 1 & 0 & 0 & 0 & 0 \\
\hline 125 & 139 & 1 & 3 & 2 & 6 & 6 & 3 & 4 \\
\hline 140 & 154 & & & & & & & \\
\hline \multicolumn{9}{|l|}{155} \\
\hline \multicolumn{3}{|c|}{ Total Completions } & 139 & & 99 & & 83 & \\
\hline \multicolumn{9}{|c|}{ Webb County } \\
\hline \multicolumn{2}{|c|}{ DRASTIC Index Range } & $\%$ Total & \multicolumn{2}{|c|}{1988} & \multicolumn{2}{|c|}{1990} & \multicolumn{2}{|c|}{1992} \\
\hline Low & High & Area & \#Wells & $\%$ of Total & \# Wells & $\%$ of Total & \# Wells & $\%$ of Total \\
\hline & 64 & 1 & 1 & 1 & 3 & 2 & 2 & 2 \\
\hline 65 & 79 & 65 & 78 & 52 & 77 & 51 & 69 & 53 \\
\hline 80 & 94 & 29 & 52 & 34 & 63 & 42 & 55 & 42 \\
\hline 95 & 109 & & & & & & & \\
\hline 110 & 124 & 4 & 20 & 13 & 7 & 5 & 5 & 4 \\
\hline 125 & 139 & & & & & & & \\
\hline 140 & 154 & & & & & & & \\
\hline 155 & & & & & & & & \\
\hline Total Cor & ions & & 151 & & 150 & & 131 & \\
\hline & & & & Nise Count & & & & \\
\hline DRASTIC & ex Range & $\%$ Total & & 88 & & 90 & & 92 \\
\hline Low & High & Area & \# Wells & $\%$ of Total & \# Wells & $\%$ of Total & \#Wells & $\%$ of Total \\
\hline & 64 & & & & & & & \\
\hline 65 & 79 & & & & & & & \\
\hline 80 & 94 & & & & & & & \\
\hline 95 & 109 & 100 & 97 & 100 & 106 & 100 & 84 & 100 \\
\hline 110 & 124 & $<1$ & 0 & 0 & 0 & 0 & 0 & 0 \\
\hline 125 & 239 & & & & & & & \\
\hline 140 & 154 & & & & & & & \\
\hline 155 & & & & & & & & \\
\hline Total Cor & ions & & 97 & & 106 & & 84 & \\
\hline
\end{tabular}


Table 4.23. Injection, plugged, and abandoned well sites versus DRASTIC regions.

\begin{tabular}{|c|c|c|c|c|c|c|c|c|}
\hline \multicolumn{9}{|c|}{ Brazoria County } \\
\hline \multicolumn{2}{|c|}{ DRASTIC Index Range } & \multirow{2}{*}{$\begin{array}{c}\% \text { Total } \\
\text { Area }\end{array}$} & \multicolumn{2}{|c|}{ Injection } & \multicolumn{2}{|c|}{ Plugged } & \multicolumn{2}{|c|}{ Abandoned } \\
\hline Low & High & & \# Wells & $\%$ of Total & \#Wells & $\%$ of Total & \# Wells & $\%$ of Total \\
\hline & 64 & & & & & & & \\
\hline 65 & 79 & & & & & & & \\
\hline 80 & 94 & & & & & & & \\
\hline 95 & 109 & 44 & 91 & 85 & 990 & 62 & 101 & 51 \\
\hline 110 & 124 & 47 & 13 & 12 & 548 & 34 & 84 & 42 \\
\hline 125 & 139 & 9 & 3 & 3 & 55 & 3 & 15 & 8 \\
\hline 140 & 154 & & & & & & & \\
\hline \multicolumn{9}{|l|}{155} \\
\hline \multicolumn{3}{|c|}{ Total Wells } & 107 & & 1593 & & 200 & \\
\hline \multicolumn{9}{|c|}{ Ector County } \\
\hline \multicolumn{2}{|c|}{ DRASTIC Index Range } & $\%$ Total & \multicolumn{2}{|c|}{ Injection } & \multicolumn{2}{|c|}{ Plugged } & \multicolumn{2}{|c|}{ Abandoned } \\
\hline \multirow[t]{2}{*}{ Low } & High & Area & \# Wells & $\%$ of Total & \# Wells & $\%$ of Total & \#Wells & $\%$ of Total \\
\hline & 64 & & & & & & & \\
\hline 65 & 79 & & & & & & & \\
\hline 80 & 94 & 29 & 815 & 28 & 1016 & 38 & 49 & 37 \\
\hline 95 & 109 & 26 & 247 & 9 & 470 & 17 & 17 & 13 \\
\hline 110 & 124 & 46 & 1841 & 63 & 1214 & 45 & 65 & 50 \\
\hline 125 & 139 & & & & & & & \\
\hline 140 & 154 & & & & & & & \\
\hline \multicolumn{9}{|l|}{155} \\
\hline \multicolumn{3}{|c|}{ Total Wells } & 2903 & & 2700 & & 131 & \\
\hline \multicolumn{9}{|c|}{ Lee County } \\
\hline \multicolumn{2}{|c|}{ DRASTIC Index Range } & $\%$ Total & \multicolumn{2}{|c|}{ Injection } & \multicolumn{2}{|c|}{ Plugged } & \multicolumn{2}{|c|}{ Abandoned } \\
\hline Low & High & Area & \# Wells & $\%$ of Total & \# Wells & $\%$ of Total & \# Wells & $\%$ of Total \\
\hline & 64 & & & & & & & \\
\hline 65 & 79 & & & & & & & \\
\hline 80 & 94 & 16 & 0 & 0 & 24 & 6. & 30 & 23. \\
\hline 95 & 109 & 14 & 0 & 0 & 108 & 26 & 25 & 19 \\
\hline 110 & 124 & 65 & 2 & 67 & 237 & 56 & 55 & 42 \\
\hline 125 & 139 & & & & & & & \\
\hline 140 & 154 & 5 & 1 & 33 & 51 & 12 & 20 & 15 \\
\hline 155 & & $<1$ & 0 & 0 & 0 & 0 & 0 & 0 \\
\hline Total Wel & & & 3 & & 420 & & 130 & \\
\hline & & & & loore Count & & & & \\
\hline DRASTIC & ex Range & $\%$ Total & Inje & ction & $\overline{\mathrm{Plu}}$ & gged & Abar & doned \\
\hline Low & High & Area & \# Wells & $\%$ of Total & \# Wells & $\%$ of Total & \# Wells & $\%$ of Total \\
\hline & 64 & & & & & & & \\
\hline 65 & 79 & 9 & 1 & 2 & 18 & 4 & 7 & 4 \\
\hline 80 & 94 & 91 & 52 & 98 & 493 & 96 & 181 & 96 \\
\hline 95 & 109 & & & & & & & \\
\hline 110 & 124 & & & & & & & \\
\hline 125 & 139 & & & & & & & \\
\hline 140 & 154 & & & & & & & \\
\hline 155 & & & & & & & & \\
\hline Total Wel & & & 53 & & 511 & & 188 & \\
\hline
\end{tabular}


Table 4.23 cont'd. Injection, plugged, and abandoned well sites vs. DRASTIC regions.

\begin{tabular}{|c|c|c|c|c|c|c|c|c|}
\hline \multicolumn{9}{|c|}{ Panola County } \\
\hline \multicolumn{2}{|c|}{ DRASTIC Index Range } & \multirow{2}{*}{$\begin{array}{c}\% \text { Total } \\
\text { Area }\end{array}$} & \multicolumn{2}{|c|}{ Injection } & \multicolumn{2}{|c|}{ Plugged } & \multicolumn{2}{|c|}{ Abandoned } \\
\hline Low & High & & \# Wells & $\%$ of Total & \# Wells & $\%$ of Total & \# Wells & $\%$ of Total \\
\hline & 64 & & & & & & & \\
\hline 65 & 79 & & & & & & & \\
\hline 80 & 94 & & & & & & & \\
\hline 95 & 109 & 56 & 14 & 45 & 158 & 32 & 27 & 36 \\
\hline 110 & 124 & 21 & 13 & 42 & 259 & 52 & 32 & 42 \\
\hline 125 & 139 & 23 & 4 & 13 & 78 & 16 & 17 & 22 \\
\hline 140 & 154 & & & & & & & \\
\hline \multicolumn{9}{|l|}{155} \\
\hline \multicolumn{3}{|c|}{ Total Wells } & 31 & & 495 & & 76 & \\
\hline \multicolumn{9}{|c|}{ Pecos County } \\
\hline \multicolumn{2}{|c|}{ DRASTIC Index Range } & $\%$ Total & \multicolumn{2}{|c|}{ Injection } & \multicolumn{2}{|c|}{ Plugged } & \multicolumn{2}{|c|}{ Abandoned } \\
\hline Low & High & Area & \# Wells & $\%$ of Total & \# Wells & $\%$ of Total & \# Wells & $\%$ of Total \\
\hline & 64 & & & & & & & \\
\hline 65 & 79 & $<1$ & 0 & 0 & 0 & 0 & 0 & 0 \\
\hline 80 & 94 & 14 & 5 & 1 & 90 & 3 & 13 & 4 \\
\hline 95 & 109 & 82 & 919 & 98 & 2496 & 92 & 311 & 93 \\
\hline 110 & 124 & 4 & 2 & 0 & 4 & 0 & 1 & 0 \\
\hline 125 & 139 & 1 & 10 & 1 & 112 & 4 & 8 & 2 \\
\hline 140 & 154 & & & & & & & \\
\hline \multicolumn{9}{|l|}{155} \\
\hline \multicolumn{3}{|c|}{ Total Wells } & 936 & & 2702 & & 333 & \\
\hline \multicolumn{9}{|c|}{ Webb County } \\
\hline \multicolumn{2}{|c|}{ DRASTIC Index Range } & \% Total & \multicolumn{2}{|c|}{ Injection } & \multicolumn{2}{|c|}{ Plugged } & \multicolumn{2}{|c|}{ Abandoned } \\
\hline Low & High & Area & \# Wells & $\%$ of Total & \# Wells & $\%$ of Total & \# Wells & $\%$ of Total \\
\hline & 64 & 1 & 0 & 0 & 60 & 3 & 27 & 13 \\
\hline 65 & 79 & 65 & 30 & 36 & 559 & 32 & 90 & 43 \\
\hline 80 & 94 & 29 & 54 & 64 & 1103 & 63 & 75 & 36 \\
\hline 95 & 109 & & & & & & & \\
\hline 110 & 124 & 4 & 0 & 0 & 37 & 2 & 19 & 9 \\
\hline 125 & 139 & & & & & & & \\
\hline 140 & 154 & & & & & & & \\
\hline \multicolumn{9}{|l|}{155} \\
\hline Total We & & & 84 & & 1759 & & 211 & \\
\hline & & & & Nise Count & & & & \\
\hline DRASTIC & ex Range & $\%$ Total & Inj & ction & Plu & gged & Abar & doned \\
\hline Low & High & Area & \# Wells & $\%$ of Total & \# Wells & $\%$ of Total & \# Wells & $\%$ of Total \\
\hline & 64 & & & & & & & \\
\hline 65 & 79 & & & & & & & \\
\hline 80 & 94 & & & & & & & . \\
\hline 95 & 109 & 100 & 43 & 100 & 851 & 99 & 151 & 99 \\
\hline 110 & 124 & $<1$ & 0 & 0 & 6 & 1 & 1 & 1 \\
\hline 125 & 139 & & & & & & & \\
\hline 140 & 154 & & & & & & & \\
\hline 155 & & & & & & & & \\
\hline Total We & & & 43 & & 857 & & 152 & \\
\hline
\end{tabular}


(266I 10 '066I '886I)

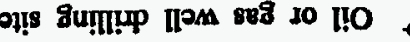

6EI - కZI = xэpuI DLLSV\&d

tZI - oII = xepuI DLSVAd EY

$60 I-\$ 6=x э p I$ JusVyd
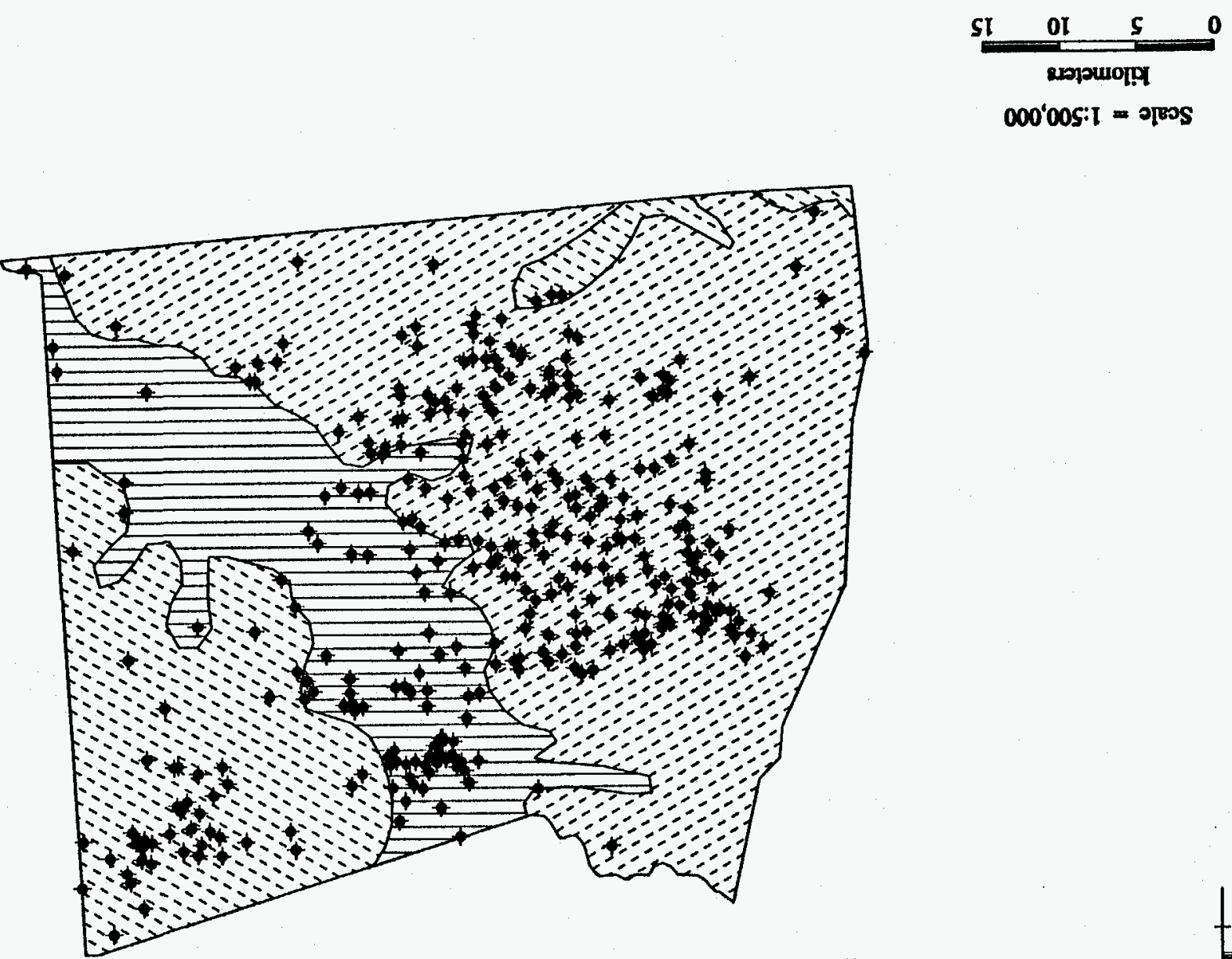
Table 4.24. Generic DRASTIC parameter values.

\begin{tabular}{|l|c|c|c|c|}
\hline \multicolumn{1}{|c|}{ County } & $\begin{array}{c}\text { Aquifer } \\
\text { Media }\end{array}$ & Soil Type & $\begin{array}{c}\text { Topography } \\
\text { (Slope) }\end{array}$ & $\begin{array}{c}\text { Impact of } \\
\text { Vadose Zone }\end{array}$ \\
\hline Brazoria & Sand \& Gravel & Clay Loam & $0-2 \%$ & Sand \& Gravel \\
\hline Ector & Sand \& Gravel & Sandy Loam & $0-2 \%$ & Sand \& Gravel \\
\hline Lee & Sand \& Gravel & Loam & $2-6 \%$ & Sand \& Gravel \\
\hline Moore & Sand \& Gravel & Loam & $2-6 \%$ & Sand \& Gravel \\
\hline Panola & Sand \& Gravel & Loam & $0-2 \%$ & Sand \& Gravel \\
\hline Pecos & & & & \\
\hline \multicolumn{1}{|c|}{ Mountains } & Sand \& Gravel & Gravel & $6-12 \%$ & Sand \& Gravel \\
\hline \multicolumn{1}{|c|}{ Uplands } & Sand \& Gravel & Loam & $0-2 \%$ & Sand \& Gravel \\
\hline Webb & Sand \& Gravel & Clay Loam & $2-6 \%$ & Sand \& Gravel \\
\hline Wise & Sand \& Gravel & Loam & $2-6 \%$ & Sand \& Gravel \\
\hline
\end{tabular}

ground slope, and vadose zone impact consistent with a sand and gravel aquifer) to compute an estimated DRASTIC index number for this EPA hydrogeologic setting in Brazoria County (i.e. 131 (Table 4.25)). This was done for all 12 EPA hydrogeologic settings in each of the 8 counties. Once the DRASTIC index numbers were computed, the EPA settings for each county were grouped by DRASTIC number according to the index ranges used by the Texas Water Commission. For example, referring to the Brazoria County column in Table 4.25, the shallow/high/low setting (DRASTIC index $=131$ ) was grouped together with the deep/high/medium setting (index $=139$ ), the $\mathrm{deep} /$ low $/$ medium setting (index $=130$ ), and the deep/low $/$ high setting (index $=134$ ) in the 125 - 139 DRASTIC index category. The EPA-developed setting distribution values were similarly grouped. For Brazoria County in the 125 - 139 index category, this grouping resulted in the following summations:

$$
\begin{array}{ll}
\text { zone } 7 \text { distribution: } & 0+0+0+0=0 \\
\text { nationwide distribution: } & 0+0+6+0=6
\end{array}
$$

Thus, the hydrogeologic settings distributions developed by EPA would predict that $0 \%$ by the zone 7 distribution, or $6 \%$ by the nationwide distribution, of drilling sites in Brazoria County would be located in a setting defined by a DRASTIC index of $125-139$. The actual distribution of drilling sites located in a setting of DRASTIC index 125 - 139 in Brazoria County is $9 \%$ (Table 4.27 ). 
Table 4.25. Estimated DRASTIC index numbers using EPA hydrogeologic settings for drilling sites.

\begin{tabular}{|c|c|c|c|c|c|c|c|c|c|c|c|}
\hline \multirow{3}{*}{$\begin{array}{c}\text { EPA } \\
\begin{array}{c}\text { Hydrogeologic } \\
\text { Setting* }\end{array} \\
\end{array}$} & \multicolumn{9}{|c|}{ Estimated DRASTIC Index Based on EPA Hydrogeologic Setting \& County-Specific Data } & \multicolumn{2}{|c|}{ \% Distribution of Seltings $f$} \\
\hline & & & & & & $\mathrm{Pec}$ & & & & & \\
\hline & Brazoria & Ector & Lee & Moore & Panola & Mountain & Uplands & Webb & Wise & $\mathrm{EPA}$-Zone 7 & Nationwide \\
\hline $\begin{array}{l}\text { Shallow } \\
\text { High } \\
\text { Low }\end{array}$ & 131 & 137 & 134 & 134 & 135 & 140 & 135 & 130 & 134 & 0 & 0 \\
\hline $\begin{array}{l}\text { Shallow } \\
\text { High } \\
\text { Medium }\end{array}$ & 159 & 165 & 162 & 162 & 163 & 168 & 163 & 158 & 162 & 2 & 5 \\
\hline \begin{tabular}{|l|} 
Shallow \\
High \\
High \\
\end{tabular} & 163 & 169 & 166 & 166 & 167 & 172 & 167 & 162 & 166 & 9 & 10 \\
\hline \begin{tabular}{|l} 
Shallow \\
Low \\
Low \\
\end{tabular} & 122 & 128 & 125 & 125 & 126 & 131 & 126 & 121 & 125 & 0 & 0 \\
\hline \begin{tabular}{|l} 
Shallow \\
Low \\
Medium \\
\end{tabular} & 150 & 156 & 153 & 153 & 154 & 159 & 154 & 149 & 153 & 70 & 53 \\
\hline \begin{tabular}{|l|} 
Shallow \\
Low \\
High \\
\end{tabular} & 154 & 160 & 157 & 157 & 158 & 163 & 158 & 153 & 157 & 0 & 1 \\
\hline $\begin{array}{l}\text { Deep } \\
\text { High } \\
\text { Low } \\
\end{array}$ & 111 & 117 & 114 & 114 & 115 & 120 & 115 & 110 & 114 & 16 & 15 \\
\hline \begin{tabular}{|l} 
Deep \\
High \\
Medium \\
\end{tabular} & 139 & 145 & 142 & 142 & 143 & 148 & 143 & 138 & 142 & 0 & 0 \\
\hline $\begin{array}{l}\text { Deep } \\
\text { High } \\
\text { High }\end{array}$ & 143 & 149 & 146 & 146 & 147 & 152 & 147 & 142 & 146 & 0 & 1 \\
\hline \begin{tabular}{|l|} 
Deep \\
Low \\
Low \\
\end{tabular} & 102 & 108 & 105 & 105 & 106 & 111 & 106 & 101 & 105 & 3 & 9 \\
\hline \begin{tabular}{|l|} 
Deep \\
Low \\
Medium \\
\end{tabular} & 130 & 136 & 133 & 133 & 134 & 139 & 134 & 129 & 133 & 0 & 6 \\
\hline \begin{tabular}{|l} 
Deep \\
Low \\
High \\
\end{tabular} & 134 & 140 & 137 & 137 & 138 & 143 & 138 & 133 & 137 & 0 & 0 \\
\hline
\end{tabular}

- In order, descriptors refer to depth to groundwater, permeability, and net recharge:

Depth to groundwater: shallow $=6.1 \mathrm{~m}$, deep $=21 \mathrm{~m}$.

Permeability: high $=10-2 \mathrm{~cm} / \mathrm{s}$, low $=10-7 \mathrm{~cm} / \mathrm{s}$.

Net recharge: $\mathrm{low}=1 \mathrm{in} / \mathrm{yr}$, medium $=10 \mathrm{in} / \mathrm{yr}$, high $=20 \mathrm{in} / \mathrm{yr}$.

+ Includes all LLM flow fields. 
Table 4.26. Estimated DRASTIC index numbers using EPA hydrogeologic settings for production sites.

\begin{tabular}{|c|c|c|c|c|c|c|c|c|c|c|c|}
\hline EPA & Estimat & DRAS & Index & sed on $\mathrm{E}$ & A Hydro & Seologic Se & ting \& $\mathrm{Cov}$ & thy-Spe & Data & $\%$ Distributio & of Settings t \\
\hline $\begin{array}{c}\text { Hydrogeologic } \\
\text { Setting }\end{array}$ & Brazoria & Ector & Lee & Moore & Panola & $\begin{array}{r}\mathrm{Pe} \\
\text { Mountain } \\
\end{array}$ & $\begin{array}{l}\text { Os } \\
\text { Uplands }\end{array}$ & Webb & Wise & EPA - Zone 7 & Nationwide \\
\hline $\begin{array}{l}\text { Shallow } \\
\text { High } \\
\text { Low }\end{array}$ & 141 & 147 & 144 & 144 & 145 & 150 & 145 & 140 & 144 & 0 & 0 \\
\hline $\begin{array}{l}\text { Shallow } \\
\text { High } \\
\text { Medium }\end{array}$ & 169 & 175 & 172 & 172 & 173 & 178 & 173 & 168 & 172 & 0 & 0 \\
\hline $\begin{array}{l}\text { Shallow } \\
\text { High } \\
\text { High }\end{array}$ & 173 & 179 & 176 & 176 & 177 & 182 & 177 & 172 & 176 & 19 & 16 \\
\hline $\begin{array}{l}\text { Shallow } \\
\text { Low } \\
\text { Low }\end{array}$ & 132 & 138 & 135 & 135 & 136 & 141 & 136 & 131 & 135 & 0 & 0 \\
\hline $\begin{array}{l}\text { Shallow } \\
\text { Low } \\
\text { Medium }\end{array}$ & 160 & 166 & 163 & 163 & 164 & 169 & 164 & 159 & 163 & 29 & 22 \\
\hline $\begin{array}{l}\text { Shallow } \\
\text { Low } \\
\text { High } \\
\end{array}$ & 164 & 170 & 167 & 167 & 168 & 173 & 168 & 163 & 167 & 1 & 15 \\
\hline $\begin{array}{l}\text { Deep } \\
\text { High } \\
\text { Low }\end{array}$ & 111 & 117 & 114 & 114 & 115 & 120 & 115 & 110 & 114 & 49 & 40 \\
\hline $\begin{array}{l}\text { Deep } \\
\text { High } \\
\text { Medium }\end{array}$ & 139 & 145 & 142 & 142 & 143 & 148 & 143 & 138 & 142 & 0 & 0 \\
\hline $\begin{array}{l}\text { Deep } \\
\text { High } \\
\text { High }\end{array}$ & 143 & 149 & 146 & 146 & 147 & 152 & 147 & 142 & 146 & 0 & 0 \\
\hline $\begin{array}{l}\text { Deep } \\
\text { Low } \\
\text { Low }\end{array}$ & 102 & 108 & 105 & 105 & 106 & 111 & 106 & 101 & 105 & 1 & 4 \\
\hline $\begin{array}{l}\text { Deep } \\
\text { Low } \\
\text { Medium }\end{array}$ & 130 & 136 & 133 & 133. & 134 & 139 & 134 & 129 & 133 & 1 & 3 \\
\hline $\begin{array}{l}\text { Deep } \\
\text { Low } \\
\text { High }\end{array}$ & 134 & 140 & 137 & 137 & 138 & 143 & 138 & 133 & 137 & 0 & 0 \\
\hline
\end{tabular}

- In order, descriptors refer to depth to groundwater, permeability, and net recharge:

Depth to groundwater: shallow $=4.6 \mathrm{~m}$, deep $=18 \mathrm{~m}$.

Permeability: high $=10-2 \mathrm{~cm} / \mathrm{s}$, low $=10-7 \mathrm{~cm} / \mathrm{s}$.

Net recharge: low $=1 \mathrm{in} / \mathrm{yr}$, medium $=10 \mathrm{in} / \mathrm{yr}$, high $=20 \mathrm{in} / \mathrm{yr}$.

tIncludes all LLM flow fields. 
Table 4.27. Comparison of DRASTIC region distributions for drilling sites.

\begin{tabular}{|c|c|c|c|c|c|c|c|c|c|c|}
\hline \multicolumn{2}{|c|}{ DRASTIC Index Range } & \multicolumn{3}{|c|}{ Brazoria } & \multicolumn{3}{|c|}{ Ector } & \multicolumn{3}{|c|}{ Lee } \\
\hline Low & High & This Study & EPA - Zone 7 & Nationwide & This Study & EPA - Zone 7 & Nationwide & This Study & EPA - Zone 7 & Nationwide \\
\hline & 64 & & & & & & & & & \\
\hline 65 & 79 & & & & & & & & & \\
\hline 80 & 94 & & & & 27 & & & 29 & & \\
\hline 95 & 109 & 56 & 3 & 9 & 15 & 3 & 9 & 15 & 3 & 9 \\
\hline 110 & 124 & 35 & 16 & 15 & 58 & 16 & 15 & 51 & 16 & 15 \\
\hline 125 & 139 & 9 & $\mathbf{0}$ & 6 & & 0 & 6 & $\mathbf{0}$ & 0 & 6 \\
\hline 140 & 154 & & 70 & 55 & & $\mathbf{0}$ & 1 & 5 & 70 & 54 \\
\hline 155 & & & 11 & 15 & & 81 & 69 & & 11 & 16 \\
\hline
\end{tabular}

\begin{tabular}{|c|c|c|c|c|c|c|c|c|c|c|}
\hline \multicolumn{2}{|c|}{ DRASTIC Index Range } & \multicolumn{3}{|c|}{ Moore } & \multicolumn{3}{|c|}{ Panola } & \multicolumn{3}{|c|}{ Webb } \\
\hline Low & High & This Study & EPA - Zone 7 & Nationwide & This Study & EPA - Zone 7 & Nationwide & This Study & EPA - Zone 7 & Nationwide \\
\hline & 64 & & & & & & & 1 & & \\
\hline 65 & 79 & 8 & & & & & & 52 & & \\
\hline 80 & 94 & 92 & & & & & & 39 & & \\
\hline 95 & 109 & & 3 & 9 & 62 & 3 & 9 & 0 & 3 & 9 \\
\hline 110 & 124 & & 16 & 15 & 15 & 16 & 15 & 8 & 16 & 15 \\
\hline 125 & 139 & & 0 & 6 & 23 & 0 & 6 & & $\mathbf{0}$ & 6 \\
\hline 140 & 154 & & 70 & 54 & & 70 & 54 & & 70 & 55 \\
\hline 155 & & & 11 & 16 & & 11 & 16 & & 11 & 15 \\
\hline
\end{tabular}

\begin{tabular}{|c|c|c|c|c|c|c|c|c|c|c|}
\hline \multicolumn{2}{|c|}{ DRASTIC Index Range } & \multicolumn{3}{|c|}{ Pecos - Mountains } & \multicolumn{3}{|c|}{ Pecos - Uplands } & \multicolumn{3}{|c|}{ Wise } \\
\hline Low & High & This Study & EPA - Zone 7 & \begin{tabular}{|l|} 
Nationwide \\
\end{tabular} & This Study & EPA - Zone 7 & Nationwide & This Study & EPA - Zone 7 & Nationwide \\
\hline & 64 & & & & & & & & & \\
\hline 65 & 79 & & & & & & & & & \\
\hline 80 & 94 & 3 & & & 3 & & & & & \\
\hline 95 & 109 & 93 & & & 93 & 3 & 9 & 100 & 3 & 9 \\
\hline 110 & 124 & 0 & 19 & 24 & 0 & 16 & 15 & & 16 & 15 \\
\hline 125 & 139 & 4 & 0 & 6 & 4 & 0 & 6 & & 0 & 6 \\
\hline 140 & 154 & & 0 & 1 & & 70 & 54 & & 70 & 54 \\
\hline 155 & & & 81 & 69 & & 11 & 16 & & 11 & 16 \\
\hline
\end{tabular}


The EPA zone 7 and nationwide hydrogeologic setting distributions were recombined according to the newly computed DRASTIC index numbers for each county to conform to the DRASTIC index ranges used by the Texas Water Commission. Table 4.27 compares the computed EPA DRASTIC distributions with the distributions developed in this study for drilling sites while Table 4.28 makes the comparison for injection well sites. Note that in both cases, the EPA distributions point to much higher aquifer vulnerability than the county-specific distributions developed in this study. None of the counties are well represented by either the zone 7 or the nationwide hydrogeologic settings distributions for drilling sites or production sites.

\subsubsection{Floodplains}

Oil and gas drilling and production activities that occur in areas subject to occasional or frequent flooding are of particular environmental concern due to the increased risk of waste constituents entering the runoff stream, particularly at sites where waste disposal pits may be inundated. For this reason, an assessment of the relative number of drilling sites and injection, plugged, and abandoned well sites that are located within designated floodplain areas was completed as part of this study. Floodplain maps of the 8 counties were requested from the Federal Emergency Management Agency (FEMA). County-wide maps are available for 5 of the counties only; 3 of the counties (Moore, Panola, and Pecos) are not mapped and therefore no analysis was performed on these counties. Rather than attempt to digitize all 225 of the individual maps, only the general index maps were digitized for each county. These index maps depict just the larger flood hazard zones but were considered to be suitable for this analysis. Tables 4.29 and 4.30 show the results.

In 4 of the 5 counties analyzed, approximately $5-15 \%$ of the annual oil and gas well drilling occurs within floodplain areas. For Brazoria County, however, this percentage is much higher ( $50-70 \%)$ owing to the floodprone coastal physiography of 
Table 4.28. Comparison of DRASTIC region distributions for injection (production) well sites.

\begin{tabular}{|c|c|c|c|c|c|c|c|c|c|c|}
\hline \multicolumn{2}{|c|}{ DRASTIC Index Range } & \multicolumn{3}{|c|}{ Brazoria } & \multicolumn{3}{|c|}{ Ector } & \multicolumn{3}{|c|}{ Lee } \\
\hline Low & High & This Study & EPA - Zone 7 & Nationwide & This Study & EPA - Zone 7 & Nationwide & This Study & EPA - Zone? & Nationwide \\
\hline & 64 & & & & & & & & & \\
\hline 65 & 79 & & & & & & & & & \\
\hline 80 & 94 & & & & 28 & & & & & \\
\hline 95 & 109 & 85 & 1 & 4 & 9 & 1 & 4 & & 1 & 4 \\
\hline 110 & 124 & 12 & 49 & 40 & 63 & 49 & 40 & 67 & 49 & 40 \\
\hline 125 & 139 & 3 & 1 & 3 & & 1 & 3 & 0 & 1 & 3 \\
\hline 140 & 154 & & 0 & 0 & & 0 & 0 & 33 & 0 & 0 \\
\hline 155 & & & 49 & 53 & & 49 & 53 & & 49 & 53 \\
\hline
\end{tabular}

\begin{tabular}{|c|c|c|c|c|c|c|c|c|c|c|}
\hline \multicolumn{2}{|c|}{ DRASTIC Index Range } & \multicolumn{3}{|c|}{ Moore } & \multicolumn{3}{|c|}{ Panola } & \multicolumn{3}{|c|}{ Webb } \\
\hline Low & High & This Study & EPA - Zone 7 & Nationwide & This Study & EPA - Zone 7 & Nationwide & This Study & EPA - Zone 7 & Nationwide \\
\hline & 64 & & & & & & & & & \\
\hline 65 & 79 & 2 & & & & & & 36 & & \\
\hline 80 & 94 & 98 & & & & & & 64 & & \\
\hline 95 & 109 & & 1 & 4 & 45 & 1 & 4 & & 1 & 4 \\
\hline 110 & 124 & & 49 & 40 & 42 & 49 & 40 & & 49 & 40 \\
\hline 125 & 139 & & 1 & 3 & 13 & 1 & 3 & & 1 & 3 \\
\hline 140 & 154 & & 0 & 0 & & 0 & 0 & & 0 & 0 \\
\hline 155 & & & 49 & 53 & & 49 & 53 & & 49 & 53 \\
\hline
\end{tabular}

\begin{tabular}{|c|c|c|c|c|c|c|c|c|c|c|}
\hline \multicolumn{2}{|c|}{ DRASTIC Index Range } & \multicolumn{3}{|c|}{ Pecos - Mountains } & \multicolumn{3}{|c|}{ Pecos - Uplands } & \multicolumn{3}{|c|}{ Wise } \\
\hline Low & High & This Study & EPA - Zone 7 & Nationwide & This Study & EPA - Zone 7 & Nationwide & This Study & EPA - Zone 7 & Nationwide \\
\hline & 64 & & & & & & & & & \\
\hline 65 & 79 & & & & & & & & & \\
\hline 80 & 94 & 1 & & & 1 & & & & & \\
\hline 95 & 109 & 98 & & & 98 & 1 & 4 & 100 & 1 & 4 \\
\hline 110 & 124 & 0 & 50 & 44 & 0 & 49 & 40 & & 49 & 40 \\
\hline 125 & 139 & 1 & 1 & 3 & 1 & 1 & 3 & & 1 & 3 \\
\hline 140 & 154 & & 0 & 0 & & 0 & 0 & & 0 & 0 \\
\hline 155 & & & 49 & 53 & & 49 & 53 & & 49 & 53 \\
\hline
\end{tabular}


the county (Figure 4.9). In Brazoria County, nearly $50 \%$ of the plugged and abandoned wells are located within the floodplain though a smaller percentage of injection wells $(22 \%)$ are so located.

Table 4.29. Drilling sites located within floodplain areas.

\begin{tabular}{|l|c|c|c|c|c|c|}
\hline \multirow{2}{*}{ County } & \multicolumn{2}{|c|}{1988} & \multicolumn{2}{c|}{1990} & \multicolumn{2}{c|}{1992} \\
\cline { 2 - 8 } & \# Wells & $\%$ of Total & \#Wells & $\%$ of Total & \# Wells & $\%$ of Total \\
\hline Brazoria & 28 & 51 & 17 & 47 & 12 & 67 \\
\hline Ector & 18 & 5 & 9 & 4 & 11 & 7 \\
\hline Lee & 2 & 2 & 6 & 15 & 2 & 5 \\
\hline Moore & - & - & - & - & - & - \\
\hline Panola & - & - & - & - & - & - \\
\hline Pecos & - & - & - & - & - & - \\
\hline Webb & 6 & 4 & 16 & 11 & 12 & 9 \\
\hline Wise & 10 & 10 & 16 & 15 & 15 & 18 \\
\hline
\end{tabular}

Table 4.30. Injection, plugged, and abandoned well sites within floodplain areas.

\begin{tabular}{|l|c|c|c|c|c|c|}
\hline \multirow{2}{*}{ County } & \multicolumn{2}{c|}{ Injection } & \multicolumn{2}{c|}{ Plugged } & \multicolumn{2}{c|}{ Abandoned } \\
\cline { 2 - 8 } & \# Wells & $\%$ of Total & \# Wells & $\%$ of Total & \# Wells & $\%$ of Total \\
\hline Brazoria & 24 & 22 & 708 & 44 & 96 & 48 \\
\hline Ector & 117 & 4 & 110 & 4 & 2 & 2 \\
\hline Lee & 0 & 0 & 56 & 13 & 27 & 21 \\
\hline Moore & - & - & - & - & - & - \\
\hline Panola & - & - & - & - & - & - \\
\hline Pecos & - & - & - & - & - & - \\
\hline Webb & 4 & 5 & 69 & 4 & 18 & 9 \\
\hline Wise & 3 & 7 & 46 & 5 & 17 & 11 \\
\hline
\end{tabular}

\subsubsection{Wetlands}

Wetlands, along with endangered and threatened species habitats, national forests, and national parks, were among the sensitive environments examined by the EPA as part of their qualitative risk assessment of oil and gas activities. As noted in the report (U.S.EPA, 1987b):

Although the proximity of oil and gas exploration, development, and production activities to sensitive environments is not an explicit criteria 


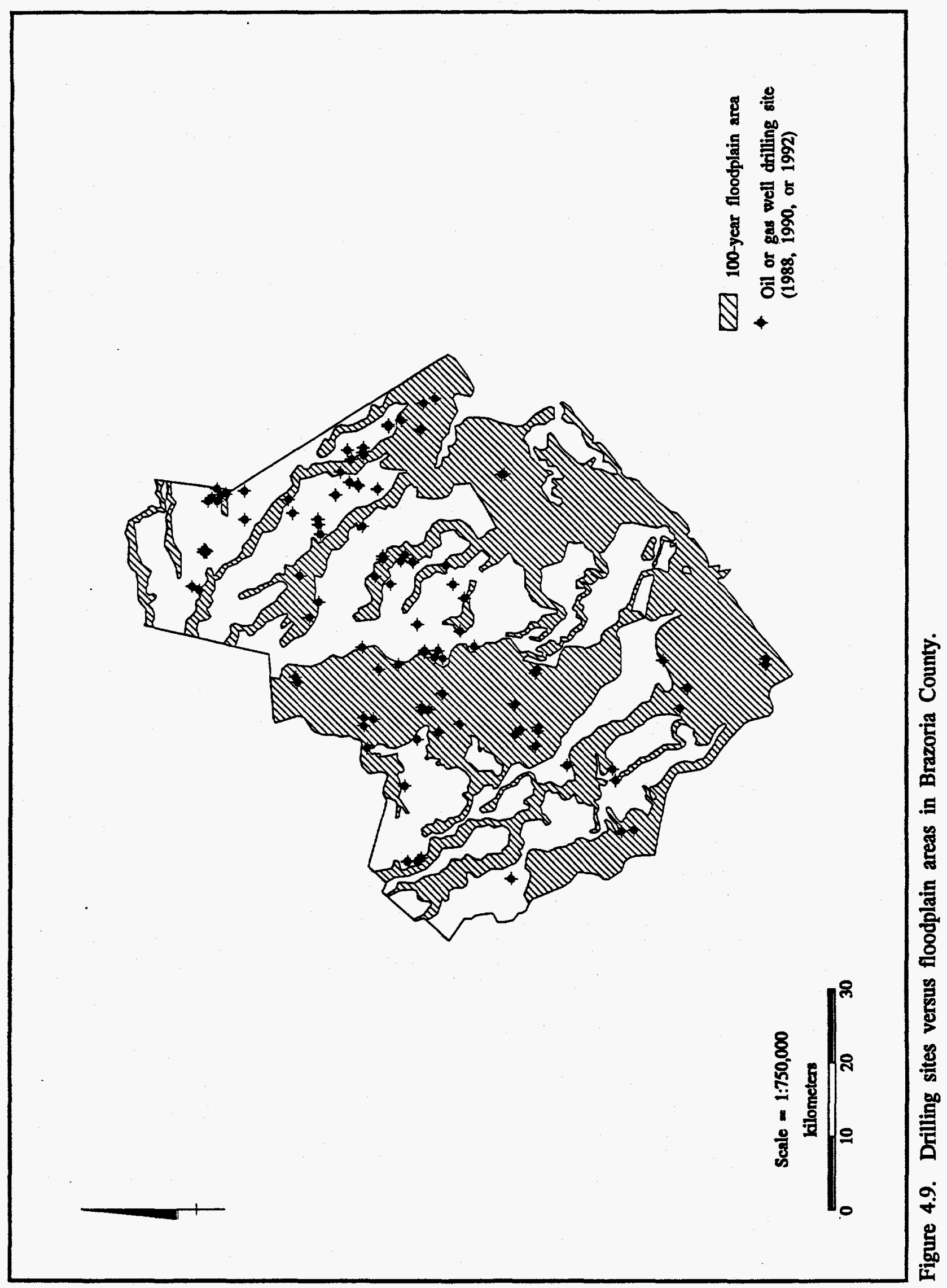


for designating oil and gas wastes as hazardous, the potential impact to sensitive environments is an important consideration in evaluating the environmental risks of wastes from oil and gas operations.

Because the EPA study was national in scope, a quantitative assessment of the volume of drilling and production activity that occurred within wetland areas was impractical. Instead, a qualitative assessment of the potential overlap of oil and gas activities and wetlands was carried out by measuring the percentage of wetland areas depicted on the set of USGS quadrangle maps used to represent typical drilling and production sites (see Section 2.1.2). The results showed little potential for overlap in Texas ( $3 \%$ wetland areas on the quad maps examined) with a somewhat larger potential nationwide ( $21 \%$ wetland areas).

The U.S. Fish and Wildlife Service has an ongoing wetlands mapping program known as the National Wetlands Inventory. Detailed wetlands maps are being produced for the entire U.S. and some of these maps are currently available in digital format. Unfortunately, only a small fraction of the maps needed to cover the 8 counties evaluated in this study are among the digital maps available. After some consideration, it was determined that the hardcopy maps were far too numerous (some 300 quad sheets are required to cover the 8 counties) and too detailed to make digitizing feasible. The next best alternative for identifying wetland areas was to use the USGS landuse/landcover coverages already on-hand.

Referring to Tables 4.8 and 4.9 (pg 107-111), note that, among the 8 counties, only Brazoria County has an appreciable quantity of delineated wetlands. Additionally, only Brazoria, Ector, and Panola Counties appear to have any oil and gas activities occurring within wetland areas. Even with a significant percentage of the county characterized as wetland, only one drill site in Brazoria County was located within a wetland area in the years examined. Meanwhile, Panola County, with a much lower proportion of wetland areas, had two drill sites located within wetlands (Figure 4.10). No drilling activity 


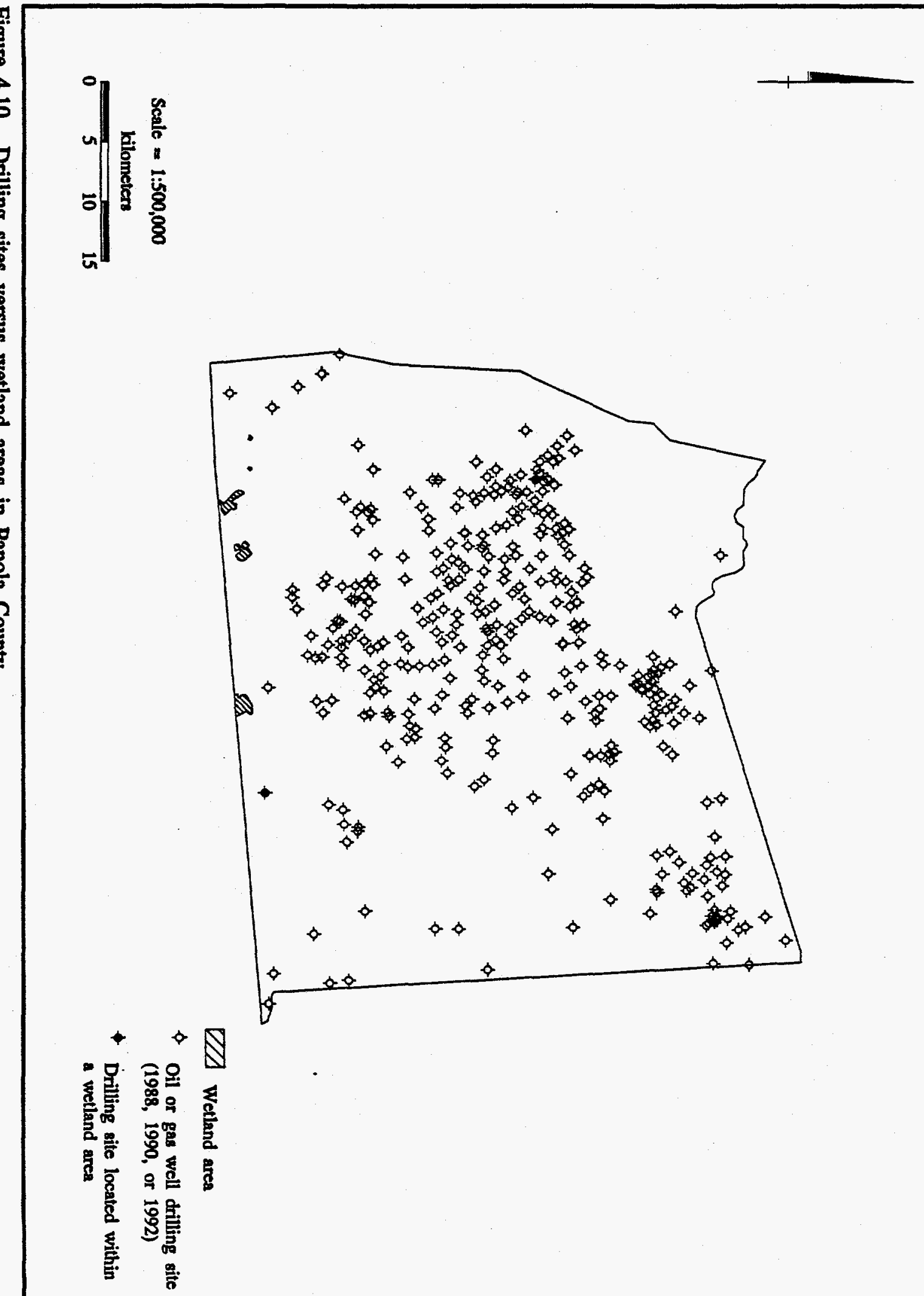


occurred within wetland areas in Ector County in the three years examined, however, one injection well site is located within a designated wetland area in that county. Several of the counties (Brazoria, Lee, Moore, and Wise) do have a few plugged and abandoned wells located within wetland areas. These wells act as potential sources of brine seepage.

\subsubsection{Parklands}

State and national parklands and wildlife management areas represent an additional class of sensitive environments that are potentially affected by oil and gas activities. The EPA found in their 1985 risk assessment that approximately $27 \%$ of the National Forest System's 191 million acres and approximately $4 \%$ of the National Park System's 80 million acres were at that time under lease for oil and gas drilling and production (U.S. EPA, 1987b). The state of Texas has relatively few national forests, but the large number of National Park System units within the state having oil and gas activity within their boundaries led the EPA to suggest that, compared with other states, sensitive environments in Texas are at relatively higher levels of risk.

With information from the Texas Parks and Wildlife Service, parklands and wildlife management areas within each of the 8 counties were identified and their boundaries digitized from state maps. Three of the counties, Ector, Panola, and Pecos, have no designated state or national parks within their boundaries. For the other 5 counties, an analysis of the volume of drilling activity and of the number of injection, plugged, and abandoned wells that are located within park or wildlife management area boundaries was completed. The results are shown in Tables 4.31 and 4.32. Lee, Moore, and Webb Counties have no oil and gas drilling activities within park boundaries. Brazoria County has limited activity within the San Bernard National Wildlife Refuge. Likewise, a limited amount of drilling activity did occur within the bounds of the Lyndon B. Johnson National Grassland in Wise County in each of the 
three years examined (Figure 4.11). Four of the 5 counties with parkland areas have some plugged or abandoned wells located within park boundaries, though only Wise County has any injection wells located within a park (Figure 4.11).

Table 4.31. Drilling sites within parklands.

\begin{tabular}{|l|c|c|c|c|c|c|l|}
\hline \multirow{2}{*}{ County } & \multicolumn{2}{|c|}{1988} & \multicolumn{2}{c|}{1990} & \multicolumn{2}{|c|}{1992} & \multirow{2}{*}{ Notes } \\
\cline { 2 - 8 } \# Wells & \% of Total & \#Wells & $\%$ of Total & \#Wells & $\%$ of Total & \multicolumn{1}{|c|}{} \\
\hline Brazoria & 1 & 2 & 0 & 0 & 1 & 6 & $\begin{array}{l}\text { San Bernard National } \\
\text { Wildlife Refuge }\end{array}$ \\
\hline Ector & - & - & - & - & - & - & no parklands \\
\hline Lee & 0 & 0 & 0 & 0 & 0 & 0 & \\
\hline Moore & 0 & 0 & 0 & 0 & 0 & 0 & \\
\hline Panola & - & - & - & - & - & - & no parklands \\
\hline Wecos & - & - & - & - & - & - & no parklands \\
\hline Wise & 0 & 0 & 0 & 0 & 0 & 0 & \\
\hline
\end{tabular}

Table 4.32. Injection, plugged, and abandoned well sites within parklands.

\begin{tabular}{|c|c|c|c|c|c|c|c|}
\hline \multirow[b]{2}{*}{ County } & \multicolumn{2}{|c|}{ Injection } & \multicolumn{2}{|c|}{ Plugged } & \multicolumn{2}{|c|}{ Abandoned } & \multirow[b]{2}{*}{ Notes } \\
\hline & \#Wells & $\%$ of Total & \#Wells & $\%$ of Total & \# Wells & $\%$ of Total & \\
\hline & 0 & 0 & 5 & $<1$ & 4 & 2 & $\begin{array}{l}\text { Brazoria National } \\
\text { Wildlife Refuge }\end{array}$ \\
\hline Brazoria & 0 & 0 & 5 & $<1$ & 2 & 1 & $\begin{array}{l}\text { San Bernard National } \\
\text { Wildlife Refuge }\end{array}$ \\
\hline Ector & $=$ & - & - & - & 二 & - & no parklands \\
\hline Lee & 0 & 0 & 1 & $<1$ & 0 & 0 & Nails Creek Park \\
\hline Moore & 0 & 0 & 8 & 2 & 3 & 2 & $\begin{array}{l}\text { Sanford Recreational } \\
\text { Area - Lake Meredith }\end{array}$ \\
\hline Panola & - & - & - & - & - & - & no parklands \\
\hline Pecos & - & - & - & $=$ & - & - & no parklands \\
\hline Webb & 0 & 0 & 0 & 0 & 0 & 0 & \\
\hline Wise & 5 & 12 & 38 & 4 & 11 & 7 & $\begin{array}{l}\text { Lyndon B Johnson } \\
\text { National Grassland }\end{array}$ \\
\hline
\end{tabular}

\subsection{Summary}

An updated assessment of the annual domestic production volume of drilling waste and produced water by onshore drilling and production activity showed there to be a general decline in the volumes of drilling waste being produced over the period 1985 - 1992 as well as an apparent reduction in the volume of produced water generated 


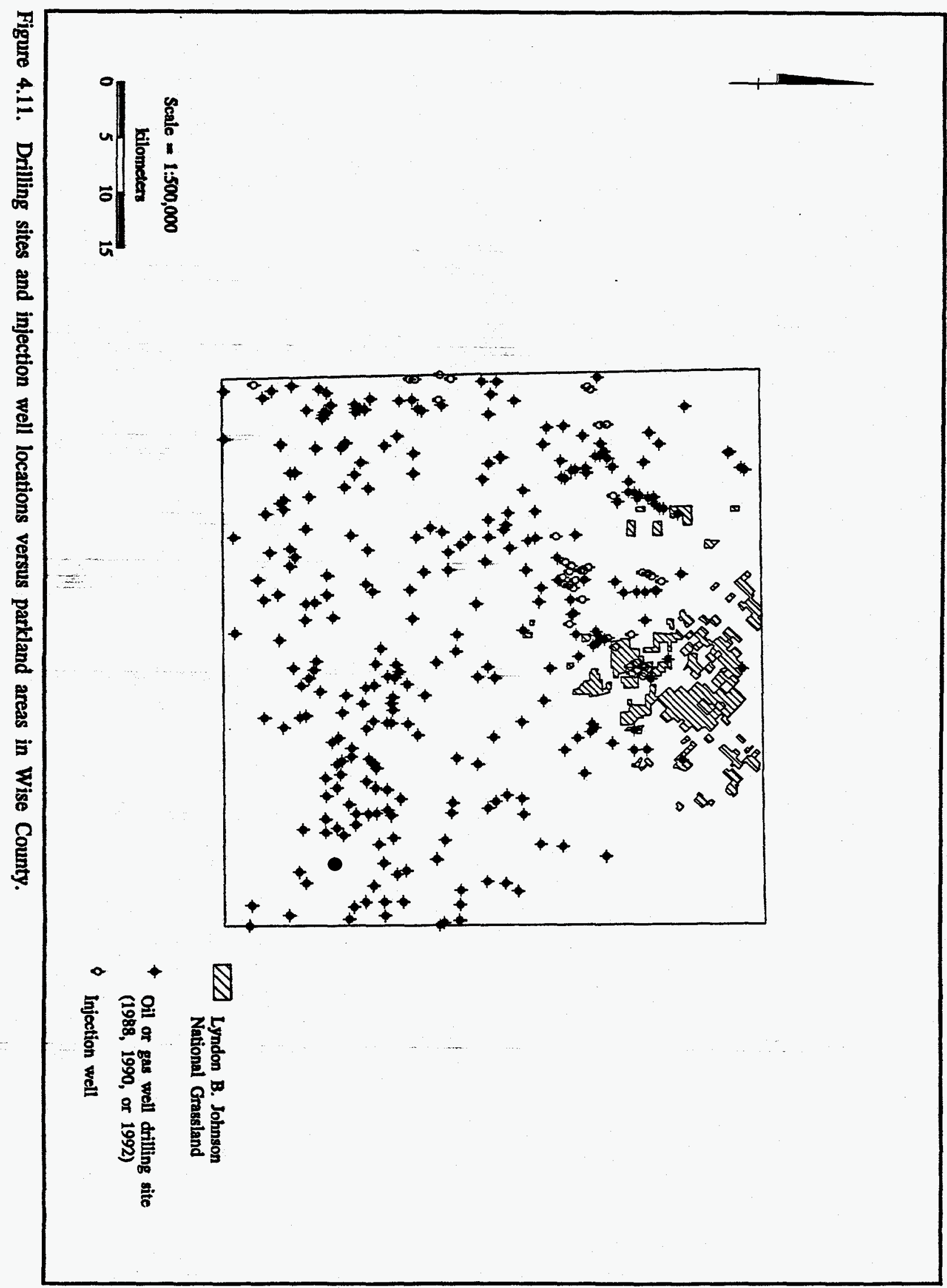


since 1986, though it is unclear whether there has been an increase or decrease in produced water volumes over 1985 levels as estimated by EPA and API. A 59\% reduction in the volume of drilling waste over 1985 levels was estimated. This reduction is tied to a reduction in the amount of drilling activity and, more closely, to a reduction in the amount of drilled footage. Current estimates show that some 150 million barrels of drilling waste and 18.3 billion barrels of produced water are being generated annually.

An analysis of the environmental settings surrounding oil and gas activities in $\mathbf{8}$ Texas counties showed that local conditions can be far different from those described by the EPA in their nationwide study and used in their risk assessment. In the counties examined, oil and gas drilling sites and injection, plugged, and abandoned well sites were generally found to be nearer to surface water features and farther from water supply wells than estimated by EPA in their nationwide analysis. Despite being distributed farther from water supply wells, however, the number of domestic and public supply wells in close proximity to oil and gas activities was found to be surprisingly high in several counties including Brazoria, Ector, Lee, Panola, Webb, and Wise. The DRASTIC indices representing hydrogeologic settings surrounding oil and gas activities in the 8 counties generally point to lower aquifer vulnerability than suggested by the EPA settings.

By placing the environmental settings data in a Geographical Information System, the relationships between oil and gas drilling and production activities and surrounding features can be quickly assessed and the scale of potential impacts can be readily quantified. In addition, drilling sites or injection well sites that pose a particular risk can be identified and singled out for more rigorous environmental control. Likewise, abandoned wells can be prioritized for plugging according to the relative level of risk defined by surrounding features. These are among the potential uses of the PED. 


\subsection{EVALUATION OF TECHNOLOGIES AND COSTS FOR PRODUCED WATER TREATMENT}

\subsection{Introduction}

This portion of the study investigates the treatment of produced waters generated during the exploration for and the production of crude oil and natural gas. This chapter includes the characterization of produced water with respect to quality and an assessment of the technical and the economic feasibility of using a wide range of technologies to achieve various levels of treated water quality. The quality of a produced water was judged by quantifying the amounts of material present in four different categories of produced water contaminants. These categories are: 1) particulate and emulsified materials, 2) volatile organic compounds, 3) adsorbable organic materials, and 4) dissolved inorganic constituents. Treatment processes were selected for evaluation based on their ability to remove contaminants in one of these four categories. A list of the produced water constituents that were used in the characterization of individual waters was given previously in Table 1.4.

Processes that potentially could be used to remove undesirable produced water constituents were evaluated. Several key processes were selected and further evaluated in order to determine produced water treatment efficiency. Treatment scenarios describing the necessity and order of these processes were created, including the requisite pretreatment of process influent streams and treatment process effluent requirements.

\subsection{Liquid/Solid Separation}

\subsubsection{Evaluation Methodology}

Liquid/solid separation is term that is generally applied to processes used for the removal of particulate materials. Processes for liquid/solid separation will remove not 
only particulate matter itself, but contaminants associated with particulate material. For example, heavy metals in produced water are often sorbed to the suspended solids in the water and will thus be removed along with these solids. Also, emulsified hydrocarbons may be removed. Package or "off the shelf" technologies are likely to be most appropriate for the low flow rates encountered in produced water treatment. These package plants are standard, commercial technologies that consist of unit processes for chemical addition, initial mixing, flocculation, settling, and dual media or diatomaceous earth filters. The cost of these units typically scales as a function of the treated water flow.

Package treatment plant costs are made up of three main components: capital costs, operation and maintenance costs, and residual waste stream management costs (usually treated as additional operating costs). Additional capital investments for residual waste disposal may also be required. In this study, the costs provided by Gumerman et al. (1979) were used to estimate both the capital and operations and maintenance costs for a package plant. Gumerman et al. (1979) provides package plant treatment costs based on the design flow rate of the waste stream. For the analysis of package plants, the rates of flow that are most representative of produced water flow regimes observed in oil fields were divided by a sizing factor of 0.7 . This sizing factor allows for the accommodation of fluctuations in the waste stream flow rate. The produced water flows evaluated, after correction by the sizing factor, were approximately equal to $0.0144,0.144$, and $1.44 \operatorname{MGD}\left(54.5,545\right.$, and $\left.5450 \mathrm{~m}^{3} / \mathrm{d}\right)$. These flow rates are common rates of produced water flow for small, medium, and large oil fields respectively.

The cost of each of the plants that could treat produced waters flowing at the two lower flow rates (0.0144 MGD and 0.144 MGD) are given by Gumerman et al. (1979). The cost of the package plant that would be necessary to treat the largest rate of produced water flow (1.44 MGD) was determined by multiplying the cost for building 
and operating the maximum capacity plant evaluated by Gumerman et al. (1.08 MGD) by a factor of 1.33 . The capital costs for this type of treatment plant as well as all other capital costs referred to in this study are assumed to be debt. This debt is amortized by multiplying it by a capitol recovery factor as defined in Section 1.5.3.

In liquid/solid separation, the principal residual waste stream results from sludges generated by settling, backwash operations, and PAC addition. The sludge handling and disposal costs typically include the costs of thickening, drying, and land filling the sludge. In some cases, some or all of these handling and disposal processes may be combined or eliminated. The method of analysis used to evaluate the handling of sludge is described in Section 5.2.2.

The chemical costs associated with liquid/solid separation were calculated by multiplying a coagulant dosage of alum or ferric sulfate at 200 and $60 \mathrm{mg} / \mathrm{L}$, respectively by the unit cost for each chemical. These doses were selected based on the typical range used in waste water treatment. The assumption made is that the average conditions represented by these doses will result in adequate removal of suspended solids and some of the associated contaminants found in produced waters. For systems smaller than 1 MGD, the prices used for alum and ferric sulfate were 500 and 200 dollars per ton respectively. These prices drop to 250 and 155 dollars per ton for systems treating waste streams processing a rate of flow greater than 1 MGD. The cost of feeding the chemicals into the waste stream, including the capital, and operation and maintenance costs of the chemical feed systems, is included in the estimate of the package treatment plant cost and therefore was not estimated separately.

Tables 5.1, 5.2, and 5.3 describe all of the component cost equations that contribute to the total average cost for the treatment of produced waters to remove particulates and emulsified materials. Capital, operating, and residual disposal costs computed using the equations given in these tables were added to the chemical costs 
Table 5.3. Cost equations for sand drying bed. From Gumerman et al. (1979).

\begin{tabular}{|c|c|c|}
\hline \multicolumn{1}{|c|}{$\begin{array}{c}\text { Capital Cost } \\
\left(\$ / \mathrm{m}^{3}\right)\end{array}$} & $\begin{array}{c}\text { Operation and Maintenance Cost } \\
\left(\$ / \mathrm{m}^{3}\right)\end{array}$ & $\begin{array}{c}\text { Disposal } \\
\text { Cost }\left(\$ / \mathrm{m}^{3}\right)\end{array}$ \\
\hline$\frac{4540+35.25 A_{B}-0.000346\left(A_{B}\right)^{2}(C R F)}{Q}$ & $\frac{2.176\left(A_{B}\right)^{1.074}+5810+K}{Q}$ & $\begin{array}{l}\text { Landfill } \\
\text { dry: }\end{array}$ \\
\hline $\mathrm{A}_{\mathrm{B}}>37,200$ & $\frac{L F C(T P)}{Q}$ \\
$(1 / Q) *\left\{9080+35.25\left(A_{B}-37,200\right)-\right.$ & $(1 / Q) *\left[2.176\left[\left(A_{B}\right)^{1.074}+\right.\right.$ & $\begin{array}{l}\text { Landfill } \\
\text { wet: }\end{array}$ \\
$\left.0.000346 A_{B}{ }^{2}+\left[\left(A_{B}-37,200\right)^{2}\right] C R F\right\}$ & $\left.\left(A_{B}-37200\right)^{1.074}+11620\right]$ & $\frac{L F H(T P)}{Q}$ \\
\hline
\end{tabular}

$\mathrm{A}_{\mathrm{B}}=$ bed area $\left(\mathrm{m}^{2}\right)=\mathrm{SP} / \mathrm{DBF}$

$\mathrm{SP}=$ Sludge production $\left(\mathrm{yd}^{3} / \mathrm{yr}\right)$ (see Table 5.2)

$\mathrm{DBF}=$ drying bed flux capacity $\left(\mathrm{yd}^{3} / \mathrm{yr} / \mathrm{m}^{2}\right)$

$\mathrm{TP}=$ thickener production $=\mathrm{SP} / 2$

LFC $=$ landfill cost $\left(\$ / \mathrm{yd}^{3}\right)$

$\mathrm{LFH}=$ landfill handling cost $\left(\$ / \mathrm{yd}^{3}\right)$

$Q=$ design flow rate $\left(\mathrm{m}^{3} / \mathrm{yr}\right)$

\subsubsection{Sludge Disposal}

Sludge is generated by several of the unit processes evaluated in this study. Coagulant addition, PAC, and settled solids and oils are all sources of sludge in liquid/solid separation. Equations describing the amount of sludge that is produced during package plant operation are listed in Table 5.2. Backwash of GAC beds will also produce some amount of sludge though the volume from this source is considered to be negligible. Post filter GAC contactors may not even have to be backwashed on a regular basis because the filterable material is removed from the influent stream before it reaches the GAC bed. Any sludge that is generated must be disposed of and should be as dense and dry as possible. The costs associated with sludge disposal are a function of the disposal volume and the percentage of water contained in the sludge. All sludges must pass a specific test for dryness before being allowed in a landfill, 
which is the typical method of sludge disposal. The cost of landfilling the sludge is based on the amount of sludge to be abated. The rate per volume is generally more than tripled should the sludge not pass the dryness test.

Gravity thickening is the first unit process used to reduce the sludge volume. The equations used to size the thickeners are presented in Table 5.2. Only the waste streams with abnormally high total suspended solids (TSS) $(>1000 \mathrm{mg} / \mathrm{L})$ will require sludge thickening below a flow rate of 1 MGD $\left(3,785 \mathrm{~m}^{3} / \mathrm{d}\right)$. The factor which will dictate whether or not a thickener will be used is the required diameter of the thickener. It is not usually economically feasible to build a thickener with a diameter of less than 6 meters. Similarly the sand drying beds must have a minimum area. If the flux rate of sludge entering the thickeners or the drying beds is large, then multiple units may be constructed. If the sludge flow rate is small, the processes may not be built at all. In some cases, however, thickening and drying processes may be constructed regardless of low sludge production rates because the most cost effective method of disposing of the sludge makes this feasible. This occurs, for example, whenever the construction of the minimum sized sand drying bed would cost less per unit of treated water than the increased landfill cost for undried sludge, even though the drying bed is oversized for the amount of sludge produced.

Gumerman et al. (1979) developed the equations given in Tables 5.2 and 5.3 used to estimate the costs associated with gravity thickening and sand drying bed processes. These costs are combined with the various landfill costs which are a function of both sludge type and amount to produce a total sludge handling cost. PAC sludge, for instance, is regularly landfilled at a cost that is six times that of primary sludge. Fortunately, the amount of sludge produced by the PAC process is relatively small compared to other sludge generating processes. 


\subsubsection{Results}

The costs associated with package plant treatment vary with several parameters. The size of a package plant will control the capital costs of the plant while, at the same time, the residual waste stream management costs resulting from plant operation will vary with the initial contaminant (TSS) concentration. Figure 5.1 shows package plant treatment costs as a function of influent TSS concentrations. All produced water streams in this analysis were assumed to be treated to drinking water quality $(8 \mathrm{mg} / \mathrm{L}$ TSS effluent). Different levels of treatment were not evaluated.

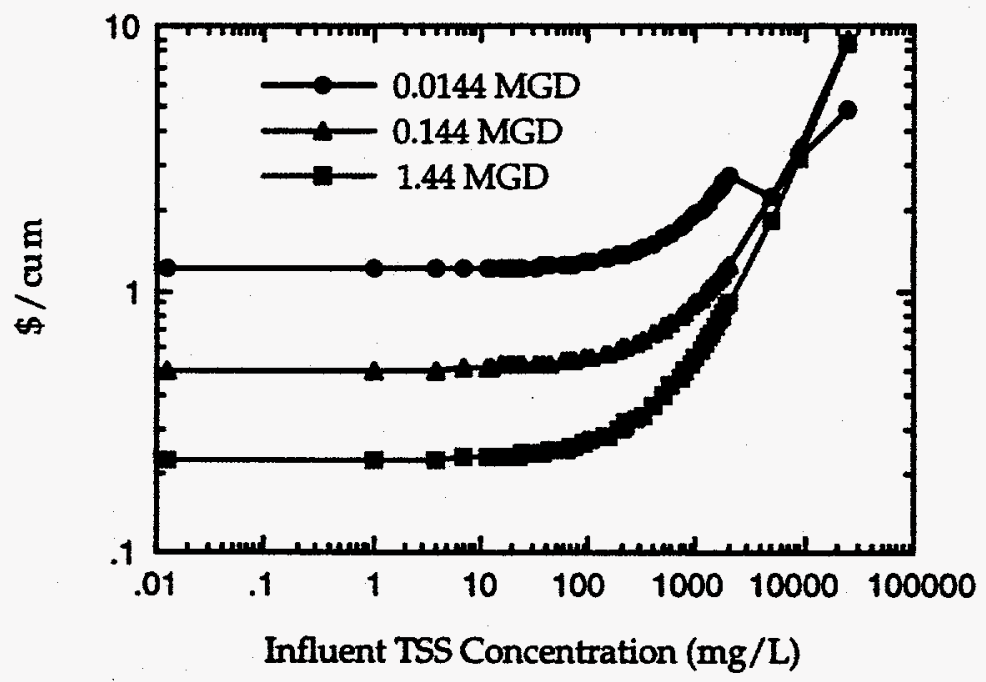

Figure 5.1. Package plant treatment costs as a function of influent TSS concentration.

In Figure 5.1, the costs of package plant treatment appear to be independent of influent TSS concentration up to about $10 \mathrm{mg} / \mathrm{L}$. Beyond this point, as the concentration of TSS in the influent increases, so does the level of treatment that must be performed on the residual waste stream (sludge) before it is disposed of. The sharp rise in unit package plant cost above an influent TSS concentration of $100 \mathrm{mg} / \mathrm{L}$ can be directly attributed to these sludge handling costs. The two sludge treatment processes, 
thickening and drying, have a large impact on costs. Thickening of the sludge is economically feasible only for the largest produced water flow rate or for waste streams having a very high TSS concentrations at lower flow rates. Sludge is assumed to undergo a $50 \%$ volume reduction when thickened. This results in a $50 \%$ reduction in landfill cost for a given waste stream when sludge thickening is used.

Sludge drying is also economically feasible only for some waste streams. The costs associated with land filling undried sludge are 3.25 times greater than those associated with dry sludge. Still, the residual waste streams generated during the treatment of produced waters at the lower rates of flow, especially those with low TSS concentrations, are not likely to be dried because the increased capital costs outweigh the reduction in disposal costs. The sharp drop in the unit cost of package plant treatment for the $0.01 \mathrm{MGD}\left(37.85 \mathrm{~m}^{3} / \mathrm{d}\right)$ waste stream which occurs at approximately $3,000 \mathrm{mg} / \mathrm{L}$ of influent TSS corresponds to the point where the use of sand drying beds becomes an economically sound choice. The use of sand drying beds reduces the unit landfill price from $\$ 29.00 / \mathrm{yd}^{3}$ to $\$ 9.00 / \mathrm{yd}^{3}$ (Gormily, 1994).

\subsection{Packed Tower Aeration}

\subsubsection{Evaluation Methodology}

Packed tower aeration, commonly referred to as air stripping, was evaluated for the removal of volatile organic compounds from produced waters. Air stripping involves the transfer of a substance from the liquid phase to the gas phase and is governed by Henry's Law which describes the equilibrium distribution of a compound between the liquid and gas phases. Organic contaminants that have Henry's Law constants greater than $1.93 \mathrm{E}-4 \mathrm{~atm}-\mathrm{m}^{3} / \mathrm{mol}$ are considered volatile and can therefore be stripped from a produced water if they are brought into contact with an adequate amount of air. This contaminant stripping occurs inside packed towers. These towers 
are filled with randomly packed inert material such as Rashig rings which promote air/water contact.

For this study, costs for the construction and operation of packed towers were taken from the work of Gumerman et al. (1979) and updated using cost indices. The equations describing cost functions used to estimate these costs are listed in Table 5.4. These costs are a function of tower volume. The tower volume can be determined using a tower design strategy described by Kavanaugh and Trussell (1980). A computer program provided by Chellam (1990) incorporating the Kavanaugh and Trussel (1980) design procedure was used to calculate the size of the packed towers evaluated in this study. The diameter and height of a packed tower, as well as the air/water ratio necessary to strip the contaminants, are a function of the Henry's Law constant for the least strippable organic contaminant present in the waste stream. The contaminant matrix of the produced water will have no discernible effect on the removal of the different volatile organic contaminants. Neither the Henry's Law constant nor the mass transfer coefficient for an individual organic contaminant are affected by other contaminants present in the waste stream to a significant degree.

Table 5.4. Cost equations for packed tower aeration. From Gumerman et al. (1979).

\begin{tabular}{|c|c|}
\hline Capital Cost $\left(\$ / \mathrm{m}^{3}\right)$ & Operation and Maintenance Cost $\left(\$ / \mathrm{m}^{3}\right)$ \\
\hline \multirow{8}{*}{$\frac{(47,258+142.2(\mathrm{TV})) \mathrm{CRF}}{\mathrm{Q}}$} & Operation: $6756+5332(T V)(F P)$ \\
\hline & $\frac{0 / 30+500.2(1 \mathrm{~V})(\mathrm{Er})}{0}$ \\
\hline & Maintenance material: \\
\hline & $259+1.123(\mathrm{TV})$ \\
\hline & $\mathbf{Q}$ \\
\hline & Labor: \\
\hline & $163.37+0.40906(\mathrm{TV}) \mathrm{LP}$ \\
\hline & $\bar{Q}$ \\
\hline \multirow{2}{*}{\multicolumn{2}{|c|}{$\begin{array}{l}\mathrm{Q}=\text { Design flow rate }=\left(\mathrm{m}^{3} / \mathrm{yr}\right) \\
\mathrm{EP}=\text { Energy cost }(\$ / \mathrm{kwh}) \\
\mathrm{LP}=\text { labor price }=\$ 15 / \mathrm{hr}\end{array}$}} \\
\hline & \\
\hline \multicolumn{2}{|l|}{$\begin{array}{l}\text { TV }=\text { Tower volume }\left(\mathrm{m}^{3}\right) \\
\mathrm{CRF}=\text { Capital recovery factor }\end{array}$} \\
\hline
\end{tabular}


A possible residual waste stream generated by packed tower aeration processes is the off gas from the tower which will contain the organic contaminants that have been removed from the treated water. Treatment of this stream was not considered in this analysis.

\subsubsection{Results}

Packed tower aeration is usually considered to be the most cost effective process for removing volatile organic contaminants from water. Capital costs, including the tower, packing material, and support for the packing material dominate total average costs for the construction and operation of this process. Energy requirements are seen to be virtually independent of flow because the air/water ratio is the same for all towers evaluated in this study (i.e. 89.4). The Chellam (1990) model, used to design the towers in this analysis, limits the variation in tower design and operation to tower size. A given Henry's Law constant will dictate the diameter of the tower and the required contaminant removal factor determines the tower height. Figure 5.2 shows the cost of treatment versus influent VOC concentration for the three evaluated flow rates. Average costs increase with decreasing flow and with increasing concentrations of VOCs in the feed.

The costs for the two smallest flow rates evaluated, 0.01 MGD and 0.1 MGD $\left(37.85\right.$ and $\left.378.5 \mathrm{~m}^{3} / \mathrm{d}\right)$, are dominated by operation and maintenance costs. The stability of the curve describing the cost of stripping VOCs from a produced water flowing at $0.01 \mathrm{MGD}\left(37.85 \mathrm{~m}^{3} / \mathrm{d}\right)$ suggests that the energy costs might be the controlling component. The larger tower volumes require more air to be pumped in order to maintain the air/water ratio for a longer period of time. These energy requirements should vary directly with the concentration level of VOCs. Construction costs, however, are subject to economies of scale. Consequently, the curves for the 
larger flow rates are not as linear as those representing costs associated with smaller rates of flow.

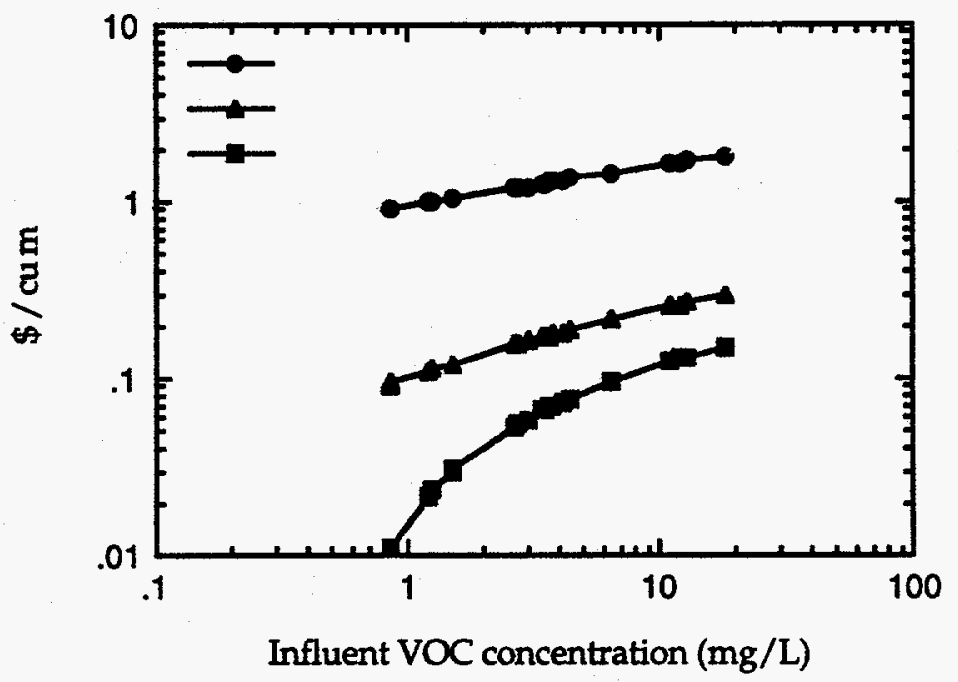

Figure 5.2. Packed tower aeration costs as a function of influent VOC concentration. Effluent concentration is equal to $0.8 \mathrm{mg} / \mathrm{L}$.

\subsection{Carbon Adsorption Processes}

\subsubsection{Evaluation Methodology}

Carbon adsorption is a well established process for the removal of organics from waters and wastewaters and involves the partitioning of a compound between the treated water and the carbon solid as described by an adsorption isotherm. While there are several models available to describe this equilibrium relationship, the empirically derived Freundlich equation is frequently used because it has been found to accurately represent much adsorption data. The Freundlich equation has the form:

$$
\mathrm{q}_{\mathrm{e}}=\mathrm{KC}_{\mathrm{e}}^{1 / \mathrm{n}}
$$

where $\mathrm{q}_{\mathrm{e}}$ (mass absorbed/mass absorbent) and $\mathrm{C}_{\mathrm{e}}$ (mass in solution/volume solution) are the equilibrium surface and solution concentrations respectively, and $\mathrm{K}$ and $\mathrm{n}$ are constants. The constant $\mathrm{K}$ is related to the capacity of the absorbent to absorb the 
compound while the constant $\mathrm{n}$ is a function of the strength of the adsorption bond. The adsorption process is influenced by a number of factors including carbon particle size and surface area, compound solubility and molecular size, and system temperature and $\mathrm{pH}$

Carbon adsorption was evaluated as the treatment option for organic materials that cannot be easily stripped (low Henry's Law constants) from produced water. In many cases, compounds of low volatility are in fact easily adsorbed as evidenced by high Freundlich coefficients. However, in some cases, weakly volatile compounds might not be considered particularly adsorbable based on determinations of their Freundlich coefficients. Indeed, there is only a weak negative correlation between Henry's Law and Freundlich constants.

For the purposes of this study, organic compounds that have Henry's Law constants higher than $1.93 \mathrm{E}-4 \mathrm{~atm}-\mathrm{m}^{3} / \mathrm{mol}$ were classified as volatile and those contaminants possessing Henry's Law constants below this level were considered to be adsorbable. The values of the Freundlich isotherm constant, $K$, for the adsorbable organic constituents found in produced waters are, on average, an order of magnitude higher than are those for the volatile compounds. Also, the average value of $1 / \mathrm{n}$ is 0.51 for the adsorbable organic contaminants while it is 0.42 for the volatile organic compounds.

The cost and performance of the PAC and GAC systems used to remove adsorbable organic compounds were compared. The two systems function on the same principles but differ in the method of contacting the carbon with the water. As the name implies, powdered activated carbon is added directly to a treatment stream in the form of a powder. After a prescribed amount of contact time, the PAC containing absorbed organics is settled out and disposed of as sludge. With GAC treatment, the carbon particles are not added to the water but are fixed within a column. Organics are adsorbed to the carbon particles as the water is passed through this column. Once the 
adsorptive capacity of the carbon in the column is reached, the carbon is removed and thermally regenerated. In this way, GAC carbon can be reused whereas PAC cannot.

Reduction of organic compounds by adsorption was evaluated in terms of the bulk reduction in total organic carbon achieved by the process. This is important to note because the performance measured in this fashion is insensitive to the specific compounds that comprise the TOC. The TOC of the raw and treated water is calculated as the sum of the mass concentrations of each of the species measured. Removal of these species, and the reduction in TOC, proceeds in order of adsorbability as reflected by the Freundlich constant of each species.

As activated carbon becomes saturated with organic compounds, the adsorptive capacity of the carbon is reduced. When the carbon capacity is exhausted, the carbon must be disposed of or regenerated. This consumption of activated carbon, termed the carbon usage rate, represents one of the principal operational costs for the adsorption process. In comparison with GAC, higher carbon usage rates and higher costs are typically encountered when PAC is used as an adsorbent (Figure 5.3). GAC contactors tend to utilize a greater percentage of the total adsorptive capacity of the activated carbon. While GAC contactors may allow for more efficient adsorption, they also entail a higher capital cost.

\subsubsection{Granular Activated Carbon}

When treating produced waters with GAC, the cost components that need to be considered are the capital costs, the operation and maintenance costs, and the cost of the carbon. The purposes of this type of treatment are best served by replacing the carbon when the carbon bed has become exhausted. In this study, the unit cost of the virgin carbon was taken as $\$ 1.10 / \mathrm{lb}$ (Calgon Corporation, 1994). This price is for carbon purchased in quantities equal to or greater than $2,000 \mathrm{lbs}$. Spent or exhausted carbon 


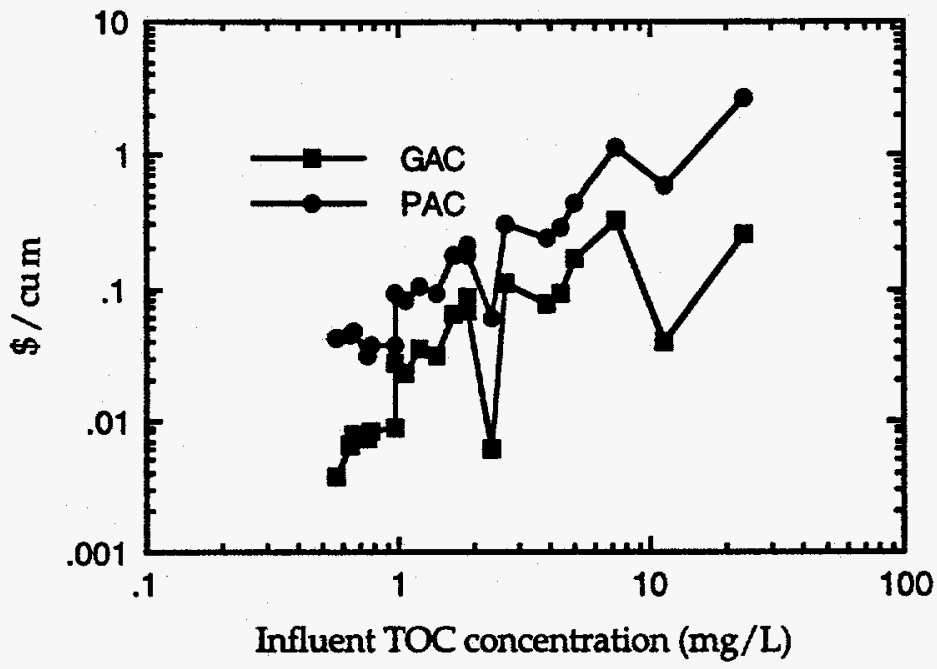

Figure 5.3. Carbon costs for powdered and granular activated carbon adsorption of organics from produced water. All waste streams treated to $0.5 \mathrm{mg} / \mathrm{L}$ TOC.

can also be replaced by regenerated carbon at a price set by the carbon supplier or it can be regenerated on site. The cost of spent carbon disposal is implicit in the supplier's price since the supplier is assumed to remove and regenerate the spent carbon. However, carbon handling losses are not included in this cost.

Equations describing the capital and operating costs of GAC systems are provided by Adams and Clark (1989). These equations are based on the cost estimating techniques of Gumerman et al. (1979). Table 5.5 lists the applicable equations.

The application (or hydraulic loading) rate for a GAC adsorption system is defined as the volume of water that can be treated per unit area per unit time. This rate is constrained by the flow characteristics of the waste stream through the carbon bed. For this study, the application rate was set at $5 \mathrm{gal} / \mathrm{min} / \mathrm{ft}^{2}\left(0.20 \mathrm{~m}^{3} / \mathrm{min} / \mathrm{m}^{2}\right)$. An empty bed contact time (i.e. hydraulic residence time) of 10 minutes was assumed for the GAC contactors. 
Table 5.5. Cost equations for GAC adsorption. From Adams and Clark (1989).

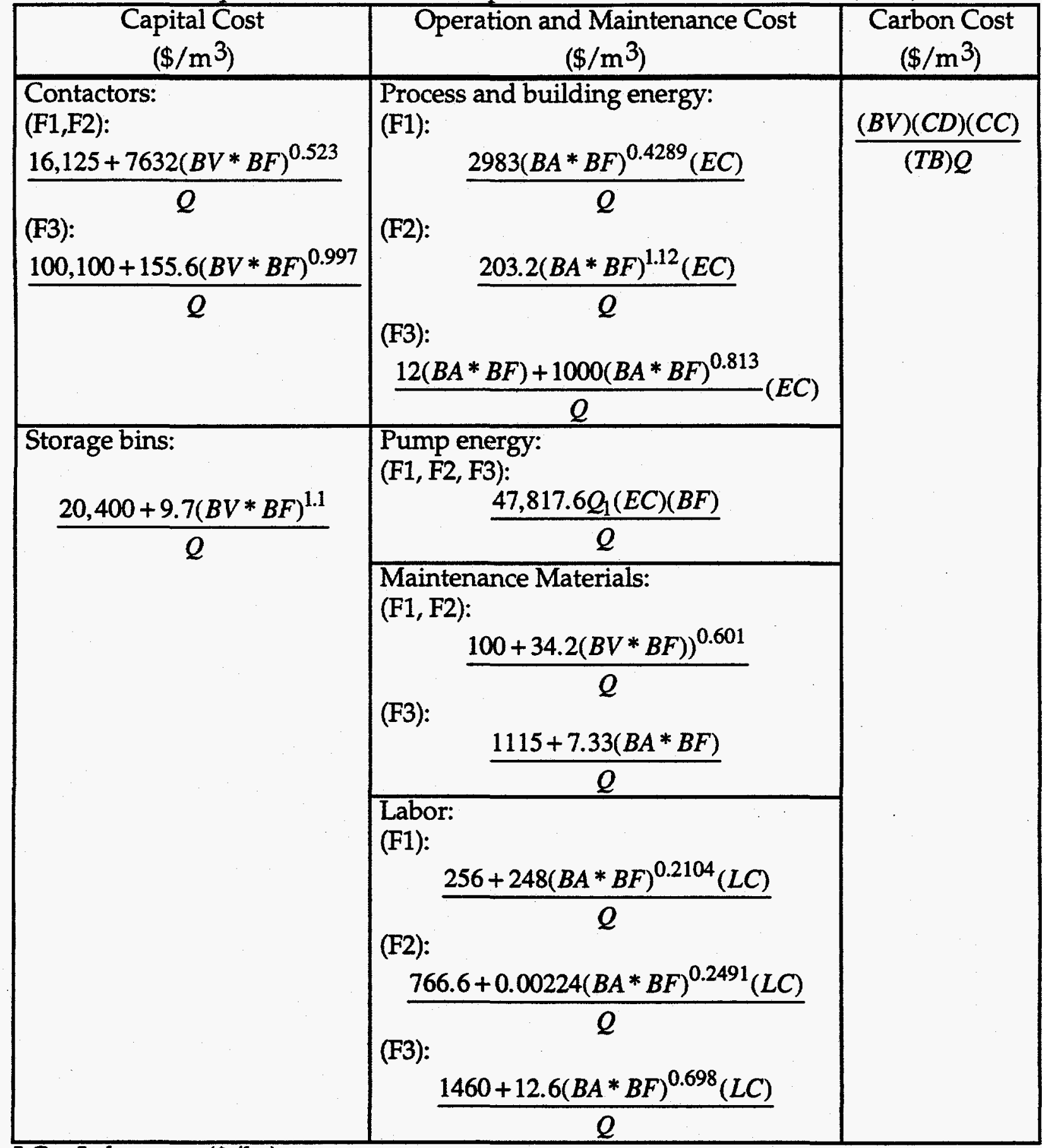

LC $=$ Labor cost $(\$ / \mathrm{hr})$

$\mathrm{EC}=$ Energy cost $(\$ / \mathrm{kwh})$

$\mathrm{BA}=$ Bed area $=\mathrm{Q} / \mathrm{A}$

$\mathrm{BV}=$ Bed volume $\left(\mathrm{ft}^{3}\right)=\mathrm{h} * \mathrm{BA}$

$\mathrm{h}=$ Bed height $(\mathrm{ft})$

$\mathrm{A}=$ Waste stream application rate $\left(\mathrm{gal} / \mathrm{ft}^{2} / \mathrm{min}\right)$

$\mathrm{Q}=$ Operating flow rate $\left(\mathrm{m}^{3} / \mathrm{yr}\right)$ 
$\mathrm{Q}_{1}=$ Operating flow rate (MGD)

$\mathrm{BF}=$ Blending factor (dimensionless)

$\mathrm{TB}=$ Time to breakthrough $(\mathrm{min})$

$\mathrm{CD}=$ Carbon density $\left(\mathrm{lb} / \mathrm{ft}^{3}\right)$

$\mathrm{CC}=$ Carbon $\cos \mathrm{(}(\$ / \mathrm{lb})$

$\mathrm{EBCT}=$ Empty bed contact time (min)

$\mathrm{CRF}=$ Capital recovery factor

F1, F2, F3 correspond to $0.01,0.1$, and 1 MGD $\left(37.85,378.5\right.$ and $\left.3,785 \mathrm{~m}^{3} / \mathrm{d}\right)$ of operating flow rate respectively.

The carbon usage is determined by multiplying the amount of carbon in the contactor by the frequency with which this amount of carbon must be replaced. The bed is assumed to be exhausted when the desired concentration of contaminant in the effluent is exceeded. The point at which this occurs is termed break-through. The contaminant concentration profile of the bed effluent can be predicted using the Homogeneous Surface Diffusion Model (HSDM) developed by Hand et al. (1984). In the HSDM, the time to break-through is calculated as the time required for the TOC in the effluent from the contactor to reach a specified level. The amount of organic contaminant that is adsorbed onto the activated carbon at equilibrium with the local solution-phase concentration must be known in order to use the HSDM.

The adsorption of individual compounds, when present in a mixture, must be considered in the context of the produced water contaminant matrix. The possible presence of at least 21 adsorbable organic compounds in produced water requires that the competition for available space on the activated carbon by each of the organic adsorbate compounds be considered. A simplified model for predicting the results of this competition is presented by Digiano et al. (1978). This model is based on the idea that if two competing organic contaminants have identical Freundlich isotherms, they behave as if there was only one contaminant in solution. This assumption is used to 
derive a formula which uses average Freundlich isotherm constants to predict quantities of compounds adsorbed to the activated carbon at equilibrium.

In some GAC applications, the untreated waste stream will be blended with portions of the treated waste stream prior to contact with the GAC bed. While smaller degrees of contaminant removal are achieved by blending, the effect is to reduce the capital costs of the system. The lower concentration of contaminant in the blended influent means that less contaminants are removed in the GAC contactor due to smaller concentration gradients and the carbon does not reach exhaustion as quickly. This allows for the design of a smaller GAC bed for a given waste stream flow rate where a lower level of treatment is acceptable.

\subsubsection{Powdered Activated Carbon}

Powdered activated carbon, rather than GAC, may be used to effect the removal of adsorbable organic compounds from produced water under certain circumstances. PAC treatment costs include capital, operation and maintenance, and carbon costs as well as the management and disposal cost for the residual, namely exhausted PAC. The capacity of the PAC is exhausted at the point when no more organic contaminant matter can be adsorbed. The exhausted or "spent" activated carbon in powdered form is not easily regenerated and must be disposed of. Residuals management costs may therefore be considerable. Prior to landfill disposal, the spent PAC must be dried in sand drying beds. When using PAC, a total of $\$ 0.005 / \mathrm{m}^{3}$ must be added to the treatment cost of produced water as the cost of drying this sludge. This cost represents the cost for drying the spent PAC generated by the waste stream with the highest PAC dosage used in this analysis.

The cost profiles for GAC and PAC (capital, operation and maintenance, and carbon) are significantly different. Since the PAC is added directly to the waste stream, there is no need for a contactor. Capital costs are therefore lower, though a small capital 
expenditure is required for the PAC feed system. Operating costs are primarily associated with carbon usage and disposal. These costs were estimated using equations found in Qasim et al. (1992) and listed in Table 5.6. These equations are again based on the cost estimating techniques of Gumerman et al. (1979).

Table 5.6. Cost equations for PAC adsorption. From Qasim et al. (1992).

\begin{tabular}{|c|c|c|c|}
\hline $\begin{array}{c}\text { Construction Cost } \\
\left(\$ / \mathrm{m}^{3}\right)\end{array}$ & $\begin{array}{c}\text { Operation \& } \\
\text { Maintenance Cost }\left(\$ / \mathrm{m}^{3}\right)\end{array}$ & $\begin{array}{c}\text { Carbon Cost } \\
\left(\$ / \mathrm{m}^{3}\right)\end{array}$ & $\begin{array}{c}\text { Disposal Cost } \\
\left(\$ / \mathrm{m}^{3}\right)\end{array}$ \\
\hline $\begin{array}{c}\text { Feed }(\mathrm{F}<1.5 \mathrm{~kg} / \mathrm{hr}) \\
8360^{*} \mathrm{CRF} / \mathrm{Q}\end{array}$ & $\begin{array}{c}\text { Feed }(\mathrm{F}<1.5 \mathrm{~kg} / \mathrm{hr}) \\
\text { Feed }(\mathrm{F}>1.5 \mathrm{~kg} / \mathrm{hr})\end{array}$ & $\begin{array}{c}\text { Carbon } \\
\text { Replacement: } \\
\frac{C_{o}}{q_{e}}(C P)\end{array}$ & $\begin{array}{l}\text { Sand drying } \\
\text { beds: }\end{array}$ \\
$2506 F^{0.7504}$ & & & 0.005 \\
$+63,780 * C R F / Q$ & $1153.44 F^{0.6539}+9650 / Q$ & & Landfill: \\
& & & $L F P\left(\frac{C_{o}}{q_{e}}\right) Q$ \\
\hline
\end{tabular}

$\mathrm{CP}=$ Carbon price $(\$ / \mathrm{kg})$

$\mathrm{LFP}=$ Land fill price $(\$ / \mathrm{kg} \mathrm{PAC})$

$\mathrm{Q}=$ Operating flow rate $\left(\mathrm{m}^{3} / \mathrm{yr}\right)$

$\mathrm{C}_{\mathrm{o}}=$ Influent $\mathrm{TOC}$ concentration $\left(\mathrm{mg} / \mathrm{m}^{3}\right)$

$\mathrm{q}_{\mathrm{e}}=$ Equilibrium sorbed concentration $(\mathrm{mg} / \mathrm{kg} \mathrm{PAC})$

$\mathrm{F}=\mathrm{PAC}$ feed rate $(\mathrm{kg} / \mathrm{hr})$

$\mathrm{CRF}=$ Capital recovery factor

The amount of carbon that is used during PAC treatment of produced water was estimated, in part, with the same competitive adsorption model that was used to estimate GAC carbon usage (e.g. Digiano et al., 1978). The absorptive capacity of the PAC was halved in this analysis to ensure that the usage rate was not underestimated. The amount of time that is necessary for the PAC to equilibrate with the waste stream varies with the molecular weight of the individual organic compounds being removed. The range of molecular weights for the organic compounds found in produced water suggests that equilibrium will not be reached for the range of contact times considered and therefore the carbon usage rate must be adjusted. 


\subsubsection{Results}

The costs of removing adsorbable organic constituents from the produced waters evaluated ranged from approximately $\$ 0.1$ to $\$ 1.50 / \mathrm{m}^{3}$. This broad range of prices can be attributed to the vast difference between the waste stream contaminant concentrations, the different levels of clean-up that were examined, and the range of treatment system sizes. Costs at the higher end of this range $\left(>\$ 0.50 / \mathrm{m}^{3}\right)$ are the result of the relatively high capital costs incurred for the carbon contactors and other equipment used to treat the $0.01 \mathrm{MGD}\left(37.85 \mathrm{~m}^{3} / \mathrm{d}\right)$ waste streams. At smaller flow rates, the investment in contactors is not compensated for by more efficient activated carbon utilization. In these instances, PAC addition is more cost effective than GAC treatment. The difference in cost between the two types of activated carbon were compared in Figure 5.3. There is a trade off between the capital cost savings realized by adsorbing these contaminants with PAC and the increase in carbon costs that will occur if PAC is chosen over GAC as an adsorbent. The costs associated with adsorbing organic compounds onto both types of carbon were calculated and these costs were plotted versus the concentration of adsorbable organic compounds found in the untreated waste stream (Figure 5.4).

The type of GAC and PAC cost curves depicted in Figure 5.4 will typically intersect at one point for some of the flow regimes. This intersection corresponds to the point where the low capital costs of a powdered activated carbon system are outpaced by the increased carbon costs of PAC (high carbon usage rates). There is no such intersection of the curves representing PAC and GAC costs for the 0.01 MGD (37.85 $\mathrm{m}^{3} / \mathrm{d}$ ) produced water flow rate shown in Figure 5.4. This simply means that, for these particular waters, the capital costs associated with GAC adsorption make PAC the preferred treatment option. 


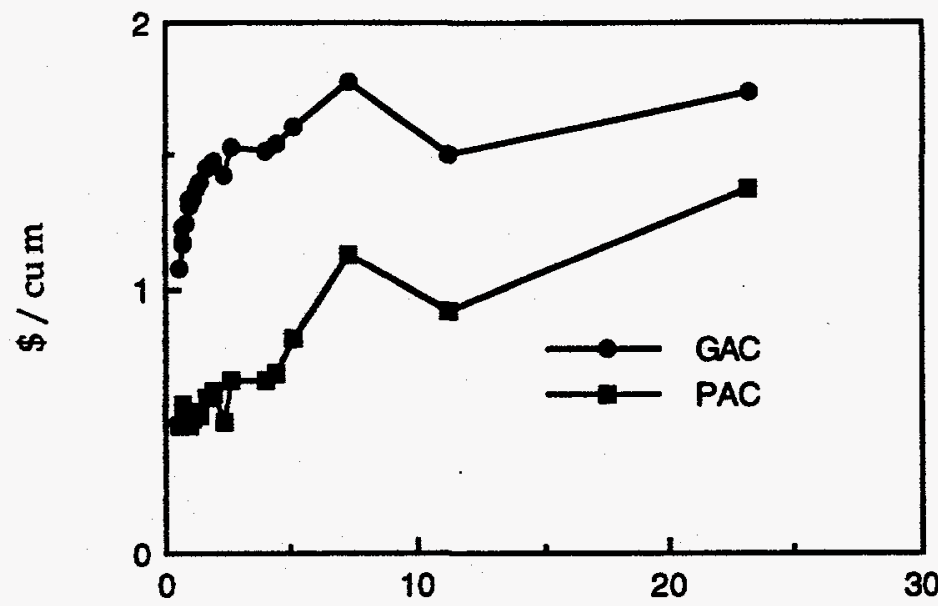

Influent concentration of adsorbable organic compounds $(\mathrm{mg} / \mathrm{L})$

Figure 5.4. A comparison of total system costs for activated carbon adsorption using PAC and GAC plotted as a function of the influent concentration of adsorbable organic compounds. The produced water flow rate is $0.01 \mathrm{MGD}\left(37.85 \mathrm{~m}^{3} / \mathrm{d}\right)$ and the effluent concentration is $0.5 \mathrm{mg} / \mathrm{L}$ adsorbable organic compounds.

At high concentrations of organic compounds in the influent waste stream, PAC systems use more carbon than do GAC systems. This is because of the greater efficiency of carbon utilization by GAC. Examples of this are depicted in Figures 5.5 and 5.6 where the costs of both a PAC and GAC system are illustrated at flow rates of 0.1 MGD $\left(378.5 \mathrm{~m}^{3} / \mathrm{d}\right)$ and $1 \mathrm{MGD}\left(3,785 \mathrm{~m}^{3} / \mathrm{d}\right)$ respectively. At approximately $6 \mathrm{mg} / \mathrm{L}$ of contaminant concentration in the influent, GAC becomes the most cost effective method of carbon adsorption at $0.1 \mathrm{MGD}\left(378.5 \mathrm{~m}^{3} / \mathrm{d}\right)$. Cost curves similar to Figures 5.5 and 5.6 were evaluated for the other relevant produced water flow regimes and treatment levels. As larger quantities of produced water are treated, GAC becomes the preferred treatment option for adsorptive removal of organics at lower and lower concentrations. At a capacity of 1 MGD $\left(3,785 \mathrm{~m}^{3} / \mathrm{d}\right)$, treatment of produced water using GAC was determined to be comparable or cheaper than using PAC over the entire range of influent concentrations that were investigated (Figure 5.6). 


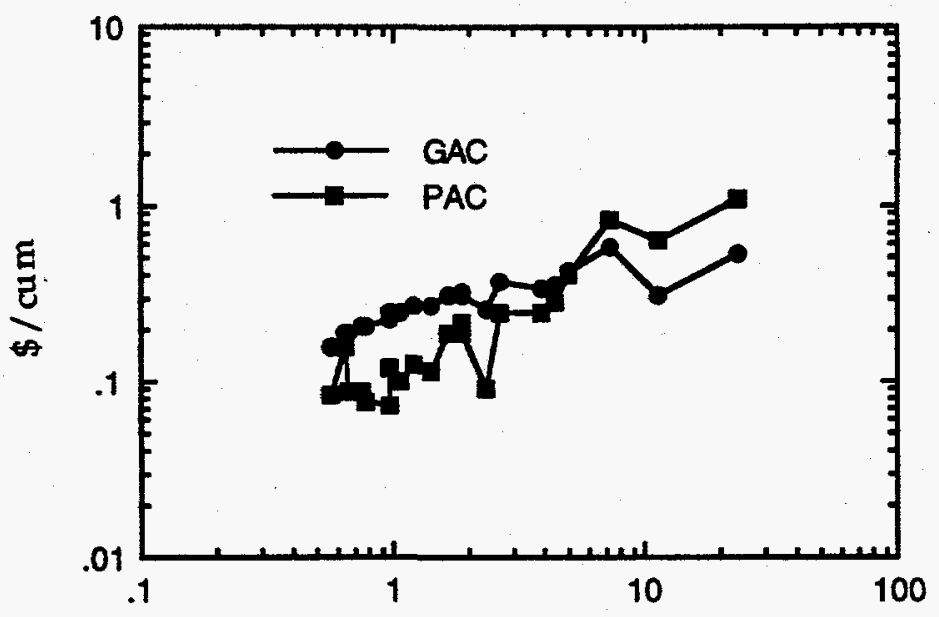

Influent concentration of adsorbable organic compounds $(\mathrm{mg} / \mathrm{L})$

Figure 5.5. A comparison of total system costs for activated carbon adsorption using PAC and GAC plotted as a function of the influent concentration of adsorbable organic compounds. The produced water flow rate is $0.1 \mathrm{MGD}\left(378.5 \mathrm{~m}^{3} / \mathrm{d}\right)$ and the effluent concentration is $0.5 \mathrm{mg} / \mathrm{L}$ adsorbable organic compounds.

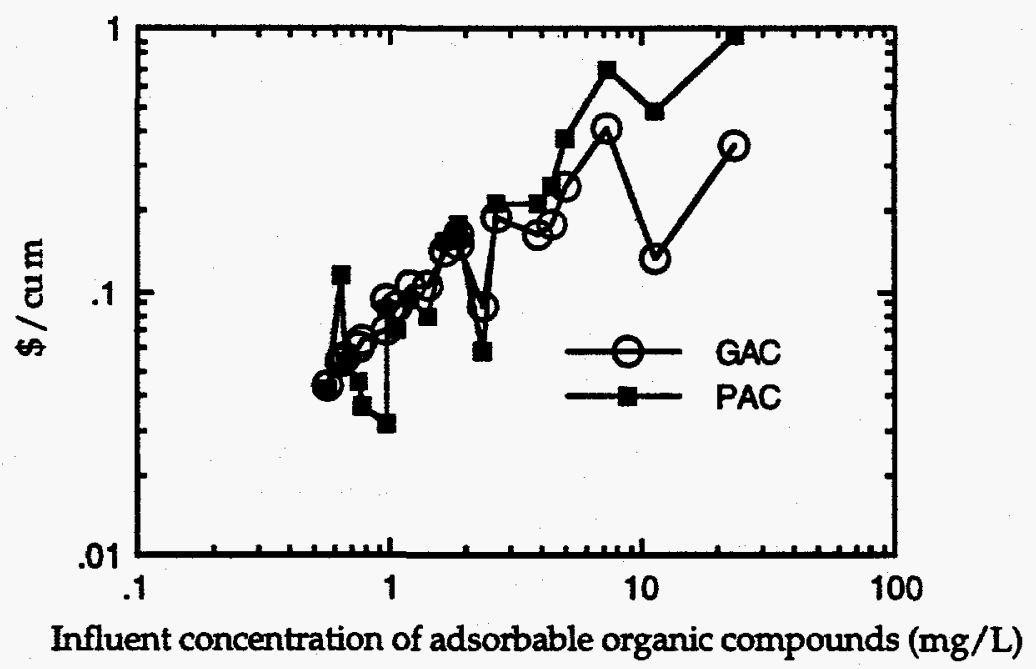

Figure 5.6. A comparison of total system costs for activated carbon adsorption using $P A C$ and GAC plotted as a function of the influent concentration of adsorbable organic compounds. The produced water flow rate is $1 \mathrm{MGD}\left(3,785 \mathrm{~m}^{3} / \mathrm{d}\right)$ and the effluent concentration is $0.5 \mathrm{mg} / \mathrm{L}$ adsorbable organic compounds. 
Curves similar to those depicted in Figures 5.4 - 5.6 were developed for different levels of treatment. Figures 5.7 - 5.9 illustrate the costs of treating produced waters to different levels of cleanliness using PAC at three separate rates of flow. Figures 5.10 5.12 show the same type of information for treatment with GAC.

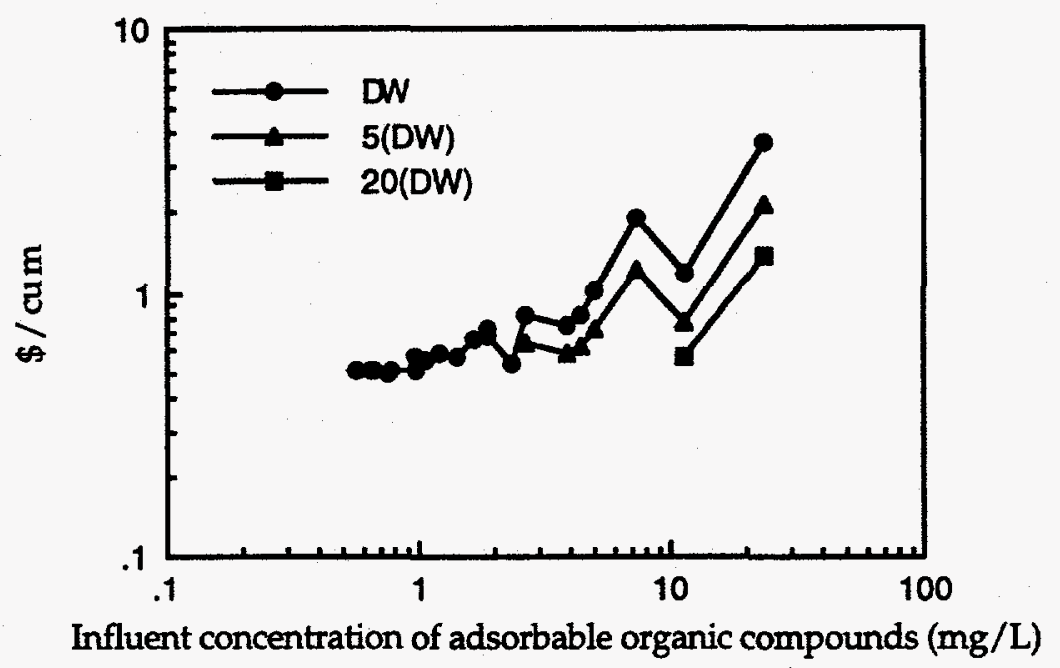

Figure 5.7. PAC treatment costs presented as a function of the initial concentration of adsorbable organic compounds. Effluent concentration levels are shown for the drinking water benchmark $(0.5 \mathrm{mg} / \mathrm{L}), 5$ times the drinking water standard, and 20 times the drinking water standard. Waste stream flow rate is $0.01 \mathrm{MGD}\left(37.85 \mathrm{~m}^{3} / \mathrm{d}\right)$. The decrease in the number of data points on the cost curves labeled 5(DW) and $20(\mathrm{DW})$ corresponds to a decrease in the number of waste streams requiring treatment. 


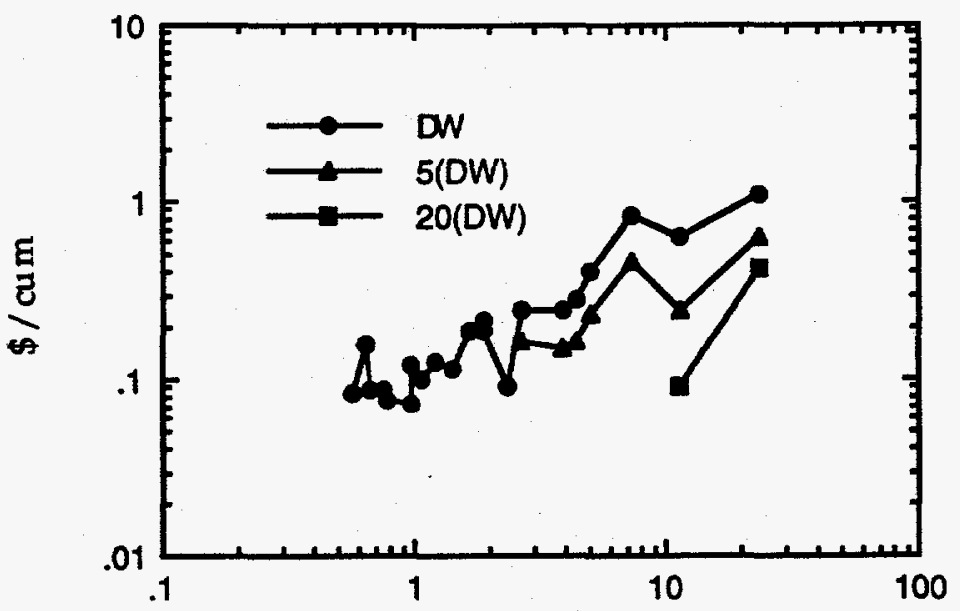

Influent concentration of adsorbable organic compounds (mg/L)

Figure 5.8. PAC treatment costs presented as a function of the initial concentration of adsorbable organic compounds. Effluent concentration levels are shown for the drinking water benchmark $(0.5 \mathrm{mg} / \mathrm{L}), 5$ times the drinking water standard, and 20 times the drinking water standard. Waste stream flow rate is $0.1 \mathrm{MGD}(378.5 \mathrm{~m} 3 / \mathrm{d})$. The decrease in the number of data points on the cost curves labeled $5(\mathrm{DW})$ and $20(\mathrm{DW})$ corresponds to a decrease in the number of waste streams requiring treatment.

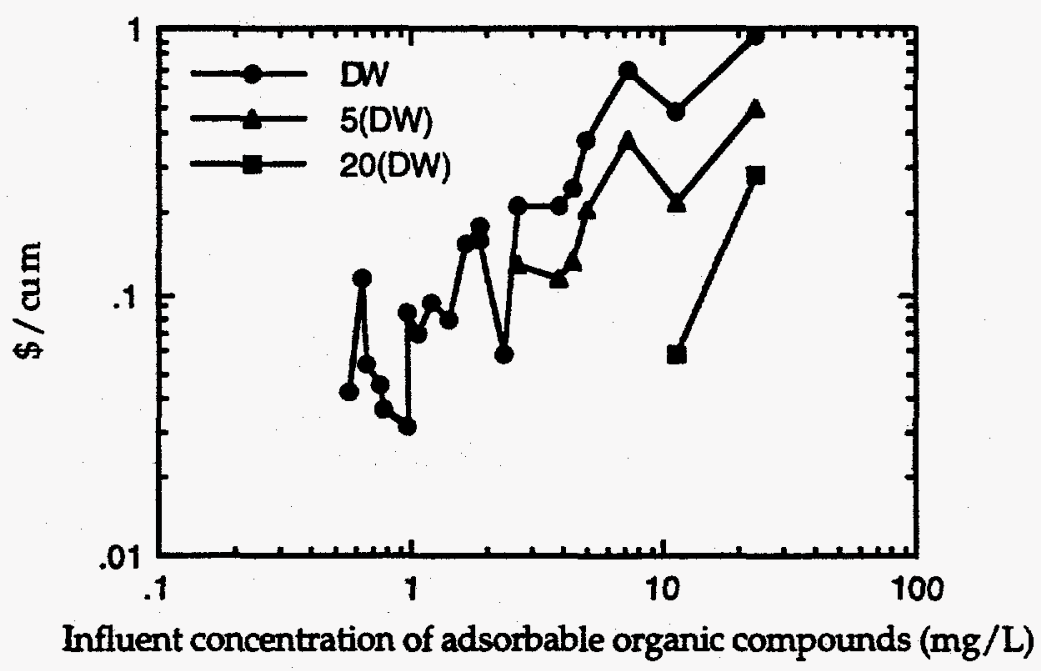

Figure 5.9. PAC treatment costs presented as a function of the initial concentration of adsorbable organic compounds. Effluent concentration levels are shown for the drinking water benchmark $(0.5 \mathrm{mg} / \mathrm{L}), 5$ times the drinking water standard, and 20 times the drinking water standard. Waste stream flow rate is $1 \mathrm{MGD}\left(3,785 \mathrm{~m}^{3} / \mathrm{d}\right)$. The decrease in the number of data points on the cost curves labeled 5(DW) and 20(DW) corresponds to a decrease in the number of waste streams requiring treatment. 


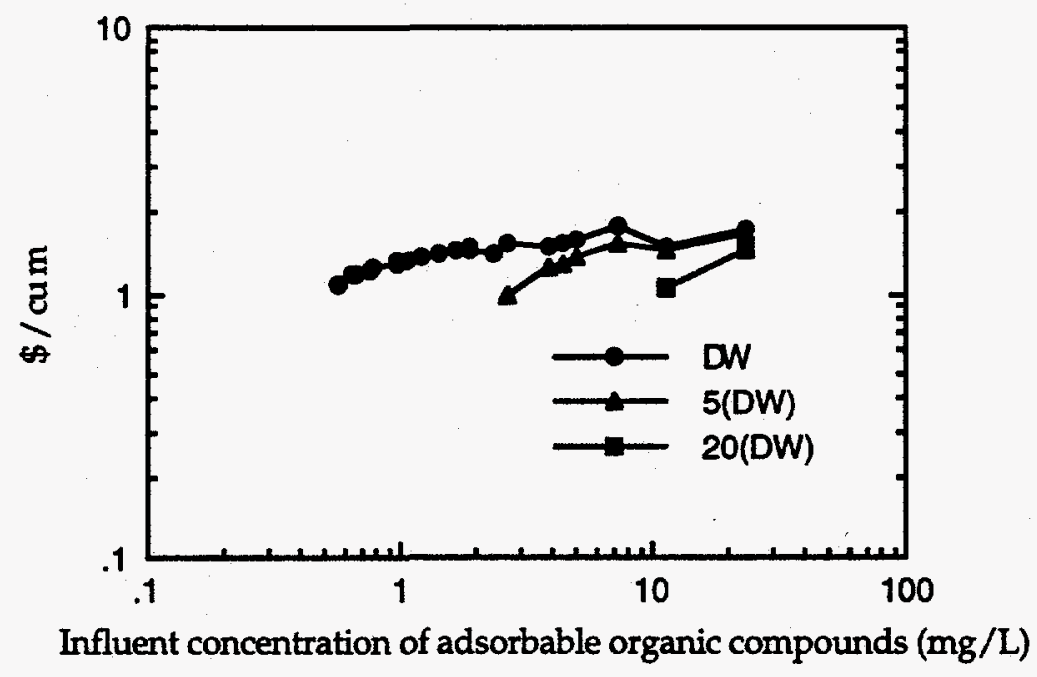

Figure 5.10. GAC treatment costs presented as a function of the initial concentration of adsorbable organic compounds. Effluent concentration levels are shown for the drinking water benchmark $(0.5 \mathrm{mg} / \mathrm{L}), 5$ times the drinking water standard, and 20 times the drinking water standard. Waste stream flow rate is $0.01 \mathrm{MGD}\left(37.85 \mathrm{~m}^{3} / \mathrm{d}\right)$. The decrease in the number of data points on the cost curves labeled 5(DW) and 20 (DW) corresponds to a decrease in the number of waste streams requiring treatment.

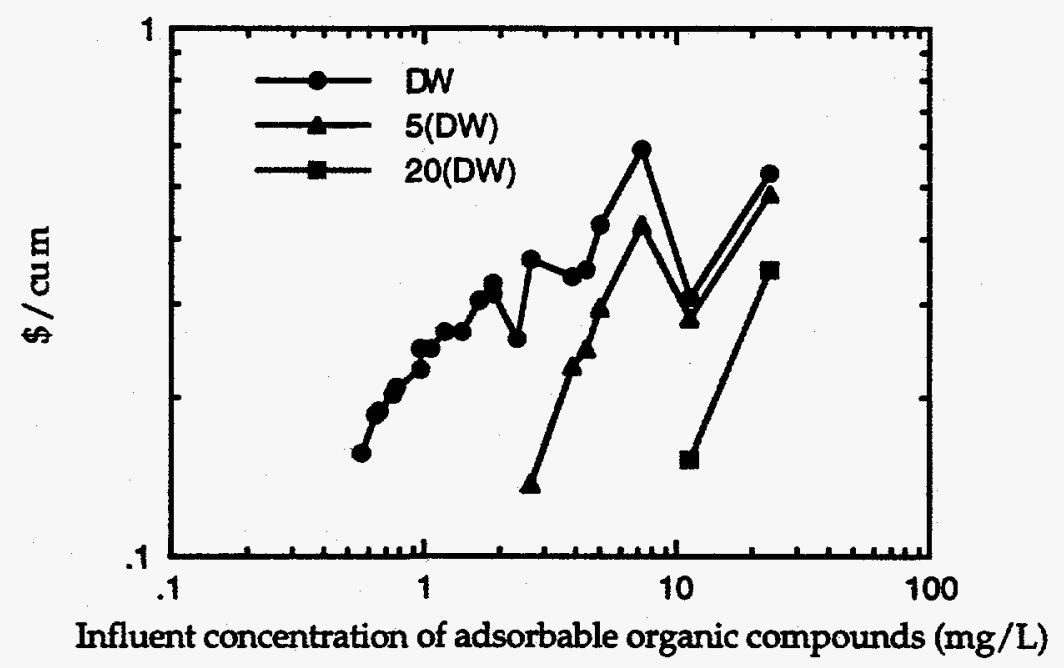

Figure 5.11. GAC treatment costs presented as a function of the initial concentration of adsorbable organic compounds. Effluent concentration levels are shown for the drinking water benchmark $(0.5 \mathrm{mg} / \mathrm{L}), 5$ times the drinking water standard, and 20 times the drinking water standard. Waste stream flow rate is $0.1 \mathrm{MGD}\left(378.5 \mathrm{~m}^{3} / \mathrm{d}\right)$. The decrease in the number of data points on the cost curves labeled 5(DW) and $20(\mathrm{DW})$ corresponds to a decrease in the number of waste streams requiring treatment. 


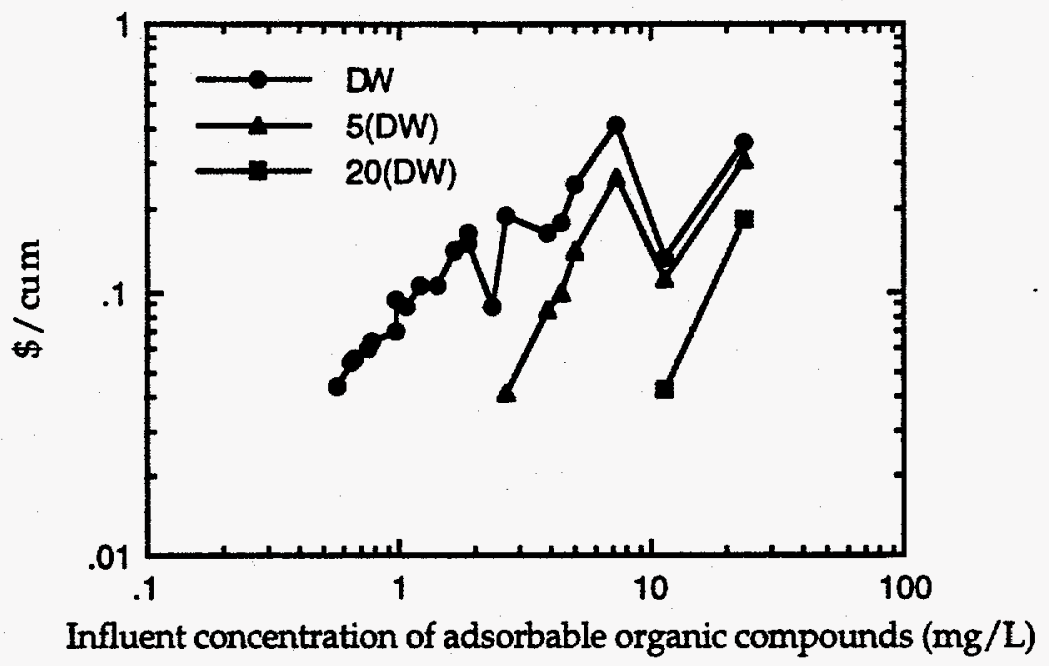

Figure 5.12. GAC treatment costs presented as a function of the initial concentration of adsorbable organic compounds. Effluent concentration levels are shown for the drinking water benchmark $(0.5 \mathrm{mg} / \mathrm{L}), 5$ times the drinking water standard, and 20 times the drinking water standard. Waste stream flow rate is 1 MGD $\left(3,785 \mathrm{~m}^{3} / \mathrm{d}\right)$. The decrease in the number of data points on the cost curves labeled 5(DW) and 20(DW) corresponds to a decrease in the number of waste streams requiring treatment.

The unexpected dips and sharp rises displayed on the cost curves in Figures 5.7 5.12 are due to carbon costs. These costs are directly proportional to the affinity of the activated carbon for a specific organic contaminant matrix contained in a waste stream. This affinity can be thought of as the relative adsorbability of the different organic waste waters. All of the produced waters evaluated were treated for the removal of the same constituents during activated carbon treatment (PAC or GAC). Each point on the activated carbon cost curves corresponds to a different produced water. The relative ratios of contaminants in each produced water are different. Thus, the cost of treatment at each concentration level of TOC reflects changes in the composition of the TOC as well as its total concentration.

Figure 5.13 depicts the variation in the cost of carbon with respect to the composition of the influent TOC for GAC treatment of produced waters. All points on 
the graph represent carbon costs associated with removing organic contaminants from distinct individual waste streams. The weighted mean value of the Freundlich isotherm constant $\mathrm{K}$ for all of the organic constituents found in three of the waste streams is shown in Figure 5.13 as $\mathrm{Kw}$. The value of $\mathrm{Kw}$ is computed as follows:

$$
K w=\frac{\sum C_{i} K_{i}}{\sum C_{i}}
$$

where $K_{i}$ is the Freundlich isotherm constant for compound $i$ and $C_{i}$ is the concentration of compound i.

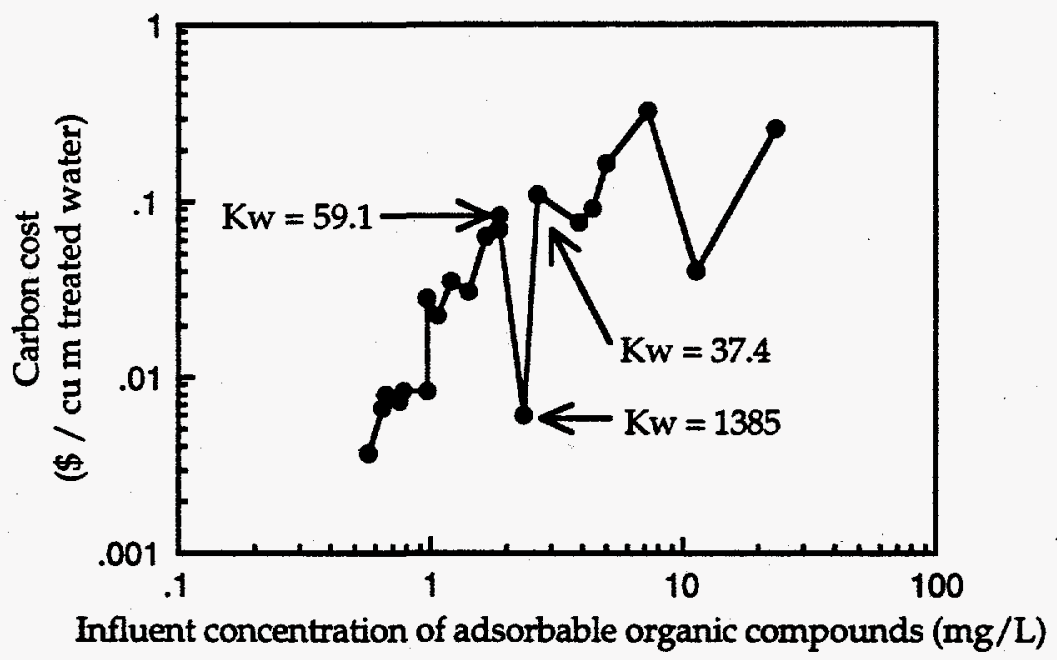

Figure 5.13. Carbon costs associated with the removal of adsorbable organic compounds onto GAC as a function of the initial concentration of adsorbable organic compounds in untreated produced waters. The value $\mathrm{Kw}$ is the weighted mean of the Freundlich coefficient $K$ for the constituents of the waste stream corresponding to the designated graph points .

In Figure 5.13 it can be seen that the GAC has a large capacity for the contaminants found in the waste stream having a $\mathrm{Kw}$ of 1385 . Conversely, the carbon does not have a large capacity for the organic contaminants found in the waste streams having $\mathrm{Kw}$ values of 59.1 and 37.4. The Freundlich isotherm coefficient, $\mathrm{K}$, can be likened to a parameter describing the capacity of the activated carbon to adsorb a 
particular organic constituent or group of constituents. The weighted average of this isotherm coefficient for the contaminants found within the waste stream corresponding to the $\mathrm{Kw}$ value of 1385 is much larger than that calculated for any of the other waters evaluated. The more favorable isotherms for the principal contaminants found in this water explain the reduction in the amount of carbon used and consequently the lower cost. In Figure 5.14, the peaks and valleys that exist within the carbon costs represented in Figure 5.13 are present in each of the total cost curves. The curves which represent the treatment costs of produced water flowing at 0.01 and $0.1 \mathrm{MGD}$ (37.85 and 378.5 $\mathrm{m}^{3} / \mathrm{d}$ ) obscure the fluctuating carbon cost trend because the capital costs of the treatment dominate at these lower capacities.

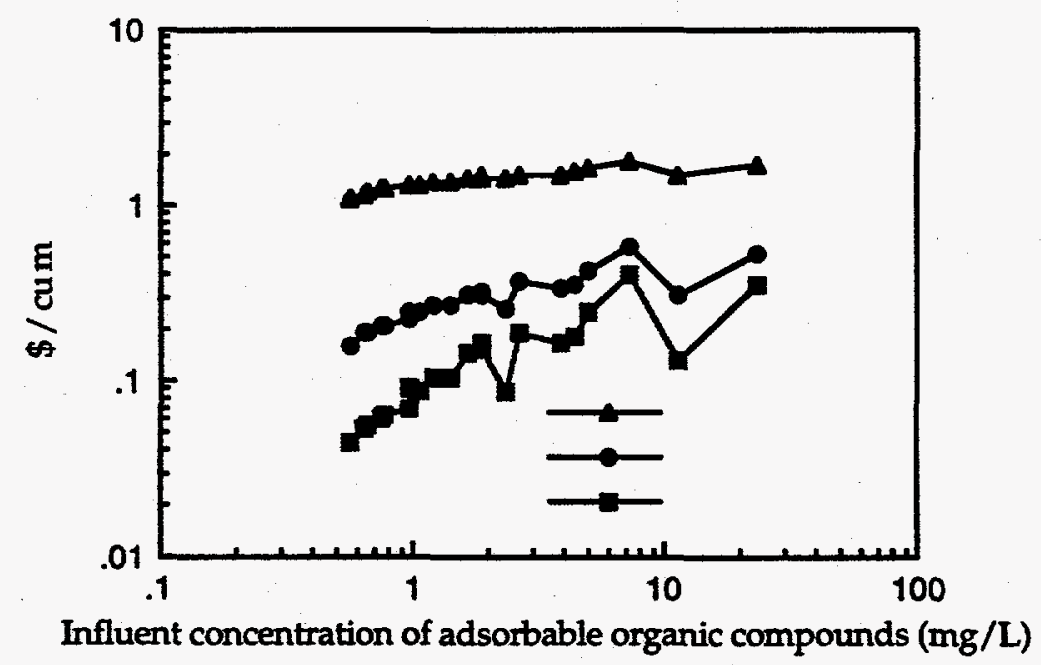

Figure 5.14. GAC adsorption costs for flow rates of 0.01, 0.1, and 1 MGD $(37.85,378.5$, and $3,785 \mathrm{~m}^{3} / \mathrm{d}$ ) plotted against the influent concentration of adsorbable organic compounds. The effluent concentration of each of the streams is $0.5 \mathrm{mg} / \mathrm{L}$.

\subsection{Desalination Processes}

\subsubsection{Evaluation Methodology}

Desalination refers to the removal of dissolved ionic species (salts) from water. Reverse osmosis and forced evaporation were the two methods of desalination 
considered in this analysis. Osmosis refers to the natural tendency for a solvent, such as water, to flow from a less concentrated solution to a more concentrated solution when the two solutions are separated by a semipermeable membrane (i.e. a membrane that is permeable to the solvent but not to dissolved substances). The two solutions tend to become equal in molecular concentration. The flow of water across the membrane exerts a pressure called the osmotic pressure. Reverse osmosis occurs when a pressure in excess of the osmotic pressure is applied to the more concentrated solution, forcing the water to move through the membrane to the less concentrated side. Dissolved substances are rejected by the membrane and are thereby effectively removed from the water.

Forced evaporation is a process in which water is removed from a waste stream by vaporization, leaving behind a dry solid. The process is accomplished using a spray dryer which atomizes the liquid feed into fine droplets that fall slowly through a chamber of hot air. The water is removed as water vapor and the dry solids are collected on the chamber floor.

The procedures used in this study to estimate the costs related to the RO and forced evaporation processes were originally developed by Remediation Technologies, Inc. for the Gas Research Institute (1993). The costs associated with RO treatment of waste streams with low salinities (TDS $<5,000 \mathrm{mg} / \mathrm{L}$ ) have also been estimated by Clark et al. (1990). Cost estimations using GRI methods and the method described by Clark et al. are compared in Figure 5.15. The GRI costs are significantly higher than those estimated using the method outlined by Clark et al. The costs are, however, of the same order of magnitude.

Reverse osmosis is the most cost effective method of produced water desalination for waters possessing total dissolved solids concentration levels at or below approximately $55,000 \mathrm{mg} / \mathrm{L}$. This criterion was used to distinguish the waste streams to be desalinated by this unit process from those assumed to be desalinated 
using forced evaporation in this study. The cost equations for RO systems used in this analysis are a function of the design rate of flow and the TDS concentrations. The forced evaporation costs are a function of flow rate only. The cost of desalination using RO includes capital, operation and maintenance, and residual management (brine disposal) costs. These same cost components comprise the costs for forced evaporation processes. The disposal cost of the salt resulting from forced evaporation are included in the evaporation costs. The resulting salt is assumed to be disposed of in a landfill.

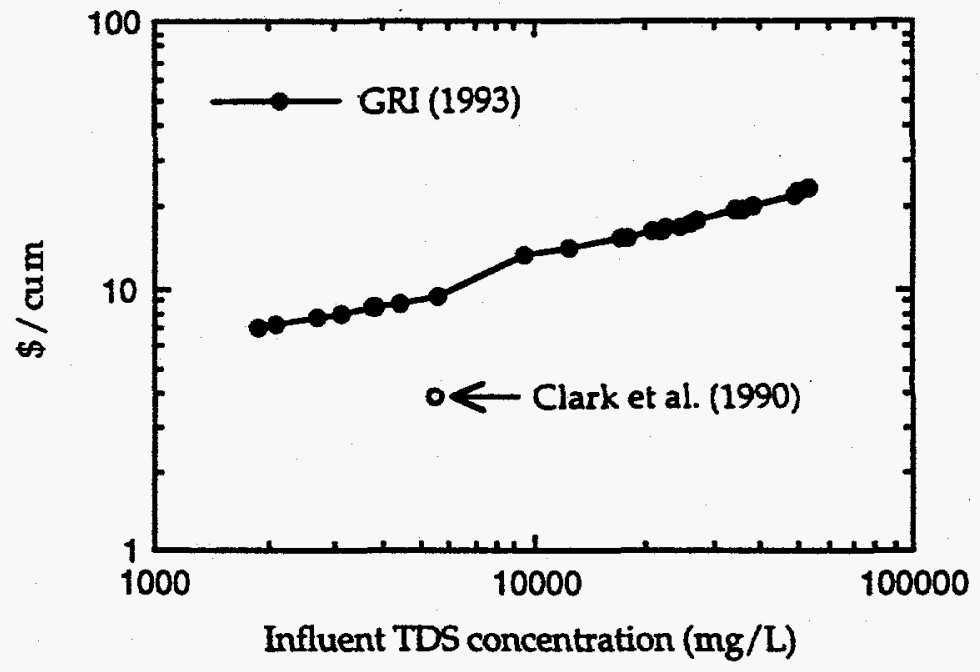

Figure 5.15. Comparison of cost estimating methods for treatment using reverse osmosis. Effluent is drinking water quality $(500 \mathrm{mg} / \mathrm{L} \mathrm{TDS})$.

\subsubsection{Reverse Osmosis}

Fundamental relationships between the produced water quality and the precise characteristics of the membrane systems and the operating parameters as they affect membrane performance were not used in this analysis. While models of this complexity are available, the cost information from these models is considered to be less reliable than that obtained from the GRI cost equations. The GRI cost functions used to estimate the desalination costs in this study are specifically applicable to the treatment of produced waters and include pretreatment costs (Table 5.7). A standard pretreatment 
scenario, which includes a cartridge filter and $\mathrm{pH}$ adjustment, is assumed for the $\mathrm{RO}$ systems. Costs calculated using this approach agree with treatment plant data for RO treatment of similar waters (Remediation Technologies, Inc., 1993). The observed costs from twelve treatment scenarios were compared to costs predicted using the cost equations in Table 5.7 (Remediation technologies, Inc., 1993). These scenarios ranged in capacity from 25 to $1,350 \mathrm{~m}^{3} / \mathrm{d}$ and in influent TDS concentration from 1,000 to 35,000 $\mathrm{mg} / \mathrm{L}$. The observed costs and those predicted by the cost functions differed by less than $10 \%$ on average. The typical RO system used in the comparison was assumed to maintain $94 \%$ rejection of TDS across the membrane (Remediation Technologies, Inc., 1993).

As with adsorption, blending of the treated RO effluent with untreated produced water may be implemented when lower TDS removals are required (in this case, less than $94 \%$ ). In the event that the $94 \%$ rejection is inadequate, the permeate from one RO stage can be treated by a second stage (i.e. the stream is treated twice). The portion of the produced water that is rejected by the RO membrane (residual waste stream) is assumed to be evaporated.

Table 5.7. Cost equations for reverse osmosis. From Remediation Technologies (1993).

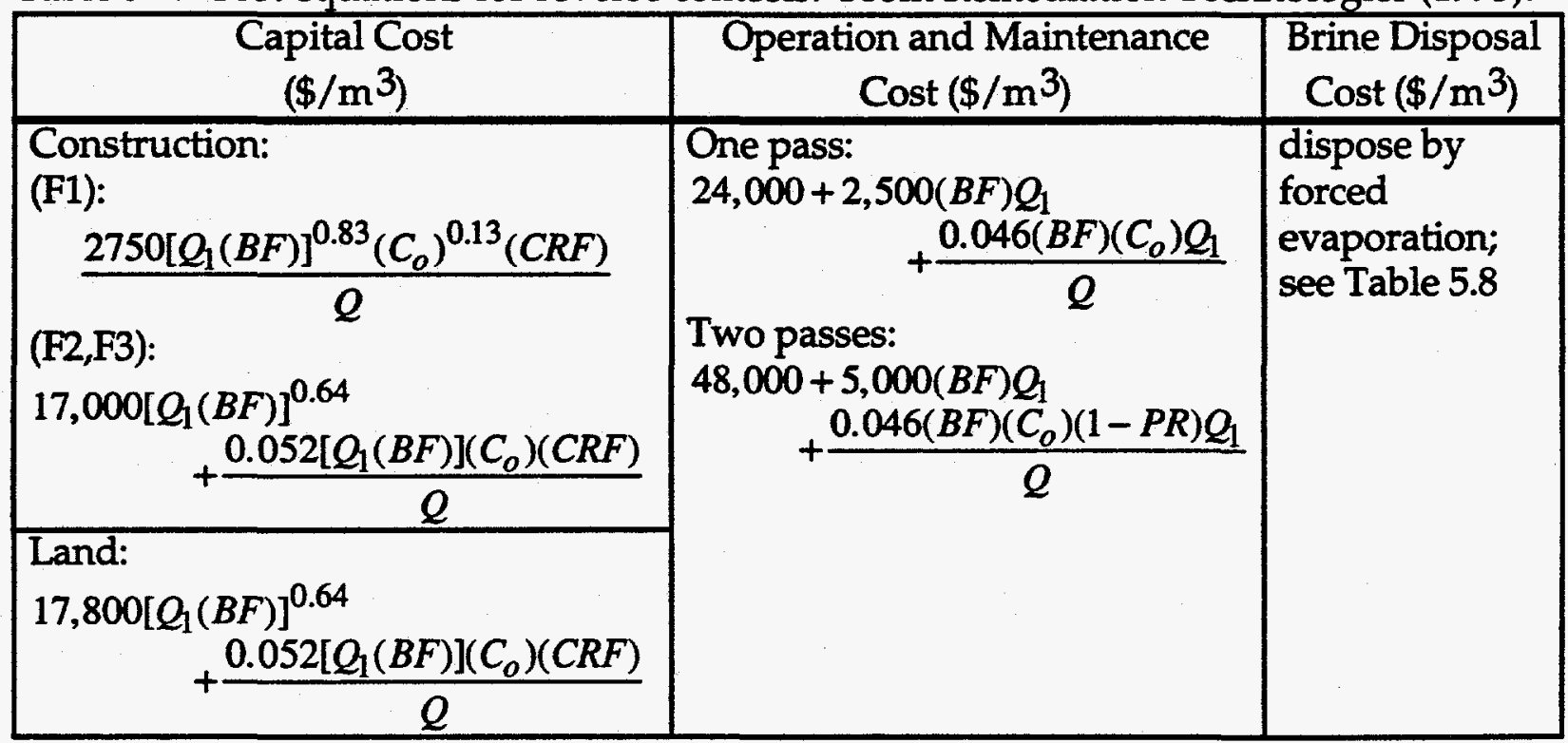


$\mathrm{C}_{\mathrm{o}}=$ Initial TDS concentration $(\mathrm{mg} / \mathrm{L})$

$\mathrm{C}=$ Final TDS concentration $(\mathrm{mg} / \mathrm{L})$

$\mathrm{BF}=\mathrm{Blending}$ factor $=\frac{1-C / C_{0}}{P R}$ for $0<\mathrm{BF} \leq 1 ;=1$ for $\mathrm{BF}>1$

$\mathrm{Q}=$ Design flow rate $\left(\mathrm{m}^{3} / \mathrm{yr}\right)$

$\mathrm{Q}_{1}=$ Operating flow rate $(\mathrm{gal} / \mathrm{min})$

$\mathrm{PR}=$ Percent recovery

$\mathrm{CRF}=$ Capital recovery factor

F1, F2, F3 correspond to $0.01,0.1$, and 1 MGD $\left(37.85,378.5\right.$ and $\left.3,785 \mathrm{~m}^{3} / \mathrm{d}\right)$ of operating flow rate respectively.

\subsubsection{Forced Evaporation}

Desalination by forced evaporation is the most expensive treatment process evaluated for the treatment of the produced waters. The cost of this type of treatment is assumed to vary as a function of the design rate of flow only (Table 5.8). This process is used only on waters with extremely high TDS concentrations and may be used to treat the rejection stream generated during RO treatment.

Table 5.8. Cost equations for forced evaporation. From Remediation Technologies, Inc. (1993).

\begin{tabular}{|c|c|}
\hline $\begin{array}{l}\text { Capital Cost } \\
\left(\$ / \mathrm{m}^{3}\right)\end{array}$ & $\begin{array}{l}\text { Operation and Maintenance Cost } \\
\qquad\left(\$ / \mathrm{m}^{3}\right)\end{array}$ \\
\hline $\begin{array}{l}\text { Construction: } \\
540,000 Q_{1}^{0.61}(C R F)\end{array}$ & \multirow{3}{*}{$\begin{array}{l}\text { System: } \\
\qquad \frac{17,000 Q_{2}{ }^{0.93}}{Q}\end{array}$} \\
\hline$Q$ & \\
\hline $\begin{array}{l}\text { Land: } \\
\frac{31 Q_{1}^{0.61}(L P)(C R F)}{Q}\end{array}$ & \\
\hline $\begin{array}{l}2_{1}=\text { Design flow rate (ga } \\
2_{2}=\text { Operating flow rate }\end{array}$ & $\begin{array}{l}\operatorname{nin}) \\
1 / \min )\end{array}$ \\
\hline
\end{tabular}




\subsubsection{Results}

Forced evaporation is assumed as the treatment process for desalination when waste streams have TDS levels above $55,000 \mathrm{mg} / \mathrm{L}$, about three times the salinity of sea water. The cost of implementing this type of treatment is very high and probably prohibitive at smaller produced water flow rates. However, where alternative sources of water may not be available, desalination of these very saline waters could be desirable. Figure 5.16 depicts the cost of forced evaporation versus system capacity. As can be seen in the figure, the average cost for evaporation varies only slightly with system size.

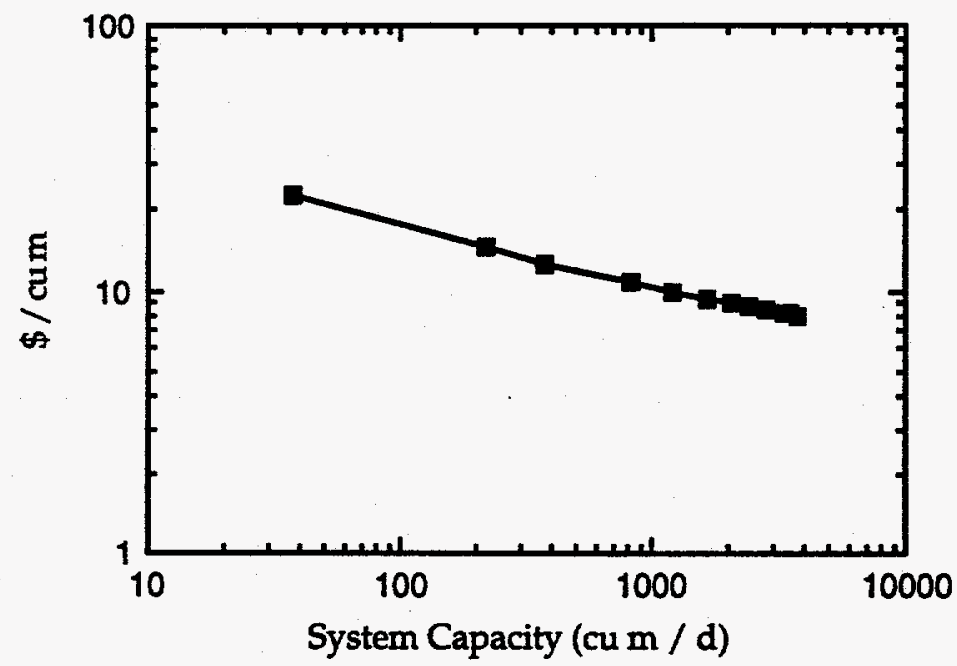

Figure 5.16. Forced evaporation costs versus system capacity. System capacity determines the system cost regardless of contaminant level.

Desalination of produced waters with lower TDS levels using reverse osmosis, though still relatively costly, is significantly less expensive than forced evaporation. The costs associated with RO treatment range from a little less than $\$ 2 / \mathrm{m}^{3}$ up to over $\$ 25 / \mathrm{m}^{3}$ (Figure 5.17).

The apparent jump in cost that can be seen in Figure 5.17 for all three rates of flow (especially for the $0.01 \mathrm{MGD}$ curve) occurs at $8,333 \mathrm{mg} / \mathrm{L}$ of influent TDS 
concentration. This is the highest level of influent concentration that can be reduced to $500 \mathrm{mg} / \mathrm{L}$ in a single pass through the system. In order to meet this effluent criterion for the waters having TDS levels above $8,333 \mathrm{mg} / \mathrm{L}$, the first pass permeate must be treated in a second pass through the RO system. Operation and maintenance requirements for the system are increased accordingly.

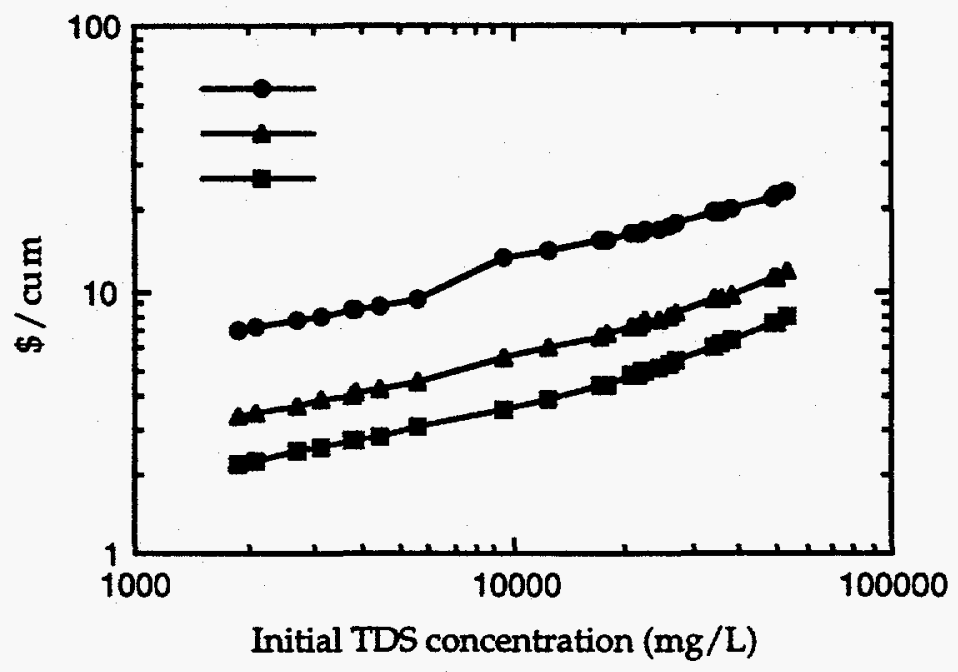

Figure 5.17. The estimated costs of RO desalination of produced waters for flow rates of $0.01,0.1$, and $1 \mathrm{MGD}\left(37.85,378.5\right.$, and $\left.3,785 \mathrm{~m}^{3} / \mathrm{d}\right)$ as a function of initial waste stream TDS concentration. Effluent TDS concentration is $500 \mathrm{mg} / \mathrm{L}$.

Figure 5.18 - 5.20 show the estimated costs of RO desalination as a function of influent TDS concentration for three different flow rates. In each of these figures, cost curves are compared for different levels of treatment. Waters that do not require the treatment level that would be accomplished by a single pass through the RO system may undergo treatment proportionate to the level needed. A portion of the influent waste stream can be diverted around the RO treatment system and later remixed with the treated portion. As the portion of the produced water being treated increases for waste streams with less stringent effluent requirements, the unit costs for all treatment streams converge. As the influent TDS concentration increases, the operation of the RO 
treatment process to achieve different effluent TDS concentration levels becomes similar. For example, the waste stream being treated to five times the drinking water standard (5(DW)) need only pass a portion of its volume through the RO system at low levels of influent concentration. As the influent TDS levels increase, a larger portion of the waste stream must be treated until, for the very highest levels of influent concentration, a second pass through the system is necessary.

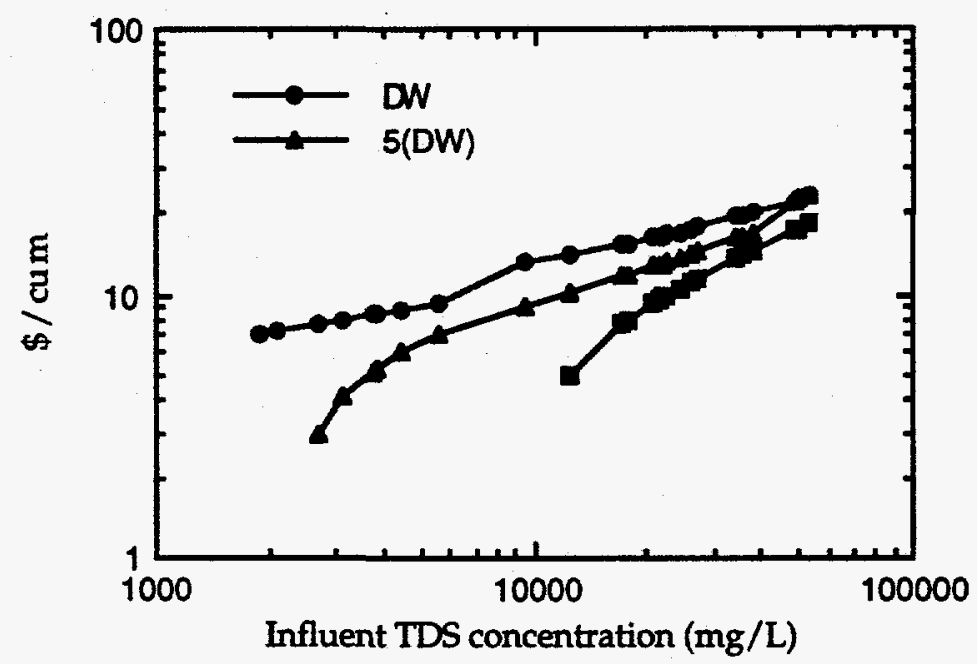

Figure 5.18. RO treatment costs presented as a function of influent TDS concentration and effluent requirements. Effluent concentration levels are shown for the drinking water benchmark $(500 \mathrm{mg} / \mathrm{L}), 5$ times the drinking water standard, and 20 times the drinking water standard. Waste stream flow rate is 0.01 MGD $\left(37.85 \mathrm{~m}^{3} / \mathrm{d}\right)$. The decrease in the number of data points on the cost curves labeled 5(DW) and 20(DW) corresponds to a decrease in the number of waste streams requiring treatment. 


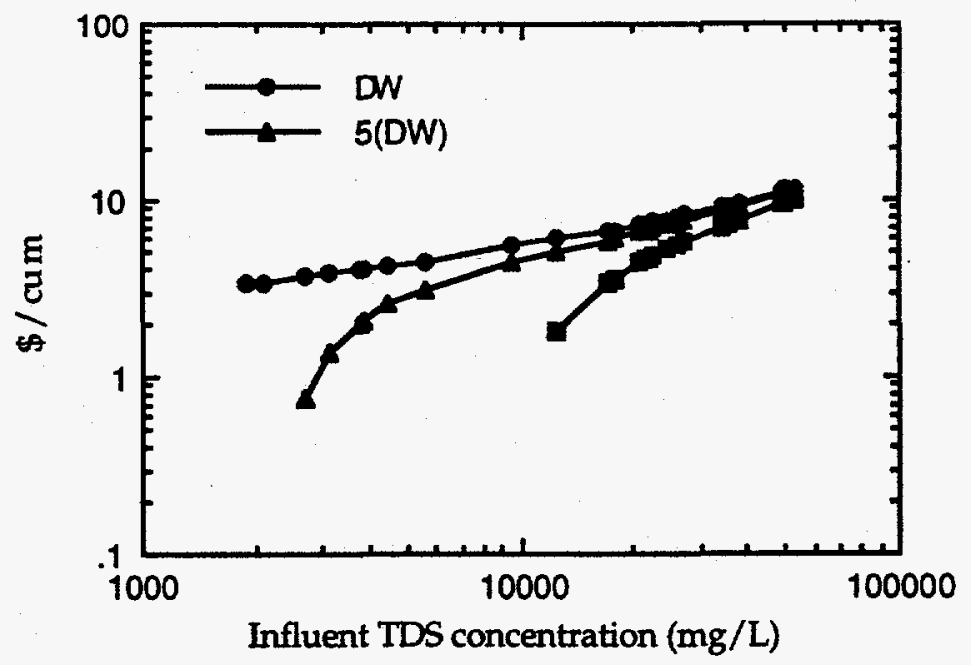

Figure 5.19. RO treatment costs presented as a function of influent TDS concentration and effluent requirements. Effluent concentration levels are shown for the drinking water benchmark $(500 \mathrm{mg} / \mathrm{L}), 5$ times the drinking water standard, and 20 times the drinking water standard. Waste stream flow rate is $0.1 \mathrm{MGD}\left(378.5 \mathrm{~m}^{3} / \mathrm{d}\right)$. The decrease in the number of data points on the cost curves labeled 5(DW) and 20(DW) corresponds to a decrease in the number of waste streams requiring treatment.

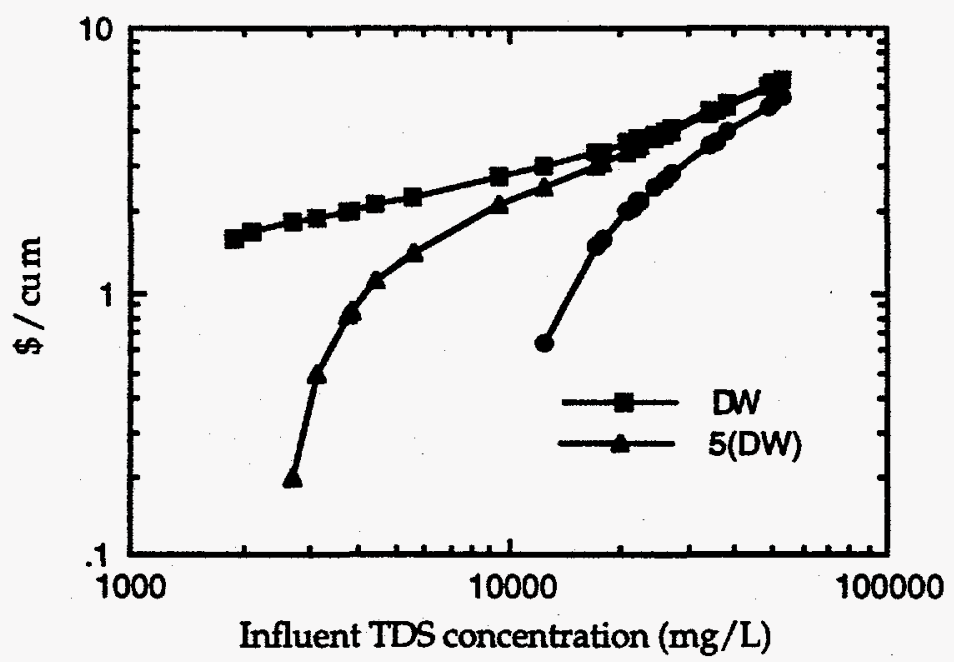

Figure 5.20. RO treatment costs presented as a function of influent TDS concentration and effluent requirements. Effluent concentration levels are shown for the drinking water benchmark $(500 \mathrm{mg} / \mathrm{L}), 5$ times the drinking water standard, and 20 times the drinking water standard. Waste stream flow rate is 1 MGD $\left(3,785 \mathrm{~m}^{3} / \mathrm{d}\right)$. The decrease in the number of data points on the cost curves labeled 5(DW) and 20(DW) corresponds to a decrease in the number of waste streams requiring treatment. 
The operating parameters for a waste stream being treated to the drinking water standard (DW) are handled in much the same way as for lower treatment levels except that the parameter changes occur at much lower influent concentration levels. Costs associated with the desalination of produced waters using reverse osmosis behave similarly, regardless of flow rate. The shapes of the cost curves for reverse osmosis treatment of produced water shown in Figures 5.18 - 5.20 are all similar. The actual costs decrease as the waste stream flow rate increases due to economies of scale.

\subsection{Aggregate Costs}

The total costs for the treatment of several representative waste streams are represented in Figure 5.21. The columns are labeled with the dominant waste stream characteristic. Representative waste stream R14 represents a produced water that has a TDS concentration of 500,000 ppm. The desalination cost for this waste stream dominates the costs associated with the removal of all other contaminants found in the water. Waste stream R7 is described as high quality because suspended solids is the only category of contaminant contained in this water that requires treatment in order to bring the quality of the waste stream to the drinking water standard. The cost bars shown in Figure 5.21 illustrate which of the waste stream constituents are the most expensive to remove. The removal of dissolved solids from any waste stream which has a significant amount of TDS will usually dominate the cost of treatment. The costs associated with the treatment necessary to remove the highest levels of contaminants found in the other categories are overshadowed by the cost of removing a significant amount of TDS.

The total treatment costs shown in Figure 5.21 can be obtained from the cost curves that have been created for each of the different processes. The package treatment plant cost curve can be used with only the knowledge of waste stream flow 
rate and TDS concentration. A packed tower aeration cost estimation requires knowledge of tower volume. Knowledge of the relative adsorbability of the organic contaminant matrix of a given produced water is required to adjust the cost found on any of the cost curves pertaining to activated carbon adsorption. An estimate of cost can be obtained from the cost curves with some knowledge of organic contaminant levels in a given produced water. More accurate costs are taken from the curves that describe the RO and evaporation processes. TDS concentration and waste stream flow rate are the necessary parameters needed to estimate these components of produced water treatment cost.

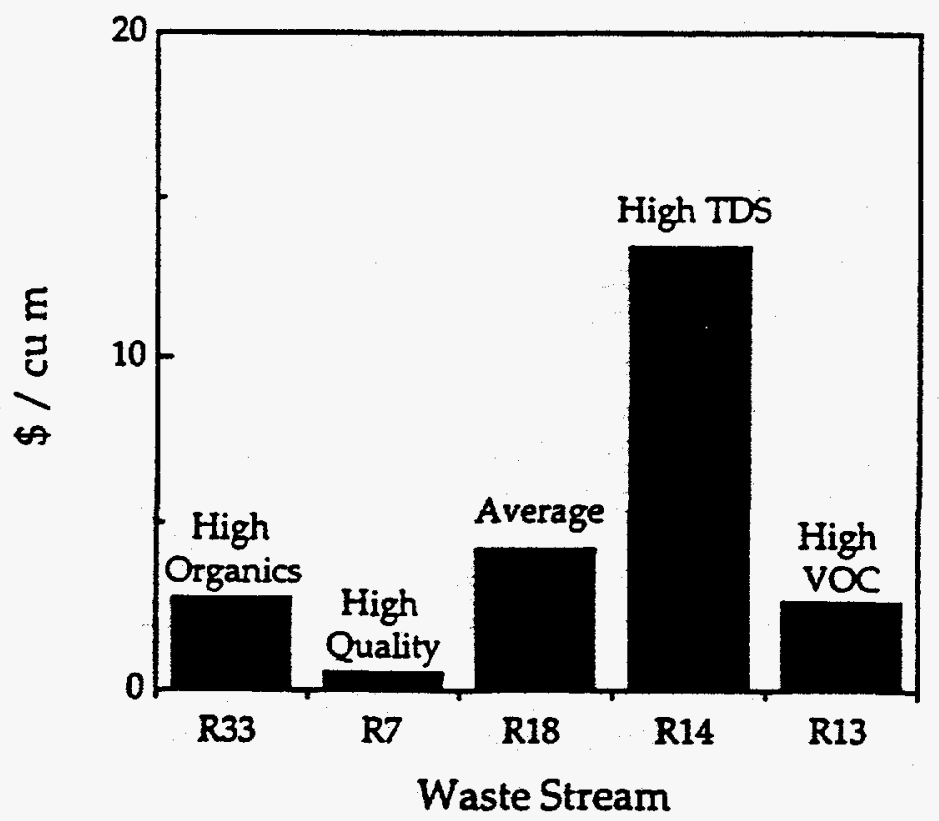

Figure 5.21. Total costs associated with the treatment of several representative waste streams. The flow rate of each stream is equal to $0.1 \mathrm{MGD}\left(378.5 \mathrm{~m}^{3} / \mathrm{d}\right)$.

The costs associated with the treatment of the representative waste streams shown in Figure 5.21 can be used to estimate the costs associated with the treatment of all of the produced water that is generated in a typical year in the United States. The relative levels of contaminants found in produced waters were identified from a simple statistical analysis of the 120 waters contained in the assembled produced water 
database. Geometric means were calculated for all of the constituents contained in the database. Using these mean values, a particular produced water that most nearly matched the mean contaminant levels was chosen to represent the average quality of produced water. This average water is labeled R18 in Figure 5.21. The estimated cost of treating this water, achieving the removal of most solids and undesirable inorganic contaminants (TDS levels at or below $500 \mathrm{mg} / \mathrm{l}$ ), as well as adsorbable and strippable organic levels of 0.5 and $0.8 \mathrm{mg} / \mathrm{l}$, respectively was found to be almost $\$ 5 / \mathrm{m}^{3}$. If the annual total U.S. volume of produced water in a given year is taken to be 3 billion $\mathrm{m}^{3}$ ( 18.3 billion bbls), the cost of treating all of it to this level would be 15 billion dollars per year. 


\section{ACKNOWLEDGMENTS}

Many state and federal agencies contributed data and information that was vital to the successful completion of this study. Special thanks are due to all of the individuals and their assistants who are listed in Table 1.2. Thanks are also due to the American Petroleum Institute and the Gas Research Institute for providing assistance. In addition, the authors would like to thank the Railroad Commission of Texas, the Texas Natural Resource Information System, and Petroleum Information Corporation for providing access to their databases. 


\section{REFERENCES}

Adams, J.Q. and R.M. Clark. 1991. Evaluating the costs of packed-tower aeration and GAC for controlling selected organics. J. AWWA, 83(1): 49-57.

Adams, J.Q. and R.M. Clark. 1989. Cost estimates for GAC treatment systems. J. AWWA, 81(1): 35-42.

Adams, J.Q., R.M. Clark, and J.M. Miltner. 1989. Controlling organics with GAC: A cost and performance analysis. J. AWWA, 81(4): 132-140.

Aller, L., T. Bennett, J. Lehr, R.J. Petty, and G. Hackett. 1987. DRASTIC: A Standardized System for Evaluating Ground Water Pollution Potential Using Hydrogeologic Settings. EPA-600/2-87-035. Washington D.C.: U.S. Environmental Protection Agency.

American Petroleum Institute. 1987. Oil and Gas Industry Exploration and Production Wastes. Document No. 471-01-09. Washington D.C.: American Petroleum Institute.

Anderson, J.R., E.E. Hardy, J.T. Roach, and R.E. Witmer. 1976. A Land Use and Land Cover Classification System for use with Remote Sensor Data. U.S. Geological Survey Professional Paper 964. Washington D.C.: U.S. Government Printing Office.

Baker, F.G. and C.M. Brendecke. 1983. Seepage from oilfield brine disposal ponds in Utah. Ground Water , 21(3): 317-324.

Bauman, E.R. 1978. Granular-media deep-bed filtration. Water Treatment Plant Design for the Practicing Engineer, R.L. Sanks ed. Ann Arbor, MI: Ann Arbor Science Publishers.

Bozzo, W., M. Chatelain, J. Salinas, and W. Wiatt. 1990. Brine impacts to a Texas salt marsh and subsequent recovery. Proceedings of the First International Symposium on Oil and Gas Exploration and Production Waste Management Practices, New Orleans, LA, September 10-13, 1990, p 129-140.

Calgon Corporation. 1994. Personal communication with offices in Pittsburgh, PA. 1 July.

Chellam, S. 1990. Design of packed towers to remove volatile organic compounds. unpublished report.

Clark, R. M. 1982. Cost estimating for conventional water treatment. J. Env. Eng. Div. A.S.C.E., 108(5): 819-834.

Clark, R.M. and B.W. Lykens. 1989. Granular Activated Carbon: Design, Operation, and Cost. Chelsea, MI: Lewis Publishers. 
Clark, R.M., C.A. Fronk, and B.L. Lykins. 1990. Removal of organic contaminants from groundwater: a cost and performance evaluation. Env. Sci. and Tech., 24(10): 21742180 .

Collins, A.G. 1975. Possible Contamination of Groundwaters by Oil and Gas Well Drilling Fluids. NTIS Report CONF75051331. Washington, D.C.: U.S. Department of Commerce.

Crawley, W.W. and R.T. Branch. 1990. Characterization of treatment zone soil conditions at a commercial nonhazardous oilfield waste land treatment unit. Proceedings of the First International Symposium on Oil and Gas Exploration and Production Waste Management Practices, New Orleans, LA, September 10-13, 1990, p $147-158$.

Digiano, F.A., G. Baldauf, B. Frick, and H. Sontheimer. 1978. A simplified competitive adsorption model. Chemical Engineering Science ,33(12): 1667-1673.

Energy Information Administration. 1991. Natural Gas Annual 1990, Volume 1. DOE/EIA-0131(90)/1. Washington D.C.: U.S. Department of Energy, Office of Oil and Gas.

Energy Information Administration. 1992. Petroleum Supply Annual 1991, Volume 1. DOE/ELA-0340(91)/1. Washington D.C.: U.S. Department of Energy, Office of Oil and Gas.

ESRI. 1992. ARC/INFO, Rev. 6.1. Redlands, CA: Environmental Systems Research Institute, Inc.

Ferrante, J.G. 1981. Fate and Effects of Whole Drilling Fluids and Fluid Components in Terrestrial and Fresh Water Ecosystems. EPA 600-4-81-031. Washington D.C.: U.S. Environmental Protection Agency.

Fillo, J.P., S.M. Koraido, and J.M. Evans. 1992. Sources, characteristics, and management of produced waters from natural gas production and storage operations. Produced Water: Technological/Environmental Issues and Solutions, J.P. Ray and F.R. Engelhardt eds. New York, NY: Plenum Press. p 151-161.

Freeman, B.D. and L.E. Deuel. 1984. Guidelines for closing drilling waste fluid pits in wetland and upland areas. Proceedings of the 1984 Industrial Pollution Control Symposium. Presented at the Seventh Annual Energy-Sources Technology Conference and Exhibition, New Orleans, LA, February 12-16, 1984, p 47-110. 
Fucik, K.W. 1992. Toxicity identification and characteristics of produced water discharges from Colorado and Wyoming. Produced Water: Technological/

Environmental Issues and Solutions, J.P. Ray and F.R. Engelhardt eds. New York, NY: Plenum Press. p 187-198.

Gormily, S. 1994. Representative of the Fairbanks Landfill, Houston, TX. Personal communication.

Gumerman, R.C., R.L. Culp, and S.P. Hasen. 1979. Estimating Water Treatment Costs, Volumes 1-4. EPA 600-2-79-162a-d. Washington D.C.: U.S. Environmental Protection Agency.

Hall, R.W. 1990. Environmental consequences of mismanagement of wastes from oil and gas exploration, development, and production. Proceedings of the First International Symposium on Oil and Gas Exploration and Production Waste Management Practices, New Orleans, LA, September 10-13, 1990, p 387-401.

Hand, D.W., J.C. Crittenden, J.L. Gehin, and B.W. Lykens. 1986. Design and evaluation of an air stripping tower for removing VOCs from groundwater. J. AWWA, 78(9): 87-97.

Henderson, G. 1982. Analysis of Hydrologic and Environmental Effects of Drilling Mud Pits and Produced Water Impoundments. Report to the American Petroleum Institute.

Hicks, B.L. 1983a. Saltwater Seeps: A Preliminary Investigation of Reserve Pit Closure Problems. Missoula, MT: U.S. Department of Agriculture, Forest Service, Northern Region Office.

Hicks, B.L. 1983b. Saltwater Seeps: An Investigation of Two Drilling Locations on the McKenzie District, Custer National Forest. Missoula, MT: U.S. Department of Agriculture, Forest Service, Northern Region Office.

Holliday, G.H. and L.E. Deuel. 1990. A statistical review of API and EPA sampling and analysis of oil and gas field wastes. Proceedings of the 65th Annual Technical Conference and Exhibition of the Society of Petroleum Engineers, New Orleans, LA, September 23-26, 1990, p 925-935.

ICF Resources, Inc. 1993. Oil and Gas Exploration and Production Waste Management: $A$ 17-State Study. DOE/FE-62017-H1. Prepared for the U.S. Department of Energy, Office of Fossil Energy and the Interstate Oil and Gas Compact Commission.

Interstate Oil Compact Commission. 1990. EPA/IOCC Study of State Regulation of Oil and Gas Exploration and Production Waste. IOCC Report. December 1990. 
Interstate Oil and Gas Compact Commission. 1991. IOGCC/EPA State Review of Oil and Gas Exploration and Production Waste Management Regulatory Programs. Wyoming State Review. IOGCC Report. October 1991.

Jones, M. 1989. Effects of drilling fluids on a shallow estuarine ecosystem - I. Characterization and fate of discharges. Drilling Wastes, F.R. Engelhardt, J.P. Ray, and A.H. Gillam, eds. New York, NY: Elsevier Science Publishing Co., Inc. p 797825.

Kaszuba, J.P. and M.W. Buys. 1993. Reclamation procedures for produced water spills from coalbed methane wells, San Juan Basin, Colorado and New Mexico. Proceedings SPE/EPA Exploration and Production Environmental Conference, San Antonio, TX, March 7-10, 1993, p 309-318.

Kavanaugh, M.C. and R.R. Trussel. 1980. Design of aeration towers to strip volatile contaminants from drinking water. J. AWWA, 72(12): 684-692.

Lawrence, A.W., J.A. Miller, D.L. Miller, and D.G. Linz. 1993. An evaluation of produced water management options in the natural gas production industry. Proceedings SPE/EPA Exploration and Production Environmental Conference, San Antonio, TX, March 7-10, 1993, p 581-595.

Leuterman, A.J.J., F.W. Jones, and J.E. Candler. 1987. Drilling Fluids and Reserve Pit Toxicity. Society of Petroleum Engineers of AIME Paper No. 017477, 26 p.

Logsdon, G.S., T.J. Sorg, and R.M. Clark. 1990. Capability and cost of treatment technologies for small systems. J. AWWA, 82(6): 60-66.

McHugh, B.H., T.C. Fox, and W.S. Deans. 1993. Characteristics of oil and gas production solid waste in Montana. Proceedings SPE/EPA Exploration and Production Environmental Conference, San Antonio, TX, March 7-10, 1993, p 9-18.

Mehrotra, A.K. and A. Banerjee. 1986. Evaluation of reverse osmosis for the treatment of oil sands produced water. Water Pollution Research Journal, 21(2): 141-152.

Miller, R. 1978. Effects of Drilling Fluid Components and Mixtures on Plants and Soils. Report to the American Petroleum Institute.

Moseley, H.R. Jr. 1983a. Summary and Analysis of API Onshore Drilling Mud and Produced Water Environmental Studies. API Bulletin D19. Washington D.C.: American Petroleum Institute.

Moseley, H.R. Jr. 1983b. Summary of API onshore drilling mud and produced water environmental studies. Proceedings of the IADC/SPE 1983 Drilling Conference, New Orleans, LA, Feb. 20-23, 1983, p 321-325. 
Mount, D.R., D.D. Gulley, and J.M. Evans. 1993. Salinity/toxicity relationships to predict the acute toxicity of produced waters to freshwater organisms. Proceedings SPE/EPA Exploration and Production Environmental Conference, San Antonio, TX, March 7-10, 1993, p 605-614.

Muller, D.A. and R.D. Price. 1979. Groundwater Availability in Texas. Report 238. Austin, TX: Texas Department of Water Resources.

Murphy, E.C. and A.E. Kehew. 1984. The Effect of Oil and Gas Well Drilling Fluids on Shallow Groundwater in Western North Dakota. Report of Investigation No. 82. North Dakota Geological Survey.

Nelson, D. 1982. Plant Uptake and Accumulation of Metals Derived From Drilling Fluids. Report to the American Petroleum Institute.

Nielsen, H.L., K.E. Carnes, and J.N. DeBoice. 1973. Alum sludge thickening and disposal. J. AWWA, 65(6): 385-394.

O'Leary, K.E., M.W. Kemblowski, and G.M. Deeley. 1989. Environmental analysis of a saline drilling waste disposal site. Drilling Wastes, F.R. Engelhardt, J.P. Ray, and A.H. Gillam, eds. New York, NY: Elsevier Science Publishing Co., Inc. p 197-211.

O'Neil, P.E., S.C. Harris, M.F. Mettee, H.R. Isaacson, and J.M. Evans. 1992. Biological fate and effect of coalbed methane produced waters discharged into streams of the Warrior Basin, Alabama. Produced Water: Technological/Environmental Issues and Solutions, J.P. Ray and F.R. Engelhardt eds. New York, NY: Plenum Press. p 315327.

Paddock, A. 1985. Restoration of saltwater damaged lands. Interstate Oil Compact Commission Committee Bulletin, 27(2): 17-18.

Payne, R.D. 1966. Salt water pollution problems in Texas. Journal of Petroleum Technology, 18(11): 1401-1407.

Qasim, S.W., W.D.L. Siang, E.M. Motley, and K.G. Heung. 1992. Estimating costs for treatment plant construction. J. AWWA, 84(8): 56-62.

Rayle, M.F. and M.M. Mulino. 1992. Produced water impacts in Louisiana coastal waters. Produced Water: Technological/Environmental Issues and Solutions, J.P. Ray and F.R. Engelhardt eds. New York, NY: Plenum Press. p 343-354.

Remediation Technologies, Inc. 1993. Produced Water Management Options Model. User's Manual, Version 2.1. Prepared for the Gas Research Institute. 
Roach, R.W., R.S. Carr, and C.L. Howard. 1993. An assessment of produced water impacts at two sites in the Galveston Bay system. Proceedings of the Second State of the Bay Symposium, Galveston Bay National Estuary Program, Galveston, TX, February 4-6, 1993, p 135-146.

Shepherd, M.C., F.L. Shore, S.K. Mertens, and J.S. Gibson. 1992. Characterization of produced waters from natural gas production and storage operations: Regulatory analysis of a complex matrix. Produced Water: Technological/Environmental Issues and Solutions, J.P. Ray and F.R. Engelhardt eds. New York, NY: Plenum Press. p 163173.

Sontheimer, H. 1976. The Use of Powdered Activated Carbon. Translation of Reports of Special Problems of Water Technology, Vol. 9, Adsorption. EPA 600-9-76-030. Washington D.C.: U.S. Environmental Protection Agency.

Stephenson, M.T. 1992. Components of produced water: A compilation of industry studies. Journal of Petroleum Technology, 44(5): 548-550, 602-603.

Steimle and Associates, Inc. 1991. Produced Water Impacts on Louisiana Wetlands. API Publ. No. 4517. Washington D.C.: American Petroleum Institute.

Texas Water Commission. 1989. Ground-Water Quality of Texas - An Overview of Natural and Man Affected Conditions. Report 89-01. Austin, TX: Texas Water Commission.

Tao, F.T., S. Curtice, R.D. Hobbs, J.L. Sides, J.D. Wieser, C.A. Dyke, D. Tuohey, and P.F. Pilger. 1993. Conversion of oilfield produced water into an irrigation/drinking quality water. Proceedings SPE/EPA Exploration and Production Environmental Conference, San Antonio, TX, March 7-10, 1993, p 571-579.

U.S. EPA. 1987a. Report to Congress: Management of Wastes from the Exploration, Development, and Production of Crude Oil, Natural Gas, and Geothermal Energy. EPA 530-SW-88-003A. Washington D.C.: U.S. Environmental Protection Agency, Office of Solid Waste and Emergency Response.

U.S. EPA. 1987b. Wastes from the Exploration, Development, and Production of Crude Oil, Natural Gas, and Geothermal Energy. Interim Report. Washington D.C.: U.S. Environmental Protection Agency, Office of Solid Waste and Emergency Response. April 1987.

U.S. EPA. 1987c. Exploration, Development, and Production of Crude Oil and Natural Gas, Field Sampling and Analytical Results. EPA 530-SW-87-005. Washington D.C.: U.S. Environmental Protection Agency, Office of Solid Waste and Emergency Response. 
Van Sickle, V. and C.G. Groat. 1990. Oil field brines: Another problem for Louisiana's coastal wetlands. Proceedings of the First International Symposium on Oil and Gas Exploration and Production Waste Management Practices, New Orleans, LA, September 10-13, 1990, p 659-675.

Wakim, P. G. 1987. API 1985 Production Waste Survey, Statistical Analysis and Survey Results. Final Report to the Production Waste Issue Group, American Petroleum Institute.

Wakim, P. G. 1988. API 1985 Production Waste Survey, Part II - Associated and Other Wastes, Statistical Analysis and Survey Results. Final Report to the Production Waste Issue Group, American Petroleum Institute.

Wesolowski, D., A. Broughton, C. Hansotte, S. Koraido, and J. Fillo. 1987. Characterization of Produced Waters from Natural Gas Production Operations. GRI Report No. 87/0335.1. Chicago, IL: Gas Research Institute.

Wesolowski, D., A. Broughton, C. Hansotte, S. Koraido, and J. Fillo. 1988. Characterization of Produced Waters from Underground Natural Gas Storage Reservoir Operations. GRI Report No. 88/0080.1. Chicago, IL: Gas Research Institute.

Whitmore, J. 1981. Water Base Drilling Mud Land Spreading and Use as a Site Reclamation and Revegetation Medium. Report to the American Petroleum Institute.

Wojtanowicz, A.K., S.D. Field, Z. Krilov, and F.L. Spencer. 1989. Statistical assessment and sampling of drilling-fluid reserve pits. SPE Drilling Engineering, 4(2): 162-170. 